

Queer Migration and Asylum

in Europe 


\title{
FRINGE
}

\author{
Series Editors \\ Alena Ledeneva and Peter Zusi, School of Slavonic and \\ East European Studies, UCL
}

The FRINGE series explores the roles that complexity, ambivalence and immeasurability play in social and cultural phenomena. A cross-disciplinary initiative bringing together researchers from the humanities, social sciences and area studies, the series examines how seemingly opposed notions such as centrality and marginality, clarity and ambiguity, can shift and converge when embedded in everyday practices.

Alena Ledeneva is Professor of Politics and Society at the School of Slavonic and East European Studies of UCL.

Peter Zusi is Associate Professor at the School of Slavonic and East European Studies of UCL. 


\section{Queer Migration and Asylum in Europe}

Edited by

Richard C. M. Mole

${ }^{\wedge}$ UCLPRESS 
First published in 2021 by

UCL Press

University College London

Gower Street

London WC1E 6BT

Available to download free: www.uclpress.co.uk

Collection (C) Editor, 2021

Text (C) Contributors, 2021

Images (C) Contributors and copyright holders named in captions, 2021

The authors have asserted their rights under the Copyright, Designs and Patents Act 1988 to be identified as the authors of this work.

A CIP catalogue record for this book is available from the British Library.

This book is published under a Creative Commons 4.0 International licence (CC BY 4.0). This licence allows you to share, copy, distribute and transmit the work; and to adapt the work and to make commercial use of the work providing attribution is made to the authors (but not in any way that suggests that they endorse you or your use of the work). Attribution should include the following information:

Mole, R. C. M. (ed.). 2021. Queer Migration and Asylum in Europe. London: UCL Press. https://doi.org/10.14324/111.9781787355811

Further details about Creative Commons licences are available at http://creativecommons.org/licenses/

Any third-party material in this book is published under the book's Creative Commons licence unless indicated otherwise in the credit line to the material. If you would like to reuse any third-party material not covered by the book's Creative Commons licence, you will need to obtain permission directly from the copyright holder.

ISBN: 978-1-78735-599-6 (Hbk.)

ISBN: 978-1-78735-587-3 (Pbk.)

ISBN: 978-1-78735-581-1 (PDF)

ISBN: 978-1-78735-605-4 (epub)

ISBN: 978-1-78735-611-5 (mobi)

DOI: https://doi.org/10.14324/111.9781787355811

\section{Co-funded by the \\ Erasmus+ Programme of the European Union}

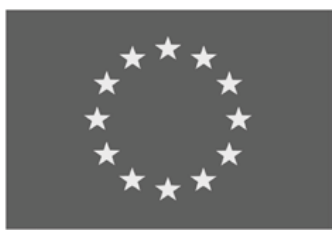




\section{Contents}

List of figures vii

List of tables viii

Contributors ix

Preface xii

Acknowledgements xiv

1. Introduction: queering migration and asylum 1

Richard C. M. Mole

2. Universal humanity vs national citizenship: the example of same-sex partner immigration in Europe

Robert Wintemute

3. 'The gay person always looks for the big European city':

the sexual migration of Latin American gay men in London

Cristian Valenzuela

4. Rethinking diaspora: queer Poles, Brazilians and

Russians in Berlin

Richard C. M. Mole

5. An exercise in detachment: the Council of Europe and sexual minority asylum claims

Nuno Ferreira

6. On the government of bisexual bodies: asylum case law and the biopolitics of bisexual erasure

Christian Klesse 
7. (Des)haciendo fronteras: Latin American LGBTIQ* asylum seekers in Spain in the process of credibility assessment

Aurora Perego

8. Between homonationalism and Islamophobia: comparing queer Caribbean and Muslim asylum seeking in/to the Netherlands

Keith E. McNeal and Sarah French Brennan

9. 'They sent me to the mountain': the role space, religion and support groups play for LGBTIQ+ asylum

claimants

Moira Dustin and Nina Held

10. The (micro-)politics of support for LGBT asylum seekers in France

Sara Cesaro

11. 'How much of a lesbian are you?' Experiences of

LGBT asylum seekers in immigration detention in the UK

Sarah Singer

Index 


\section{List of figures}

Figure 5.1 Jurisprudence of the Strasbourg Court on sexual minority asylum claims, 1990-2019. Source: author. 84

Figure 7.1 Appeals issued by Latin American LGBTIQ* applicants before the Spanish National and Supreme Courts between 1998 and 2016. Source: author's elaboration of the rulings available at http://www. poderjudicial.es/search/. 


\section{List of tables}

Table 3.1 Demographic information of the 14 research participants. Eight different Latin American countries are represented, although half of the participants are from Colombia. All participants are between 27 and 42 years of age. This is also a highly educated sample of Latin American men, as all have finished secondary education and most have university degrees. 


\section{Contributors}

Sara Cesaro is a PhD candidate in Sociology at the Université Paris VIII VincennesSaint-Denis, where she is attached to the Laboratoire d'Études de Genre et Sexualité.

Moira Dustin is a research fellow in the Department of Law at the University of Sussex and a visiting fellow at the Centre for Analysis of Social Exclusion at the London School of Economics. Her research interests include gender, sexuality, ethnicity, equality and human rights. She was previously Director of Research and Communications at the Equality and Diversity Forum, a network of equality and human rights organisations, and also worked at the Refugee Council.

Nuno Ferreira is Professor of Law at the University of Sussex. He is an expert in human rights, discrimination, European and asylum and refugee law. He uses socio-legal, comparative, empirical and policy-oriented perspectives in his work, has published widely with top publishers and journals and participated in several high-profile externally funded research projects. He is currently a Horizon 2020 ERC Starting Grant recipient, leading the project SOGICA - Sexual Orientation and Gender Identity Claims of Asylum (2016-20).

Sarah French Brennan received her PhD in Applied Anthropology from Columbia University's Teachers College. Within the scope of her broader research interests in the contexts, practices and technologies involved in the production of sexual identities and minority subjectivities, her PhD examines queer Muslim asylum seekers in the Netherlands and the ways in which the processes of narrating and claiming asylum as an 'LGBT' (the legal terminology in the asylum process) leads individuals to produce, rather than simply represent, a specific type of subject.

Nina Held is a research and teaching fellow in Sociology at the University of Sussex. Her research interests are situated within the areas of gender and sexuality studies, critical race and whiteness studies, sexual and emotional geographies and LGBTIQ+ asylum and human rights. She has published in Sexualities, Ethnic and Racial Studies, Emotion, Space and Society and the Journal of Lesbian Studies. 
Christian Klesse is Reader in the Department of Sociology at Manchester Metropolitan University. His research interests lie in the fields of gender and sexual politics, including non-monogamy and polyamory, transnational LGBTQI activism and queer film festivals. His work is interdisciplinary and often collaborative. He is the author of The Spectre of Promiscuity: Gay male and bisexual non-monogamies and polyamories (Ashgate, 2007). Recent journal articles have appeared in Sexualities, Signs: Journal of Women in Culture and Society, Sociological Research Online and The Sociological Review.

Keith E. McNeal is Associate Professor of Anthropology in the Department of Comparative Cultural Studies at the University of Houston. In 2011-12 he was a Fulbright Scholar at the University of the West Indies, St Augustine, Trinidad and Tobago. He is a cultural and historical anthropologist with a specialisation in Caribbean ethnology. He is the author of Trance and Modernity in the Southern Caribbean: African and Hindu popular religions in Trinidad and Tobago (University Press of Florida, 2011, New World Diasporas series) and the forthcoming Queering the Citizen: Dispatches from Trinidad and Tobago, and is working on a third book project, The Lotus in the Oil Drum: Globalising Hinduism in a Caribbean petro-state.

Richard C. M. Mole is Professor of Political Sociology at the School of Slavonic and East European Studies, UCL. His research focuses on the relationship between identity and power, with particular reference to nationalism, sexualities and migration. He is the editor of Soviet and Post-Soviet Sexualities (Routledge, 2019) and has published in Slavic Review, East European Politics and Societies, Ethnicity and Health, Nations and Nationalism, the European Journal of Social Psychology and Sexualities.

Aurora Perego is a PhD student in Sociology and Social Research at Trento University. She holds a Research Master's degree in Gender and Ethnicity from Utrecht University, where her thesis on the legal status of LGBTI* asylum seekers in Spain was awarded the 2018 Best Research Master's Thesis Prize of the Humanities at Utrecht University. Her current research interests concern the articulation of political claims and collective actions around categories of gender and sexuality.

Sarah Singer is Senior Lecturer in Refugee Law at the Refugee Law Initiative, School of Advanced Study, University of London, and Programme Director of the distance-learning MA in Refugee Protection and Forced Migration Studies. Her research interests are refugee law and policy, human rights and migration. She has published broadly on the topic of asylum seekers and migrants suspected of serious criminality. She is currently co-investigator on a four-year-funded project, 'Research capacity building and knowledge generation to support preparedness and response to humanitarian crises and epidemics' (RECAP), leading research on accountability and protection in forced displacement contexts. 
Cristian Valenzuela is a Research Associate at the American Institutes for Research in Washington, D.C. He holds an MSc in Urban Studies from UCL's Department of Geography and an MA in Gender Studies from the University of Chile. His research interests are sexual and reproductive health and inequalities, and issues of sexual practices, politics and identities.

Robert Wintemute is Professor of Human Rights Law at King's College London. He is a specialist in human rights law, anti-discrimination law and sexual orientation law, on which he has published in the King's Law Journal, the Industrial Law Journal, Modern Law Review, Social and Legal Studies and the European Human Rights Law Review, among others. 


\section{Preface}

The UCL Press FRINGE series presents work related to the themes of the UCL FRINGE Centre for the Study of Social and Cultural Complexity.

The FRINGE series is a platform for cross-disciplinary analysis and the development of 'area studies without borders'. 'FRINGE' is an

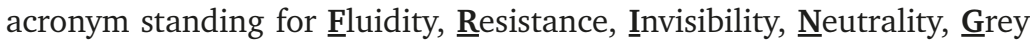
zones, and Elusiveness - categories fundamental to the themes that the Centre supports. The oxymoron in the notion of a 'FRINGE CENTRE' expresses our interest in (1) the tensions between 'area studies' and more traditional academic disciplines, and (2) social, political and cultural trajectories from 'centres to fringes' and inversely from 'fringes to centres'.

The series pursues an innovative understanding of the significance of fringes: rather than taking 'fringe areas' to denote the world's peripheries or non-mainstream subject matters (as in 'fringe politics' or 'fringe theatre'), we are committed to exploring the patterns of social and cultural complexity that are characteristic of fringes and emerge from the areas we research. We aim to develop forms of analysis of those elements of complexity that are resistant to articulation, visualisation or measurement.

In line with the ethos of the FRINGE series, this volume offers a trans-regional and cross-disciplinary approach to the topics of queer migration and asylum. Queer migrants and asylum seekers often live on the fringes of society, yet the way they are viewed and treated reveals a lot about the nature of those societies. In this volume an international team of sociologists, anthropologists, political scientists and legal scholars takes readers on a tour through the migration and asylum systems of a range of European states, uncovering the lived experiences of LGBTQ individuals who have moved, or are in the process of moving, to or within the European Union and the United Kingdom. The volume shines a light on the lives of migrants and asylum seekers from Africa, Asia, the Caribbean, Central and Eastern Europe, the Middle East and Latin America, who have migrated to or sought asylum in France, 
Germany, the Netherlands, Spain and the UK. Identifying the underlying patterns, cleavages and ambiguities in these migrations - whether voluntary or forced - as well as the motivations and strategies for migrating, this volume explores the dynamics of ethnic and queer diasporas and engages in legal debates about what constitutes a 'legitimate' or 'credible' queer asylum seeker.

Alena Ledeneva and Peter Zusi School of Slavonic and East European Studies, UCL 


\section{Acknowledgements}

This edited volume grew out of a workshop and conference on Queer Migration and Asylum in Europe organised by the UCL European Institute in 2017 with the support of the Erasmus + Programme of the European Union. I would like to thank Uta Staiger and Oli Patel for their invaluable help in organising both events.

I would like to thank Cambridge University Press for their permission to reproduce sections of R. C. M. Mole, 2018, 'Identity, belonging and solidarity among Russian-speaking queer migrants in Berlin', Slavic Review 77:77-98. I would also like to thank Rowman and Littlefield for their permission to reproduce C. Klesse, 2018, 'On the government of bisexual bodies: asylum case law and the biopolitics of bisexual erasure', in Biopolitical Governance: Race, gender and economy, edited by Hannah Richter, 163-90. London: Rowman and Littlefield. 


\section{Introduction: queering migration and asylum}

Richard C. M. Mole

In June 2011 the UN Human Rights Council approved a resolution expressing 'grave concern at acts of violence and discrimination in all regions of the world, committed against individuals because of their sexual orientation and gender identity' (United Nations 2011a), with Secretary-General Ban Ki-moon emphasising that such persecution was 'an attack on the universal values that the United Nations and I have sworn to defend and uphold' (United Nations 2011b). Through these actions, the rights of lesbian, gay, bisexual and transgender (LGBT) people were recognised as human rights at the highest level of international society. However, while respect for LGBT rights is promoted as a universal value, this is a view that is far from universally accepted. As at March 2019 there are 70 UN member states which criminalise homosexuality, with six imposing the death penalty for same-sex sexual acts. In addition, 32 member states have introduced laws limiting freedom of expression regarding LGBT issues - the so-called 'gay propaganda' laws (ILGA World 2019, 15-16). Even in states where homosexuality is not a crime, LGBT people often face marginalisation, discrimination, hostility and violence. It is thus not surprising that sexual and gender minorities from such states migrate to or seek refuge in countries in which attitudes are more accepting and LGBT rights are more widely respected.

In this context, Europe is a popular destination, as European institutions have done much to promote the legal equality of sexual minorities, while a number of European states pride themselves on their tolerance of sexual diversity. However, the image of European tolerance and the reality faced by LGBT migrants and asylum seekers are often 
quite different (see Colpani \& Habed 2014). LGBT asylum seekers' longhoped-for escape from persecution inevitably comes into conflict with attempts by legal and political institutions in the destination country to keep them out. Even if they do not migrate specifically to escape persecution, LGBT migrants often discover that Europe is not as welcoming as they were led to believe and they find themselves marginalised, both as ethnic minorities in the destination society and as sexual minorities within the diaspora community.

Against this backdrop, the aim of this book is to bring together scholars from politics, sociology, anthropology and law to analyse: LGBT individuals' motivations for migrating to or seeking asylum in an EU member state; the extent to which they engage with their homelands and their ethno-national diasporic communities; the renegotiation of their identities in the context of dispersal; the role of European institutions in facilitating or restricting queer migration and asylum; and the legal, social and political frameworks queer migrants and asylum seekers need to navigate to regularise their status in the destination society. To situate the contributors' research within a broader theoretical context, the aim of this introductory chapter is to set out some of the key debates in studies of queer migration and asylum in the extant literature.

But, first, a note on terminology. Why is the book called Queer Migration and Asylum in Europe rather than LGBT Migration and Asylum in Europe? As the authors in this volume use a number of different terms to refer to the non-heterosexual and non-cisgendered subjects of their research, I have chosen the term queer as an umbrella term for individuals who, in the Western context at least, would normally be referred to as lesbian, gay, bisexual or trans. A further benefit of queer is that the term reflects the fact that lesbian, gay, bisexual and trans are often seen as specifically Western terms and not reflective of the sense of identity of sexual and gender minorities in other parts of the world. It is noteworthy that the very idea of queer was to a significant extent brought about by migration in that the mass movement of people to the West from various nonWestern cultures brought into sharp relief the numerous 'sexual identity categories and practices that [did] not depend on Western conceptions of selfhood and community', thereby producing a range of queer identities and subjectivities (Manalansan 2006, 229). With reference to queer migration and queer asylum, queer is used in part to take account of the queer subjects of the processes of migration and asylum but also to refer to the ways in which sexual and gender minorities problematise hegemonic understandings of migration and asylum. 


\section{Queering migration}

Since the early 1990s there has emerged a small but growing body of literature on the topic of queer migration, comprising: theoretical analyses of the relationship between migration and sexuality (Binnie 1997; Mai \& King 2009; Manalansan 2006); studies of rural-to-urban domestic migration (Gorman-Murray 2007, 2009); border crossing by queer migrants and the legal hurdles they have to overcome (Cantú 2009; Luibhéid 2002, 2009; Luibhéid \& Cantú 2005); the (re)construction of sexual identities following migration (Kuntsman 2009); and the emergence and lived experiences of queer diasporas (Eng 1997; Watney 1995; Manalansan 2003; Mole 2018). While these scholars share an interest in migration by sexual and gender minorities, there is no shared understanding of how best to define the concept of 'queer migration' itself.

To some scholars, queer migration is any migration by queer people, whatever the reason. For others, you can only speak about queer migration if the motivation for migration is related to the migrant's sexual orientation. According to Andrew Gorman-Murray, migration is only queer where 'the needs or desires of non-heterosexual identities, practices and performances' are implicated in the queer migrant's decision to move $(2009,443)$. To this group of scholars, a gay man or a lesbian moving across the country or abroad to take up a new job or to go to university, for instance, would not constitute queer migration, as it was not motivated by the migrant's sexuality. This understanding of queer migration posits a one-way relationship between sexuality and migration, with sexuality prompting migration. However, I argue that queer migration should be understood as a more dynamic, two-way process, whereby the experience of migration can also influence sexuality - the way it is understood, performed and experienced - even if the stated motivation is not sexuality-related. This less restrictive understanding of queer migration overlaps with that of Héctor Carrillo, who suggests that to fully conceptualise queer migration (which he calls 'sexual migration'), we have to 'consider a number of dimensions associated with this kind of transnational movement, including sexual immigrants' transportation of practices across international borders, their lives in their places of origin, their exposure to local and foreign sexual ideologies prior to migrating, their agency in adapting and appropriating ideologies and practices prevalent in both home and host countries, and the transformations in sexual identities and behaviors that they experience after migration' $(2004,58)$. Even when looking at the influence of sexuality on migration, I would also argue that an individual's sexual or gender identity can indirectly 
or subconsciously influence their decision to migrate even if this is not declared as a key motivating factor. In my research on queer migration from Poland to the UK, for example, one of my respondents suggested that being gay means that you are more likely to be open to difference, which makes you more open to trying different things, such as experiencing foreign cultures (Mole 2019).

In terms of the reasons why people migrate, the hegemonic understanding in migration studies is that the main motivation is economic, with individuals moving abroad to gain higher wages or acquire marketable skills (see Stark \& Bloom 1985). Such 'rational' explanations for migrating have been challenged by research that highlights the emotional reasoning behind the decision to move - particularly by queers (Mai \& King 1995; Stella, Flynn \& Gawlewicz 2018). While not discounting the economic motivation entirely, queer migration research shows that 'emotional' factors relating to sexuality and gender identity play an equally, if not more, important role in prompting queer men and women to relocate. ${ }^{1}$ With the aim of understanding the motivations for queer migration, Gorman-Murray identified three main patterns. The first is 'coming-out migration', whereby queer people move for the purpose of 'self-reinvention as non-heterosexual and to explore bodily sexual desires in the process' $(2009,446)$. Moving away from home enables those who are not yet out to perform their sexuality in line with their own desires but at the same time reduce the risk that their sexual behaviour and identity will be reported back to their parents before they feel ready to tell them. For those who are not ready to come out but who want to explore their sexuality, living in their home town may increase the risk of word getting out that they are queer. The second pattern is 'gravitational group migration', i.e. 'moving to be near a neighbourhood with a gay and lesbian presence' $(2009,446)$. Even if you come out in your home town and are accepted by your family and friends, you may not necessarily be able to meet other queer people for friendship or a romantic relationship if your town has no gay or lesbian bars and clubs. This lack of queer venues may not only influence the decision to move away from home in the first place but also determine which town or city you move to. The third pattern identified by Gorman-Murray is 'relationship migration', where individuals move 'with a partner to consolidate a same-sex relationship - or conversely, mov[e] away after a relationship breakdown' $(2009,446)$. While moving within your home country should be largely unproblematic, whether you are permitted to migrate to another country with your boyfriend or girlfriend will depend on whether that country legally recognises same-sex partnerships, an issue discussed in detail in 
Chapter 2. This takes us to a fourth motivation for queer migration to add to Gorman-Murray's three: moving to another country to take advantage of a more comprehensive range of sexual citizenship rights, such as same-sex marriage or anti-discrimination legislation.

Previous research shows that, once queer migrants have made the move to the 'big city' or to another country, in line with the motivations identified by Gorman-Murray, they appreciate being able to perform their sexuality or gender identity in line with their own desires and enjoy going to gay and lesbian bars and clubs, even if access is sometimes mediated by their economic capital or their ethnic and racial profile (see Ibañez, Van Oss Marin, Flores, Millett \& Diaz 2012). However, it is also clear that the communities of belonging which queer migrants seek out are not defined exclusively with relation to sexual and gender identity but also to ethnicity or nationality. While, for most migrants, co-ethnic diasporas in the destination society would provide a sense of belonging and social, economic and psychological support, queer migrants often find these communities unappealing or unwelcoming (Fortier 2002). In Chapter 3 and Chapter 4, Cristian Valenzuela and Richard Mole discuss migration motivations and communities of belonging with reference to Latin American and East European queer migrants in London and Berlin, respectively.

\section{Queering asylum}

While queers have always been among those granted asylum since the signing of the Refugee Convention in 1951, it is only much more recently that queer migrants have received asylum because of their non-normative gender or sexual identity. The recognition that persecution related to an individual's non-normative sexual or gender identity constitutes legitimate grounds for claiming asylum has resulted in a sharp increase in the number and complexity of such claims; in Chapter 5, Nuno Ferreira offers a critical legal analysis of how the Council of Europe - and, in particular, the European Court of Human Rights - have dealt with this situation in the European context.

While Article 1A (2) of the Refugee Convention, which defines a refugee as an individual who has a 'well-founded fear of being persecuted for reasons of race, religion, nationality, membership of a particular social group or political opinion', does not specifically refer to homosexuality as a protected category, sexual minorities are generally understood to constitute 'a particular social group' for the purposes of seeking 
asylum. (Of course, members of sexual minorities can also claim asylum on the basis of one of the other protected categories.) This is because they meet the two preconditions: 'First, members of that group share an innate characteristic, or a common background that cannot be changed, or share a characteristic or belief that is so fundamental to identity or conscience that a person should not be forced to renounce it. Second, that group has a distinct identity in the relevant country, because it is perceived as being different by the surrounding society. ${ }^{2}$ In Germany, for instance, the fact that sexual orientation is 'irreversible' [unabänderlich] and thus comparable to race or nationality as grounds for seeking asylum was recognised by the Federal Administrative Court as early as $1988 .{ }^{3}$ However, as Christian Klesse argues in Chapter 6, bisexual asylum seekers often have a more difficult time convincing adjudicators that they belong to the 'particular social group' of sexual minorities and that their sexual orientation is innate.

Although there is now a general consensus among legal scholars and the courts that sexual minorities should be recognised as legitimate potential refugees, there is less agreement as to whether all persecution of lesbian, gays and bisexuals in their home countries is - as stipulated in the Refugee Convention - for reasons of their sexuality and thus grounds for asylum. Such debates have raised questions as to whether LGBT individuals have a duty to exercise discretion in their home countries in a bid to avoid persecution, whether only specific forms of harm to queer asylum seekers make the latter worthy of protection, and consequently whether there are 'acceptable' and 'unacceptable' forms of homophobic persecution.

For asylum seekers to be successful in gaining international protection, they need to demonstrate a 'well-founded fear of being persecuted' in their country of origin. Until relatively recently, however, it was common practice in a range of European states to expect queer asylum seekers to exercise discretion about their sexual orientation in their home countries so as to avoid persecution (Jansen 2013). ${ }^{4}$ This expectation would allow adjudicators to deny the existence of a 'well-founded fear of being persecuted' and so to turn down applications for asylum, as demonstrated by this rejection letter sent by the UK Border Agency to an Iranian asylum seeker in 2010:

Legislation which renders homosexuality illegal in Iran may cause you to be secretive in the conduct of your homosexual relationships there. However, this does not engage the UK's obligations under Art. 8 [of the European Convention on Human Rights]. This is because 
it is clear from your own evidence that you have demonstrated neither past nor future intention of publicly engaging in any homosexual conduct which ... would expose you to any real risk on return to Iran. ... when an individual's right to pursue his sexuality is placed within the context of a civilised society, the need for discretion in relation to sexual practices is the accepted norm.

(UKLGIG 2010, 4)

The claim that it was reasonable to expect gays and lesbians to return to their home countries and exercise discretion was highly controversial. First, it assumed that discretion on the part of the applicant was a free choice and not the result of 'oppressive social forces' (Millbank 2009, 392). In addition, sexual orientation was understood as a form of behaviour ('sexual practices'), which one could choose to engage in (or not), rather than part of an innate characteristic of an individual's sense of self. Were sexuality reduced to sexual practice, one could perhaps reasonably expect everyone, both homosexuals and heterosexuals, to be 'discreet' in the sense of not engaging in sex in public. If we understand sexuality as a fundamental aspect of an individual's identity, however, it is clear that homosexuals were being treated inequitably, in that heterosexuals are never asked to exercise discretion in expressing their heterosexuality. Hence it is not discretion that is asked of homosexuals but rather concealment. Such a requirement runs counter to the 2012 UNHCR Guidelines on International Protection No. 9, 'Claims to Refugee Status based on Sexual Orientation and/or Gender Identity', which specify that 'a person cannot be denied refugee status based on a requirement that they change or conceal their identity, opinions or characteristics in order to avoid persecution'. Moreover, the idea that LGBT individuals can always conceal their queerness, even assuming they wished to do so, is erroneous.

The discretion argument was abolished in the EU in 2013 on the basis of a ruling by the Court of Justice of the European Union (CJEU) ${ }^{5}$ and following a number of high-profile cases in Australia and the UK. The duty to be discreet had been rejected in the UK in 2010 in the HJ (Iran) v Secretary of State for the Home Department ruling by the Supreme Court. Recognising that there was more to being gay than sexual practices, Lord Hope ruled that 'what is protected is the applicant's right to live freely and openly as a gay man. That involves a wide spectrum of conduct, going well beyond conduct designed to attract sexual partners and maintain relationships with them. ${ }^{6}$ Acknowledging that his examples of 'gay conduct' were trivial and stereotypical, Lord Hope argued that 'just as male heterosexuals are free to enjoy themselves playing rugby, drinking 
beer and talking about girls with their mates, so male homosexuals are to be free to enjoy themselves going to Kylie concerts, drinking exotically coloured cocktails and talking about boys with their straight female mates'?

While the rejection of the discretion requirement was welcomed by LGBT activists, the ruling itself was criticised for presenting an essentialist and universal understanding of what it means to be gay, defined in specifically Western and consumerist terms. It was also criticised by certain legal scholars. While supporting the repeal of the requirement, James Hathaway and Jason Pobjoy, for example, disagreed with the reasoning given - particularly the idea that not being able to drink colourful cocktails and attend Kylie concerts was grounds for LGBT individuals to claim asylum for reasons of their sexual orientation. They argued that "the "for reason of" clause was included in the Refugee Convention precisely to delimit the scope of the refugee class to those persons at risk of serious harm for reasons deemed fundamental' (Hathaway \& Pobjoy 2012, 339; emphasis in original). To suggest that attending a Kylie concert is a fundamental part of a universal gay experience - in addition to prioritising a very Western understanding of homosexuality - thus cast the net far wider than the Refugee Convention originally intended. Other scholars, such as Janna Wessels, also criticised the Supreme Court ruling, but for not going far enough. Wessels (2013) argues that the discretion reasoning has not been completely rejected but rather that a distinction has been made between acceptable and unacceptable forms of discretion. Lord Hope's ruling continued:

If the tribunal concludes that the applicant would choose to live discreetly simply because that was how he himself would wish to live, or because of social pressures, e.g. not wanting to distress his parents or embarrass his friends, then his application should be rejected. ${ }^{8}$

Again, this suggests queers choose to adhere to social pressure and, more importantly, implies that the concealment of sexual identity as a result of social pressure does not inflict the serious harm to LGBT individuals that would justify a claim for asylum. Nevertheless, despite the fact that other branches of human rights law recognise that 'acts that cause mental suffering' constitute cruel and inhuman treatment just as much as 'acts that cause physical pain', asylum adjudicators are more likely to be persuaded by evidence of exogenous, physical harm perpetrated by state actors than by endogenous, psychological harm resulting from social and 
family pressures (see Hathaway \& Pobjoy 2012, 362). ${ }^{9}$ As Rachel Lewis confirms, 'it is still the case that the closer one's application conforms to the traditional model of the male political activist fleeing an oppressive regime, the more likely one is able to obtain asylum' $(2013,178)$.

Now that most EU member states no longer (in theory) turn down asylum applications for reasons of sexual orientation on the grounds that the applicants could reasonably be expected to return home and be discreet about their sexual identity, the key means of rejecting queer asylum applications has shifted from 'discretion' to 'disbelief' (see Hertoghs \& Schinkel 2018). While few countries have taken the extreme measure adopted by the Czech Republic of using a phallometer to test male applicants' reactions to gay pornography, most EU states have sought to verify the sexual orientation of asylum seekers during the interview process. What research by academics and LGBT rights organisations has identified, however, is that the sexuality of asylum seekers from non-Western states is being tested against the benchmark of Western consumerist gay and lesbian identities. As Thibaut Raboin (2016, 673) demonstrated with reference to the UK as early as 2010, 'Home Office case owners have sometimes assessed claimants' gayness by testing their knowledge of the commercial gay scene in London, such as describing the layout of Heaven, a large club in central London with multiple rooms:

You have to ask, what is his behaviour in the UK? If you were a gay man and you had been repressed or ostracised in your home country, then presumably coming to London would give you the chance to go to Soho or Heaven and enjoy the kind of lifestyle and bars and opportunities that that presents.

(Nicholas, UKBA senior caseworker (Stonewall 2010, 16))

Similarly, judges in the UK have disbelieved that lesbian asylum seekers were indeed lesbian because they did not show any interest in lesbian magazines, or had been married or had children, thereby demonstrating a failure to understand the social pressure on sexual minorities in states outside of the 'West' to conform to heteronormative gender and sexual roles and identities so as to remain invisible and thus safe (see, for example, Stonewall 2010, 15, and Lewis 2013, 175). To be deemed credible, therefore, queer asylum seekers need to be able to translate their identities and 'experiences of persecution into the kinds of asylum narratives that are recognizable to the state' (Lewis 2013, 176). This is exemplified in Chapter 7 by Aurora Perego, who examines how the 'credibility' of Latin American asylum seekers in Spain is constructed and evaluated, while in 
Chapter 8 Keith E. McNeal and Sarah French Brennan demonstrate how the Dutch system creates worthy and unworthy queer asylum seekers on the basis of their country of origin and religious affiliation.

The final three chapters shift the focus away from purely legal deliberations to examine the social dimensions of the asylum experience. In Chapter 9 Moira Dustin and Nina Held argue that the legal asylum process does not operate in isolation from social phenomena and that space, faith, and support groups play important roles in determining the well-being of sexual and gender minorities claiming asylum in the UK, Italy and Germany. Similarly, in Chapter 10, Sara Cesaro analyses the (micro-)politics of the support that LGBT organisations in France provide to asylum seekers, as well as the sociological and political implications of that support. In the final chapter, Chapter 11, Sarah Singer highlights the impact of immigration detention on the asylum claims as well as the physical, mental and social well-being of queer asylum seekers in the UK.

\section{Notes}

1. In her research on queer East European migrants in Iceland, Linda Sólveigar-Guðmundsdóttir (2018) shows that the rational and emotional are often intertwined, in that, while her respondents did decide to migrate to Iceland for economic reasons, it was because of the more extensive sexual citizenship rights in Iceland that they decided to stay.

2. Court of Justice of the European Union - C-199/12 to C-201/12, Minister voor Immigratie en Asiel $v X, Y$ and $Z, 7$ November 2013.

3. German Federal Administrative Court 1988.

4. According to Jansen (2013, 3, fn. 12), the discretion requirement was used in the adjudication of queer asylum applications of the following states: Austria, Belgium, Bulgaria, Cyprus, Denmark, Finland, France, Germany, Hungary, Malta, the Netherlands, Poland, Romania, Spain, Norway and Switzerland.

5. Court of Justice of the European Union - C-199/12 to C-201/12, Minister voor Immigratie en Asiel $v$ X, Y and Z, 7 November 2013.

6. UK Supreme Court 2010, 36.

7. UK Supreme Court 2010, 36.

8. UK Supreme Court 2010, 38.

9. See also: United Nations Human Rights Committee, General Comment No. 20, Article 7 (Prohibition of Torture, or Other Cruel, Inhuman or Degrading Treatment or Punishment).

\section{References}

Binnie, Jon. 1997. 'Invisible Europeans: Sexual citizenship in the New Europe', Environment and Planning A 29:237-48. https://doi.org/10.1068/a290237.

Cantú, Lionel, Jr. 2009. The Sexuality of Migration: Border crossings and Mexican immigrant men, edited by Nancy A. Naples and Salvador Vidal-Ortiz. New York: New York University Press.

Carrillo, Héctor. 2004. 'Sexual migration, cross-cultural sexual encounters, and sexual health', Sexuality Research and Social Policy 1:58-70. https://doi.org/10.1525/srsp.2004.1.3.58.

Colpani, Gianmaria and Adriano José Habed. 2014. "'In Europe it's different": Homonationalism and peripheral desires for Europe'. In LGBT Activism and the Making of Europe: A rainbow 
Europe?, edited by Phillip M. Ayoub and David Paternotte, 73-93. Basingstoke: Palgrave Macmillan.

Court of Justice of the European Union. 2013. 'Judgment of the Court (Fourth Chamber): in joined cases C-199/12 to C-201/12, Minister voor Immigratie en Asiel v X, Y and Z, 7 November. Available at: https://fra.europa.eu/en/caselaw-reference/cjeu-joined-cases-c-19912c-20112- judgment (accessed 4 August 2020).

Eng, David. 1997. 'Out here and over there: Queerness and diaspora in Asian American studies', Social Text 52-3:31-52. https://doi.org/10.2307/466733.

Fortier, Anne-Marie. 2002. 'Queer diaspora'. In Handbook of Gay and Lesbian Studies, edited by Diane Richardson and Steven Seidman, 183-97. London: SAGE.

German Federal Administrative Court. 1988. BVerwG 9 C 278.86, 15 March. Available at: https:// dejure.org/dienste/vernetzung/rechtsprechung?Gericht=BVerwG\&Datum=15.03.1988\&Ak tenzeichen=9\%20C\%20278.86 (accessed 4 June 2017).

Gorman-Murray, Andrew. 2007. 'Rethinking queer migration through the body', Social and Cultural Geography 8:105-21. https://doi.org/10.1080/14649360701251858.

Gorman-Murray, Andrew. 2009. 'Intimate mobilities: Emotional embodiment and queer migration', Social and Cultural Geography 10:441-60. https://doi.org/10.1080/ 14649360902853262.

Hathaway, James C. and Jason Pobjoy. 2012. 'Queer cases make bad law', New York University Journal of International Law and Politics 44:315-89.

Hertoghs, Maja and Willem Schinkel. 2018. 'The state's sexual desires: The performance of sexuality in the Dutch asylum procedure', Theory and Society 47:691-716. https://doi.org/ 10.1007/s11186-018-9330-x.

Ibañez, Gladys E., Barbara Van Oss Marin, Stephen A. Flores, Gregorio Millett and Rafael M. Diaz. 2012. 'General and gay-related racism experienced by Latino gay men', Journal of Latina/o Psychology 1: 66-77. https://doi.org/10.1037/2168-1678.1.s.66.

ILGA World. 2019. State-Sponsored Homophobia (13th edn). Geneva: ILGA.

Jansen, Sabine. 2013. 'Introduction: Feeling homophobia, asylum claims related to sexual orientation and gender identity in Europe'. In Fleeing Homophobia: Sexual orientation, gender identity and asylum, edited by Thomas Spijkerboer, 1-31. Abingdon: Routledge.

Kuntsman, Adi. 2009. Figurations of Violence and Belonging: Queerness, migranthood and nationalism in cyberspace and beyond. Oxford: Peter Lang.

Lewis, Rachel. 2013. 'Deportable subjects: Lesbians and political asylum', Feminist Formations 25:174-94. https://doi.org/10.1353/ff.2013.0027.

Luibhéid, Eithne. 2002. Entry Denied: Controlling sexuality at the border. Minneapolis: University of Minnesota Press.

Luibhéid, Eithne and Lionel Cantú, Jr. (eds). 2005. Queer Migrations: Sexuality, U.S. citizenship, and border crossings. Minneapolis: University of Minnesota Press.

Mai, Nicola and Russell King. 2009. 'Love, sexuality and migration: Mapping the issue(s)', Mobilities 4:295-307. https://doi.org/10.1080/17450100903195318.

Manalansan, Martin F. 2003. Global Divas: Filipino gay men in the diaspora. Durham, NC: Duke University Press.

Manalansan, Martin F. 2006. 'Queer intersections: Sexuality and gender in Migration Studies', International Migration Review 40:224-49. https://doi.org/10.1111/j.1747-7379. 2006. 00009.x.

Millbank, Jenni. 2009. 'From discretion to disbelief: Recent trends in refugee determinations on the basis of sexual orientation in Australia and the United Kingdom', International Journal of Human Rights 13:391-414. https://doi.org/10.1080/13642980902758218.

Mole, Richard C. M. 2018. 'Identity, belonging and solidarity among Russian-speaking queer migrants in Berlin', Slavic Review 77:77-98. https://doi.org/10.1017/slr.2018.11.

Mole, Richard C.M. 2019. 'The post-communist identity crisis and queer migration from Poland'. In The Oxford Handbook of Migration Crises, edited by Cecelia Menjívar, Marie Ruiz and Immanuel Ness, 691-704. Oxford: Oxford University Press.

Raboin, Thibaut. 2016. 'Exhortations of happiness: Liberalism and nationalism in the discourses on LGBTI asylum rights in the UK', Sexualities 20:663-81. https://doi.org/10.1177/ 1363460716645802.

Sólveigar-Guðmundsdóttir, Linda. 2018. 'Exclusionary moments: Queer desires and migrants' sense of (un)belonging', Emotion, Space and Society 28:32-8. https://doi.org/10.1016/ j.emospa.2018.06.003. 
Stark, Oded and David E. Bloom. 1985. 'The new economics of labor migration', American Economic Review 75:173-8.

Stella, Francesca, Moya Flynn and Anna Gawlewicz. 2018. 'Unpacking the meanings of "a normal life" among lesbian, gay, bisexual and transgender Eastern European migrants in Scotland', Central and Eastern European Migration Review 7:55-72.

Stonewall. 2010. 'No going back: Lesbian and gay people and the asylum system'. London: Stonewall.

UKLGIG (UK Lesbian and Gay Immigration Group). 2010. 'Failing the grade: Home Office initial decisions on lesbian and gay claims for asylum', April. Available at: http://uklgig.org.uk/wpcontent/uploads/2014/04/Failing-the-Grade.pdf (accessed 1 May 2017).

UK Supreme Court. 2010. HJ (Iran) v Secretary of State for the Home Department, 7 July. Available at: https://www.asylumlawdatabase.eu/sites/default/files/aldfiles/Judgment.pdf (accessed 18 August 2020).

UNHCR. 2012. 'Guidelines on International Protection No. 9: Claims to refugee status based on sexual orientation and/or gender identity within the context of Article 1A(2) of the 1951 Convention and/or its 1967 Protocol relating to the status of refugees', 23 October 2012. Available at: http://www.refworld.org/docid/50348afc2.html (accessed 4 June 2017).

United Nations. 2011a. UN Resolution 17/19 on 'Human rights, sexual orientation and gender identity', A/HRC/17/L.9/Rev.1.

United Nations. 2011b. 'To those who are lesbian, gay, bisexual or transgender, Secretary-General says in message: You are not alone in your struggle to end violence, discrimination'. Press release, SG/SM/14145 HRC/13, 7 March. Available at: https://www.un.org/press/en/2012/ sgsm14145.doc.htm (accessed 4 June 2017).

United Nations Human Rights Committee, General Comment No. 20, Article 7 (Prohibition of Torture, or Other Cruel, Inhuman or Degrading Treatment or Punishment). Available at: http://www.refworld.org/docid/453883fb0.html (accessed 5 June 2017).

Watney, Simon. 1995. 'AIDS and the politics of queer diaspora'. In Negotiating Lesbian and Gay Subjects, edited by Monica Dorenkamp and Richard Henke, 53-70. New York and Abingdon: Routledge.

Wessels, Janna. 2013. 'Discretion in sexuality-based asylum cases: An adaptive phenomenon'. In Fleeing Homophobia: Sexual orientation, gender identity and asylum, edited by Thomas Spijkerboer, 55-81. Abingdon: Routledge. 


\section{2}

\section{Universal humanity vs national citizenship: the example of same-sex partner immigration in Europe}

Robert Wintemute

\section{Introduction}

To a lesbian, gay or bisexual (LGB) person ${ }^{1}$ in Asia, Africa or the Caribbean who sees no hope of legal or social progress in their own country in the near future, travelling to Europe to claim asylum ${ }^{2}$ might seem their best option. But how to get there? European governments rarely, if ever, issue asylum-seeker visas to people who are still in their own country. ${ }^{3}$ Without a visa, they cannot board a flight out of their country. They could apply for a visa for a conference, internship or summer school (if they have a sponsor) or for a tourist visa (if they have enough money) and conceal their plan to claim asylum. Or they could pay people-smugglers to get them on a boat across the Mediterranean and risk drowning. Is there another, safer option?

In November 2013, I spoke at a seminar in Dhaka about the Yogyakarta Principles ${ }^{4}$ and how they might be used in the struggle for LGB equality in Bangladesh. A question from one of the male participants surprised me: 'How can I find a boyfriend in the United Kingdom?' Although I wanted him to be inspired by the Yogyakarta Principles to stay at home and work for a better future for LGB persons in his country, he had identified a much quicker route to equality. In the remainder of this chapter, I will discuss developments since 2016 under the European Convention on Human Rights and European Union law with regard to applications for residence permits for the same-sex partners of citizens of European countries. But first I will consider a much more general and fundamental question: why should any human being ever have to apply for a visa to travel to any country? 


\section{The great contradiction between principle (the universal equality of human beings) and political reality (national border controls based on citizenship)}

The rules of immigration and asylum law can be seen as 'exceptions to the exception'. Our starting principle should be Article 1 of the Universal Declaration of Human Rights (UDHR), adopted by the United Nations General Assembly on 10 December 1948: 'All human beings are born ... equal in dignity [value or worth] and rights.' Taking Article 1 literally, a human being who arrives at an international border should be able to say simply: 'I am a human being. I am equal in dignity and rights to the human beings who are already living and working in your country. Please let me cross your border to live and work in your country, as they are doing.' Unfortunately, this innocent human being would receive a rude introduction to the political reality of national citizenship, which trumps universal humanity. They would be asked: 'What kind of human being are you? Please show us your passport.'

The exception to our principle ('all human beings are born ... equal in dignity and rights') is not spelled out in Article 1 but might read 'except when approaching a border'. To find the exception, one must read Article 1 and then notice what is not mentioned in Article 13 UDHR: '(1) Everyone has the right to freedom of movement and residence within the borders of each state [not across the borders between states]. (2) Everyone has the right to leave any country, including his [or her] own, and to return to his [or her] country [but not to enter any country that he or she would like to enter].' This exception operates throughout international and national human rights law on the prohibition of discrimination: differences in treatment based on national citizenship are generally considered justifiable (and therefore not discrimination) with regard to the rights to enter, reside, work and vote in the territory of a particular country.

The rules of immigration and asylum law operate as 'exceptions to the exception (of national citizenship)', which returns us to our general principle of non-discrimination among human beings, at least for the lucky few who qualify. The lucky few might be granted a visa (permission to enter) under national immigration law (e.g. a work permit, an investor's visa or a family reunification visa, including for a spouse, fiancé(e) or partner), or refugee status after a successful asylum claim. The right to claim asylum (another 'exception to the exception'), 
protected by subsequent international treaties and EU or national legislation, is found in Article 14(1) UDHR: 'Everyone has the right to seek and to enjoy in other countries asylum from persecution.'

The long-term question for every country is whether we should uphold our principle (equal rights for all human beings, and therefore an equal right to freedom of movement for all human beings), eliminate the national-citizenship exception and therefore eliminate the need for 'exceptions to the exception' (a visa or refugee status). I hope that, in the very long term, our principle will be upheld, once economic and political differences between countries have been reduced sufficiently. But, in the short term, an equal right to freedom of movement for all human beings is politically unthinkable. Apart from the social tensions that a sudden increase in linguistic and cultural diversity might produce, affluent democratic societies would fear that abolishing all restrictions on immigration and sharing the problem of global poverty would overwhelm their health and social security systems (much more completely than any virus could do). This means, unfortunately, that visas and asylum claims will be with us for a long time to come.

\section{'Exceptions to the exception': the example of same-sex partner immigration in Europe}

As with all aspects of LGB equality, the struggle for legal change begins at the national level. Only when sufficient countries have amended national law (through executive, legislative or judicial action) is it possible to claim a particular right at the European level. In immigration law, the challenge has been to extend the exception for the differentsex spouses of citizens (to the exception for unequal treatment based on national citizenship) to the same-sex partners of citizens. Rules or policies on same-sex partner immigration were introduced in, for example, the Netherlands as early as $1975,{ }^{5}$ Denmark in $1989,{ }^{6}$ Australia in $1991,{ }^{7}$ New Zealand in $1993,{ }^{8}$ Canada in $1994,{ }^{9}$ the United Kingdom in $1997,{ }^{10}$ South Africa in $1999,{ }^{11}$ the USA in $2013^{12}$ and Hong Kong in $2018 .{ }^{13}$ At the global level, the progress seen in these and other countries remains the exception. Given that 63 per cent (122 of 193) of UN member states (including China, India, Indonesia, Japan, Russia and Turkey) either criminalise same-sex sexual activity or do not prohibit sexual-orientation discrimination and do not allow same-sex couples to register their relationships, it is likely that (at least) the same percentage 
of member states do not recognise same-sex partners in their immigration laws. ${ }^{14}$

\section{Same-sex partner immigration under the European Convention on Human Rights}

Less than two years after the European Court of Human Rights (ECtHR) found, in Dudgeon $v$ United Kingdom (22 October 1981), that blanket criminalisation of private, consensual, adult, same-sex sexual activity violated the right to respect for private life expressed in Article 8 of the European Convention on Human Rights (EConHR), the first case brought by a same-sex couple seeking legal recognition reached the former European Commission of Human Rights (EComHR). X \& YvUK (3 May 1983) concerned a male citizen of the UK whose male partner, a citizen of Malaysia, had been denied a UK residence permit and whose deportation had been ordered. The couple left the UK voluntarily for Sweden in January 1983. The EComHR declared their application inadmissible as manifestly ill-founded (not arguable): ${ }^{15}$ 'Despite the modern evolution of attitudes towards homosexuality, the [EComHR] finds that the applicants' relationship does not fall within the scope of the right to respect for family life ensured by Article 8.' Nor had there been an interference with their right to respect for private life, because they were 'professionally mobile': 'it has not been shown that the applicants could not live together elsewhere than the [UK], or that their link with the [UK] is an essential element of the relationship'.

In 1983 the EComHR was not ready to require an equal age of consent in criminal law (that would take until 1997), ${ }^{16}$ so it was too early to expect equal treatment in immigration law. First, the ECtHR (into which the EComHR was merged in 1998) would have to require equal treatment of unmarried same-sex and different-sex couples, ${ }^{17}$ find that 'the relationship of ... a cohabiting same-sex couple living in a stable de facto partnership, falls within the notion of "family life", just as the relationship of a different-sex couple in the same situation would' ${ }^{18}$ and require a residence permit for a same-sex partner when an unmarried different-sex partner would qualify. ${ }^{19}$

These developments set the stage for the case of Roberto Taddeucci \& Douglas McCall v Italy (30 June 2016). Mr Taddeucci, a citizen of Italy, and Mr McCall, a citizen of New Zealand, had been living together as a couple in New Zealand when they decided to move to Italy in December 2003. Their application for a family-member residence permit for Mr McCall was rejected in 2004, because the only kind of partner that 
Italian immigration law recognised was a different-sex spouse. Their final appeal to the Corte di Cassazione, the highest civil court, was dismissed in 2009, on the basis that there had been no discrimination contrary to Karner v Austria (ECtHR, 24 July 2003): same-sex couples were treated in the same way as unmarried different-sex couples, who were also ineligible for residence permits. In July 2009, after Mr McCall became legally obliged to leave Italy, he and Mr Taddeucci moved to the Netherlands, where Mr McCall was quickly granted a residence permit as the cohabiting partner of an EU citizen. There, they became 'love exiles'. ${ }^{20}$

The main legal obstacle in Taddeucci \& McCall was that the ECtHR had allowed Council of Europe member states to restrict marriage to different-sex couples ${ }^{21}$ and to restrict second-parent adoption to married different-sex couples. ${ }^{22}$ And the ECtHR had yet to require the extension of any specific right enjoyed by married different-sex couples (such as a residence permit) to same-sex couples. But, as the lawyer for the applicants, I argued that the ECtHR's 'indirect discrimination' analysis in Thlimmenos $v$ Greece (6 April 2000) could be applied:

44. The Court has so far considered that the right under Article 14 not to be discriminated against ... is violated when States treat differently persons in analogous situations ... However, the Court considers that this is not the only facet of the prohibition of discrimination ... The right... is also violated when States ... fail to treat differently persons whose situations are significantly different.

The applicants, who were unable to marry in Italy, were in a significantly different situation from that of an unmarried different-sex couple, who could easily solve their immigration problem by marrying in Italy.

The ECtHR agreed and found sexual orientation discrimination violating Article 14 combined with Article 8, respect for family life. The ECtHR first determined that, unlike in $X \& Y v U K$ in 1983, the relationship of the applicants "fell within the notion of "family life" "23 and that 'the refusal to grant [Mr McCall] a residence permit ... meant that he was legally obliged to leave Italy ... That decision ... prevented the applicants from continuing to live together in that country and thus amounted to an interference with ... their [Article 8] right to respect for family life ....24 Having found Article 14 applicable, combined with Article 8, the ECtHR noted that, under Article 14, 'an issue will arise when States fail to treat differently persons whose situations are significantly different (see Thlimmenos, ... [44] ...)': ${ }^{25}$ 
82. The Court finds that ... it does not appear that the applicants, an unmarried homosexual couple, were treated differently from an unmarried heterosexual couple. ... 83. That said, the applicants' situation cannot ... be regarded as analogous to that of an unmarried heterosexual couple. Unlike the latter, the applicants do not have the possibility of contracting marriage in Italy. ... [O]nly homosexual couples faced an insurmountable obstacle to obtaining a residence permit for family reasons. Nor could they obtain a form of legal recognition other than marriage, ... [such as] a registered partnership ... 85. ... [W]ith regard to eligibility for a residence permit for family reasons, the applicants - a homosexual couple were treated in the same way as persons in a significantly different situation from theirs, namely, heterosexual partners who had decided not to regularise their situation. ... 90.... [W] ith regard to the burden of proof ... under Article 14 ... once the applicant has shown the existence of comparable treatment in significantly different situations it is for the Government to show that such an approach was justified ...

With regard to justification, the ECtHR concluded:

93. ... regarding the matter in question here - granting a residence permit for family reasons to a homosexual foreign partner - [protection of the traditional family] cannot amount to a 'particularly convincing and weighty' reason capable of justifying ... discrimination on grounds of sexual orientation ... 94. Without any objective and reasonable justification the Italian State failed to treat heterosexual couples differently and take account of their ability to obtain legal recognition of their relationship ..., an option that was not available to the applicants (see Thlimmenos, ... [44]). ... 97. ... [T] he Government did not dispute ... the comparative-law survey carried out by ECSOL concluding that there was an emerging European consensus recognising, for the purpose of immigration rights, same-sex relations as 'family life' ...

In his concurring opinion, Judge Spano (now the President of the ECtHR) added:

2. ... [I]f States decide to exclude same-sex couples from being able to marry, such a decision may have consequences when this 
Court is called upon to examine a claim of unjustified discrimination within a specific context that falls within ... Article 8 taken in conjunction with Article $14 \ldots 3$. As Italy decided to afford foreign nationals the ability to request residence permits if they were 'family members' of citizens, the application of that system of domestic law could not be discriminatory ... It follows that the impossibility in Italy at the material time for same-sex couples to acquire marital status or other legal recognition of their relationship could not ... have made their relationships any less worthy of being treated as constituting a family unit within the particular context of immigration proceedings. ... 4.... [T] he fundamental principle of human dignity, ... one of the cornerstones of Article $8 \ldots$, guarantees to each and every individual the right to found a family with whomever they choose, irrespective of their ... sexual orientation.

Taddeucci \& McCall requires all 47 Council of Europe countries to treat a same-sex couple differently from an unmarried different-sex couple, with regard to a residence permit for a foreign partner (with no independent EU law right of residence), i.e. the same-sex couple must be granted some means of qualifying for the residence permit, other than by getting married (if that is how a different-sex couple qualifies). That could involve recognising a minimum period of cohabitation (two years in the UK) or creating an alternative registration system for them.

An unusual feature of Taddeucci \& McCall is that Italy complied with the judgment (provided a means for same-sex couples to qualify) before the judgment was published, through a law on civil unions for same-sex couples. ${ }^{26}$ This happened because the ECtHR had prioritised Oliari \& Others $v$ Italy (21 July 2015), perhaps as a 'reply' to the samesex marriage judgment of the Supreme Court of the United States (Obergefell $v$ Hodges, 26 June 2015). In Oliari \& Others, the ECtHR went as far towards equality as it could. It prioritised the case even though the legal issue was more difficult, and the applications had been lodged 18 months after the application in Taddeucci \& McCall. In Oliari \& Others, the ECtHR found that Italy's failure to provide a 'specific legal framework' for same-sex couples was a violation of Article 8 (respect for family life). Through a law on civil unions for same-sex couples, Italy complied both with Oliari \& Others (less than 10 months after the judgment) and with Taddeucci \& McCall (45 days before the judgment). ${ }^{27}$ 
After moving from Italy to the Netherlands in July 2009, Mr Taddeucci and Mr McCall were married at Amsterdam City Hall in May 2010. In theory, they could have asked Italy to recognise Mr McCall as a 'spouse' under Directive 2004/38 (on free movement of EU citizens and their family members) and, in the event of a refusal, they could have requested a reference to the Court of Justice of the European Union (CJEU). But, without their bringing a new case based on EU law, and without any guidance from the CJEU, Italian courts began to recognise same-sex marriages contracted in other EU member states in 2012. ${ }^{28}$ This helped many same-sex couples in Italy but, in the absence of a reference, the CJEU remained silent on the interpretation of 'spouse'. The ECtHR ruled in Taddeucci \& McCall that the developments in Italy in relation to EU law after July 2009 were irrelevant, because it was sufficient to examine the interference with the applicants' family life between October 2004 and July $2009 .{ }^{29}$

After the Taddeucci \& McCall judgment of 30 July 2016, the question of whether 'spouse' in Directive 2004/38 could include a same-sex spouse remained unanswered. An interpretation of 'spouse' was requested in 1986 by Ann Florence Reed, an unemployed British woman living with an employed British man in the Netherlands. Ms Reed and her male partner were not married but she argued that she should qualify for the right to reside in the Netherlands through a broad interpretation of 'spouse' in Article 10 of Regulation 1612/68 (repealed and replaced by Directive 2004/38). In Netherlands $v$ Reed (17 April 1986), at a time when the 12 EU member states included Ireland, Portugal, Spain, Italy and Greece (all conservative at the time with regard to the definition of the family), the CJEU was not ready to include an unmarried different-sex partner in the category of 'spouse': 'In the absence of any indication of a general social development which would justify a broad construction, ... it must be held that the term "spouse" in Article 10 of the Regulation refers to a marital relationship only. ${ }^{30}$

A similar question was posed 15 years later in $D$. \& Sweden $v$ Council (31 May 2001). At a time when only the Netherlands of the then $15 \mathrm{EU}$ member states allowed same-sex couples to marry, the CJEU was not willing to require that the Swedish-registered partnership of two men be treated in the same way as a different-sex marriage (in relation to a benefit for employees of EU institutions): 
34. ... [A]ccording to the definition generally accepted by the Member States, the term 'marriage' means a union between two persons of the opposite sex. ... 36.... [A]rrangements for registering relationships between couples not previously recognised in law are regarded in the Member States concerned as being distinct from marriage. 37. ... [T] he [CJEU] cannot interpret the Staff Regulations in such a way that legal situations distinct from marriage are treated in the same way as marriage. ${ }^{31}$

Another case was needed to give the CJEU a chance to change its mind. But taking a human rights issue to the CJEU is more difficult than taking the same issue to the ECtHR. In the EConHR legal system, an individual has an Article 34 right to take their case to (lodge an application with) the ECtHR, after exhausting remedies at the national level. In the EU legal system, an individual generally has no right to take their case directly to the CJEU, even after exhausting national remedies. They may only present their human rights issue to the CJEU if they can persuade a national court to refer their case to the CJEU. A case on the interpretation of 'spouse' would therefore require the right facts (a determined samesex couple, consisting of an EU citizen and a non-EU citizen, who had married in one EU member state and were seeking a residence permit in another EU member state) and some luck in the national court, which cannot be forced to make a reference to the CJEU. In 2005, an attempt to persuade an Austrian court to refer the case of a German-US same-sex couple, who had married in the Netherlands, was unsuccessful.

In October 2011, over 10 years after D. \& Sweden $v$ Council, I met Adrian Coman, a citizen of Romania, at a conference. He told me that he had married Clabourn Hamilton, a male citizen of the USA, in Belgium in 2010, while he was exercising his right as an EU citizen to work in Belgium (at the European Parliament). I urged him to request a residence permit for Mr Hamilton in Romania, challenge the likely refusal in the Romanian courts and request a reference to the CJEU. On 29 November 2016, Romania's Curtea Constitutională (Constitutional Court) referred four questions to the CJEU for a preliminary ruling. The CJEU held a 15judge Grand Chamber hearing on 21 November 2017 and published its judgment in Coman \& Hamilton on 5 June 2018, at a time when same-sex couples had (or were about to have) access to marriage in 14 of $28 \mathrm{EU}$ member states. ${ }^{32}$

The CJEU began its analysis by holding that Mr Coman and Mr Hamilton could not rely on Directive 2004/38, which provides in Article 3(1) that it applies to 'Union citizens who move to or reside in a Member 
State other than that of which they are a national'. They could rely on the Directive if they were seeking a residence permit for Mr Hamilton in Bulgaria or Poland, but not in Romania (the member state of which $\mathrm{Mr}$ Coman is a national). ${ }^{33}$ They could, however, rely on Article 21(1) of the Treaty on the Functioning of the EU or TFEU ('Every citizen of the Union shall have the right to move and reside freely within the territory of the Member States'), under conditions no stricter than those in Directive 2004/38, which must be applied by analogy: 'during the period of his genuine residence in Belgium [as a worker] pursuant to Article 7(1) of Directive 2004/38, Mr Coman created or strengthened a family life with Mr Hamilton'. ${ }^{34}$ Mr Coman's Article 21(1) TFEU rights 'include the right to lead a normal family life, together with [his] family members, both in the host Member State [Belgium] and in the Member State of which [he is a] national[] when [he] return[s] to that Member State [Romania]'. ${ }^{35}$

Does Mr Hamilton qualify as a 'family member' of Mr Coman, his 'spouse', under Article 2(2) (a) of Directive 2004/38? The CJEU finally answered the question left open when the EU legislature chose not to define 'spouse' in 2004: 'As to whether that term ['spouse'] includes a third-country national of the same sex as the Union citizen whose marriage to that citizen was concluded in a Member State in accordance with the law of that state [it is not clear whether it is essential that the marriage was concluded in an EU Member State], it should be pointed out ... that the term "spouse" within the meaning of Directive 2004/38 is gender-neutral and may therefore cover the same-sex spouse of the Union citizen concerned.' ${ }^{36}$

Under Article 2(2) (b) of Directive 2004/38, Romania would not be obliged to recognise a same-sex registered partnership from another EU member state, because Romania has no such law 'treat[ing] registered partnerships as equivalent to marriage'. But the absence of a reference to 'the legislation of the host Member State' in Article 2(2)(a) means that Romania 'cannot rely on its national law as justification for refusing to recognise ..., for the sole purpose of granting a ... right of residence to a third-country national, a marriage concluded by that national with a Union citizen of the same sex in another Member State in accordance with the law of that state'. ${ }^{37}$ This is true even though Romania, exercising its competence over family law, is 'free to decide whether or not to allow marriage for persons of the same sex' in Romania. ${ }^{38}$ EU law intervenes, exceptionally, because the effect of refusing to recognise a same-sex marriage from another member state is that 'a Union citizen may be denied the possibility of returning to the Member State of which he is a national together with his spouse' ${ }^{39}$ The recognition required by Article 
21(1) 'does not undermine the institution of marriage' in Romania, because it is 'for the sole purpose of enabling persons [of the same sex] to exercise the rights they enjoy under EU law'. ${ }^{40}$ This obligation 'does not undermine the national identity or pose a threat to the public policy of the Member State concerned'. ${ }^{41}$

What is striking about Coman \& Hamilton is that the CJEU was determined to base its judgment on liberty (the right of an EU citizen to freedom of movement), rather than on equality (the right of an EU citizen to be free from discrimination based on sexual orientation). Even though Romania recognises different-sex marriages from other EU member states, and from non-EU countries, the word 'discrimination' does not appear in the CJEU's reasoning. It appears only in references to Recital 31 of Directive 2004/38 and to the proceedings in the Romanian courts. Article 21 of the Charter of Fundamental Rights of the EU ('Any discrimination based on any ground such as ... sexual orientation shall be prohibited.') is not cited, even though it was cited by the Constitutional Court of Romania in its first two questions (the ones that the CJEU answered), and should influence the interpretation of the term 'spouse' in Directive 2004/38.

The CJEU was also careful not to cite Taddeucci \& McCall, despite its obvious relevance (probably because it found sexual orientation discrimination), and Oliari \& Others, to avoid appearing to suggest that Romania is also obliged to introduce a 'specific legal framework' for same-sex couples. Advocate General Wathelet's Opinion (11 January 2018) cited Article 21 of the Charter and sought to avoid sexual orientation discrimination: "A definition of the term "spouse" that was limited to heterosexual marriage would inevitably give rise to situations involving discrimination on grounds of sexual orientation. ${ }^{42} \mathrm{He}$ concluded that 'refusal to grant the application for ... residence of a third-country national, of the same sex as the citizen of the [EU] to whom he or she is married ..., may not be ... based on his or her sexual orientation, without infringing Articles 7 [respect for family life] and 21 of the Charter. ${ }^{43}$ He cited Taddeucci \& McCall seven times, and Oliari \& Others five times.

Coman \& Hamilton is a very important judgment, because it is the first time that the CJEU has included same-sex couples in the concepts of 'spouse' and 'marriage'. It has already been followed by national courts: the Constitutional Court of Lithuania on 11 January 2019, and the Supreme Court of Bulgaria on 24 July 2019. But it is important to recognise the judgment's limits. It requires Romania to recognise a same-sex marriage from another member state 'for the sole purpose of granting a derived right of residence to a third-country national', a phrase the CJEU 
used four times. ${ }^{44}$ The CJEU does not yet require Romania to recognise a married same-sex couple for any other purpose of Romanian law. Nor does Coman \& Hamilton help the majority of Romanian same-sex couples who are in 'internal situations': they have yet to exercise their EU law right to reside in another member state, have stayed in Romania and have not been able to marry. Such couples may rely on Taddeucci \& McCall, who were also in an 'internal situation' to which EU law did not apply but to which the EConHR did apply. As for their having access neither to marriage nor to registered partnership, 13 same-sex couples have taken a case to the ECtHR, seeking to extend Oliari \& Others to Romania. ${ }^{45}$

\section{Conclusion}

The 'exception to the exception' in immigration law for the foreign samesex spouse or partner of a citizen is valuable. Indeed, for binational samesex couples, the right to live together in the same country is essential for their relationship to survive. Because of its urgency, it is often the first form of legal recognition of same-sex couples, as it was in the UK in 1997, seven years before the Civil Partnership Act 2004. The ECtHR now requires recognition in the immigration law of all 47 Council of Europe countries. And the CJEU has incorporated the same-sex 'spouse' into the more favourable rules applying to EU citizens moving with their family members to other member states or returning to their own member state.

Many lucky same-sex couples will benefit from these developments. But what if the gay man in Bangladesh does not succeed in finding a European boyfriend and cannot find a way to get to Europe to claim asylum? Let us hope that, someday in the future, visas and asylum claims will no longer be required. It is hard to predict which will take longer to achieve: global LGB equality or global freedom of movement.

In closing, it is worth noting the astonishing hypocrisy of European anxiety about immigration from other continents. ${ }^{46}$ People should not arrive in Europe on boats without permission. How did Europeans travel, from 1492 on, to Canada, the USA, Mexico, Colombia, Brazil, Argentina, Australia and New Zealand? By boat and without the permission of the indigenous peoples who formed 100 per cent of the population of those territories before the European invasion began. The big mistake of the indigenous peoples of the Americas was their failure to deny Christopher Columbus entry, for want of a valid visa, and to put him on the first boat back to Spain. 


\section{Epilogue}

As of August 2020, Mr Hamilton had not received his Romanian residence permit, more than two years after the CJEU's judgment in Coman \& Hamilton. Let us hope that the European Commission will take action to enforce the supremacy of EU law.

\section{Acknowledgement}

Thanks to Alina Tryfonidou for her comments on an earlier draft.

\section{Notes}

1. I will not discuss transgender or intersex persons in this chapter, but successful same-sexpartner immigration claims make legal sex irrelevant for immigration claims based on being a member of a couple, and therefore benefit transgender and intersex persons. The term 'queer', used in the title of this book, is one that I consider pejorative and would not use myself.

2. See Chapter 5 by Nuno Ferreira.

3. See Case C-638/16 PPU, $X$ and $X v$ État belge (CJEU, 7 March 2017) (no EU law obligation to grant a humanitarian visa to a Syrian family seeking to escape from Aleppo); M.N. and Others $v$ Belgium (ECtHR, 5 May 2020) (no EConHR obligation either: 'the applicants [at the Belgian embassy in Beirut] were not within Belgium's jurisdiction as regards the circumstances in respect of which they complain').

4. See http://yogyakartaprinciples.org (accessed 30 April 2020).

5. Waaldijk 2005, 146-7, C2.

6. Lov om registreret partnerskab (Law on registered partnership), Act No. 372, 7 June 1989.

7. Migration Regulations (Amendment) 1991 No. 60 (Cth), reg. 17.

8. Stewart 1993, 33, cited in Seuffert 2009, 131.

9. See LaViolette 2004, 969.

10. Concession Outside the Immigration Rules for Unmarried Partners (13 October 1997). Available at: www.refworld.org/docid/3ae6b5764.html (accessed 30 April 2020). Moved to Immigration Rules on 2 October 2000 (see now Rule 295).

11. National Coalition for Gay and Lesbian Equality $v$ Minister of Home Affairs (Constitutional Court, 2 December 1999).

12. United States $v$ Windsor, 570 U.S. 744 (26 June 2013), required that federal immigration law recognise same-sex marriages for the first time.

13. Q.T. $v$ Director of Immigration, [2018] HKCFA 28 (Hong Kong Court of Final Appeal, 4 July 2018).

14. See ILGA World 2019.

15. (No. 9369/81) (Decision of 3 May 1983). The EComHR later declared three other applications in same-sex partner immigration cases inadmissible: W.J. \& D.P. v UK (No. 12513/86) (Decision of 11 September 1986); C. \& L.M. $v$ UK (No. 14753/89) (Decision of 9 October 1989); B. $v$ UK (No. 16106/90) (Decision of 10 February 1990).

16. Sutherland $v$ UK (No. 25186/94) (Report of 1 July 1997).

17. Karner v Austria (24 July 2003). Compare Grant $v$ South-West Trains (CJEU, 17 February 1998) (at the time, EU law permitted sexual orientation discrimination against unmarried same-sex couples, compared with unmarried different-sex couples).

18. Schalk \& Kopf v Austria (24 June 2010), para. 94.

19. Pajić v Croatia (23 February 2016).

20. See www.loveexiles.org/home.htm, a pre-2013 website (accessed 30 April 2020).

21. Schalk \& Kopf v Austria (24 June 2010).

22. Gas \& Dubois v France (15 March 2012).

23. Taddeucci \& McCall, para. 58. 
24. Para. 59.

25. Para. 81.

26. Legge 20 maggio 2016 (Law of 20 May 2016), n. 76, Regolamentazione delle unioni civili tra persone dello stesso sesso. Available at: www.gazzettaufficiale.it/eli/gu/2016/05/21/118/sg/ pdf (accessed 30 April 2020).

27. Legge 20 maggio 2016, Art. 1, para. 20; 'Circolare n.3511 del 5 agosto 2016 [Circular of 5 August 2016] che fornisce indicazioni operative ... ai fini del rilascio del nulla osta al ricongiungimento familiare'. Available at: www.libertaciviliimmigrazione.dlci.interno.gov. it/sites/default/files/allegati/circ._prot._nr._3511_del_05.08.2016.pdf (accessed 30 April 2020). See also Orlandi and Others $v$ Italy (ECtHR, 14 December 2017) (the 'specific legal framework' of Oliari and Others must be applied to same-sex couples who married outside of Italy).

28. Tribunale di Reggio Emilia, 13 February 2012. Available at: www.ilcaso.it/giurisprudenza/ archivio/7052.pdf (accessed 20 April 2020).

29. Taddeucci \& McCall, paras 61-3.

30. Case $59 / 85$, para. 15 .

31. Joined cases C-122/99 P and C-125/99 P.

32. Case C-673/16. I advised the Romanian lawyers of Mr Coman and Mr Hamilton throughout the case and attended the hearing. For a list of the 14 member states, see Opinion of Advocate General Wathelet (11 January 2018), para. 58, nn. 37, 42.

33. Paras 19-21.

34. Paras 24-6. The 'genuine residence' requirement precludes 'marriage tourism'.

35. Para. 32.

36. Para. 35.

37. Para. 36.

38. Para. 37

39. Para. 40

40. Para. 45.

41. Para. 46.

42. Paras 5,75 .

43. Para. 98.

44. Paras $36,40,45,46$ (emphasis added).

45. Buhuceanu \& Ciobotaru v Romania, Application no. 20081/19 (communicated on 16 January 2020). Available at: http://hudoc.echr.coe.int/eng?i=001-200952 (accessed 30 April 2020).

46. See the poster of the Northern League political party in Italy, showing an indigenous North American man: 'Loro hanno subito l'immigrazione. Ora vivono nelle riserve!' ('They suffered from immigration. Now they live on reservations!'). Available at: http://news.bbc.co.uk/2/ hi/europe/7350691.stm (accessed 30 April 2020). See also the 'Breaking Point' poster of the United Kingdom Independence Party, showing a queue of non-EU migrants at an EU border, which was published on 16 June 2016, one week before the referendum on the UK's membership of the EU. Available at: www.theguardian.com/politics/2016/jun/16/nigel-faragedefends-ukip-breaking-point-poster-queue-of-migrants (accessed 30 April 2020).

\section{References}

ILGA World. 2019. State-Sponsored Homophobia (13th edn). Geneva: ILGA.

LaViolette, Nicole. 2004. 'Coming out to Canada: The immigration of same-sex couples under the Immigration and Refugee Protection Act', McGill Law Journal/Revue de droit de McGill 49:974-1003.

Seuffert, Nan. 2009. 'Same-sex immigration: Domestication and homonormativity'. In Changing Contours of Domestic Life, Family and Law: Caring and sharing, edited by Anne Bottomley and Simone Wong, 131-49. Oxford: Hart Publishing.

Stewart, Blair. 1993. 'New Zealand immigration law and gay and lesbian couples', Australian Gay and Lesbian Law Journal 3, 30-8.

Waaldijk, Kees (ed.). 2005. More or Less Together: Levels of legal consequences of marriage, cohabitation and registered partnership for different-sex and same-sex partners: A comparative study of nine European countries. Paris: INED. Available at: http://www.ined.fr/fichier/s_rubrique/ 19409/document_de_travail_125.fr.pdf (accessed 30 April 2020). 


\section{'The gay person always looks for the big European city': the sexual migration of Latin American gay men in London}

Cristian Valenzuela

\section{Introduction}

Every day, LGBTQ ${ }^{1}$ individuals from different parts of the world leave their countries and embark on a new chapter in their lives in a new city. For decades, major cities - such as London - have offered a safe haven of self-expression and community for all kinds of queer ${ }^{2}$ people who, for one reason or another, have left their homes. LGBTQ migrants who have settled in new urban spaces and communities have, on the one hand, seen their identity and sexuality transformed by their destination cities and, on the other, also impacted the development of queer spaces and neighbourhoods (Weston 1995; Binnie 2004).

Most scholarship on migration research, however, has historically conceived migrants as heterosexual, depicted the (hetero) family as the main focus of migration policies, and rendered queers and sexual characteristics invisible (Luibhéid 2008; Epstein \& Carrillo 2014). Migration literature has traditionally focused on the economic drives behind migration, assuming that people move abroad prioritising labour skills, higher income or work opportunities (Cantú 2009). It was not until recent decades that scholars explored the relationship between migration and sexuality further, developing concepts such as 'sexual migration' and 'queer migration', which analyse the motives and effects of migration through a gendered and sexualised lens (Lewis 2014). Scholars have shown that queer people migrate for reasons linked 
to their sexuality and not exclusively because of economic or familial drivers - although different reasons do overlap and intertwine (GormanMurray 2009) - and that migration (re)shapes sexual practices and identities (Carrillo 2004).

In order to elucidate these experiences fully, Carrillo characterises 'sexual migration' as a multidimensional concept and defines it as 'international relocation that is motivated, directly or indirectly, by the sexuality of those who migrate' $(2004,58)$. He additionally suggests that in order to 'conceptualize sexual migration fully, we need to consider a number of dimensions associated with this kind of transnational movement' $(2004,58)$. This conceptualisation is relevant because it considers not only pre-migration aspects, such as migration motives, but also post-migration characteristics and dimensions, including:

sexual immigrants' transportation of practices across international borders, their lives in their places of origin, their exposure to local and foreign sexual ideologies prior to migrating, their agency in adapting and appropriating ideologies and practices prevalent in both home and host countries, and the transformations in sexual identities and behaviors that they experience after migration.

Following Carrillo's holistic understanding, this article aims to explore the sexual migration experiences of Latin American gay men in London, by focusing on three key dimensions of this phenomenon: (1) sexual migration motives, (2) sexual resocialisation, ${ }^{3}$ and (3) sexual migrants' relationship with spaces and communities. Each dimension engenders its corresponding research question(s):

1. Sexual migration motives: What motivated Latin American gay men to leave their home country, and why did they choose London? What role has their sexuality played in their decision to move to and stay in London?

2. Sexual resocialisation: How has migrating to and living in London influenced and transformed Latin American gay men's perception, experience and understanding of sexuality, including their sexual practices and their knowledge of sexual health?

3. Spaces and communities: What are the communities and spaces with which Latin American gay men interact once settled in London? What is their relationship with London's Latin American and LGBTQ spaces and communities? 
This study is one of the first original pieces of social research on the lived experience of queer individuals from Latin America in London. While the migration experiences of Latin American non-heterosexual men has been extensively researched in the USA (Cantú 2009), it is understudied in the United Kingdom and Europe. Significant research exists on Latin American migrants in London (McIlwaine \& Bunge 2016), LGBTQ urban spaces in London (Venturi 2016; Andersson 2009), gay migrants in Europe (Mole et al. 2014, 2017) and Latin American queer migrants in other cities such as New York, Miami and Sydney (Bianchi et al. 2007; Egan et al. 2011; Lewis 2014). However, to my knowledge, this study is the first piece of academic research focused on Latin American gay or queer migrants in the UK's capital. In McIlwaine, Cock and Linneker's (2011) terms, this social group remains an 'invisible population', and this study is a step towards Latin, queer, and queer Latin visibility.

This chapter uses qualitative data, gathered from in-depth interviews with 14 Latin American gay men who were living and working in London. It cannot account for the experience of all Latin American gay men, in London or elsewhere, nor are its findings intended to be generalised or applicable to other contexts. As with most qualitative studies, the knowledge gathered and constructed in this study is intended to fill a gap in the existing literature, shed light on certain non-hegemonic voices, and develop new insights for migration and queer theory across the social sciences.

\section{Methodology}

As mentioned above, this study analyses qualitative data collected through in-depth semi-structured interviews with 14 participants. Participants were asked about their sexual identity, their motives for migration, their perceptions of their home country and of London, changes in their understanding of sexuality and sexual health and practices, and Latin American and queer/LGBTQ spaces and networks.

Interviews were conducted in Spanish ${ }^{4}$ in June and July 2017 in a location agreed with each interviewee, and lasted between 50 and 80 minutes. All the participants received a description of the study's objectives and methodology, signed an individual consent form and were informed that responses were confidential and that they would remain anonymous. Interviews were analysed and coded via an open coding process (Flick 2014). Most of the codes were developed and grouped 
according to the three pre-identified research dimensions and then related via an axial coding process. Codes unrelated to the three original dimensions, which emerged inductively out of topics that arose spontaneously during the interviews, were then included in the analysis and axial code-relating process.

Participants had to be originally from a Spanish-speaking Latin American country, ${ }^{5}$ identify as gay/homosexual or queer, ${ }^{6}$ live and work in London ${ }^{7}$ and have resided in London for at least one year. The average participant age was 35.7, with a range of 27 to 44 . All participants except three were in their thirties and originated from eight different countries. On average, participants had lived in London for 9.6 years and all selfidentified as gay.

It is important to highlight that this study focuses on Latin American gay men. This means, unfortunately, that other queer or non-heterosexual subjectivities and identities - from lesbian women to transgender individuals - are not represented. Considering the effectiveness of small-scale qualitative research on smaller participant pools (Choubak 2014), I focused on one particular group as a way of acquiring in-depth knowledge about these participants. I strongly believe that future research on sexuality and migration must continue to shed light on a wider variety of identities and subjectivities.

It is also important to highlight the sample's educational levels. As shown in Table 3.1, 10 of the 14 interviewees had obtained an undergraduate or postgraduate university degree, which indicates a highly educated sample of gay men. The high proportion of welleducated migrants in this group, however, aligns with Latin American migrants in London as a whole: Latin Americans in the city are a particularly well-educated group (an estimated 50 per cent have reached university-level education), possibly the most highly educated migrant community in London (McIlwaine \& Bunge 2016). ${ }^{8}$ This is due, in part, to high educational and/or employment requirements for overseas visa applicants. According to Adam and Rangel (2015), migrants from Latin America with lower educational or economic attainment have more difficulties in crossing the Atlantic and therefore exclude Europe as an option (or need to apply for European asylum). ${ }^{9}$ Additionally, while university-educated, many participants do not work in their areas of study or expertise and some have experienced downward mobility, which is not uncommon among Latin Americans in London (McIlwaine \& Bunge 2016). 
Table 3.1 Demographic information of the 14 research participants. Eight different Latin American countries are represented, although half of the participants are from Colombia. All participants are between 27 and 42 years of age. This is also a highly educated sample of Latin American men, as all have finished secondary education and most have university degrees.

\begin{tabular}{|l|l|l|l|l|l|}
\hline Pseudonym & $\begin{array}{l}\text { Country } \\
\text { of origin }\end{array}$ & City of origin & Age & $\begin{array}{l}\text { Years in } \\
\text { London }\end{array}$ & $\begin{array}{l}\text { Highest } \\
\text { completed } \\
\text { education } \\
\text { level }\end{array}$ \\
\hline Luis & Argentina & Buenos Aires & 30 & 2 & $\begin{array}{l}\text { Secondary } \\
\text { Education }\end{array}$ \\
\hline Adrián & Bolivia & Santa Cruz & 36 & 3 & $\begin{array}{l}\text { Postgraduate } \\
\text { Degree }\end{array}$ \\
\hline Manuel & Chile & Santiago & 35 & 9 & $\begin{array}{l}\text { Postgraduate } \\
\text { Degree }\end{array}$ \\
\hline Bernardo & Colombia & Cartagena & 35 & 10 & $\begin{array}{l}\text { Undergraduate } \\
\text { Degree }\end{array}$ \\
\hline Emilio & Colombia & Montería & 30 & 5 & $\begin{array}{l}\text { Undergraduate } \\
\text { Degree }\end{array}$ \\
\hline Gabriel & Colombia & Manizales & 38 & 8 & $\begin{array}{l}\text { Postgraduate } \\
\text { Degree }\end{array}$ \\
\hline Hernán & Colombia & Bogotá & 42 & 13 & $\begin{array}{l}\text { Postgraduate } \\
\text { Degree }\end{array}$ \\
\hline Ignacio & Colombia & Medellín & 36 & 7 & $\begin{array}{l}\text { Postgraduate } \\
\text { Degree }\end{array}$ \\
\hline José & Colombia & Bogotá & 37 & 12 & $\begin{array}{l}\text { Postgraduate } \\
\text { Degree }\end{array}$ \\
\hline Orlando & Colombia & Tunja & 37 & 14 & $\begin{array}{l}\text { Secondary } \\
\text { Education }\end{array}$ \\
\hline Déstor & Uruguay & Montevideo & 44 & 17 & $\begin{array}{l}\text { Secondary } \\
\text { Education }\end{array}$ \\
\hline
\end{tabular}




\section{'Get thee to a big city': sexual migration, urban space and London}

During the late twentieth century, as major Western cities became destinations for both intra-national and international migrants, the idea of 'moving to the big city' became a central element in the sexual identities and biographies of non-heterosexuals. Kath Weston (1995) titled her seminal work on migration and gay narratives 'Get thee to a big city', as it became a widespread goal for countless gays in the USA during the 1970s and 1980s. Large city crowds offered freedom and urban migration became the key component of coming-out stories (D'Emilio 1997; Morales, Corbin-Gutierrez \& Wang 2013).

The distinction between the big city and the small town came to be embedded in Western gay consciousness and became a symbolic opposition 'at the heart of many narratives of identity formation' of queer individuals (Binnie 2004, 92). In this narrative, large Western cities became 'queer homelands' (spaces which ensured self-expression, anonymity and liberation, offering gay villages which served as safe spaces for queer individuals to reside and interact with each other, many for the first time; Hubbard 2012), often in opposition to small towns or rural areas which are, in turn, conflated with homophobia and oppression. Gay villages, therefore, are responsible for historic patterns of gravitational gay migration, by queers seeking peers, community and relationships (Gorman-Murray 2009).

Through transnational and globalising processes, media and cultural products, the gay lives of cities like New York (Chauncey 1994) and London (Houlbrook 2006) are known worldwide. Intertwined with the development of consumer capitalism, commodified gay lifestyles - which conflate notions of freedom and self-expression with the consumption of products and spaces - have been key in the construction of contemporary Western gay identities and led countless queer individuals to major urban centres (Bell \& Binnie 2004).

London has positioned itself as an international pole of queer culture and LGBTQ migration, largely through media portrayals and cultural products (Binnie 2004) and important advances in rights and sexual citizenship in both the UK and the EU (Richardson 2000). In addition to Soho, London's most famous and touristy gay village (Venturi 2016), multiple clusters of LGBTQ spaces can be found throughout the capital, from Shoreditch to Vauxhall, creating a polycentric network of LGBTQ scenes, which cater to a wide variety of alternative styles, subjectivities and sexualities (Andersson 2009, 2011). Venues and events serving to a 
range of queer communities of colour have also emerged in the city, such as Exilio in Soho and Maricumbia in East London, oriented to London's Latinx communities (Campkin \& Marshall 2017).

A magnet for international migrants, London is home to a wide variety of nationalities and ethnicities (Stillwell 2010), including an estimated 145,000 Latin Americans (McIlwaine \& Bunge 2016). However, despite a large growth in Latin American migration to London during the first decade of the twenty-first century, ${ }^{10}$ this group remains underrepresented in the UK's media, policy and academic research, to the point of being referred to as London's invisible population (McIlwaine, Cock \& Linneker 2011).

While the first significant wave of Latin Americans migrating to London occurred in the 1970s and 1980s, as a result of dictatorships and political unrest, over half of all migrants have arrived since 2000, making it a fairly new population in the city (McIlwaine \& Bunge 2016). From census data, London's Latin American population is composed mainly of Brazilians (37.7 per cent), Colombians (23.2 per cent), Ecuadorians (8.6 per cent), Argentinians (5.5 per cent), Venezuelans (4.6 per cent) and Mexicans (4.5 per cent). ${ }^{11}$ Approximately a third had previous migration experiences, typically arriving in London from another European country (in most cases Spain). Slightly over 50 per cent have tertiary education, which indicates a highly educated population, especially compared with other migrant communities (only 34 per cent of London's population has some level of university qualification; McIlwaine \& Bunge 2016). Despite this, almost half of Latin Americans in the city work in service, care or low-paid elementary jobs, which suggests significant levels of downward mobility and possible social vulnerability. Much of the existing in-depth qualitative research on Latin Americans in London has been carried out by Cathy Mcllwaine, who has found that, among a variety of interconnected motives, most Latin American migrants leave their home countries for economic reasons, were drawn to London's image of tolerance and openmindedness, relied on existing connections and social networks to access early jobs, and went through changes in their gendered practices and ideologies after migrating to London (McIlwaine 2010; McIlwaine, Cock \& Linneker 2011; McIlwaine \& Bunge 2016).

Aside from census data which states that 2.4 per cent of Latin Americans in London are in legally recognised same-sex partnerships, all existing data focuses on the Latin American migrant population in general, and thereby renders sexuality-related topics invisible. This study, therefore, adds to the existing literature by focusing specifically on the experience of Latin American gay male migrants in London. 


\section{The tensions and contradictions between LGBTQ and Latin America}

The reality of LGBTQ people in Latin America, a region of contradictions and contrasting realities regarding gender and sexuality, is complex. Latin American cultures, while different in every country and region, are known for the primacy of family relations, highly differentiated gender roles, elevated levels of Catholicism, and a history of machismo (McIlwaine 2010), which strongly reproaches homosexuality. Latin American men who have sex with men also perform binary gendered patterns and reproduce dichotomous active/passive roles in sexual and romantic relationships more frequently than gay men in Anglo-Western and European contexts (Carrier 1995; Carrillo \& Fontdevila 2014). Strict gender roles and religiosity persist in the region, and homophobic and transphobic violence is still a common reality in cities and rural areas alike. $^{12}$

Nonetheless, many Latin American countries and cities have progressed towards cultural acceptance and legal recognition. For instance, Argentina and the district of Mexico City were pioneers in legalising same-sex marriage, in 2010 and 2009 respectively (Pierceson 2012). At the time of writing, six countries in the region have legalised same-sex marriage and two others have legally binding civil partnership. Additionally, cities like Bogotá and Mexico City have thriving gay villages and queer nightlife industries, which have become nodes of LGBTQ-oriented venues, gay tourism and Pride events (Figari 2010). Thus, the experience of queer people in Latin America varies significantly in different areas. It is a region characterised by diverse (and frequently conflicting) understandings of homosexuality as well as by tensions between advances in progressive values, queer rights and visibility, which coexist with persistent homophobia, violence and normative gender expectations (Adam \& Rangel 2015).

Differences between rural and urban areas are especially stark, as well as those between social classes. Acceptance and support of LGBTQ rights are higher in major cities and at higher socio-economic levels. Large Latin American capitals have therefore become attractive to queer youth from towns or rural areas (Brown, Larson \& Saraswathi 2002). Nonetheless, sexual intra-regional Latin American migration is vastly under-studied in academic literature and would be an interesting area to explore in future studies.

Most research on international queer migrants from Latin America focuses on experiences in the USA (Bianchi et al. 2007; Cantú 
2009; Epstein \& Carrillo 2014), a country which receives thousands of immigrants per year and holds a Latino-identifying population of approximately 60 million (Pew Research Center 2019). There is an important gap in the academic literature regarding the experience of Latin American queer people outside of North America, in contexts where 'Latino' does not carry the same expectations, cultural connotations and specific kind of Otherness (Lewis 2014). The USA, in contrast to the UK, is a country with a strong geographical proximity to Latin America, important geopolitical conflicts and connections with the region, and a large Latin American population and Spanish-speaking communities, which have attracted significant levels of discrimination in everyday experiences as well as discriminatory policies (Pérez, Fortuna \& Alegria 2008; Pew Research Center 2018).

Like other Latin American migrants to the USA, non-heterosexual migrants from Latin America may seek to improve their finances and education, find better jobs and have a series of other economic and professional motives in addition to reasons relating to well-being and their sexuality (Bianchi et al. 2007; Shedlin et al. 2006). Researchers have highlighted that a macho culture, high levels of Catholicism, strong family structures and heteronormative spaces propel sexual and queer migration of Latin Americans towards the USA. In line with Weston's narrative (1995), migration to large American cities is an opportunity to express oneself in a space free of religion and family ties.

While Latin American neighbourhoods and communities exist in many major cities, queer Latin American migrants, or 'brown queers', may find difficulties in connecting with Latin American spaces and communities, many of which are family-oriented, heteronormative, or populated with unsupportive family members, forcing some Latin American migrants to 'downplay their sexual orientation' amongst co-nationals (Gray, Mendelsohn \& Omoto 2015). Furthermore, while many migrants access queer networks, many feel excluded from gay spaces, which in many cases are dominated by mainstream white representations of homosexuality (Teunis 2007; Gray, Mendelsohn \& Omoto 2015). Nonetheless, at the same time, as Gray, Mendelsohn \& Omoto (2015) assert, the intersectional positioning of queer Latino migrants may give them the particular privilege of accessing at first hand not only Latin American LGBTQ spaces but also both LGBTQ and Latin American communities in their cities of residence, reaching a greater number of support networks.

Furthermore, migration experiences and processes of sexual resocialisation may significantly impact Latin American queer men's sexual identity and practices. Carrillo \& Fontdevila (2014) found 
that the post-migration experiences of Mexican gay immigrant men in California influenced their desires and practices: while most men left Mexico with rigid and highly gendered conceptions of same-sex roles, many transformed their perception towards a more egalitarian understanding of homosexuality. When analysing the experience of Latin American gay migrants in New York City, both Bianchi et al. (2007) and Egan et al. (2011) concluded that the initial period after migration can be related to an increase in sexual activity and encounters, as the urban anonymity as well as the number of spaces to meet other gay men resulted in a feeling of sexual freedom, sexual exploration with a greater number of partners and, in some cases, greater drug use.

\section{Sexual migration motivations and London's multicultural big-city anonymity}

Among the sample of participants for this study, all but three had already come out of the closet - at least to some friends or family - in their home countries. Therefore, while participants' sexuality always held an important place in their migration experiences, the tales of these men do not necessarily fit the 'coming out in the big city' narratives established by Weston (1995) and often present in sexual migration findings (Rodriguez 2011), which conflate urban migration and coming out processes. Participants' experiences reveal, however, that migration processes are deeply intertwined with sexuality for reasons beyond coming out, such as the search for greater freedom, self-expression and new sexual experiences.

In many cases, the migration experiences of participants were multi-motivated, combining sexuality-related reasons with economic or professional ones. Ignacio, for example, left Medellín because it seemed dangerous, because he wanted to improve his English, and also because it felt closed-minded: he wanted somewhere he could be himself and more comfortable with his sexuality. When asked about the role of his sexuality in his migratory decisions, he said: ${ }^{13}$

I could be myself in my city and with my friends but not with my family. And that is something that definitely had an influence. Obviously when I made the decision to leave, I wanted an open-minded place, which accepted homosexuality as something normal. I mean, I would not have gone to a country where I couldn't be myself.

(Ignacio, 36; emphasis added) 
One day a girl in the university screamed at me, 'Walk like a man!', and everyone looked at me. ... Situations like this didn't happen regularly to me. I can count them on the fingers of one hand. However, they have been enough to, sometimes, hide my feathers. ... I eventually felt trapped. I felt trapped in this culture; I felt that I couldn't completely come out of the closet. I knew there were places where I could be free ... where there were gay cafés and institutions that fought for gay rights, which wasn't a big thing in Bogotá at the time.

(Orlando, 37; emphasis added)

Yes, sexuality played an important role [in my deciding to migrate]. As I mentioned, I wasn't happy working in Chile, mainly because of my experience working in my company. It wasn't the company's fault - it was actually a really good job. It was the social context. The fact that you could not talk about your partner if you were gay or about what you did at the weekend. ... You are not being completely genuine.

(Manuel, 35)

The participants' decision to migrate was driven by the impossibility of fully expressing their queer selves in one or multiple contexts. As shown in the previous quotes, Orlando felt 'trapped' in his culture, Manuel did not feel he could be 'completely genuine' or talk about his partner at work and Ignacio could not 'be himself' with his family. Despite their already being out - at least in certain social circles - migrating would bring greater freedom and self-expression, less self-policing and more possibilities to be their genuine selves.

In their home countries, many participants had gay friends and were (or had been) in long-term relationships. This means they had at least some spaces where they could express their non-heterosexuality, some even with their families. However, despite the privilege of accessing such spaces, participants shared a feeling of dissatisfaction, restriction and lack of the freedom to fully be themselves. These examples reaffirm tensions between homosexuality and heteronormative culture in Latin America (Adam \& Rangel 2015), where gay men may tend to be in the closet in certain circles and openly gay in others.

Most of these men-like Manuel-were employed in good jobs in their home countries but decided to migrate anyway, a finding which reaffirms Carrillo's (2004) call to assess economic migration theories critically and challenges the primacy of economic motivations among the (mostly heterosexual) Latin Americans in London interviewed by McIlwaine, Cock and Linneker (2011). As Binnie asserts, 'the desire to produce a queer 
self means people are willing to make economic sacrifices to leave settled lives and jobs behind to relocate to the big city and make do with temporary, less well-paid jobs' (Binnie 2004, 89). While some interviewees indeed escalated to higher-paid positions after moving to London, most took a step down professionally, entering positions of lower status than their previous employment, at least initially. This is well exemplified by Luis: 'I could have lived in Buenos Aires peacefully; it wasn't bothering me that much; my job was good. ... But I think there were other things to see. ... I think the gay person always looks for the big city in Europe.'

Migration processes do not only involve leaving one place and arriving at another; they also entail adjusting and adapting to that new place. The following paragraphs focus on aspects of London which have made it an attractive destination. According to the participants, London's anonymity, multiculturalism and potential for self-expression stand out as its most desirable qualities. Interviewees appreciated London because it felt big: it made them feel anonymous and free from the possible surveillance of family members and society in general. This was a feeling shared by participants migrating from both small and large cities in Latin America. José, for example:

I wanted to be out of Colombia, [to be in a place] where everything that I did was completely irrelevant to everyone. I mean, I wanted to be completely anonymous. Even though the situation for gays has improved in Colombia, your family is still there, people still judge. ... Get out of there, become anonymous.

(José, 37; emphasis added)

In Bogotá, a city of over eight million inhabitants, José had a good, stable job, was out to his family, was an active participant in nightlife spaces and had already been in romantic and sexual relationships with men. However, he still felt that the city was small and that he was exposed to his family and family friends constantly. This feeling operated as a sense of surveillance, or self-surveillance, as often interviewees were not actually being controlled by their family, yet restricted themselves in doing or saying things related to their sexuality because of the constant presence of their family. Bernardo, who initially moved from the town of Cartagena to the large city of Medellín, had similar thoughts of always feeling observed by his family and by Colombian society as a whole:

[In Cartagena], being a small place, people recognise you and they identify you. ... Then [in Medellín], even though I was living in a 
city away from my family home, I still always lived a bit under the control of my family and of Colombian society. But being here in London, with an ocean in between us, I now tell myself 'I am free'.

(Bernardo, 35)

The attraction of the 'big European city' described by multiple respondents echoes the ideas set forth by classic urban theorists, such as Simmel (2012), who denotes that city life offers a kind of freedom and anonymity which is unavailable in traditional and non-urban spaces. As Weston stated as long ago as 1995 (p. 26), the anonymity of city life is a key trait which nurtures the growth of sexual diversity in urban spaces, through channels of self-expression and reduced feelings of surveillance. Participants' accounts echo the town-to-city or ruralto-urban narratives in sexual migration literature, where the physical displacement from town to metropolis parallels the thrilling process of entering an anonymous sea of urbanites and encountering communities of like-minded queers which contrast with traditional home-town patterns (Weston 1995; Binnie 2004). The respondents' trajectories, however, mostly occur from a (Latin American) city to a (European) city. Experiencing the 'town vs city' binary therefore does not depend on urban expansion or city size per se. In the words of Néstor, 'Montevideo is tiny. ... Well, it isn't that small. It has about 1.5 or 2 million inhabitants, but it seems smaller than it is. It feels small. And it has a small mentality' (Néstor, 44).

I can suggest two major qualities of Latin American urban life, regardless of a city's size, which can contribute to participants' feeling of smallness, entrapment and surveillance. First, there is the region's traditional, normative, familial culture. Even though these qualities are changing because of cultural and demographic transformations, Latin American extended families tend to be large and present in people's lives, regardless of city size (Arriagada 2002), possibly to the point of making family members feel they are under surveillance. Given their magnitude and primacy, family ties can operate as a source of heteronormative control. Additionally, because of low intra-national migration (Aponte 2002), it is not uncommon for nuclear- and extended-family members to live in the same city for decades.

The second quality is the spatial arrangements of cities. Major Latin American cities, which are notable for their large populations and extensive urban footprints, are often highly segregated by socio-economic status, and inhabitants tend to circulate among specific neighbourhoods and interact almost exclusively with people of the same social and 
economic background (Sabatini 2006). This is especially true of middle and upper classes in capital cities, who tend to interact amongst themselves in closed social-elite circles, which leads to high levels of homogamy (López-Ruiz, Esteve \& Cabré 2009). This resonates with the narratives of participants, as several come from educated middle-class backgrounds, including José:

[Bogotá] is a city of eight million people. It is a big city. But if you reduce that to your family, your friends and the gays you encounter and that you're with gays who are similar to you - who went to the same universities, same schools - then it isn't so big any more. A city of millions of people becomes a circle of two thousand and they all know what you do and stop doing. It is a very Third World society. They love to gossip and get in each other's business. ... In London, on the other hand, a lawyer can meet a plumber in a bar. It doesn't matter what you do or where we come from, we can always sit at the same bar. In Colombia that could never happen.

(José, 37; emphasis added)

The respondents frown upon the social homogeneity experienced in their home cities - which makes them feel like small towns - and value the 'multicultural' (a concept deployed by participants themselves) social, cultural, economic and ethnic mixture they experience in London. Participants also underscored the peaceful way the city managed difference and socially integrated cultural diversity. In the words of Manuel and Luis, London's diversity is 'harmonious' or 'no big deal':

I like that it is so international. ... On the street you hear millions of languages. People of all colours living harmoniously. ... It is a global centre.

(Manuel, 35)

It is also interesting how ethnicity is important but at the same time it's not a big deal. ... This is a multi-ethnic society. It is a fluid society where everyone can try whatever they want. It is like a big laboratory to try different things. Different clothing, different couples. Meet and date people from Asia, of African descent. ... I also see so many queer, gay and bisexual people. ... Everything is here in London.

(Luis, 30) 
The interviewees' appreciation of London's multiculturalism echoes what has been called London's 'super-diversity', a 'notion intended to underline a ... kind of complexity surpassing anything the country has previously experienced' in terms of its diversity (Vertovec 2007, 1024). This means that its population, particularly in London's LGBTQ spaces, is very diverse in terms of ethnicity, nationality, class, gender, age and immigration status, as well as in gender and sexual identities.

The participants in this study seem drawn to and feel part of the city's apparently harmonious multicultural social fabric, and barely referenced experiences of discrimination after migrating. However, like any other metropolis, London faces issues of ethnic exclusion and discrimination (Herbert et al. 2008; Eade, Drinkwater \& Garapich 2007). Nonetheless, Latin American migrants are probably not the target of Othering and marginality in the way queer Latin Americans in major USA cities are (Rodriguez 2011; Morales, Corbin-Gutierrez \& Wang 2013). For interviewees, being Latin American and being non-heterosexual - key qualities of their intersectional migrant status - are elements that made them feel integrated and part of the super-diverse social fabric that defines London and provides a sense of belonging, of feeling like a 'Londoner'.

\section{Sexual resocialisation: education, practices and new understandings of sexuality}

By moving to London, many interviewees became exposed to new identities, sexual experiences and understandings of sexuality. Several respondents met trans or non-binary individuals for the first time or encountered the existence of non-monogamous relationships or sex fetish groups. Adrián, for example, asserted that he became aware of his 'internal homophobia and machismo' in London and that, after exploring the world of drag queens and meeting people of various gender expressions, he realised he had previously shunned things like androgyny and gender-bending.

In comparison to their home countries, participants encountered greater openness and positivity towards sexual practices and talking about sexuality in general, highlighting that there was space for every sexual desire or interest. London's 'openness' towards sexuality as well as the exposure to such a wide array of new identities and experiences influenced respondents' perception of their own sexuality and sexual practices: 
I thought I already knew everything about the gay world and about sexuality. But when I arrived to London it was like ... 'Wow!' Another shock. I mean, while I was in Madrid I had met every kind of person, but here .... People are much more open, more liberal. There are many kinds of things related to sex. I also began to do things I never thought I would. Certain sexual practices, games. ... Sexually, I think that London is teaching me to do things that I never thought I would.

(Claudio, 27)

I discovered parts of my sexuality which, if I was in Colombia, would probably have been much more difficult to know or maybe I never would have discovered them. ... In Colombia I was normally a top. You know, because of fulfilling the macho ideal. But here in London I began to discover new things, to be more versatile, sexually. And overall to accept and value myself more.

(Bernardo, 35; emphasis added)

This exposure even impacted participants' mental well-being, as interviewees felt encouraged to try new things and found greater levels of self-acceptance. While Claudio expanded his knowledge of sexuality, Bernardo explored new aspects of his own sexual practices and critically examined his own masculinity: performing sexually as a bottom was unusual for him in Colombia. ${ }^{14}$ However, in the context of London's gender and sexual diversity, he opened up to new sexual acts and questioned his own gendered actions. This flexibilisation of gender practices and desires in sexual relationships resonates with queer Latin American migrants in the USA, who 'experience changes in relation to their interpretations of same-sex desires, practices, sexual lifestyles, and partners post-migration' (Carrillo \& Fontdevila 2014, 933). While such changes are in no way homogeneous, these experiences suggest that Latin American gay men negotiate traditional understandings of gender roles, sexual identity and macho expectations after residing in metropolitan areas of Europe and North America.

Many interviewees also framed London as an educational space, which expanded their knowledge of sexuality and issues relating to sexual health. While participants, in their home countries, were generally aware of the importance of informing oneself about sexually transmitted infections (STIs) and general sexual health information, for most of them different people and places in London have been relevant for their educating themselves further on these issues, learning more about 
diseases and safer-sex techniques and reducing stigma when talking about STIs and sexual health. Participants highlighted the importance of sexual health clinics in this experience: their abundance in the city, the fact that they are free and the ease and lack of stigma with which people and medical professionals address sexual practices were all qualities which positively impacted interviewees:

Here, there are many sexual health clinics where you can go and ask for help or information. If you have something you can go and they offer assistance. ... There have been times when I have been fairly ignorant about some things but here in London it is truly easy to approach any of these places. It has helped me take my sexual protection more seriously. ... It is very different to Ecuador, which is very behind in terms of sexual education.

(Claudio, 27)

London definitely has a spectacular sexual health system. It is so easy to go to a sexual clinic and talk to a specialist. It is also very easy to approach people about their experiences. ... The subject of HIV is also an interesting thing. Now if I meet someone who is positive here and I feel a certain level of attraction, I do stay.

(Adrián, 36; emphasis added)

This quality, as mentioned by Adrián, stood in sharp contrast with experiences in Latin American cities, where (homo)sexual issues were largely taboo and stigmatising attitudes prevailed. For example, Orlando described the gays in his home city in Colombia as chichipatos, which meant they would frequent LGBTQ spaces and were sexually active but were shy and judgemental about STIs and others' sexual practices yet another expression of Latin America's cultural contradictions and tensions regarding sexuality (Adam \& Rangel 2015).

In addition to clinics and sites dedicated to sexual health, recreational spaces and nightlife venues also had an educational role. For example, interviewees were surprised to find condoms and STI information leaflets in gay pubs and clubs around the city. The idea of a nightlife space - typically associated with alcohol and leisure - as a place of sexual education (of sexual-health resocialisation), where issues like HIV were addressed openly and directly, was new for several Latin American gay men. 'You can find pamphlets and condoms everywhere!' said Néstor. 'It wasn't like that in Uruguay.' 
At the same time, and in line with findings on Latin American gay migrants in the USA (Bianchi et al. 2007; Egan et al. 2011), many respondents' first years in London included a significant rise in their number of sexual contacts and greater access to sex with other men in comparison to their home cities and countries. Orlando says: 'Since I came to this city, I've always had sex regularly. It's just so easy here in London.' Participants attributed this, on the one hand, to the city's inclusive, sex-positive atmosphere and abundance of LGBTQ nightlife spaces (including spaces particularly designed for sexual encounters, such as saunas), and, on the other, to the initial reaction that gay men have when they move to a new city after spending most of their lives in the same Latin American city. As José says, London no longer requires the discreetness which he so cautiously followed in Colombia:

One becomes a bit of a libertine in London. The place offers itself for that, especially if you're constantly going out to clubs. One weekend you're with one guy, the next with another. ... It becomes routine. ... Bogotá is a bit more reserved, cautious and discreet. That's the thing. Here you don't have to be discreet with these things

(José, 37)

When I had just arrived in London, everything was fascinating. ... There were gay bars in every neighbourhood, even in the most suburban ones. Everything was big, intense and diverse. It was very exciting. There was sex everywhere. I had sex for one year, non-stop.

(Néstor, 44)

Even though participants had had sexual experiences and relationships in Latin America, and were not necessarily 'making up for lost time' because of not being out of the closet (Egan et al. 2011), London offered these men a new setting for sexual expression and activities, precisely because of its 'big city' traits of anonymity and diversity, serving as a postmigration sexual exploration playground. In the words of Néstor, 'sex is everywhere'. In accordance with previous research, the post-migration sexual experience of Latin American gay migrants can consist of a whirlwind of sexual activity (Bianchi et al. 2007). As thrilling as this may be for queer migrants, it can also lead to significant rates of anxiety, substance misuse and depression (Egan et al. 2011), and, in turn, to rises in unprotected sex and STI transmission. This situation is particularly problematic when accompanied by a lack of sexual education in migrants' home countries (Morales, Corbin-Gutierrez \& Wang 2013). 
Thus, for sexual migrants, London serves as a double-edged sword for gay men's sexual health; on the one hand, it can operate as an effective educational platform, and on the other it offers a plethora of opportunities for sexual contacts and increases risky practices. This is yet another 'paradoxical' quality of queer nightlife (Valentine \& Skelton 2003), clearly voiced by Gabriel, who remarked on London's informative sex-positivity as well as its abundance of risks caused by the availability of sexual encounters:

There is much more awareness [in London]. There are the health clinics in Soho, spaces where you can get checked. ... I think there is much more awareness of getting checked regularly [for HIV]. There is much more available information and less prejudice than in Colombia. In fact, I think I never took an HIV test while living in Colombia. ... So yes, there has been a change [in my sexual health knowledge] but I have also taken more risks. I think sex is more easily available in London, in general. On the one hand there is more education, but there is also greater risk.

(Gabriel, 38; emphasis added)

\section{Communities and spaces: feeling Latino, feeling queer}

Extensive research on Latin Americans in the USA highlights the centrality of community ties created in post-migration urban experiences (Zúñiga \& Hernández-León 2005). Participants in the current study, however, felt disconnected from and uninterested in London's Latin American spaces and the idea of participating in a 'Latin American community'.

When asked about their ethnic or national identification, all interviewees identified as 'Latino' and often stated qualities of their own personality or history that made them feel so: their outgoingness, social warmth, taste in music and food, closeness to family. Also, all respondents easily identified existing Latin American neighbourhoods and spaces in London, such as Seven Sisters Latin Market, Burgess Park or venues around Elephant and Castle. Nonetheless, not a single participant felt part of a 'Latin American community', or expressed an interest in forming part of one or had significant connections to Latin Americanidentified spaces. While some said they would occasionally attend Latin American events or venues - mostly restaurants - none visited them regularly. Furthermore, many interviewees conveyed an active lack of interest in or even rejection of them: 
Anything like a Latin American party or event produced the opposite effect: I rejected them. ... Any Latin American thing was like, 'No thank you.' ... I mean, I initially came to London to study and part of that original idea was not to socialise with the same kind of Latinos I knew before but with people from here ... but, well, it is a funny idea. I look now, 12 years later, and my closest friends are a Colombian and a Venezuelan.

(José, 27; emphasis added)

No, I don't really go to those places. ... I don't go and I wouldn't really like to. They don't catch my attention. I always rejected the idea of being an immigrant and having to gather with your own national community. ... I don't identify with it. The 'let's get together because we are Latin American and listen to Latin American music and talk about Latino things'. ... But I do have my Latin American friends. My deepest friendships are with people who I knew from over there and are now here.

(Néstor, 44)

I don't feel the need to interact with Latinos but when I do, I feel comfortable. But I wouldn't want to create a Colombian ghetto and have been around Colombians most of my life. If I wanted that, I would have just stayed in Colombia. ... I don't feel part of a Latin American community. It would mean to live like you were in Colombia but in London. Because they eat Colombian food and listen to Colombian music all the time. And they speak Spanish all the time.

(Gabriel, 38; emphasis added)

Participants were aware of the importance of Latin American communities and spaces (especially for other Latin American migrants) and not everyone was equally categorical in their lack of interest in or disconnection from them. Nonetheless, not even one felt a strong connection to such spaces and, as the excerpts show, getting involved in a sort of 'Latin American community' reminded interviewees of Latin American social and cultural homogeneity, which they so adamantly avoided.

Globalisation literature has stated that this possibility of feeling connected to home countries at a distance (for example, experiencing Colombia in London) is a constitutive quality of relational geographies in a globalised world. Massey $(1991,24)$ calls this 'a global sense of place', an essential experience for individuals who rely on spaces built by 
migrant communities to bring 'home' to a foreign context (Pratt 1999). These Latin American gay men, however, experience the opposite: getting involved in London's Latin American spaces, it seems, defeats the exact purpose of migrating to London in the first place. In the participants' experiences and imaginaries, such spaces detach them from the multicultural and queer fabric that London has to offer and, in the end, remind them of the ghetto-like homogeneity they experienced in their home countries, which is exactly what they intentionally left behind.

Previous quotes also show that, despite not feeling part of London's Latin American community per se, some of the interviewees' closest and most trustworthy friends are other Latin American individuals (some of whom they met in London, others in their home countries). In the context of a different culture and a second language, friends from Latin America offer a space of support, familiarity, language and shared humour, as expressed by José (37): 'My two best friends are also Latin American. We share things that you know only another Latin American person would understand. Certain jokes, words. ... And humour. Humour is key.' For respondents, Latin American friends are not considered a 'Latin American community', at least not in a sense that suggests social closure or homogeneity. While they offer support and cultural complicity, like-minded - and, in many cases, also gay or queer - Latin American friends do not transport participants back to their home countries in the way Latin American spaces, filled with other co-nationals and possibly heteronormative families and Latin traditions, do.

This is a major difference from findings in the USA, where the relationship between Latin American queer migrants and Latin American communities was complex (Randazzo 2005; Gray, Mendelsohn \& Omoto 2015), as they felt attachment - mainly for family reasons - but at the same time distanced, often because of religious or homophobic practices, which could lead to their hiding their sexual orientation or aligning their gender expression with normative masculine conducts. Also, for Latin American queers in the USA, existing Latin American communities or neighbourhoods serve as spaces of contention in moments of adversity or marginalisation. This contradictory relationship did not appear in the narratives of respondents in this study.

In contrast, when asked about what kind of community they felt part of, respondents did not hesitate to mention the LGBTQ or queer community, which felt like an important component of their identity and, at first glance, was not perceived as homogeneous or ghetto-like. Daniel stated: 
I'm not interested in being part of any closed community. ... Perhaps, if I had to say that I was part of a community, I think I would say I'm part of a gay community, more than a Mexican or Latino one. ... Being gay has defined me more than being Latin American, I think.

(Daniel, 37; emphasis added)

The interviewees had queer and gay friends, voiced connections with LGBTQ spaces, and are, or were at least at some point of their time in London, active participants in the city's various queer nightlife spaces, mentioning a wide variety of venues in Soho, Vauxhall and East London. They were well aware of the variety of venue clusters in London's nightlife scene and felt a strong connection to them. They highlighted the geographical, musical, aesthetic and sexual diversity that the city's night economy had to offer (Campkin \& Marshall 2017) in ways that Latin American cities, as gay-friendly as they were becoming, were far from achieving. Most participants find in London's queer scenes just another reflection of the city's super-diversity, with various ethnicities and lifestyles coexisting in one large urban space. Furthermore, several participants frequented non-nightlife LGBTQ sites, which also strengthened their feeling of belonging to an LGBTQ community, such as Orlando, who assisted regularly in a gay support group, or Gabriel, who spent time with an organisation which supported couples seeking samesex parenthood. These men regularly met like-minded people, many of them queer migrants like themselves, in London's LGBTQ spaces, which provided a feeling of belonging to the city's super-diverse social fabric and LGBTQ community, as expressed by José:

Yes, of course I consider myself [part of the LGBTQ community], well, because I am. ... I'm gay. ... I've been to London Pride almost every time. Every time I go, I hang out with friends, have some drinks. ... It's those kinds of activities that make you feel part of a community. ... I also go out to gay places with friends.

(José, 37)

It's not about a choice of being part of it or not [an LGBTQ community].... I am part of it because of the simple fact that I am gay ... As I have grown I think I have developed more pride in being part of this community. It is basically a collective which has been through a lot. We've been through a lot.

(Emilio, 30; emphasis added) 
Almost all of my friends are gay. ... Yes, I feel part [of an LGBTQ community]. ... I think that the majority of us have felt discrimination, in all parts of the world. We understand where we come from and it's easier for someone who lived the same thing to understand you.

(Luis, 30)

The participants were also aware of having shared experiences with other queer individuals, such as common histories of migration or discrimination. Emilio and Luis, as quoted above, feel part of an LGBTQ community because of their common experiences of discrimination or exclusion. Interestingly, this feeling is shared with other individuals because of their queerness, and not necessarily because of their nationality or ethnic background.

Additionally, another relevant finding expressed in the quotes above is that many respondents considered themselves part of a LGBTQ or queer community as a consequence of, simply, being gay. Following a quasi-'born-this-way' paradigm of Western homosexuality (Williams 2014), Emilio states that his belonging in that community is not a choice but a quasi-automatic affiliation as a result of being gay. This is a sharp contrast to identifying as 'Latino', which is not considered a strong enough criterion to create an inevitable sense of belonging to a specific community, nor to spark interest in Latin American spaces. Identifying as gay, in contrast, emerges as a seemingly natural trait that connects these individuals to a certain community or to specific spaces in the city. While Latin American gay men are tied to multiple identification categories, these respondents, at least regarding their community and spatial connections, highlight the gay/queer aspect of their identity as what intersectional theorists have called a 'master' category (McCall 2005). This does not make other qualities invisible or irrelevant but rather highlights specific aspects of an individual's identity which are primarily felt or deployed in social interactions and networks.

Finally, the participants were not interested in finding or creating specifically queer or gay Latin American experiences or events in the city. Aside from the other Latin American queer friends they had, respondents did not identify any sense of a LGBTQ-Latin community or a strong interest in Latino-queer spaces. While the definition of 'community' is clearly a difficult one and goes beyond the scope of this single study, these findings suggest that, for Latin American gay men in London, an element which significantly inspires a sense of 'community' is a shared 
experience of oppression or marginalisation, which was primarily felt not with co-nationals but with other queers.

\section{Conclusion}

This chapter has analysed the sexual migration experiences of Latin American gay men in London, focusing on three dimensions: migration motives and relationship with London, sexual resocialisation, and communities and spaces. First, this work has presented Latin American gay men's motivations for leaving Latin America, which were often related to lack of spaces for self-expression. Furthermore, participants' narratives highlighted London's anonymity, multiculturalism and super-diversity, all of which characterise it as a 'big European city', as a desirable set of qualities, particularly in contrast to Latin America and its traditionalism, homogeneity and 'smallness'. Second, it has also shown that London and its multiple queer spaces sexually resocialise Latin American gay men by exposing them to new identities and sexual practices, and offering easy access to sex and sexual education alike. Finally, this chapter has highlighted the lack of interest that Latin American gay men felt towards Latin American spaces and communities in London (while still identifying as Latinos and having close friends from their home countries) and the strong link they have with LGBTQ spaces and communities in London, which have been key in their processes of selfexpression and community building and connecting with London's diversity. While presented as separate dimensions, all these aspects are intrinsically related and correspond to the same sexual migration phenomenon (Carrillo 2004). London's queerness is deeply intertwined with its multiculturalism. As recognised in the respondents' narratives, the city's acceptance and celebration of homosexuality and queer culture - which make it an attractive destination for international nonheterosexuals - cannot be separated, in lived experience, from its social and cultural integration and ethnic diversity. They are both part of the city's 'openness' and constitute part of what makes it super-diverse (Vertovec 2007) and, in opposition to Latin America's homogeneity, an attractive destination for Latin American gay men. Furthermore, considering that London's social fabric itself is constituted of many migrant subjectivities and communities (Stillwell 2010), it is not difficult for Latin American queer men to feel part of London's superdiversity. This clearly distinguishes their experience from much of that of Latin American queer migrants in the USA, who encounter greater 
marginalisation because of the Otherness felt by Latino subjectivities in that context (Gray, Mendelsohn \& Omoto 2015).

Furthermore, the respondents' lack of interest in London's Latin American spaces not only is in sharp contrast to experiences of Latin American migration on the other side of the Atlantic but makes perfect sense when we consider their migration motivations and their interest in London: participating in Latin American spaces transports respondents back to the exact Latin American qualities which they escaped from. Thus, it goes against the queerness and super-diversity available in London. Finding strong networks and community bonds in LGBTQ spaces - and with other like-minded, multiculturally interested Latino friends - Latin American gay men in London do not need or feel any familial obligation to these spaces or communities. This is somewhat ironic, as these men's experiences of migrant communities in London are actually of homogeneity and of a threat to multiculturalism, instead of a celebration of it, as scholars would typically argue when considering ethnic communities (Allen \& Turner 1997).

Latin American gays in London create their own Latin American networks - without calling them 'communities' - which keep them connected to the language, humour and support relationships of their home country, but also harmoniously fit in with their interests in London's super-diversity. These individuals reveal one way, among many, of being a Latin American immigrant in London, beyond typical depictions of Latin Americans. In effect, if Latin Americans are London's invisible population (McIlwaine, Cock \& Linneker 2011), Latin American gay men are one of the invisible groups among the invisible population. There are many other Latin 'invisible' populations that must be heard and taken into account, from youth to the elderly, to trans and lesbian communities, all of which will hopefully be part of future studies.

Also, the fact that gay Latin American men, coming from major capitals, describe them as small towns - particularly in contrast to their London experience - forces us to rethink the small town/big city dichotomy. Weston's symbolic opposition of small town/big city is still relevant in this scenario, but as a Latin American city/European city distinction, opposed not in terms of size but, phenomenologically, in terms of the lived experience of the city (Simmel 2012). Thus, for the study of the migration patterns of gay men worldwide, looking at lived or embodied experiences of cities (Gorman-Murray 2009) is as important as measurable urban data.

Finally, the urban gay 'Promised Land' (Weston 1995) or 'gay haven' (Binnie 2004) described by previous scholars is definitely in play when 
the respondents refer to London, but it inevitably includes multiple layers of super-diversity. London serves as a kind of 'super-diversity haven' for Latin American queers, which they feel a part of. London's draw for Latin American gay men operates in a similar way to Gorman-Murray's principle of 'gravitational group' migration (2009); however, its gravitational pull would not be due simply or exclusively to LGBTQ-identifying communities but also to its intertwining with a range of cultural and national diversities. In the words of Young (1990), the city is an erotic experience for Latin American migrants. Following her definition of the term, we can say that a city's eroticism comes from 'the pleasure and excitement of being drawn out of one's secure routine to encounter the novel, strange, and surprising' (Young 1990, 239), a kind of pleasure which is contrary to the repetitiveness and homogeneity of smaller towns or, in this case, of Latin American urban spaces. Understanding that London's openness towards queers and towards various interwoven traits of social diversity is part of the same phenomenon, the sexual (and erotic) migration of Latin American men cannot isolate London's LGBTQ diversity from its super-diverse mixture of subjectivities.

\section{Notes}

* This chapter is based on my MSc Urban Studies dissertation, carried out in 2017 in UCL's Department of Geography.

1. LGBTQ is an umbrella term which means lesbian, gay, bisexual, trans, queer and all other nonheterosexual and gender-non-conforming identities and subjectivities.

2. Queer is a contested and debated term in both activism and academia (Sullivan 2003). In this project, however, I will follow Gorman-Murray's (2009) use, which conceives queer as a 'pragmatic umbrella' referring to lesbian, gay, bisexual, transgender (LGBT) and other non-heterosexual and/or non-cisgender identities and will serve as a synonym for LGBT. Therefore, 'queer population/people/individuals' will refer to the said identities. As a researcher, I am aware of the academic debates regarding the term and its use as a deconstructive and destabilising concept. However, in this research project I prioritise its pragmatic use. When speaking about the research participants I explicitly refer to them as 'gay', as this is how they identified themselves. The concept of 'queer' is, therefore, useful for referring to groups, collectives, communities, venues, spaces, and so forth, which are not exclusively gay, but include gay(s) as well as other non-heterosexualities.

3. Migration is not only driven by sexuality; sexuality is also impacted by migration. Drawing on the work of Mole et al. (2014, 2017) and Bianchi et al. (2007), I understand sexual resocialisation as the process by a new urban and cultural context influences and transforms an individual's sexual knowledge, attitudes, practices and behaviours.

4. All the interviewees elected to conduct their interview in Spanish. Participants were contacted in Spanish, and the original interactions established with them were in Spanish. It therefore felt natural to continue the interviews in that language, as it was the one in which the rapport building began (Welch \& Piekkari 2006).

5. The definition of Latin American used in this project is based on the work of Mcllwaine and Bunge (2016): people who use Spanish or Portuguese as their first language and who were born in Central (including Mexico) or South America (p. 6). I selected individuals only from Spanish-speaking countries because I am fluent in English and Spanish. Unfortunately, this means that Brazilians were not included, even though they are the largest Latin American population in London. While Colombians are overrepresented in this sample, their majority 
among the participants is not surprising, as they are the largest Spanish-speaking Latin American population in London (Mcllwaine \& Bunge 2016).

6. In the recruitment phase, all the identification categories were mentioned. However, those who eventually participated all identified as 'gay'.

7. Full-time students were excluded from the research project, as student migration follows different motives and patterns from non-student migration (Agasisti \& Dal Bianco 2007). Some participants, however, had arrived in the UK to study years earlier.

8. They also report high levels of employment (85 per cent, according to McIlwaine, Cock \& Linneker (2011), much higher than other migrant populations in London). However, many are concentrated in service and low-skilled jobs, which means that a significant proportion of this population face downward occupational mobility after leaving their country.

9. Instead of being considered a limitation, this characteristic must simply be taken into account when the research results are analysed and conclusions generated. Additionally, the educational attainment of this sample coincides with the highly educated samples used in qualitative studies of Latin American queer migrant populations elsewhere (such as Adam \& Rangel 2015, and Morales, Corbin-Gutierrez \& Wang 2013), which supports the validity of the selected sample and the prevalence of highly educated Latin American migrants in many metropolitan areas of the global North.

10. The population of Latin Americans in London grew almost fourfold between 2001 and 2013, reaching an estimated 145,000 . This makes it a significant migrant community of similar size to, for example, the Polish population (McIlwaine \& Bunge 2016).

11. The exact number of Latin Americans in London is hard to find because (1) the current numbers include individuals who have responded to the census or to surveys conducted by formal organisations, which most likely underrepresent harder-to-reach populations of migrants who may not speak English or find themselves in more marginalised situations, and (2) Latin Americans who are dual nationals (and also hold, for example, an EU passport) may be excluded from these calculations. For more on counting Latin Americans in London, see Mcllwaine and Bunge 2016.

12. Hundreds of violent offences against queer people are registered in Latin American countries every year (Morales et al. 2013), and it is the region which reports the highest levels of physical transphobic violence in the world.

13. All interview quotes have been translated by me from Spanish to English.

14. 'Top' and 'bottom' describe sexual roles taken by men who have sex with men. 'Top' is the active/insertive partner, and 'bottom' the passive/receptive partner. In Latin America these roles go far beyond sexual acts and are often highly gendered and linked to expectations of gender expression, body type and masculinity/femininity traits (Carrier 1995).

\section{References}

Adam, Barry D. and J. Cristian Rangel. 2015. 'The post-migration sexual citizenship of Latino gay men in Canada', Citizenship Studies 19:682-95. https://doi.org/10.1080/ 13621025.2015.1053797.

Agasisti, Tommaso and Antonio Dal Bianco. 2007. 'Determinants of college student migration in Italy: Empirical evidence from a gravity approach', SSRN working paper, $11 \mathrm{pp}$. Available at: https://ssrn.com/abstract=1063481 (accessed 2 November 2019).

Allen, James Paul and Eugene Turner. 1997. The Ethnic Quilt: Population diversity in Southern California. Northridge: Center for Geographical Studies, California State University.

Andersson, Johan. 2009. 'East End localism and urban decay: Shoreditch's re-emerging gay scene', The London Journal 34:55-71. https://doi.org/10.1179/174963209x398144.

Andersson, Johan. 2011. 'Vauxhall's post-industrial pleasure gardens: "Death wish" and hedonism in 21st-century London', Urban Studies 48(1):85-100. https://doi.org/10.1177/ 0042098009360238.

Aponte, Luis Armando Galvis. 2002. 'Determinantes de la migración interdepartamental en Colombia, 1988-1993', Revista de Economía del Rosario 5:93-118. https://doi.org/10.32468/ dtseru.29. 
Arriagada, Irma. 2002. 'Cambios y desigualdad en las familias latinoamericanas', Revista de la CEPAL 77:143-62.

Bell, David and Jon Binnie. 2004. 'Authenticating queer space: Citizenship, urbanism and governance', Urban Studies 41:1807-20. https://doi.org/10.1080/0042098042000243165.

Bianchi, Fernanda T., Carol A. Reisen, Maria C. Zea, Paul J. Poppen, Michele G. Shedlin and Marcelo M. Penha. 2007. 'The sexual experiences of Latino men who have sex with men who migrated to a gay epicentre in the USA', Culture, Health \& Sexuality 9:505-18. https://doi.org/ $10.1080 / 13691050701243547$.

Binnie, Jon. 2004. The Globalization of Sexuality. London: SAGE.

Brown, B. Bradford, Reed W. Larson and T. S. Saraswathi (eds). 2002. The World's Youth: Adolescence in eight regions of the globe. Cambridge: Cambridge University Press.

Campkin, Ben and Laura Marshall. 2017. 'LGBTQ+ cultural infrastructure in London: Night venues, 2006-present'. London: UCL. Available at: https://www.ucl.ac.uk/urbanlab/docs/ LGBTQ_cultural_infrastructure_in_London_nightlife_venues_2006_to_the_present.pdf (accessed 13 August 2018).

Cantú, Lionel, Jr. 2009. The Sexuality of Migration: Border crossings and Mexican immigrant men. New York: New York University Press.

Carrier, Joseph. 1995. De Los Otros: Intimacy and homosexuality among Mexican men. New York: Columbia University Press.

Carrillo, Héctor. 2004. 'Sexual migration, cross-cultural sexual encounters, and sexual health', Sexuality Research \& Social Policy 1:58-70. https://doi.org/10.1525/srsp.2004.1.3.58.

Carrillo, Héctor and Jorge Fontdevila. 2014. 'Border crossings and shifting sexualities among Mexican gay immigrant men: Beyond monolithic conceptions', Sexualities 17:919-38. https:// doi.org/10.1177/1363460714552248.

Chauncey, George. 1994. Gay New York: Gender, urban culture and the making of the gay male world, 1890-1940. New York: Basic Books.

Choubak, Melisa. 2014. 'The experiences of lesbian and gay first generation immigrants to Canada: Negotiating identities post-migration.' MA thesis, University of Guelph.

D'Emilio, John. 1997. 'Capitalism and gay identity'. In The Gender/Sexuality Reader: Culture, history, political economy, edited by Roger N. Lancaster and Micaela di Leonardo, 169-78. New York and London: Routledge.

Eade, John, Stephen Drinkwater and Michal Garapich. 2007. 'Class and ethnicity: Polish migrant workers in London'. Full Research Report: ESRC End of Award Report, RES-000-22-1294. Swindon: ESRC.

Egan, James E., Victoria Frye, Steven. P. Kurtz, Carl Latkin, Minxing Chen, Karin Tobin, Cui Yang and Beryl A. Koblin. 2011. 'Migration, neighborhoods, and networks: Approaches to understanding how urban environmental conditions affect syndemic adverse health outcomes among gay, bisexual and other men who have sex with men', AIDS and Behavior 15 Suppl.:S35-50. https://doi.org/10.1007/s10461-011-9902-5.

Epstein, Steven and Héctor Carrillo. 2014. 'Immigrant sexual citizenship: Intersectional templates among Mexican gay immigrants to the USA', Citizenship Studies 18:259-76. https://doi.org/ 10.1080/13621025.2014.905266.

Figari, Carlos. 2010. 'El movimiento LGBT en América Latina: Institucionalizaciones oblicuas', Movilizaciones, Protestas e Identidades Políticas en la Argentina del Bicentenario, edited by Astor Massetti, Ernesto Villanueva and Marcelo Gómez, 225-40. Buenos Aires: Nueva Trilce.

Flick, Uwe. 2014. An Introduction to Qualitative Research. London: Sage.

Gorman-Murray, Andrew. 2009. 'Intimate mobilities: Emotional embodiment and queer migration', Social \& Cultural Geography 10:441-60. https://doi.org/10.1080/14649360902853262.

Gray, Nicole N., David M. Mendelsohn and Allen M. Omoto. 2015. 'Community connectedness, challenges, and resilience among gay Latino immigrants', American Journal of Community Psychology 55:202-14. https://doi.org/10.1007/s10464-014-9697-4.

Herbert, Joanna, Jon May, Jane Wills, Kavita Datta, Yara Evans and Cathy McIlwaine. 2008. 'Multicultural living? Experiences of everyday racism among Ghanaian migrants in London', European Urban and Regional Studies 15(2):103-17. https://doi.org/10.1177/ 096776407087544.

Houlbrook, Matt. 2006. Queer London: Perils and pleasures in the sexual metropolis, 1918-1957. Chicago, IL: University of Chicago Press. 
Hubbard, Phil. 2012. Cities and Sexualities. Abingdon: Routledge.

Lewis, Vek. 2014. 'Nuevos ambientes, ¿historias compartidas? Sexuality, cultural and sexual identity and practices among gay-identified Latin American migrants in Sydney', Journal of Intercultural Studies 35:513-31. https://doi.org/10.1080/07256868.2014.944110.

López-Ruiz, Luis, Albert Esteve and Anna Cabré. 2009. 'Uniones consensuales y matrimonios en América Latina: ¿Dos patrones de homogamia educativa?', Papeles de Población 15:9-40.

Luibhéid, Eithne. 2008. 'Queer/migration: An unruly body of scholarship', GLQ: A Journal of Lesbian and Gay Studies 14:169-90. https://doi.org/10.1215/10642684-2007-029.

Massey, Doreen. 1991. 'A global sense of place', Marxism Today, June: 24-9.

McCall, Leslie. 2005. 'The complexity of intersectionality', Signs 30:1771-1800.

McIlwaine, Catherine. 2010. 'Migrant machismos: Exploring gender ideologies and practices among Latin American migrants in London from a multi-scalar perspective', Gender, Place \& Culture 17:281-300. https://doi.org/10.1080/09663691003737579.

McIlwaine, Catherine and Diego Bunge. 2016. Towards Visibility: The Latin American community in London. London: Queen Mary, University of London.

McIlwaine, Catherine, Juan Camilo Cock and Brian Linneker. 2011. No Longer Invisible: The Latin American Community in London. London: Queen Mary, University of London.

Mole, Richard C. M., Christopher J. Gerry, Violetta Parutis and Fiona M. Burns. 2017. 'Migration and sexual resocialisation: The case of Central and East Europeans in London', East European Politics and Societies 31:201-22. https://doi.org/10.1177/0888325416682813.

Mole, Richard C. M., Violetta Parutis, Christopher J. Gerry and Fiona M. Burns. 2014. 'The impact of migration on the sexual health, behaviours and attitudes of Central and East European gay/bisexual men in London', Ethnicity \& Health 19:86-99. https://doi.org/10.1080/ 13557858.2013.789829.

Morales, Alejandro, Edwin E. Corbin-Gutierrez and Sherry C. Wang. 2013. 'Latino, immigrant, and gay: A qualitative study about their adaptation and transitions', Journal of LGBT Issues in Counseling 7:125-42. https://doi.org/10.1080/15538605.2013.785380.

Pérez, Debra Joy, Lisa Fortuna and Margarita Alegria. 2008. 'Prevalence and correlates of everyday discrimination among U.S. Latinos', Journal of Community Psychology 36:421-33. https://doi. org/10.1002/jcop.20221.

Pew Research Center. 2018. 'Latinos and discrimination.' 25 October. Available at: https:// www.pewresearch.org/hispanic/2018/10/25/latinos-and-discrimination/ (accessed 2 December 2019).

Pew Research Center. 2019. 'U.S. Hispanic population reached new high in 2018, but growth has slowed.' 8 July. Available at: https://www.pewresearch.org/fact-tank/2019/07/08/ u-s-hispanic-population-reached-new-high-in-2018-but-growth-has-slowed/ (accessed 2 December 2019).

Pierceson, Jason. 2012. 'Variations in the judicialization of same-sex marriage politics in Latin America'. In Same-Sex Marriage in Latin America: Promise and resistance, edited by Jason Pierceson, Adriana Piatti-Crocker and Shawn Schulenberg, 53-69. Lanham, MD: Lexington Books.

Pratt, Geraldine. 1999. 'Geographies of identity and difference: Marking boundaries'. In Human Geography Today, edited by Doreen Massey, John Allen and Philip Sarre, 151-67. Cambridge: Polity Press.

Randazzo, Timothy J. 2005. 'Social and legal barriers: Sexual orientation and asylum in the United States'. In Queer Migrations: Sexuality, U.S. citizenship, and border crossing, edited by Eithne Luibhéid and Lionel Cantú, Jr, 30-60. Minneapolis: University of Minnesota Press.

Richardson, Diane. 2000. 'Constructing sexual citizenship: Theorizing sexual rights', Critical Social Policy 20:105-35. https://doi.org/10.1177/026101830002000105.

Rodriguez, Sarah V. 2011. 'Latino/a LGBTQ migrations.' MA thesis, University of San Francisco. Available at: http://repository.usfca.edu/thes/19/ (accessed 3 August 2019).

Sabatini, Francisco. 2006. The Social Spatial Segregation in the Cities of Latin America. Washington, D.C.: Inter-American Development Bank, Sustainable Development Department.

Shedlin, Michele G., Ernest Drucker, Carlos U. Decena, Susie Hoffman, Gauri Bhattacharya, Sharlene Beckford and Ricardo Barreras. 2006. 'Immigration and HIV/AIDS in the New York metropolitan area', Journal of Urban Health 83(1):43-58. https://doi.org/10.1007/ s11524-005-9006-5. 
Simmel, Georg. 2012. 'The metropolis and mental life'. In The Urban Sociology Reader, edited by Jan Lin and Christopher Mele, 23-31. New York: Routledge. https://doi.org/10.4324/ 9780203103333.

Stillwell, John. 2010. 'Ethnic population concentration and net migration in London', Environment and Planning A: Economy and Space 42:1439-56. https://doi.org/10.1068/a438.

Sullivan, Nikki. 2003. A Critical Introduction to Queer Theory. Edinburgh: Edinburgh University Press.

Teunis, Niels. 2007. 'Sexual objectification and the construction of whiteness in the gay male community', Culture, Health \& Sexuality 9:263-75. https://doi.org/10.1080/13691050601035597.

Valentine, Gill and Tracey Skelton. 2003. 'Finding oneself, losing oneself: The lesbian and gay "scene" as a paradoxical space', International Journal of Urban and Regional Research 27:84966. https://doi.org/10.1111/j.0309-1317.2003.00487.x.

Venturi, Marco. 2016. 'Chasing community: From Old Compton Street to the online world of Grindr'. In Sex, Time and Place: Queer histories of London, c.1850 to the present, edited by Simon Avery and Katherine M. Graham, 239-54. London: Bloomsbury.

Vertovec, Steven. 2007. 'Super-diversity and its implications', Ethnic and Racial Studies 30:102454. https://doi.org/10.1080/01419870701599465.

Welch, Catherine and Rebecca Piekkari. 2006. 'Crossing language boundaries: Qualitative interviewing in international business', Management International Review 46:417-37. https:// doi.org/10.1007/s11575-006-0099-1.

Weston, Kath. 1995. 'Get thee to a big city: Sexual imaginary and the great gay migration', GLQ: A Journal of Lesbian and Gay Studies 2:253-77. https://doi.org/10.1215/10642684-2-3-253.

Williams, Juliet. 2014. 'Same DNA, but born this way: Lady Gaga and the possibilities of postessentialist feminisms', Journal of Popular Music Studies 26:28-46. https://doi.org/ 10.1111/jpms.12058.

Young, Iris Marion. 1990. Justice and the Politics of Difference. Princeton, NJ: Princeton University Press.

Zúñiga, Victor and Rubén Hernández-León (eds). 2005. New Destinations: Mexican immigration in the United States. New York: Russell Sage Foundation. 


\section{4 \\ Rethinking diaspora: queer Poles, Brazilians and Russians in Berlin}

Richard C. M. Mole

\section{Introduction}

That diasporas can play a valuable role in facilitating cross-border migration and subsequent integration in the destination society, offer migrants social, economic and psychological support, and help maintain their national identities and cultural practices, is recognised by academics, governments, international institutions and, of course, diasporas themselves (see Cohen 2008, 7; Turner 2018). At the same time, however, if diaspora communities enforce boundary maintenance too rigidly or insist on the strict maintenance of cultural norms from the homeland, they can impede rather than facilitate integration in the new society and risk alienating potential members who choose not to conform to the desired conceptualisation of the shared identity - often a particular challenge for queer migrants. The latter's unwillingness or inability to engage with their diasporic community, however, runs the risk of their double marginalisation: as ethnic minorities within the host society and as sexual minorities within the ethnic diaspora. What this demonstrates is that there is no a priori relationship between migrants and diasporas in general and that the multiple possible modalities and outcomes of diaspora engagement for queer migrants, in particular, are complex and will differ both across and within queer communities.

Against this backdrop, the aim of this chapter is to explain the patterns of engagement of queer Polish, Brazilian and Russian migrants in Berlin with their ethnic diasporas. To achieve this, the chapter will briefly set out the methodology used and provide a theoretical discussion of diaspora, before analysing the different modalities of diaspora 
engagement among queer Poles, Brazilians and Russians in the German capital. It will then identify the factors that influence the decisions of these queer migrants to engage or not to engage with ethno-national or queer diasporas as social forms, and highlight the benefit of using 'queer diaspora' as a heuristic device for thinking about questions of belonging, identity and solidarity in contexts of dispersal.

\section{Methodology}

The qualitative data on which this article is based was collected as part of a project conducted in 2012-14 on queer migration from Eastern Europe and Latin America to Berlin and London. ${ }^{1}$ Respondents eligible for the specific research on which this chapter is based were literate individuals aged 18 years or over who self-identified as non-heterosexual migrants and as Polish, Brazilian or Russian. ${ }^{2}$ Poland, Brazil and Russia/former Soviet Union were chosen as sending societies, as they represented a mix of European and non-European states, EU and non-EU member states, and states that are geographically close to and distant from Germany. The sample was recruited through dating and community websites on the internet, community venues as well as snowballing. Informed consent was sought using information sheets in Polish, Portuguese, Russian, English and German. ${ }^{3}$ In total, 60 in-depth interviews were conducted: 19 with Poles, 20 with Brazilians and 21 with Russians. The interviewees were aged between 21 and 41; 29 identified as men, 30 as women and one as non-binary. The interviews were carried out in English, German, Polish, Portuguese or Russian, depending upon the preference of the interviewee, took place in a university office, and lasted, on average, 4550 minutes. Participants were offered 25 euros as an incentive. Purposive sampling was used for the interviews to ensure a gender balance, but the sample does not otherwise claim to be representative. The interviews were recorded, and transcribed verbatim. Data management and analysis were facilitated by the use of the qualitative software NVivo. The verbatim data was coded and ordered within a thematic matrix, which emerged both from reviewing the extant literature and from the interview data itself. NVivo helped identify key themes in the respondents' narratives, around which the chapter has been structured: their migration to Germany, their integration into German society, their sense of identity, their lives as queers in the destination society and their relationships with members of their ethnic communities in Germany and at home. In addition, participant observation (subsequently, observer participation) 
was conducted over a period of six months at the fortnightly meetings, social gatherings and activist events of Quarteera, an association of queer Russian speakers and their friends. As a result of attending the Quarteera meetings, I became friends with a number of its members. Being granted access to their private spheres allowed me to gain greater insight into their day-to-day lives as queer migrants. Pseudonyms have been used to protect the participants' identities.

\section{Queering diaspora ${ }^{4}$}

The concept of diaspora has been the subject of much academic debate, although one could argue that there is now greater consensus as to its key characteristics. The term 'diaspora' initially referred exclusively to the scattering of the Jews following their exile in Babylon, before being broadened to include the dispersion inter alia of Greeks, Africans and Armenians and was originally understood to constitute the 'traumatic dispersal from an original homeland and the salience of the homeland in the collective memory of a forcibly dispersed group' (Cohen 2008, 4). Accordingly, initial understandings of the concept were associated with the traumatic wrench from the homeland and a 'historical experience of victimhood at the hands of a cruel oppressor' (Cohen 2008, 1). However, by the early 1990s these key defining characteristics of diaspora were being challenged by scholars such as William Safran (1991), who argued that the concept could be usefully applied to a broader range of expatriate communities, such as labour migrants, colonial migrants and trade migrants, who left their homelands voluntarily. This more flexible understanding of diaspora cast the conceptual net much wider than before, resulting in what Robin Cohen subsequently called a 'diaspora craze', whereby the term was applied to a wide range of communities, spaces and practices (Cohen 2008, 8). While greater awareness of the analytical benefit of 'diaspora' could be seen as an encouraging development, the problem with casting the net so wide is that the concept becomes 'stretched to the point of uselessness. ... If everyone is diasporic, then no one is distinctively so' (Brubaker 2005, 3). Rogers Brubaker therefore called for the conceptualisation of diaspora to be consolidated, insisting that communities would need to meet three criteria if they were to be considered diasporas: dispersion, homeland orientation and boundary maintenance.

Although some academics use 'diaspora' to refer to settled communities living outside of the ethnic homeland as a result of shifting borders 
rather than physical relocation, dispersion is generally accepted as the sine qua non of diaspora (see Waterbury 2006). While there is some disagreement as to whether, to be described as diaspora, dispersion should be forced or can include the voluntary, and whether people have to cross the state frontier or can be dispersed within the state, there is general agreement that members of a diasporic community should be scattered beyond the homeland.

The role of the homeland orientation in definitions of diaspora is more contentious. For Safran, the existence of diaspora is conditional on a very particular relationship with the homeland, one in which the latter is seen inter alia as 'the true, ideal home and as the place to which one would (or should) eventually return' (Safran 1991, 83-4). The focus on homeland orientation and, in particular, on the 'teleology of return' has been criticised by many, however, with James Clifford pointing out that many members of the African diaspora, for example, would not necessarily know to which homeland they should return (Clifford 1994, 305). The same, one could argue, is true of migrants from states such as the Soviet Union, which no longer exists. Moreover, it has been argued that focusing on the homeland as the original source of the diaspora reinforces its primordial ethnic character and fails to take account of difference within the diaspora along lines of class, gender and sexuality, let alone allow for the possibility of diasporas to be formed around an identity other than the ethnic (Anthias 1998, 557). Yet, while we could agree that ' $\mathrm{d}$ ] ]ecentred, lateral connections may be as important as those formed around a teleology of origin/return', the identities underpinning the diaspora still derive, at least in part, from the identity of the original homeland (Clifford 1994, 305-6). While they may be hybrid, hyphenated identities, the culture of the homeland - even if it is rejected - remains the key point of reference (see Hall 1990).

Debates about the relative homogeneity or hybridity of diaspora identities also figure in the third of Brubaker's key conditions of diaspora: boundary maintenance. Whether self-policed as a means to resist assimilation and safeguard the migrant community's original identity or religion, or externally imposed as part of a policy of segregation, the maintenance of a clear boundary between the migrant community and the host society is seen as a key condition of diaspora existence. Or at least it was in the past. As there is less pressure on migrants today to assimilate fully into the culture of the host society, and as new technologies and cheap flights enable some migrants to maintain interpersonal ties with the homeland, endogamy and unbending adherence to the cultural practices of the 'old country' are no longer essential for the survival 
of the diasporic community. Historical experience has shown that incorporating elements of other cultures into its own does not signal the demise of a diaspora. The existence of a diaspora is therefore conditional not on rigid demarcation but on a sense of difference between the migrant community and the host society. As long as diasporas do not assimilate completely, cultural syncretism does not pose the threat to their continued existence as distinct communities that it once did.

Decentring rigid boundary maintenance and the teleology of origin/return from the definition of diaspora, while nevertheless maintaining a distinct (perhaps hybrid) identity oriented towards the homeland (however understood), provides a degree of flexibility in the application of 'diaspora' to individual cases, without losing cohesion in its conceptualisation. Moreover, not only are the borders of diasporas not fixed, but the idea that all members of a diaspora share a single identity is also not credible. When considering the contents of specific identities, it is important to remember that they are not given but 'are a reflection of the perceptions, priorities and aspirations of those people who have the power to both construct categories and promote them as "natural" or superior' (Penrose and Mole 2008, 277). What the leaders of a particular diasporic community may present as the one true representation of the national culture is therefore unlikely to chime with all members of the diaspora. At the very least, individuals will attach different meanings to the shared culture, precluding the possibility of a single, unified, shared identification.

In relation to the de-essentialisation of diaspora discussed above, scholars have also classified different forms of diaspora, the two most important for this research being 'diaspora as a social form' and 'diaspora as a type of consciousness' (Vertovec 1997, 278). 'Diaspora as a social form' refers to the diaspora as a community, which comes together to provide its members with economic services (such as offers of employment), social support (for example, ethnic cultural spaces) or psychological support (such as the opportunity to relax by speaking one's native tongue), all of these factors contributing to the maintenance of migrants' national identity in the destination society. 'Diaspora as a form of consciousness', by contrast, refers to the diaspora not as a group or community but rather as a state of mind, whereby a sense of diaspora identity is generated through positive identification with the cultural heritage of the homeland.

This reconceptualisation allows us to think of 'diaspora' not solely as a rigidly demarcated, bounded community, defined exclusively with reference to an ethnic homeland, with a shared identity and joint 
interests (although diasporic social forms of this kind clearly do exist at the micro level). Rather, it opens up a space for 'diaspora' to be used flexibly and applied to migrant communities defined not solely in ethnic terms, while also recognising that diasporic subjects are diverse inter alia in terms of their age, gender, class, political affiliation and, not least, sexuality.

The incorporation of sexuality into the study of diaspora has produced a number of works on 'queer diaspora', although there is no consensus as to how best to understand the concept. Basing their analyses on a comparison with the ethno-cultural model and focusing on the scattering of diasporic subjects, sexuality scholars initially dismissed the very possibility of its existence as a social form in that it would have "no locale from which to wander' (Warner 1993, xvii). Subsequent analyses understood the concept more as a form of consciousness, applying it to a feeling of exile, locating queer individuals outside the 'home' of the heterosexual family or the nation (see Eng 1997). The dispersal here is thus metaphorical, rather than physical. Stripping diaspora of its ethnocultural content and decentring the original homeland as a defining feature, Simon Watney uses 'queer diaspora' to refer to the diasporisation of queer culture and politics, whereby 'queer diaspora' is used metaphorically but also implies that the queer diaspora does exist as a social form:

Unlike the tendency of seventies and eighties lesbian and gay theory to develop overly monolithic notions of identity and cultural politics, the concept of diaspora is suggestive of diversification, of scattering, fracturing, separate developments, and also, perhaps, of a certain glamor. It also suggests something of a collective interest, however difficult this may be to pin down. It implies a complex divided constituency, with varying degrees of power and powerlessness.

(Watney 1995, 59)

Problematising the conceptualisation of 'queer diaspora' as the diasporisation of queer, Anne-Marie Fortier understands it more as the queering of diaspora, whereby queer spaces are created 'within ethnically defined diasporas' in order to challenge 'the heterosexist norms supporting definitions of ethnic diasporas' (Fortier 2002, 183). This does, however, assume that the 'ethnically defined diasporas' are willing to make space for their queer members. To understand whether this is indeed the case, I will examine the lived experience of three groups of queer migrants in Berlin - Poles, Brazilians and Russians - and analyse their relationships with their co-ethnic diaspora communities. 


\section{Diaspora engagement}

What was immediately apparent from the analysis of the interview data was that the desire to engage with the ethnic diaspora was much weaker among the Poles than among the Brazilians and Russians. (It was also much lower than among the Polish queers I interviewed in London.) Very few declared an interest in meeting other Poles in Berlin, whereas the Brazilians and Russians, to use Vertovec's words, were keen to connect themselves "with others, both "here" and "there", who share the same "routes" and "roots"' (Vertovec 1997, 281). To determine why interest in engaging with their diaspora was different among the three groups, I first sought to analyse whether there was simply less need among the Poles for the benefits that membership of a diasporic community can provide in terms of economic, social and psychological support and the maintenance of national identity.

A key difference between the Poles, on the one hand, and the Brazilians and Russians, on the other, relates to European Union membership. All Poles have the automatic right to live and work in Germany (unlike Russians and Brazilians ${ }^{5}$ ), while the fact that Poland shares a border with Germany means they can visit the country to sort out employment and accommodation in advance of relocating full time. All of this lessens the need to rely on contacts provided by the Polish community in Berlin to find work and housing. Also, German is more commonly taught at school in Poland than in Russia or Brazil; indeed, more of my interviews with Poles were conducted in German than was the case with the Brazilians and Russians. Many of my Polish respondents did not therefore need more established members of the Polish community in Berlin to translate for them, a role frequently played by diasporas. Cyryl reminisced:

I didn't have the problem of being lost. I mean, first, I visited the city before moving here. Second, I spoke German fluently. I had the opportunity to get to know the city without first problems like, 'Oh my God. How should I find a place to live and a job?'

Nevertheless, while the queer Poles I spoke to did not need the economic support diasporas can provide, what emerged from the interviews was that, despite attempts by Polish politicians to construct homosexuality and Polish national identity as mutually exclusive, national identity particularly with reference to language and culture - was a central part of the sense of self of almost all my respondents (see Graff 2010). The ability to speak one's mother tongue with other native speakers was 
identified by respondents as particularly important. For Edyta speaking Polish every day was one of the main things that she missed about living in Poland: 'It's just more fun to use your language.' When asked if it mattered to him whether he spoke German or Polish in Berlin, Lukasz noted that the language he spoke did have an influence on his sense of self: 'When I speak German, I feel a bit different, as if I am a slightly different person.' However, despite the general feeling that maintaining a sense of Polishness through Polish language and culture was important, few of the Polish respondents turned to the diaspora in Berlin to achieve this. A number of reasons for this emerged from the interview data.

The first factor was geographical proximity. While many diaspora communities seek to re-create the homeland in the destination society, the need to do so is reduced if the homeland is so close that you can visit regularly. Acknowledging that Polish language and culture were important to him but admitting that he did not engage with the Polish community in Berlin, Dawyd explained, 'Berlin is first of all pretty close to Poland. So, if you really miss it, you can always go to Szczecin, to Wroclaw, to Poznan or even to Warsaw, and have fun with Polish music and stuff.' Indeed, a significant number of the survey respondents did visit Poland regularly, with almost a quarter going at least once a month, compared with less than 5 per cent of the Polish respondents in London. Geographical proximity therefore seems to be in inverse relationship to diaspora engagement, a view supported by Henryk in explaining his lack of contact with the Polish community: 'If I miss something Polish, I go to Poland. If I lived in California, it would be different.' In addition, given the close proximity of Berlin and Poland and the fact that both Poland and Germany are in the Schengen Area, ${ }^{6}$ a number of Polish respondents explained that they lived transnational lives, moving back and forth between the two states, thereby removing the need to seek out a Polish community in Berlin in a bid to maintain a sense of Polishness. This was particularly true of Poles who lived in the west of Poland, the part of the country that was German territory until the end of World War II. For those Poles who moved to Berlin from there, the cultural difference was considered to be narrower than it would have been had they migrated to the UK or Spain, for instance. Cyryl confirmed:

German culture, for me, I would say, actually, is as familiar as the Polish one. Silesia is already historically influenced by the German culture. ... They have many traditions that you would find here as well. ... I came here and I was not, like, pretty shocked about this or that pattern of behaviour. It's just okay. Nothing new. 
As the cultural dissonance for Cyryl was not as marked as it would be for migrants from other countries and as Berlin was thus familiar because of shared modes of behaviour, there would be less need for him to engage with the city's Polish community to feel 'at home'.

What the interviews with the Polish queers demonstrate is that geographical and cultural proximity to Berlin was the main reason for their lower levels of diaspora engagement. If they wanted to speak the Polish language or enjoy Polish culture, it was simple enough for them to visit Poland rather than engage with the diaspora in Berlin, which, in any case, was not seen by some respondents as particularly appealing in that, according to Henryk, for example, it mainly comprised 'young mums with kids and religious communities'. In total, only 6 per cent of the Polish survey respondents had visited a 'Polish venue' (such as a restaurant, bar, café or shop) in the previous month, compared with 28 per cent of the Polish respondents in London.

As expected, given that - as I suggested above - engagement with the diaspora is in inverse relationship to geographical proximity, there was a far greater desire among the queer Brazilians and Russians to engage with the Brazilian and Russian communities in Berlin. Despite the fact that, as in Poland, politicians in both Brazil and Russia seek to construct homosexuals as a threat to the nation (Parker 2004; Mole 2018), it was apparent from the interviews that national identity was central to the sense of self of almost all the queer Brazilian and Russian migrants I spoke to. Yet, while the Brazilians and Russians thus shared a desire to seek out communities of belonging defined in relation to shared nationality, the modalities of diaspora engagement were quite different between the two groups.

\section{Brazilians: queering the diaspora, take 1}

Brazilian migration to Germany is quite a recent phenomenon, the first wave of migrants having arrived in the early 1990s in a bid to escape the serious economic downturn and widespread corruption at home. The Brazilian community in Germany is also relatively small. At the time the research was conducted, there were some 95,000 Brazilians in Germanycompared with around two million Poles and 1.3 million migrants from Russia alone (that is, not including Russian speakers from other former Soviet republics). ${ }^{7}$ Although relatively small and quite new, the Brazilian community in Berlin has made its mark with the establishment of various Brazilian bars, cafés, restaurants, cultural centres and schools - the sine qua non of a diasporic community as a social form, enabling members to 
speak their language, perform their culture and maintain their collective identity. The desire on the part of almost all the respondents to engage with the Brazilian diaspora or make use of their Brazilian networks was apparent from the interviews. While Alberto did not see the point in moving to Germany, only then to hang out with Brazilians ('I wanted to immerge [sic] in the German culture, in Germany. And I didn't want to find Brazilians.'), few of the other queer Brazilians I spoke to shared his view.

First, a number of my respondents used their queer Brazilian social networks to get to Germany themselves or help other queer Brazilians move there. ${ }^{8}$ For Laura, having a Brazilian friend already in Berlin is the reason she chose Germany over other destinations. She reminisced: 'My best friend was living here already, so she helped me out a lot with it. ... She had lived here for a year already and then she came back [to Brazil] and then I thought Berlin would be a nice place to go.' Having himself received advice from gay friends about how he could legally move to Germany as a Brazilian citizen, Geraldo used his new-found knowledge to help other Brazilian queers migrate to the German capital. Once they had arrived in Berlin, a number of the respondents made use of their Brazilian contacts to find accommodation and work, sort out health insurance, navigate German bureaucracy and deal with day-to-day living in a new country. Fausto felt at home in Berlin very quickly thanks to the support of the Brazilians he met there: 'It was very easy and because, like, I had so many recommendations, and I think Brazilians have this thing that they embrace, so when you get here, "Oh, I'm going to help you", so everybody helped me, like "Where do I buy a bed, where do I buy shoes?"'

In addition to giving more practical assistance, the Brazilian community was a source of social and psychological support and a means to maintain a sense of national identity, of which the Portuguese language is a key part. Indeed, the desire to speak Portuguese with other native speakers was mentioned more often than any other reason for engaging with the Brazilian community. As Diego put it, "We are still attached ... to our Brazilian identities and to our backgrounds and to the language that we speak, and it's very difficult to let go of your own language because it constitutes your thoughts and your whole subjectivity. I mean, no other language comes out as natural as your mother tongue, so, for that, I think it's nice to hang out with Brazilians.' The role of language in fostering a sense of national identity is also related to the way it conveys meaning and cultural references, enabling native speakers to share jokes, without having to provide context. Célia commented: 'It's amazing to have friends 
from other nationalities but the Brazilians can really understand what you're saying and can understand your background and everything.' However, Brazilianness went beyond the Portuguese language and was understood as a way of being. As Jacinta put it, 'I'm Brazilian, so the way I speak, the way I react to things, the way I feel things, these are all Brazilian things.' These more affective aspects of Brazilianness were often contrasted with Germanness and presented as a reason for preferring to spend time with Brazilians rather than with locals, who, according to Fausto, were 'more difficult to get to know'. While she had a lot of German acquaintances in Berlin, Célia acknowledged that, without the Brazilian community, 'I think I'd feel a little lost and a little alone, yes, because, for sure, like I have my friends here, but, like, with Germans, I really appreciate them but ... to be your friends, they take, like, four months, five months.' For the practical, social and psychological reasons set out above, all but one of my queer Brazilian respondents sought out other Brazilians to provide a sense of belonging.

Existing research into diaspora communities has demonstrated that, as a strategy aimed at avoiding assimilation into the host society, they often promote very traditional shared norms and values, especially regarding gender and sexuality - often more traditional than in the homeland they left behind (see Goodenow \& Espin 1993). This is particularly the case in long-established diaspora communities with limited integration and rigid boundary maintenance. The promotion of strict norms on sexuality and the construction of the nation in heterosexual terms often make it difficult for queer members of the community to be accepted (see Nagel 1998). However, this was not the case with the queer Brazilians in Berlin. Of course, there are, according to Bernardo, Brazilians in Berlin who do not integrate into German society but continue to live in a Brazilian bubble ('They are in Berlin but don't live in Berlin but are still living in Brazil but in Berlin.') and who carry their homophobic beliefs with them to Germany. But the impression I gained from my respondents was that the latter group, with their traditional norms regarding sexuality, do not alone determine what it means to be Brazilian in Germany. As Brazilian migration to Germany is relatively new, the first wave of immigrants included not just economic migrants seeking better earning opportunities in Europe but also artists, DJs, musicians and dancers, attracted by Germany's liberal values compared with the traditional, Catholic and patriarchal norms of their home country. Whereas queer migrants elsewhere have often had to fight their way into their diasporas or hide their sexuality in order to be accepted by their co-ethnic communities, ${ }^{9}$ my queer Brazilian respondents in Berlin - along with their 
progressive allies - have co-constituted what it means to be Brazilian in the migration context, resulting in a Brazilian community that is more open to diversity than other diaspora communities in Berlin. According to Camilo, the more liberal nature of the Brazilian diaspora in Berlin is due to self-selection, in that 'Conservative Brazilians do not come to Berlin, they stay in Brazil'. Bernardo, however, argues that the Brazilian diaspora in Berlin is more liberal as a result of migration, in that it is in Germany that many Brazilians come into contact with, for example, feminist and queer politics - often for the first time. According to Camilo, this means that 'the Brazilians that migrate to Berlin' are 'a very specific crowd, you know. ... We're mostly very alternative and we are like the crazy puppies of the bunch.' When asked whether his sexuality affected his ability to engage with the Brazilian community, Geraldo confirmed that the Brazilians he had met in Berlin 'have the same interests, ... go out to the same places', and that his gay and straight Brazilian friends mix very well. My queer Brazilian respondents did not thus have to hide their sexuality to be accepted by the broader Brazilian community. The queer Brazilians in Berlin have thus successfully queered the diaspora, by creating queer spaces within the ethnic diaspora and thereby challenging 'the heterosexist norms supporting definitions of ethnic diasporas' (Fortier 2002, 183).

\section{Russians: queering the diaspora, take 2}

As with the Brazilians I spoke to, the general impression given by my Russian respondents was that Russianness - particularly with reference to Russian language, culture and mentality - was a central part of the sense of self of almost all of them. ${ }^{10}$ At the same time, the respondents recognised that their sense of Russianness was often just one of a 'palette of identities' which changed as their 'priorities changed' (Darya). Nevertheless, while many had been acculturated into a range of identity groups and could therefore function unproblematically in a range of cultural contexts, all but one resisted completely losing their sense of Russianness, which was understood to shape 'the way I'm thinking, the way I'm talking, the behaviour, the values', to quote Evgeniy. Sexual identity is thus not the only identity that is important to LGBQ migrants: national identity too plays a key role in their self-identification, their ability to make sense of the world, as well as their personal wellbeing. Moreover, Russianness was not understood as an individual sense of self, which could be sustained on one's own, but rather as emerging out of interaction with others. 
The ability to speak Russian with other native speakers was identified by respondents as particularly important. For Sonya, it played an important role in shaping her self-identification as Russian, despite neither of her parents being ethnically Russian. While for some the desire to speak Russian was related more to their inability to communicate very well in German in the initial post-migration period, for others it had more to do with the comfort of 'switching off your brain' (Yuriy) or being able to use language in a more sophisticated manner than they would be able to in German. The Russian language provided a 'common denominator' for many of the respondents, enabling individuals from different parts of the former USSR, for example, to reminisce about their childhoods, the children's TV shows they used to watch and the songs they used to sing. Olga recalled: 'It does not matter if you are from Uzbekistan or Russia, you all had the same two TV channels and sang the same songs.'

This shared socialisation into the norms of Soviet society also produced what was frequently referred to as a 'Russian mentality', an important aspect of Russianness that distinguished Russians from Germans. A key aspect of this mentality was the perception that Russians are governed more 'by emotion than reason' (Galina) and that they take more of an interest in others than do other nationalities. While in extremis this could be seen as a problem, as Russians 'tend to stick their noses in everywhere' (Masha), it was generally understood as the desire of Russians to make personal connections with others and was thus seen as a factor enhancing well-being and a sense of belonging. Indeed, the perceived standoffishness of Germans was seen by some, such as Galina, as a cause of feelings of isolation: 'Initially, I tried really hard to integrate into this society but, for some reason, it was difficult. I found them [Germans] not as warm-hearted as Russians. Perhaps that is just a stereotype, but I found it to be true.' For Olga, the fear that the freedom that Berlin offered to LGBQ migrants could potentially be offset by a sense of loneliness were she to leave behind her Russian-speaking friends and family weighed on her decision as to whether she should migrate at all:

I must admit that there was a thought somewhere in the back of my mind: when I am in Berlin, I will be free for the first time in my life to do whatever I want ... if I go. Because I had the feeling that I would be completely alone. I am the only one like this - especially among Russian speakers.

Again, like the Brazilian respondents, the Russians were keen to maintain a sense of national identity in the post-migration context by seeking 
out people of their own ethno-cultural background in Berlin. Unlike the Brazilians, however, the Russian queers I spoke to had limited interaction with the broader Russian community in the city, despite the existence of a large Russian-speaking diaspora in Germany.

Germany is home to the largest population of Russian speakers outside of the former USSR. Precise figures are unavailable, however; as soon as they are granted German citizenship, they are not counted as anything other than German in official statistics. However, it is known that over 1.5 million ethnic Germans from the former Soviet republics emigrated to Germany between 1992 and 2007, and that some 100,000 Jews arrived during the 1990s (Wolff 2013, 308-9; Kil \& Silver 2006, 103). It is estimated that around 300,000 Russian speakers live in Berlin alone, the largest concentration being found in Marzahn-Hellersdorf, a socially disadvantaged district in the east of the city (Bossina 2013, 119). The earliest of these descendants of Germans who migrated to the Russian Empire - or Spätaussiedler - were provided with apartments by the authorities in the housing estates on the edge of the city, while later waves of German-Russians who had to make their own arrangements also headed to Marzahn-Hellersdorf as they 'preferred living among their compatriots' (Kil \& Silver 2006, 103). Ethnographic researchers found that in this residential enclave the German-Russians lived closely together in 'vertical villages, high-rise buildings completely settled by immigrants of one national origin', where Russian remained the dominant language of communication and a range of restaurants, businesses and cultural venues catered to the sizeable Russian-speaking population (Kil \& Silver 2006, 109). Ethnic density together with the existence of ethnic commercial and cultural spaces are generally the sine qua non for the development of a diaspora community as a social form, enabling members to speak their language, perform their culture and maintain the collective identity.

However, as discussed above, diaspora communities often promote a very traditional understanding of shared identity, norms and values especially regarding gender and sexuality - in a bid to avoid assimilation into the host society. This is particularly true if there is limited integration and rigid boundary maintenance on the part of the diaspora, which, according to a number of my respondents, is the case with many Russian speakers in Berlin. Vladimir suggests: 'There are many Russian Jews and many German-Russians and they are very closed communities.' As Galina argues, by 'living in ghettos' and 'only mixing with other Marzahn Russians', the Russian-speaking migrants can live their lives as if they had never left Russia: 'I can only imagine that the older generation think they are still there.' Given that attitudes towards sexual minorities in Russia 
and other post-Soviet states are generally negative, Russian-speaking migrants often bring their 'Soviet experiences, attitudes and prejudices regarding homosexuality' with them to Germany (Bossina 2013, 119). While research has shown that migration can under certain conditions liberalise attitudes towards homosexuality, it is less likely to do so if there is limited integration into the host society (Mole et al. 2017). This was the experience of Katya, who had migrated to Germany as a child with her family. After migrating, the family only ever watched Russian TV and read the Russian press, only spoke Russian, and had little contact with Germans, and their circle of acquaintance was limited to 'compatriots', as she put it. When she came out to her family, the attitudes towards homosexuality they had imported from the former Soviet Union resulted in their breaking off all contact with her.

While not all migrants are necessarily keen to be part of their ethnocultural diaspora community, they may still define their identities with reference to the ethnic homeland and visit diasporic spaces to enjoy their national culture, traditions and cuisines, i.e. they have a 'diaspora consciousness' (Vertovec 1997, 281). Yet, even for those who sought to limit their involvement with the diaspora to visiting diasporic spaces, these spaces were felt by a number of respondents to be unwelcoming to queer people, or they felt that the representation of Russianness being propagated was unappealing. Vladimir stopped visiting 'traditional restaurants, where there are Russians and only Russians', for example, as he was made to feel unwelcome because of his sexuality. Similarly, Boris only ever attended one 'Day of Russian Culture' (an annual event, comprising Russia-related talks, films and art exhibitions) because of the behaviour of the members of the ethno-cultural diaspora: 'It reminds me of the Russia I left behind. Drunk, uncivilised people, swearing exactly what I wanted to escape from.' Other respondents, such as Darya, objected to the very traditional and fixed understanding of Russianness propagated by the Russian Embassy and Russia House, which failed to take account of more alternative cultural perspectives:

What the Embassy and Russia House do in terms of culture is so absolute. This is authentic Russian culture.... It's true that there are Goethe Institutes in other countries and they propagate German culture, but it's not just Goethe and Schiller but much more. It is more varied.

While the interviews revealed that almost all respondents were keen to maintain a sense of Russianness as part of an ethno-cultural community, 
the Russian ethno-cultural diaspora and diasporic spaces in Berlin were perceived to be unappealing or unwelcoming to those identifying as queer. Unlike with the Brazilian community, the pre-existing Russian diasporic ethno-scape did not meet the need among the respondents for queer-friendly spaces and the queer Russians in Berlin were thus unable to queer the diaspora in the sense defined by Fortier, i.e. by creating queer spaces within the ethnically defined diaspora $(2002,183)$.

It was recognition of the fact that being 'a migrant and queer' could lead to 'double discrimination' (Polina) that prompted the establishment of Quarteera, an association of queer Russian speakers and their friends. The aims of Quarteera are to represent the interests of Russian-speaking gays and lesbians in Berlin, to counteract the homophobia in the Russian ethno-cultural diaspora, to provide a space to discuss personal problems relating to sexuality, to protest against the homophobic policies of the Russian government and to support queer activists in Russia (Bossina 2013, 117-19). In this sense, it could be understood simply as a social movement. However, if we are to understand the affective appeal of Quarteera to its members, the role it plays as a specifically Russian space, the social and psychological support it offers its members, the desire of its members to change the socio-political situation in Russia and the sense of solidarity they feel towards queer people in the 'homeland', I argue that we need to recognise Quarteera as a form of 'queer diaspora', albeit a form that challenges existing conceptualisations in the academic literature.

While understanding queer diaspora as the diasporisation of queer culture and politics is a useful way of conceptualising transnational networks of queer political activists - of whom Quarteera has many 'privileging sexuality', rather than ethnicity, as the "primary "identity" throughout the diaspora' runs the risk, for example, of Western/nonWestern hierarchies being produced within the supposedly ethno-neutral global queer diaspora (Gopinath 1996, 123). This was the experience of one Quarteera member's cooperation with a German queer organisation, which attempted to teach him how to do activism, despite his many years of fighting for queer rights in Russia. While Fortier's understanding of queer diaspora as 'the creation of queer spaces within ethnically defined diasporas' in the context of Russian-speaking queers in Berlin would apply to diaspora as a form of consciousness, it assumes a willingness on the part of the ethno-cultural diaspora as a social form to create a space for non-heterosexuals, which is not necessarily the case $(2002,183)$. For this reason, I argue that the Russian 'queer diaspora' is better understood as a community of migrants as a social form, united by shared sexual as 
well as ethno-cultural identities, which operates not necessarily within but also outside (or largely outside) the larger ethno-culturally defined diaspora.

The benefit of understanding Quarteera as a form of queer diaspora will become clear when we examine the roles that it plays in providing social and psychological support to the Russian-speaking queer community in Berlin as well as solidarity with other queers in the postSoviet space. First, it provides a space where non-heterosexual Russian speakers can meet other non-heterosexual Russian speakers and are free to perform their sexual identities in a specifically Russian-speaking environment. Leonid reminisced: 'Only in the past two years, thanks to the people who organised Quarteera, have I had Russian friendships that are stable. And in part this has to do with the ability to be open [about my sexuality].' For Katya, Quarteera offered the psychological support of community she needed after her family disowned her when she came out to them. Having gone through this experience, she felt a sense of responsibility to others in the same situation. While there are various German organisations and support networks aimed at LGBTQ individuals, they lack the affective appeal of Quarteera. As Olga explained, Russianspeaking 'individuals and their families can go and receive support' from people who not only speak Russian but also understand the sociocultural factors underlying the conflict; because of the linguistic and cultural specificities of the Russian-speaking community, 'these people cannot be helped in a "normal" German-speaking association'.

Quarteera is also active in protesting against the situation for queer people in Russia and other post-Soviet states. Analysing its actions through the prism of 'queer diaspora' helps us understand how the shared sexual and ethno-cultural identity, oriented towards the (former) homeland, facilitates its ability 'to make claims, to articulate projects, to formulate expectations, to mobilise energies, to appeal to loyalties' among Russian-speaking queer migrants in Berlin (Brubaker 2005, 12). Likewise, the participation of Quarteera in a Rainbow FlashMob, whereby individuals simultaneously release rainbow-coloured balloons in towns and cities across the world to mark the International Day against Homophobia and Transphobia, was understood by Zoya as 'an action of solidarity' with queer people in various post-Soviet states. While many of the queer Russian speakers were part of a globalised queer politics, taking part in protests against the queer rights situation in Russia and other post-Soviet states, this feeling of solidarity with queer Russians derived as much from their shared ethno-cultural identity as from their shared sexual identity. 


\section{Conclusions}

This chapter has sought to contribute to the literature challenging the traditional understanding of 'diaspora' as a rigidly demarcated, bounded community, defined exclusively with reference to an ethnic homeland and with a shared identity and joint interests and social mores, to show how diasporas can be queered in different ways to ensure that queer migrants are also able to make use of support provided by diasporic communities.

As the interviews with my respondents showed, in the context of migration, diasporas play an important role in mobilising collective identity, creating a sense of community and solidarity with co-ethnic members within and across state boundaries and providing economic, social and psychological support. In particular, the desire to maintain a sense of national identity - despite political attempts in their home countries to construct non-heterosexuals as being outside the nation - was something shared by queer Poles, Brazilians and Russians alike. Yet, the degree and modalities of diaspora engagement differed from case to case. Among the Brazilians and Russians there was a strong desire to seek out communities of belonging defined in ethno-national terms so as to maintain their national identity and gain social and psychological support. There was, however, limited interest in this among the Polish queers.

The main reason for the queer Poles' lower levels of diaspora engagement was the geographical and cultural proximity between Germany and Poland. It is easy enough to visit Poland to enjoy Polish culture, rather than engage with the diaspora in Berlin. In addition, as European Union citizens, Poles have the automatic right to live and work in Germany and can visit the country to sort out employment and accommodation in advance of relocating permanently. All of this lessens the need to rely on contacts provided by the Polish community. The fact that the existing diaspora was understood to be centred on families and the Church was another reason for the lack of interest in engaging with the Polish diaspora.

In contrast, both the Brazilians and the Russians were keen to engage with their cultural communities. As the Brazilian diaspora in Berlin is relatively new, queer Brazilians - along with their progressive allies - were among the first wave of migrants to Germany and were thus able to co-constitute what it means to be Brazilian in the migration context. While there were conservative Brazilians in Berlin, the diaspora was nevertheless more open to diversity - including sexual diversity - than other ethnic communities in Berlin. 
While the Russians were also able to queer the Russian diaspora, they did so by different means. The experience of my Russian-speaking respondents demonstrated that shared homeland orientation and sense of Russianness were insufficient to create a sense of a 'we' feeling within the diaspora community as a whole, in that the latter was perceived as unwelcoming or unappealing by many queer russophones. Recognition that queer migrants risked being doubly marginalised - as ethnic minorities within the host society and sexual minorities within the co-ethnic diasporic community - prompted the creation of Quarteera. While Quarteera could be described simply as a social movement, the role it plays as a forum for performing and maintaining both sexual and ethnocultural identities, its provision of social and psychological support to its members, its orientation towards the post-Soviet homeland and the feelings of solidarity it expresses towards other Russian-speaking queers have an affective quality that can best be understood with reference to diaspora. My findings thus showed that 'diaspora' can be used flexibly and applied to migrant communities defined not exclusively in ethnic terms but also defined with reference to sexuality.

While I argue in favour of the potential benefit of using 'queer diaspora' as a heuristic device to think about identity, belonging and solidarity among sexual minorities in the context of dispersal, I critique the conceptualisation of queer diaspora as the diasporisation of ethnoculturally neutral queer communities, as emptying the queer diaspora of its ethno-cultural content weakens the latter's affective appeal and runs the risk of reproducing Western/non-Western hierarchies. At the same time, understanding 'queer diaspora' exclusively as 'the creation of queer spaces within ethnically defined diasporas' assumes a willingness on the part of ethno-cultural diasporas to create a space for non-heterosexuals, which is not always the case (Fortier 2002, 183). For this reason, this research calls for the concept of 'queer diaspora' to be rethought to include its conceptualisation as a community of migrants as a social form, united by shared sexual as well as ethno-cultural identities, which operates not necessarily within but also outside (or largely outside) the larger ethno-culturally defined diaspora.

\section{Acknowledgement}

This research was made possible by an Alexander von Humboldt Fellowship for Experienced Researchers. 


\section{Notes}

1. A survey of 800 individuals was also carried out. While the quantitative results do not form a key part of the analysis in this chapter, some descriptive statistics are provided.

2. While my respondents identified as Russian culturally, they were not all Russian ethnically. The USSR's policy of requiring all citizens to learn Russian and the frequent conflation of Soviet and Russian culture produced subjects who would often consider themselves culturally Russian, even if they were ethnically Ukrainian, Belarusian, Jewish, German, etc.

3. Ethical approval for the research was provided by the UCL Research Ethics Committee (REC 3596/001).

4. A more detailed version of this section is available in Mole 2018.

5. While Russian or Brazilian citizenship does not confer the automatic right to live and work in Germany, a number of the respondents did possess EU passports as a result of having German, Italian or Portuguese ancestors.

6. The Schengen Area comprises 26 European states, mainly member states of the European Union, which have no passport or any other type of control at their shared borders.

7. Ministério das Relações Exteriores, 'Estimativas populacionais das comunidades brasileiras no mundo - 2012'. Available at: www.brasileirosnomundo.itamaraty.gov.br/a-comunidade/ estimativas-populacionais-das-comunidades/APENDICE\%20Diplomacia\%20Consular\%20\%20Brasileiros\%20no\%20Mundo.pdf (accessed 8 February 2020); Zensusdatenbank Ergebnisse des Zensus 2011. Available at: https://ergebnisse.zensus2011.de/\# (accessed 8 February 2020).

8. For the role of social networks in facilitating migration, see Ryan, Sales, Tilki and Siara 2008.

9. See, for example, Cantú 2009.

10. A more detailed version of this section is available in Mole 2018.

\section{References}

Anthias, Floya. 1998. 'Evaluating “diaspora”: Beyond ethnicity?', Sociology 32:557-80. https://doi. org/10.1017/s0038038598000091.

Bossina, Zlata. 2013. 'Politisch wider Willen: Russisch in Berlin: queer + art $=$ Quarteera', Osteuropa 63:117-25.

Brubaker, Rogers. 2005. 'The “diaspora” diaspora', Ethnic and Racial Studies 28:1-19. https://doi. org/10.1080/0141987042000289997.

Cantú, Lionel, Jr. 2009. The Sexuality of Migration: Border crossings and Mexican immigrant men. New York: New York University Press.

Clifford, James. 1994. 'Diasporas', Cultural Anthropology 9:302-38. https://doi.org/10.1525/ can.1994.9.3.02a00040.

Cohen, Robin. 2008. Global Diasporas: An introduction (2nd edn). Abingdon: Routledge.

Eng, David L. 1997. 'Out here and over there: Queerness and diaspora in Asian American studies', Social Text 15:31-52. https://doi.org/10.2307/466733.

Fortier, Anne-Marie. 2002. 'Queer diaspora'. In Handbook of Gay and Lesbian Studies, edited by Diane Richardson and Steven Seidman, 183-97. London: SAGE.

Goodenow, Carol and Oliva M. Espin. 1993. 'Identity choices in immigrant adolescent females', Adolescence 28:173-84.

Gopinath, Gayatri. 1996. 'Funny boys and girls: Notes on a queer South Asian planet'. In Asian American Sexualities: Dimensions of the gay and lesbian experience, edited by Russell Leong, 119-27. London and New York: Routledge.

Graff, Agnieszka. 2010. 'Looking at pictures of gay men: Political uses of homophobia in contemporary Poland', Public Culture 22:583-603. https://doi.org/10.1215/08992363-2010-010.

Hall, Stuart. 1990. 'Cultural identity and diaspora'. In Identity: Community, culture, difference, edited by Jonathan Rutherford, 222-37. London: Lawrence \& Wishart.

Kil, Wolfgang and Hilary Silver. 2006. 'From Kreuzberg to Marzahn: New migrant communities in Berlin', German Politics and Society 24:95-121. https://doi.org/10.3167/gps.2006.240404.

Mole, Richard C. M. 2018. 'Identity, belonging and solidarity among Russian-speaking queer migrants in Berlin', Slavic Review 77:77-98. https://doi.org/10.1017/slr.2018.11. 
Mole, Richard C. M., Christopher J. Gerry, Violetta Parutis and Fiona M. Burns. 2017. 'Migration and sexual resocialisation: The case of Central and East European in London', East European Politics and Societies 31:201-22. https://doi.org/10.1177/0888325416682813.

Nagel, Joane. 1998. 'Masculinity and nationalism: Gender and sexuality in the making of nations', Ethnic and Racial Studies 21:242-69. https://doi.org/10.1080/014198798330007.

Parker, Richard G. 2004. 'Migration, sexual subcultures, and HIV/AIDS in Brazil'. In Sexual Cultures and Migration in the Era of AIDS: Anthropological and demographic perspectives, edited by Gilbert Herdt, 55-69. Oxford: Clarendon Press.

Penrose, Jan and Richard C. M. Mole. 2008. 'Nation-states and national identity'. In The SAGE Handbook of Political Geography, edited by Kevin R. Cox, Murray Low and Jennifer Robinson, 271-84. London: SAGE. https://doi.org/10.4135/9781848607880.n16.

Ryan, Louise, Rosemary Sales, Mary Tilki and Bernadette Siara. 2008. 'Social networks, social support and social capital: The experiences of recent Polish migrants in London', Sociology 42:672-90. https://doi.org/10.1177/0038038508091622.

Safran, William. 1991. 'Diasporas in modern societies: Myths of homeland and return', Diaspora: A Journal of Transnational Studies 1:83-99. https://doi.org/10.1353/dsp.1991.0004.

Turner, Simon. 2018. 'The social construction of diasporas: Conceptual development and the Rwandan case'. In Routledge Handbook of Diaspora Studies, edited by Robin Cohen and Carolin Fischer, 40-6. Abingdon: Routledge.

Vertovec, Steven. 1997. 'Three meanings of “diaspora”, exemplified among South Asian religions', Diaspora 6:277-99. https://doi.org/10.1353/dsp.1997.0010.

Warner, Michael. 1993. 'Introduction'. In Fear of a Queer Planet: Queer politics and social theory, edited by Michael Warner, vii-xxxi. Minneapolis: University of Minnesota Press.

Waterbury, Myra A. 2006. 'Internal exclusion, external inclusion: Diaspora politics and partybuilding strategies in post-communist Hungary', East European Politics and Societies 20:483515. https://doi.org/10.1177/0888325405280897.

Watney, Simon. 1995. 'AIDS and the politics of queer diaspora'. In Negotiating Lesbian and Gay Subjects, edited by Monica Dorenkamp and Richard Henke, 53-70. New York and Abingdon: Routledge.

Wolff, Stefan. 2013. 'Germany and German minorities in Europe'. In Divided Nations and European Integration, edited by Tristan James Mabry, John McGarry, Margaret Moore and Brendan O’Leary, 276-312. Philadelphia: University of Pennsylvania Press. 


\section{5}

\section{An exercise in detachment: the Council of Europe and sexual minority asylum claims}

Nuno Ferreira

\section{Introduction}

Both key regional organisations in Europe - the European Union (EU) and the Council of Europe (CoE) - have played an increasingly significant role in moulding current asylum law in Europe. ${ }^{1}$ The EU now has a fully fledged, reasonably sophisticated asylum policy, constituted by a range of legal instruments and jurisprudence covering all key aspects of asylum claims (Peers 2016). This body of law and policy has a direct and explicit impact on sexual minority asylum claims (SMACs) (Ferreira 2018). ${ }^{2}$ Although the activity of the CoE in the field of asylum is considerably scattered and patchy compared to the EU's, the CoE has nevertheless gradually produced an important body of law and policy that affects SMACs. This is mostly because of the work of the European Court of Human Rights (the Strasbourg Court).

I will consider how the CoE has contributed to shaping the current European legal and policy framework relating to SMACs. While there is already academic work that comprehensively analyses this theme in the context of the EU and the Court of Justice of the EU (CJEU) (Ferreira 2018), that is not the case in relation to the CoE. My focus in this chapter will be, in particular, on how the jurisprudence of the Strasbourg Court has dealt with SMACs. Similarly to the general situation in relation to the Strasbourg jurisprudence on sexual orientation (Johnson 2013), the CoE policy and the Strasbourg jurisprudence have a significant influence on how domestic authorities address SMACs, so it is critical to address this 
gap in the academic literature and develop a thorough understanding of the framework developed in the context of the CoE on this matter. Enforcement issues will fall outside the scope of this chapter.

Through this work, I wish to contribute to a growing body of literature that adopts a queer perspective on the activity of the Strasbourg Court. Inspired by an extensive body of queer literature that explores the sociocultural nature, diversity and fluidity of gender and sexuality (for example Butler 1990; Sedgwick 2008) and uses 'queer' as a tool of critique in the field of migration (Fernandez 2017), I add my voice to those that offer a queer deconstructive reading of human rights discourse to challenge the lack of universality of sexuality rights and foster emancipation (see, for example, Gonzalez-Salzberg 2019; Langlois 2018). While acknowledging that merely granting rights will not achieve sufficiently radical change for sexual minorities from a queer perspective, one cannot but also demand the recognition of rights as at least part of the solution (Langlois 2018). In addition to a queer perspective, it is important to consider an intersectional perspective. Building on the work of intersectional scholars such as Crenshaw (1989) and Yuval-Davis (2006), which requires us to ponder the range of individuals' characteristics and their interactions in order to understand people's social and political experiences, I will consider how the Strasbourg Court can offer a holistic analysis of SMAC applications in order to vindicate applicants' rights and challenge injustice.

The key argument put forward in this chapter is that, despite some isolated positive developments, the CoE in general and the Strasbourg Court in particular are failing SMAC applicants. The jurisprudence of the Strasbourg Court shows an astonishing degree of deference to member states' policies and decision-making in this field, thus effectively not upholding the European Convention on Human Rights (ECHR) and betraying the applicants' rights. This deference creates a worrying detachment from the suffering and risks to which SMAC applicants are exposed when the Court denies their claims, something that has been argued in relation to the Strasbourg jurisprudence on migration in general as well (Dembour 2015). This argument will be substantiated throughout this chapter through an analysis of the relevant policy documents and numerous examples drawn from the jurisprudence in question. The significance of this analysis thus lies mainly in the identification of the shortcomings of the CoE's policy and the Strasbourg Court's jurisprudence in this field, which will allow commentators, policy-makers and decision-makers to gain a systematic and critical understanding of this field and plan their response accordingly. 
I will proceed by delineating in the next section the role of the CoE, and the Strasbourg Court in particular, in developing both asylum and sexual orientation law at a European level, albeit by adopting lines of direction that are essentially divergent. The third section, 'The sexual minority asylum jurisprudence of the Strasbourg Court', explores the Strasbourg jurisprudence on SMACs, by offering an overview and a summary assessment of the relevant decisions. Next, 'Exposing the skeletons in the Court's closet' explores three key themes that emerge in that jurisprudence, namely the threshold for violation of ECHR articles, the rules of evidence and credibility assessment, and how the Court deals with intersecting characteristics and sociocultural factors. The final section summarises why the CoE, and the Strasbourg Court in particular, should deal more forcefully with these claims.

\section{Asylum and sexual orientation in the Council of Europe: resisting the meeting of the roads?}

All CoE member states are bound by the 1951 Refugee Convention, ${ }^{3}$ but not all are bound by the 1967 Protocol, ${ }^{4}$ which extends the geographical scope of the 1951 Convention beyond Europe and removes its temporal restriction to pre-1951 events. Moreover, the CoE itself is not bound by the Refugee Convention or its Protocol and does not have a fully fledged policy on asylum matters. Nonetheless, the CoE has acquired a progressively significant role in the field of asylum. Despite the absence of an asylum policy as such, several of its bodies have taken a noteworthy role in this field. For example, in 2005 the CoE's Parliamentary Assembly warned domestic asylum authorities about the need to implement an efficient asylum system without jeopardising the standards in the Refugee Convention and its Protocol and the ECHR and its protocols. ${ }^{5}$ Furthermore, the European Committee for the Prevention of Torture and Inhuman or Degrading Treatment or Punishment (CPT) produces guidelines on the treatment of migrants and asylum claimants, which are a valuable tool to advocate for better conditions at a domestic level (Danisi 2009). The Committee has also urged CoE member states to use detention only as a measure of last resort and to provide detainees with adequate conditions (European Committee for the Prevention of Torture and Inhuman or Degrading Treatment or Punishment 2017), which is directly consequential for asylum claimants.

The Strasbourg Court, above all, along with the now extinct European Commission of Human Rights, ${ }^{6}$ has developed a strong line 
of jurisprudence that applies the ECHR to asylum claimants, despite the ECHR not possessing any norm explicitly related to asylum. In short, although the Strasbourg Court does not take decisions that consider the final outcome of asylum claims as such, it does decide on the violation of ECHR articles that may protect asylum claimants. In doing so, the Court engages in a 'balancing exercise between the effective protection of human rights, and the Contracting States' autonomy to regulate migration and refugee flows' (Buchinger \& Steinkellner 2010, 421). The Strasbourg Court offers asylum claimants protection mostly on the basis of Articles 3 ECHR (prohibition of torture) ${ }^{7}$ and, to a lesser extent, 2 ECHR (right to life). ${ }^{8}$ In the Court's own words:

its case-law has found responsibility attaching to Contracting States in respect of expelling persons who are at risk of treatment contrary to Articles 2 and 3 of the Convention. This is based on the fundamental importance of these provisions, whose guarantees it is imperative to render effective in practice ... Such compelling considerations do not automatically apply under the other provisions of the Convention. On a purely pragmatic basis, it cannot be required that an expelling Contracting State only return an alien to a country which is in full and effective enforcement of all the rights and freedoms set out in the Convention. ${ }^{9}$

The Court may, nevertheless, also consider violations of Articles 4 (prohibition of slavery and forced labour), ${ }^{10} 5$ (right to liberty and security), ${ }^{11}$ 8 (right to respect for private and family life) ${ }^{12}$ and 13 (right to an effective remedy $)^{13}$ of the ECHR, if the asylum claimant has suffered or risks suffering a flagrant denial of these rights in the CoE host country. The Court will not, however, entertain claims based on Article 6 (right to a fair trial), because it only applies to civil and criminal matters, asylum (and migration) being neither. Most important, the Court not only limits itself for the most part to considering Articles 2 and 3 ECHR violations, which restricts immensely the scope of rights asylum claimants may claim (Dembour 2015), but it also adopts an excessively high threshold for finding a violation of these articles by requiring that they be 'systematically' violated (see the subsection 'A bird's-eye view' below). This is the cornerstone of the detachment Strasbourg adopts in relation to asylum claimants. Moreover, jurisprudence is also in tension with the intersectional approach adopted in this analysis, because asylum applicants whose particular combination of characteristics may expose them to greater levels of violence and persecution may not see 
their experiences fully acknowledged or their rights vindicated in such broad-brush, excessive requirement of 'systematic' violation of Articles 2 or 3 ECHR. The greatest indictment in this respect comes from the fact that applicants have come to find United Nations (UN) bodies, particularly the Commission Against Torture, more effective in staying removals of asylum claimants than the Strasbourg Court (CDDH \& DHSYSC 2019, 100), despite the widely known shortcomings of the UN human rights system. Undoubtedly, the CoE needs to further refine its legal and policy framework on asylum and render it more responsive to the needs, interests and rights of the individuals affected. This will be illustrated by the analysis of SMAC jurisprudence in subsequent sections.

In parallel, the CoE has also developed a rich body of jurisprudence on sexual orientation but this has so far not influenced the SMAC jurisprudence of the Court. Despite some legitimate criticism (see, for example, Ammaturo 2017), the CoE has been active in facilitating what has been termed the 'law of small change' in relation to sexual orientation matters: slowly but steadily, there has been progress, from decriminalisation of homosexual activity to same-sex marriage and same-sex adoption (Waaldijk 2003). Indeed, the CoE has contributed considerably to such progress, including by making some positive changes at a domestic level. Yet the legal framework of the CoE has been slow in tackling the violation of sexual orientation-related rights, which have been increasingly recognised at the domestic and international levels (Human Rights Council 2016; 'Yogyakarta Principles'14 2007), thus revealing an insufficiently queer reading of the ECHR.

Although the ECHR does not contain a stand-alone nondiscrimination clause, ${ }^{15}$ the Strasbourg Court has developed a nondiscrimination jurisprudence that also protects sexual minorities. This has included the use of Article 8 ECHR on the right to family and private life, often in combination with Article 14 ECHR, to prohibit the criminalisation of homosexuality, ${ }^{16}$ preclude bans on homosexuals in the armed forces, ${ }^{17}$ eliminate discrimination in relation to the age of sexual consent on grounds of sexual orientation, ${ }^{18}$ condemn discrimination against samesex couples in relation to tenancy rights, ${ }^{19}$ protect the parental rights of homosexual fathers, ${ }^{20}$ recognise that same-sex relationships are a form of 'family life ${ }^{21}$ and safeguard the family reunification rights of same-sex couples. ${ }^{22}$

The work of the Strasbourg Court has thus been increasingly supportive of sexual minorities' legal claims and this has been welcomed by activists and community groups. As van der Vleuten states, 
'LGBTI [lesbian, gay, bisexual, trans and intersex] activists have been empowered vis-à-vis their governments by their access to the European courts when access to the national political arena was blocked, and ... the ECJ [CJEU] and, to a lesser extent, the ECtHR [Strasbourg Court] have been empowered by LGBTI activism' (van der Vleuten 2014, 119). It may be the case that the Strasbourg Court has not been sufficiently progressive in relation to all sexual minority matters and the case of SMACs may in fact be one such matter, as the jurisprudence analysis below will show. Nonetheless, the Strasbourg Court has been found to be more proactive than the CJEU in relation to sexual minorities, to the extent that the CJEU tends only to offer protection to sexual minority claims when the Strasbourg Court has already initiated that legal direction (Wintemute 2015). ${ }^{23}$ In this regard, Ammaturo importantly points out that human rights frameworks inform a sense of European exceptionalism in relation to sex, sexuality and gender, which contributes to a 'European sexual and gendered citizenship' that has at its core the recognition of LGBTIQ+ (lesbian, gay, bisexual, trans, intersex, queer and other) rights in the European political community (Ammaturo 2017, 100). Consequently, Europe is no longer just a 'geo-political area and becomes a prescriptive and normative idea, almost an aspiration' (Ammaturo 2017, 100). And yet, homonationalist agendas attempt to instrumentalise advancements on LGBTIQ + rights for xenophobic and racist purposes (Bracke 2012; Mole 2017), and the Court's jurisprudence on sexual minorities has contributed to the construction of an 'essentialised, privatised, victimised and respectable "homosexual", simultaneously de-politicising, normativising and domesticating the "homosexual subject"' (Ammaturo 2018, 576; emphasis in original).

There undoubtedly remains much work to be done in the context of the CoE to ensure that asylum claimants are able to vindicate their right to international protection, and much could still be done to improve how sexual minorities are treated and recognised as fully fledged members of society. From a queer theoretical perspective, the Court's jurisprudence is clearly still a long way from adequately acknowledging and respecting human sexual and gender variety and fluidity. Moreover, asylum claimants are re-victimised by Strasbourg's detachment from their needs, interests and rights. The snapshot above suggests that Strasbourg has become an increasingly 'pro-LGBT' court, but 'anti-migrant' as well. This might explain the hesitant and often inconsistent way the CoE, in general, and the Strasbourg Court, in particular, have dealt with SMACs so far, as will now be explored. 


\section{The sexual minority asylum jurisprudence of the Strasbourg Court}

It has been clear for several years in the context of CoE asylum law and policy that SMACs deserve legal protection. For example, the CoE Committee of Ministers has called on member states to fulfil their international obligations in relation to SMACs:

Asylum seekers should be protected from any discriminatory policies or practices on grounds of sexual orientation or gender identity; in particular, appropriate measures should be taken to prevent risks of physical violence, including sexual abuse, verbal aggression or other forms of harassment against asylum seekers deprived of their liberty, and to ensure their access to information relevant to their particular situation. ${ }^{24}$

The European Commission of Human Rights (which until 1998 acted as scrutiniser of claims before they were allowed to reach the Court) and the Strasbourg Court have had a growing number of opportunities over the years to establish a position in relation to SMACs. ${ }^{25}$ This jurisprudence is quantitatively summarised in Figure 5.1. ${ }^{26}$

Amongst the 23 decisions that have been identified, the great majority - 20 (87 per cent) - have been of inadmissibility (including

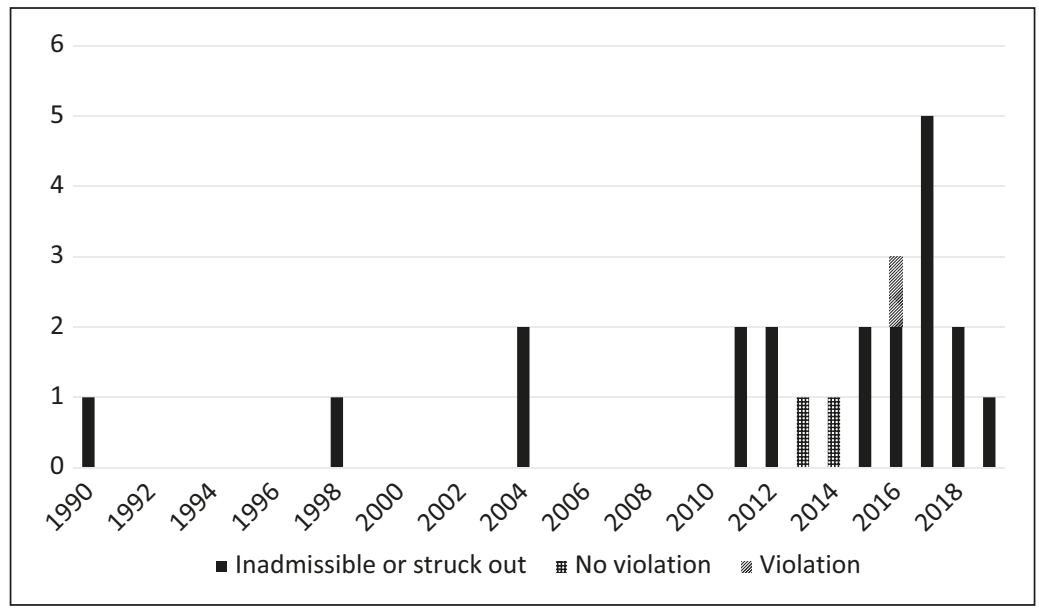

Figure 5.1 Jurisprudence of the Strasbourg Court on sexual minority asylum claims, 1990-2019. The figure sets out the number of sexual minority asylum cases per year and their outcomes. Source: author 
applications found to be manifestly ill-founded) or striking out, ${ }^{27}$ two (9 per cent) have been of no violation of an ECHR article and only one (4 per cent) has been of violation of an ECHR article. These figures alone suggest a reluctance on the part of the Court to support sexual minority applicants claiming asylum. The figures also suggest a growing number of relevant decisions over time, with figures increasing since 2015, which tallies with the growing body of scholarly, NGO and media discussion on this theme. ${ }^{28}$ A qualitative analysis of these decisions, however, tells us much more: it presents a severely inadequate picture from a queer intersectional perspective.

\section{A bird's-eye view}

The first time the Strasbourg Court decided on a case involving a SMAC was in 1990, in B. v United Kingdom, when a gay Cypriot man claimed his deportation to the Turkish Republic of Northern Cyprus (TRNC) would constitute a violation of Articles 8, 13 and 14 ECHR in the light of the criminalisation of same-sex acts in TRNC and the intimate relationship the applicant had developed with a British citizen in the meantime. ${ }^{29}$ On this occasion, the Court found the application inadmissible for being manifestly ill-founded. Almost a decade later, in 1998, the Commission again dealt with a SMAC in Shahram Sobhani $v$ Sweden, where an Iranian gay man who applied for asylum in Sweden on grounds of his homosexuality saw his claim denied. ${ }^{30}$ While his application to the Commission for violation of Articles 2, 3 and 8 ECHR was being considered, the Swedish government quashed the expulsion order and granted the applicant a permanent residence permit, thus leading the claimant to withdraw his application and the application to be struck out by the Commission.

These two cases set a leitmotif: ever since, the Court has for the most part found applications related to SMACs inadmissible for being manifestly ill-founded or has struck them out. For example, $F$. $v$ United Kingdom $^{31}$ and I.I.N. $v$ the Netherlands, ${ }^{32}$ both involving Iranian gay men, were found manifestly ill-founded, as well as A.N. $v$ France, involving a Senegalese gay man, ${ }^{33}$ and M.B. $v$ the Netherlands, involving a Guinean gay man. ${ }^{34}$ The Court has also found inadmissible the application in the interesting H.A. and H.A. $v$ Norway case, involving two Iranian brothers with asylum claims on multiple grounds (religion and sexual orientation). In this case, sexual orientation was a perceived characteristic of the applicant..$^{35}$ Although the Court also found the application manifestly ill-founded in I.K. $v$ Switzerland, ${ }^{36}$ based on the domestic authorities' negative assessment of the applicant's credibility, this decision seems to 
signal a change in rhetoric: the Court acknowledged sexual orientation as a fundamental characteristic, talked about the need to be sensitive in the assessment of applicants' credibility and asserted the inappropriateness of 'concealment reasoning' in asylum claims (see 'Exposing the skeletons in the Court's closet' for further discussion). At any rate, the outcome remained negative, which suggests there is still a long way to go until the Court is ready to truly protect the rights of applicants in the case of SMACs.

Several applications have been struck out on the basis that national authorities had in the meantime taken measures that addressed the applicant's claim, such as suspending a return order in K.N. and Others $v$ France, ${ }^{37}$ granting an asylum-based residence permit in A.S.B. $v$ the Netherlands ${ }^{38}$ conceding a continuous residence permit for work for one year, with the possibility of requesting a renewal, in A.E. $v$ Finland, ${ }^{39}$ agreeing to re-examine the asylum claim in M.B. $v$ Spain, ${ }^{40}$ accepting a fresh asylum claim in A.T. $v$ Sweden, ${ }^{41}$ ordering that the claim be reassessed in E.S. $v$ Spain ${ }^{42}$ and granting a residence permit to the applicant in A.R.B. $v$ the Netherlands. ${ }^{43}$

On a few occasions, the Court has also struck out applications because of the applicants having lost contact with their legal representative, such as in R.A. $v$ France, ${ }^{44}$ involving a Pakistani gay man, and D.B.N. $v$ United Kingdom, ${ }^{45}$ involving the first lesbian asylum claimant to file a case with the Strasbourg Court. On other occasions, applications were struck out owing to the lack of a reply from the applicant to the observations submitted by the respondent State and third parties, as in M.T. $v$ France, involving a gay Cameroonian man..$^{46}$ In a different context, the Court has also struck out the application in Khudoberdi Turgunaliyevich Nurmatov (Ali Feruz) $v$ Russia, which referred to an Uzbek gay man detained in Moscow. ${ }^{47}$ What set this case apart from all other SMAC applications before Strasbourg is that the applicant was a publicly known journalist, who regularly contributed to a weekly newspaper with national coverage - Novaya Gazeta - and who had dealt with a wide array of issues, including LGBTIQ+ rights. After several months in detention in Russia, the applicant was allowed to travel to Germany, where authorities granted him asylum. On this account, the Court struck out the Article 3 claim as well as considering the Article 5 claim inadmissible.

The Court has only considered admissible three SMAC-related applications, and two of these led to a finding of no violation of an ECHR article. The first was the decision in M.K.N. $v$ Sweden, in which the Court finally recognised that SMACs fall within the remit of the ECHR. ${ }^{48}$ Although the Strasbourg Court accepted the importance of 
affording the benefit of the doubt to asylum claimants, it sided with the Swedish authorities regarding the possibility of internal relocation and the negative credibility assessment. The Court thus held that returning the claimant to Iraq did not constitute a violation of Article 3 ECHR. The second one was the infamous decision in M.E. $v$ Sweden, ${ }^{49}$ in which the Court had to deal with the case of a Libyan asylum claimant in a samesex relationship in Sweden, who had been required to return to Libya to obtain a family reunification visa. Although the applicant had been the target of death threats from his family for having married someone of the same sex, the Strasbourg Court found that the requirement that the claimant be 'discreet' about his sexuality (effectively 'concealing' it) for a period of time in Libya was not a violation of Article 3 ECHR. This decision was severely criticised in a powerful dissenting opinion by Judge Power-Forde, who stated: 'The majority's conclusion in this case does not "fit" the current state of International and European law on this important question of fundamental human rights. ... The reasoning is flawed and unconvincing.' While this decision was being referred to the Court's Grand Chamber, the Swedish Migration Board decided to grant the applicant a permanent residence permit because of the deterioration of conditions in Libya, leading the Court to strike out the case..$^{50}$

The only finding of a violation of an ECHR article in a SMAC-related application came with O.M. v Hungary, ${ }^{51}$ in which the Strasbourg Court dealt with the case of an Iranian gay man who was detained for two months in Hungary and then granted refugee status. Here, the Court found that there had been a violation of Article 5 ECHR, especially in view of the authorities' disregard for the particular vulnerability of O.M. during his detention, and awarded the claimant compensation. The positive decision in O.M. $v$ Hungary had given hope of a Court more sensitive towards SMACs. Nonetheless, what has followed is a long string of SMAC applications either being held inadmissible or struck out, with no single finding of violation of an ECHR right ever since, quickly dashing any such hopes of a more supportive Court. Furthermore, O.M. v Hungary did not relate to the asylum claim itself, so there is effectively no finding of a violation of an ECHR article in relation to a SMAC as such.

\section{A summary assessment}

Overall, the body of Strasbourg jurisprudence that has developed around SMACs indicates an insufficient willingness to protect these applicants from persecution. Even decisions significant for introducing positive developments, such as the recognition in M.K.N. $v$ Sweden that SMACs 
fall within the remit of Article 3 ECHR, reinforce the image of a Court unsympathetic towards SMACs. One might attribute such results to the fact that the asylum claims found credible by domestic authorities are decided positively at domestic level, and only the ones that are not found credible reach Strasbourg. Yet that does not justify the substantive decisions across all the jurisprudence discussed above. Moreover, this image of an unsympathetic Court - or 'static and unresponsive', in the words of Falcetta and Johnson - becomes even more apparent when one contrasts this restrictive line of jurisprudence with the judgments the Court has produced in relation to cases involving sexual orientation and migrants' residence issues (Falcetta \& Johnson 2018, 215). All this reinforces the idea of a Court detached from the suffering of SMAC applicants, thus dehumanising them.

As Ammaturo points out, 'If there were a genuine interest in defending individuals - either citizens or non-citizens - from human rights abuses, stories of structural violence or harassment would be enough to grant protection, without the applicants having to demonstrate a threat of death or an extreme punishment' (Ammaturo 2017, 57). In none of the decisions discussed here is there any reference to the Yogyakarta Principles and only in one case - I.K. $v$ Switzerland - is there a reference to the UNHCR's guidelines on refugee claims based on sexual orientation or gender identity (UNHCR 2012). This practically inexistent consideration of international standard-setting documents in this field reinforces the lack of willingness from the Strasbourg Court to engage fully with the scope of rights of SMAC applicants, especially considering that the Court regularly refers to external sources in other types of claims. ${ }^{52}$ If the Court were open to genuinely considering such external sources, this would go some way to address the concerns raised by a queer intersectional perspective, by recognising and engaging with the variety of rights, characteristics and experiences of sexual minorities.

The increasingly frequent references by the parties and the Strasbourg Court to the jurisprudence of the CJEU could, in theory, translate into better outcomes for SMAC applicants. The CJEU has slowly developed a body of SMAC jurisprudence that, despite room for improvement, does possess many positive elements (Ferreira 2018). Moreover, although the relationship between the CJEU and Strasbourg Court has not always been clear or mutually supportive, there are plenty of examples of positive judicial dialogue (Rackow 2016). Yet, in practice, the CJEU jurisprudence has been used either to reinforce the argumentation in favour of a negative outcome or to dot negative argumentation with some positive references to the legal protection afforded 
to the applicants. As an example of the former, in I.K. $v$ Switzerland the CJEU's decision in $X, Y$ and $Z$ is only alluded to by the Swiss authorities to support the conclusion that the applicant's claim was unfounded. ${ }^{53}$ As an example of the latter, in A.N. $v$ France the Court acknowledged that the third parties intervening in the case referred to the decision in $X, Y$ and $Z$ to highlight the wrongness of the 'discretion argument', but the Court still concluded that the application was manifestly ill-founded on other grounds. Similarly, in M.B. $v$ the Netherlands the Court referred to the CJEU decisions in $X, Y$ and $Z$ and $A, B$ and $C$, drawing some positive elements from these cases for the applicant, but nevertheless again found the application to be manifestly ill-founded on other grounds. ${ }^{54}$ Finally, the initial reference to $X, Y$ and $Z$ in the Court's first decision in M.E. $v$ Sweden was ignored when the Court subsequently imposed an obligation on the applicant to conceal his sexuality upon return. The fact that the majority agreed on this point is stunning, as the CJEU's decision in $X, Y$ and $Z$ could not have been clearer about there being no room for the 'discretion argument' in the asylum procedure. This deviation from a positive feature in $X, Y$ and $Z$ indirectly weakened the asylum system in Europe, by undermining the CJEU's authority and the persuasiveness of its decisions. This tension may be a mere reflection of the often fraught relationship between the CJEU and Strasbourg (including in the field of asylum), and of the heavily politicised debates that affect these Courts, such as the debate about the EU's accession to the ECHR (Rackow 2016). When the consequences include a potential danger to an applicant's life, the Strasbourg Court should be able to rise to the occasion and protect human rights above all.

Another noticeable and disappointing feature in this body of Strasbourg jurisprudence is the apparent strategy of the member states to solve, delay or revisit the applicant's claim for international protection in an obvious attempt to pre-empt negative decisions from the Court or simply lead the Court to strike out the application. The long list of cases (partially or completely) struck out on account of the respondent state's decision to somehow revisit its refusal of international protection -10 out of the 23 analysed - is clearly suggestive of that. ${ }^{55}$ Specific examples can be found in A.E. $v$ Finland, for example: the Finnish authorities avoided a substantive decision from the Court by granting to the applicant a continuous residence permit for work for one year, with the possibility of requesting a renewal. This not only led to the Court striking out the application, but crucially also overlooks the fact that the applicant's life remained in limbo and the Finnish authorities might very well deny the renewal of the residence permit for work. Similarly, in M.B. $v$ Spain, 
the Spanish authorities decided to reopen the administrative procedure and re-examine the asylum claim in question while the Court was analysing the application, so the Court struck out the application. Although this decision is perfectly legitimate in the light of the Court's rules and its jurisprudence in such circumstances, it has been lamented for missing the opportunity to provide greater clarity on the issues it raised (ILGAEurope 2017). A third example can be seen in A.T. $v$ Sweden, in which the Swedish authorities considered the expulsion order statute-barred and accepted a fresh asylum claim while the Court was analysing the original claim, which led to the Court's decision to strike out the application. In a slightly different scenario, but with similar consequences, Russia escaped condemnation in Nurmatov (Ali Feruz) v Russia by letting the applicant travel to Germany, where authorities granted him asylum. While it is fortunate that the applicant is now in safety, it is lamentable that once again the Court was deprived (or deprived itself) of the possibility of analysing the substance of the claim. The most recent example of this strategy can be seen in A.R.B. $v$ the Netherlands, in which the Netherlands granted a residence permit to the applicant, which led to the Court striking out the case.

One may believe that such a state strategy is legitimate and that the Court should not be criticised for simply using the ECHR rules to manage its workload as effectively as possible. Yet, Article 37 ECHR also states that the Court 'shall continue the examination of the application if respect for human rights as defined in the Convention and the Protocols thereto so requires' and that it 'may decide to restore an application to its list of cases if it considers that the circumstances justify such a course'. The strategy of these states not only affects migrants more generally but also seriously undermines applicants' human rights (Dembour 2015, 325). In the light of the vulnerable and precarious position in which these applicants are left by states in these circumstances, the Court would be not only entitled, but also required, not to strike out several of the applications mentioned above, for the sake of effectively protecting the rights of the applicants. In this process, the Court also disregards the particular characteristics of the applicants in these cases and likewise the fact that the Court's refusal to analyse the substance of the applications may leave them even more vulnerable. An intersectional approach to these cases is thus in order.

Overall, we are faced with a disappointing body of jurisprudence from the Strasbourg Court, which can be criticised on a range of grounds and is severely lacking from a queer intersectional perspective. In the next section, three further key areas of criticism are analysed, which 
will render more evident the flaws and the scope for improvement of the decisions in question.

\section{Exposing the skeletons in the Court's closet}

The Strasbourg Court does not apply the Refugee Convention, so it is not directly concerned with ensuring the fulfilment of requirements such as 'demonstrating a fear of persecution', membership of a 'particular social group', 'credibility' or lack of 'internal relocation alternative' (UNHCR 2019). Instead, the Court analyses such international protection claims from the prism of the ECHR. Such analysis - as carried out in the Strasbourg SMAC jurisprudence so far - entails many 'skeletons' that need to be exposed.

\section{The threshold for violation of ECHR articles}

Instead of determining whether there is a 'risk of persecution' under the Refugee Convention, the Court is concerned with determining whether there is a risk of violation of an ECHR right upon the return of the applicant to their country of origin. As mentioned above, however, in this context the Court is generally only concerned with possible violations of Articles 2 and 3 ECHR, and only more rarely with violations of other ECHR articles. To carry out this assessment, the Court often refers to the information submitted by the parties in relation to the situation in the applicant's country of origin. The analysis of the quality of such information will serve as a springboard for this section. The analysis will then move to the restrictive use of the ECHR, the high threshold adopted by the Court to find a violation and the way the Court has dealt with the notion of 'discretion'.

To carry out their assessment of international protection claims, national authorities are expected to rely on precise and up-to-date country of origin information (COI) and information regarding countries through which the claimant may have transited. Despite the lack of relevant COI on sexual minorities, asylum claimants may well be victims of persecution warranting international protection, as the information gathered in relation to the country of origin, 'first country of asylum' and 'third countries' often omits elements regarding sexual minorities. Based on COI, national authorities often adopt lists of 'safe countries', which are seen as countries from where one would generally not expect to see a 'legitimate' asylum claim. This has been a notion widely criticised by 
both scholars and civil society for undermining the right to international protection (Costello 2016; ECRE 2016). Furthermore, the very notion of a 'safe country' is in tension with an intersectional approach to asylum claims, which requires an individual consideration of each claimant's circumstances and is not compatible with wholesale analyses of countries of origin. The Strasbourg jurisprudence has, positively, adopted a highly critical view of the mechanistic way in which asylum authorities use the notion of 'safe country' (be it country of origin or third country/ country of passage). In Ilias and Ahmed, relating to Hungarian border procedures, the Court reiterated that the use of this notion needs to be carefully scrutinised against Article 3 ECHR. ${ }^{56}$ To this purpose, public authorities cannot simply rely on a list of 'safe countries' and expect asylum claimants to rebut that legal presumption of 'safety': it is 'unfair and excessive' for the public authorities to lay the whole burden of proof on asylum claimants and not carry out any work of assessment of the risk of violation of Article 3 ECHR in case of refoulement. The Court thus ascertained that 'it is incumbent on the domestic authorities to carry out an assessment of that risk of their own motion when information about such a risk is ascertainable from a wide number of sources' (para. 118).

On a less positive note, however, the Court does not offer the full power of the ECHR and its jurisprudence to asylum claimants. For example, in F. $v$ United Kingdom, the Court oddly asserted that, despite all the evidence it had received about the treatment of gay men in Iran, it had not been proven that returning the applicant to Iran would entail treatment falling within the scope of Article 8 ECHR. The Court blatantly downplayed the risk of criminal punishment for homosexual conduct and asserted that returning the applicant to Iran would not engage Article 8 ECHR, let alone constitute a violation of that norm. ${ }^{57}$ The Court adopted a similar approach in subsequent cases, such as M.E. $v$ Sweden. This is at odds with the Strasbourg jurisprudence on 'sodomy laws' that criminalised same-sex conduct in many countries across Europe and that were finally held to have been a violation of human rights law since the 1980s by the Strasbourg Court in seminal cases such as Dudgeon $v U K,{ }^{58}$ Norris $v$ Ireland ${ }^{59}$ and Modinos $v$ Cyprus. ${ }^{60}$ While in these cases the mere existence of 'sodomy laws' in a member state (even if not enforced) was considered a violation of Article $8 \mathrm{ECHR}$, in relation to SMAC applications the Court does not believe Article 8 ECHR is engaged at all by 'sodomy laws' that may well be enforced. For this reason, Judge De Gaetano used his separate opinion in M.E. $v$ Sweden to criticise the Court's reliance on $X, Y$ and $Z$ and its tolerance of laws criminalising homosexual acts. More recently, in I.K. $v$ Switzerland, the applicant had also invoked a violation 
of Article 14 ECHR, but the Court brushed that aside by asserting that the substance of the claim had already been analysed from the perspective of Article 3 ECHR, thus circumventing any analysis of Article 14 ECHR in the context of asylum. Foreign queer bodies are blatantly dehumanised, in a sort of legalised erasure of humanity, with the alleged blessing of established legal doctrinal principles.

What transpires evidently is that international protection claimants can only rely on a very limited scope of ECHR protection. While nationals of CoE member states can expect to benefit from the full scope of the ECHR while they remain within their jurisdiction (unless they are subject to extradition), ${ }^{61}$ migrants in general should expect a more limited scope of protection (Dembour 2015). People seeking asylum, in particular, should generally not expect to benefit from more than the protection of Articles 2 and 3 when it comes to analysing the risks they may face upon return to their countries of origin. In the words of Spijkerboer, with this sort of decision the Court is effectively asserting that 'some fundamental rights are, actually, not fundamental because facilitating their violation by removal is not in violation of these rights' (Spijkerboer 2018, 228). Although one may say that Strasbourg is not responsible for the state of human rights across the globe, this application of double standards on the basis of one's citizenship status sits uneasily with the universality of human rights, has rightly been criticised by commentators (Jansen 2019, 133), and affects SMACs in particularly acute ways.

Even if one limits oneself to relying on Articles 2 and 3 ECHR, it is striking how the Strasbourg Court applies these articles to SMACs on the basis of an extremely high threshold, thus overlooking the absolute nature of these norms. For example, in both F. $v$ United Kingdom and I.I.N. $v$ the Netherlands, the Court ignored the possibility of prosecution for consensual and private homosexual relationships, the under-reporting of such instances, and the reported instances of criminal punishment of homosexual conduct. In I.I.N. $v$ the Netherlands, in particular, the Strasbourg Court considered a range of materials submitted as evidence, including a UNHCR position paper which stated:

In view of the multiplicity of executions and lashings, it cannot be excluded the victims thereof include persons being punished - on grounds of homosexuality - by death or lashing as provided for on the Iranian Criminal Code. Against this background, it cannot be asserted with certainty that the criminal law provisions on homosexuality only have a theoretical significance. 
Yet, similarly to F. $v$ United Kingdom, the Court found the application manifestly ill-founded. In both F. $v$ United Kingdom and I.I.N. $v$ the Netherlands, gay Iranian asylum claimants conformed to the Western, popular notion of a 'gay man' and described the violence they had suffered in their home country. This 'hypervisible Iranian queer' (Shakhsari 2012) is someone who engages to as great a degree as one can expect with the asylum system and addresses all the requirements one may be expected to fulfil in asylum claims. And yet that was not enough, as the Strasbourg Court overlooked their humanity and dismissed their claims, denying the risk of cruel or inhuman punishment upon their return to Iran.

The same approach was to be adopted in subsequent decisions. In M.E. $v$ Sweden, for example, although the applicant had been the target of death threats from his family for having married someone of the same sex in Sweden, the Court denied his application. This decision was widely criticised for disregarding the fact that, independently of whether the criminal penalties for homosexuality in Libya were enforced or not, 'a hostile attitude towards anyone suspected of being homosexual permeated local culture', instances of massive violence against gay men had been reported, and all diplomatic representations in Libya had been closed down (Falcetta 2015). The decision itself referred to - but remained uninfluenced by - official reports by international organisations and domestic authorities confirming violence against civilians, active extremist groups, continued arbitrary detention of thousands of persons outside state control, and persecution of homosexuals. Again, a queer foreign body is the victim of a violent process of dehumanisation, betraying an acutely detached Court.

More recently, in A.N. v France, involving a Muslim gay Senegalese man, the Court determined that, although same-sex conduct is criminalised in Senegal, with a prison sentence of up to five years, and there are on average ten convictions each year on this basis, the enforcement of this norm was not 'systematic'. The Court pursued the same line of argumentation in M.B. $v$ the Netherlands, involving a gay man from Guinea, where - according to the Dutch authorities' own official country guidance report - 'there are deeply rooted social, religious and cultural taboos with respect to homosexuality'. Despite NGO and Dutch authorities' own reports indicating the opposite, the Court found that the Guinean criminal offence of same-sex conduct was not 'systematically applied'. 'Systematically' implies that the Court intends to cover all or practically all instances of violation of the law, which is unreasonable: it effectively means that no criminal norm in any system is enforced in a systematic way, as there are always instances where criminally punishable 
conducts are not prosecuted for the most various reasons. Furthermore, this line of argumentation overlooks the widespread dangerous societal, structural and institutional effects that the mere criminalisation of samesex conduct, even when the prohibition is not actively enforced by public authorities, can have on the well-being and protection of sexual minorities, including the facilitation of blackmail, extortion, severe discrimination and other forms of serious harm (Phillips 2009; UNHCR 2012, para. 26).

The unreasonably high threshold of the Court in these cases is thus excruciatingly obvious and is in contradiction with the standards of the UN bodies, which have asserted that 'inconsistencies and ambiguities' in particular cases 'are not of a nature as to undermine the reality of the feared risks' ${ }^{\prime 2}$ and that the fact that domestic authorities 'are not actively persecuting homosexuals does not rule out that such prosecution can occur'. ${ }^{63}$ Moreover, such a high threshold is also arguably in contradiction with the Court's own jurisprudence, to the extent that, in these cases, the Court should be considering whether there is a 'real risk' of even a single violation of Articles 2 or 3 ECHR, rather than whether there is a 'systematic application' of norms that violate ECHR rights. Crucially, this jurisprudence ignores the need to adopt an intersectional approach to SMACs and neglects how SMAC applicants' particular range of characteristics and specific socio-economic context may affect potential violations of Articles 2 and 3.

The Court's focus on the way such criminal offences are enforced can, furthermore, be denounced as hypocritical: while in relation to (heterosexual) women asylum claimants the Court is only concerned with whether there are laws in place to protect women from ill-treatment irrespective of whether those norms are applied in practice (Peroni 2018, 353), when it comes to SMACs the Court does the opposite and is only concerned with signs of lack of enforcement of laws criminalising same-sex conduct irrespective of whether or not those laws still cause harm even when not enforced. What is clear, then, is that the Court is not concerned with any actual harm the applicants may risk suffering but rather with finding more or less formulaic methods of denying the applications. Crucially, there is a growing movement to consider the criminalisation of same-sex conduct between consenting adults to be a violation of Article 3 ECHR in itself, owing to the degrading and dehumanising nature of these criminal offences (Danisi 2015, 298-300; Johnson \& Falcetta 2018).

The Strasbourg jurisprudence on SMACs has also touched on the idea that applicants may be returned to their countries of origin and be 
'discreet' about their sexuality (effectively concealing it), so as to avoid any harm coming their way. In M.K.N. $v$ Sweden, the Strasbourg Court had already hinted at sympathising with this argument when it denied the applicant's claim, perhaps influenced by the Swedish government's argument that, as the claimant intended to go on living with his wife, there was no risk of him demonstrating his sexual orientation upon his return - and thus he would remain 'discreet'. Although such a 'discretion' or 'concealment' argument or requirement was widely used across Europe for many years, in 2013 the CJEU condemned this idea beyond doubt in $X, Y$ and $Z$. Yet, somewhat anachronistically, the Strasbourg Court's decision in M.E. $v$ Sweden retained the 'discretion requirement' as appropriate, even if for a relatively short period of time, and thus found no violation of Article 3 ECHR under these circumstances. Although the Swedish authorities subsequently granted the applicant a permanent residence permit, the harm had been done: the Court had offered legitimacy to the 'discretion requirement' at a time when most European domestic jurisdictions had abandoned it, and this was rightly criticised by commentators (Fraser 2014; Steendam 2014). In the light of the eradication of the 'discretion requirement' in most of its forms from most of the European domestic jurisdictions, one could legitimately expect a different position from the Strasbourg Court in subsequent, similar cases. That is what happened in I.K. $v$ Switzerland, in which the Court acknowledged that there was no room for discretion in relation to such a fundamental aspect of one's identity and conscience. And yet the outcome was negative for the applicant. The Court again neglects SMAC applicants' individual composite of characteristics and how it may expose them to violence and persecution. Ultimately, this makes one wonder when rhetoric will translate into genuine queer rights vindication.

\section{Rules of evidence and assessment of credibility}

SMACs are notoriously difficult to prove in any jurisdiction (Jansen \& Spijkerboer 2011). As with any other asylum claim, the success of SMACs is fundamentally dependent on the evidentiary standards adopted and the credibility assessment carried out by the decision-maker. As many scholars have already pointed out, a 'culture of disbelief' pervades some domestic asylum authorities, such as the Home Office in the UK (Millbank 2009; Souter 2011). Even more worryingly, the Strasbourg Court adopts a dangerously hands-off approach to the scrutiny of the credibility assessment carried out by domestic authorities, leaving applicants at the mercy of often hostile domestic authorities. Although the Court is 
admittedly constrained by its own statute and procedural rules, such as admissibility criteria (Article 35 ECHR) and striking-out rules (Article 37 ECHR), there is scope to scrutinise more thoroughly member states' rules of evidence and assessment of credibility.

The Strasbourg jurisprudence's leitmotif in this field is deference towards domestic authorities, something recognised by the Court's judges themselves and justified on the basis of the Court's subsidiary role and limited tools (Ravarani 2017, 3-4). This deference is blatant in the decisions subscribing to negative credibility assessments. Clear examples can be found in relation to the UK and French domestic authorities. In F. $v$ United Kingdom, the domestic authorities questioned F.'s credibility in relation to the length of time he spent in prison and his nationality. They also queried why he had not claimed asylum in Turkey. On appeal, the UK authorities reiterated the assessment of lack of credibility. The Court also chose to accept the assessment of lack of credibility of the domestic authorities, thus siding with the 'culture of disbelief' of the UK asylum authorities. In A.N. v France, the Court also subscribed to the French authorities' assessment of the facts, thus accepting the 'verdict' of lack of credibility. Although the Court acknowledged the difficulty of proving SMACs owing to the personal nature of the matters at hand, it sided with the French government to reiterate the insufficiency of the evidence submitted by the applicant. Deference - and detachment - once again prevailed.

Further examples of such deference to the negative assessments of credibility carried out by domestic authorities can be found in Strasbourg jurisprudence, such as M.E. $v$ Sweden, M.B. $v$ Spain, E.S. $v$ Spain and I.K. $v$ Switzerland. Even when the Court rhetorically highlights that the credibility assessment has to be carried out in an individual and delicate manner, as it asserted in I.K. $v$ Switzerland, deference prevails and the domestic authority's negative credibility assessment stands. A particularly crass example of such excessive deference can be seen in M.B. $v$ the Netherlands, in which the Court deferred to the Dutch authorities' assessment of the applicant's credibility, even though the Dutch authorities expected that the applicant would be able to state the number of people involved in a mob attack against him and the number of police officers who arrived afterwards. It is submitted that it would have been 'incredible' if the applicant had been able to point out the exact number of such attackers and police officers, as it is highly unlikely that an individual would be able to count the number of people beating up or detaining them. Moreover, the Court shows no sign of reflecting on the possible influence of individual mental health and trauma, or local 
cultural or social factors, on the accounts of applicants that may appear incredible to European decision-makers, although such impact has been analysed and evidenced at length (Bögner, Herlihy \& Brewin 2007). On the contrary, the Court is too easily convinced by the domestic authorities' preoccupation with apparent inconsistencies or oddities. ${ }^{64}$

The principle of the benefit of the doubt - a principle whose importance in asylum adjudication is highlighted in the UNHCR guidance (UNHCR 2019) - is ultimately ignored by both domestic authorities and the Strasbourg Court, thus unlawfully depriving SMAC applicants of a key legal tool. A striking example can be seen in M.K.N. $v$ Sweden, in which, despite all the evidence submitted by the applicant, the Swedish Migration Board claimed that M.K.N.'s account was not credible. The Migration Court reiterated this assessment of lack of credibility owing to the late disclosure of his sexuality (see the subsection 'Intersecting characteristics and sociocultural factors', below). Before the Strasbourg Court, M.K.N. claimed to have provided a reasonable explanation for the late disclosure and asked to be given the benefit of the doubt. The Strasbourg Court confirmed the importance of affording the benefit of the doubt to asylum claimants but also agreed with the Swedish authorities regarding the possibility of internal relocation and the credibility assessment, in particular in relation to the claimant's homosexual relationship. In the end, the Court refused to give the claimant the benefit of the doubt, thus again deferring to the credibility assessment of the domestic authorities. The same approach by the Court can be seen in the first decision in M.E. $v$ Sweden.

The Court thus seems willing to accept member states' choices as to which aspects of asylum claimants' testimonies matter, and how they should matter, without offering domestic authorities any critical comments, positive guidance or admonition for the clearly inadequate application of rules on evidence and findings on credibility. Both member states and the Strasbourg Court are accomplices in this violence caused to foreign queer bodies in search of international protection. It is thus apt to ask: Who's afraid of the benefit of the doubt?

\section{Intersecting characteristics and sociocultural factors}

Besides analysing the risk of violation of an ECHR article upon return (see 'The threshold for violation of ECHR articles'), and the overall credibility of the applicant ('Rules of evidence and assessment of credibility'), the Court is often called upon to consider a range of other legal and social aspects relevant to asylum claims that are intertwined with a range of individual characteristics and sociocultural factors. How the Court deals 
with these other aspects (including in the light of COI, discussed in 'The threshold for violation of ECHR articles') has an impact on how the Court analyses both the risk of violation of an ECHR article upon return and the credibility of the applicant. It is thus crucial to consider those as well and to bring to fruition an intersectional approach to the Court's SMAC jurisprudence.

One such aspect is the 'internal relocation alternative', i.e., an individual seeking asylum being able to return to their country of origin and relocate within it to escape the risk of persecution. In the light of how widespread discrimination and violence against sexual minorities can be in the countries of origin of most SMAC applicants, 'internal relocation' is rarely available to them (UNHCR 2012, paras 51-6). In M.K.N. v Sweden, the Strasbourg Court uncritically endorsed the Swedish authorities' assertion that the Christian religious beliefs of the Iraqi claimant - who had had a homosexual relationship in Iraq and had been discovered would allow him to relocate to the Kurdistan region. Similarly, in A.N. v France, the applicant - a Muslim man who had been the victim of blackmail, physically assaulted by rioters and held captive and violently assaulted by relatives - submitted evidence that sexual minorities had to move residence regularly in Senegal to avoid being found out, but the French government insisted that internal relocation was realistic and the Court simply referred back to the domestic assessment of the facts, without showing any interest in questioning the reasonableness of internal relocation in Senegal.

Another aspect of SMAC applicants' experiences that can have a negative impact on the success of their claims is the 'late disclosure' of one's sexuality. The reality is that SMAC applicants often do not know that their sexual orientation can be of relevance for the purposes of obtaining international protection and, even if they do, many do not know how to structure their narratives or that they should include all the elements that may possess relevance to a European decision-maker. Most importantly, many SMAC applicants will not feel comfortable - or may even feel utterly mortified for religious, cultural or personal reasons at the thought of discussing their sexual orientation with a complete stranger, in what is often a hostile environment. The Strasbourg Court's decision in M.K.N. $v$ Sweden is a good example of how asylum authorities fail to grasp the difficulties a sexual minority asylum claimant may have in disclosing their past experiences. In this case, the claimant's account of his past homosexual relationship was denied credibility for having been reported late, although the late disclosure could be justified by the fact that the claimant had an opposite-sex spouse, had children 
and had lived in a strongly conservative and unstable country affected by religious conflicts. M.K.N. himself attributed the late disclosure of this element of his account to not knowing that homosexuality was (socially and legally) accepted in Sweden. The Court, however, chose to disregard the difficulties involved in disclosing to authorities one's past homosexual relationships, even in such complex and adverse circumstances. Similarly, in M.E. $v$ Sweden, the Court chose to side with the Swedish authorities in their assessment of lack of credibility on account of the late disclosure of M.E.'s sexuality. More recently, however, the CJEU asserted in $A, B$ and $C$ that delays in disclosing one's sexuality should not automatically be held against asylum claimants to harm their credibility. One can only hope that this will prove valuable in guiding domestic authorities towards not placing excessive importance on late disclosures. ${ }^{65}$

More generally, the Court fails to grasp the complexity of applicants' lives and sociocultural backgrounds and reduces them to 'siloed' identities that can fit neatly into domestic asylum systems and the ECHR system as envisaged by European mindsets. In I.I.N. $v$ the Netherlands, for example, the gay Iranian asylum claimant had come into contact with the Iranian authorities not only because of his homosexuality but also because of his participation in protests. Yet his political activism only merits a brief mention amongst the facts reported and is ignored in the Court's analysis. Similarly, in M.K.N. $v$ Sweden, although the applicant had an opposite-sex spouse, had children and risked persecution on grounds of his sexuality, religious beliefs and (relatively good) economic condition, the Court paid no heed to the 'messiness' of the applicant's account and simply relied on the Swedish authorities' negative credibility assessment, focusing on only one of the applicant's characteristics - his sexuality. Generally, one can find passing references to some of the applicants' characteristics or circumstances: the applicant in M.E. $v$ Sweden fearing that the Libyan diaspora in Sweden would pass the news about his same-sex marriage to Libya; the applicant in A.N. $v$ France being gay, Muslim and afraid of discrimination from his diaspora community; or the gay male applicant in M.B. $v$ the Netherlands not knowing many details about his partner, perhaps owing to the clandestine nature of their relationship in a society oppressive towards sexual minorities.

Yet, disappointingly, the Court only mentions these aspects but never addresses or analyses them to any extent as the significant sociocultural dynamics and identifiers that they are or allows them to have any positive bearing on the outcome of the case. It would have been particularly interesting in M.B. $v$ Spain - involving a lesbian woman of a particular ethnicity that was at the origin of her exposure to human 
rights violations - to see how the Court would deal with issues of criminalisation and credibility in a context where ethnicity, gender and sexuality intersect. Similarly, the decision in H.A. and H.A. - where one of the brothers feared persecution on the basis of both religion and sexual orientation - would have been an excellent opportunity to engage with the way in which religion and sexuality may potentiate persecution and human rights violations, but the Court - worryingly - opted to dismiss that matter with a very terse analysis of the applicant's concerns, despite the widely known severe treatment of gay (or just perceived as gay) men in Iran (Mendos 2019).

Strasbourg's overall lacklustre approach to SMACs and the richness of these applicants' lives can ultimately dissuade applicants from pursuing their claims, with potentially terrible effects on their lives, aggravated in cases where specific combinations of characteristics render claimants particularly vulnerable to gender and sexual oppression. Consciously pursuing a queer intersectional approach to these cases can support better decision-making in Strasbourg, and we can legitimately expect more from the Court in terms of how it handles such complex lives and applications.

\section{Which way forward for the European sexual minority asylum framework?}

The CoE, and in particular the Strasbourg Court, have undoubtedly contributed to many positive developments for sexual minorities across Europe. Yet, in relation to SMACs, the current inadequacies are conspicuous. Although many of these inadequacies may seem necessary byproducts of the structure and functioning rules of the CoE and the Court, it is realistic to expect a fairer treatment of SMACs. Both quantitative and qualitative analyses of the Strasbourg jurisprudence on SMACs clearly reveal the unwillingness of the Court to genuinely and respectfully engage with these applicants' accounts and rights. Sporadic references to more positive CJEU decisions in this field have so far not led to any progress in Strasbourg. Worse, member states have been successful in strategically prompting the Court to strike out applications by solving, delaying or revisiting applicants' claims. This leaves applicants in precarious situations and circumvents jurisprudential developments in this field. Whether the Court adopts this approach to avoid antagonising member states, to respect their margin of appreciation, to manage its workload, to avoid opening the 'floodgates' to this type of claim, or for 
any other reason, it needs to change its course to honour its mission and preserve the humanity of these claimants, even if that may well mean 'exporting' the Convention's values and applying them to seven billion people (Ravarani 2017, 4). Foreign queer bodies have human rights as well.

To vindicate the rights of SMAC applicants and foster judgments better informed by a queer intersectional perspective, the Strasbourg Court needs to improve its jurisprudence on several levels. First, the Court needs to apply the full range of ECHR articles (in particular Articles 8 and 14) to these claims when analysing the risks the applicants will encounter if they are returned to their country of origin. The Court also needs to lower the current threshold at which a risk becomes so severe as to be incompatible with the ECHR. States would still retain considerable agency to deport individuals with no human rights claims under a newly reduced threshold for deeming a risk 'severe enough' to be incompatible with the ECHR. In short, this would not mean 'opening the floodgates' to any challenge to deportation orders, because some leeway to deport individuals would remain.

Second, the Court needs to stop deferring to the "culture of disbelief' engrained in many domestic authorities and start taking the principle of the benefit of the doubt seriously and hold domestic authorities against an appropriate standard of proof in these cases. If this means - as some may argue - that a small number of 'fake claims' succeed, then this is a reasonable price to pay for robust and fair international protection and human rights systems. Third, the Court needs to immerse itself in the applicants' whole stories and consider seriously all the individual characteristics, identifiers and sociocultural factors involved in each case. This means adopting an intersectional approach to deal in a more culturally and socially appropriate way with issues such as assessing whether there is any 'internal relocation alternative' and whether the 'late disclosure' of one's sexuality should have any bearing on an applicant's claim. Although this may at first seem to require further resources, it can in effect be pursued by making use of quality training materials and COI already in existence.

Essentially, it is submitted that the Court has so far failed to do justice to SMAC applicants by detaching itself from the violence to which they are submitted in their countries of origin and in Europe. The Court has repeatedly ignored the complexity and richness of applicants' accounts and tended to operate within the limited parameters of narrow legal readings of the ECHR and the Court's relationships with the member states. This does a disservice to the applicants' claims and leads to unfair 
outcomes. If the Strasbourg Court were to become more sensitive to a queer intersectional approach to SMAC applications, better justice would be done.

\section{Acknowledgements}

This contribution has been produced within the context of the project 'Sexual Orientation and Gender Identity Claims of Asylum: A European human rights challenge - SOGICA' (http://www.sogica.org). This project has received funding from the European Research Council (ERC) under the European Union's Horizon 2020 research and innovation programme (grant agreement No 677693). The author wishes to thank Marie-Benedicte Dembour, Kanstantsin Dzehtsiarou, Richard Mole, Moira Dustin, Nina Held, Carmelo Danisi, Stephanie Berry, Gianluca Gentili, Melody Greaves and Lisa Harrington for the constructive critique they offered on earlier drafts of this contribution.

\section{Notes}

1. Despite their different legal and technical meanings, the expressions 'asylum', 'refuge' and 'international protection' will be used somewhat interchangeably throughout this text for convenience.

2. The expression 'sexual minorities' will be used in this chapter to refer to non-heterosexual persons. The expression 'sexual orientation' will also be used to refer to people's sexuality. I acknowledge that not everyone I wish to refer to may identify as a member of a 'sexual minority' or see the matters discussed as a matter of 'sexual orientation', but I will use these expressions for practical reasons. The words 'homosexual' and 'homosexuality' will also be used; despite being increasingly disfavoured and replaced with the word 'gay' in Englishspeaking contexts, they are still very much used in judicial decisions, in policy documents and in other languages, so they will be used here without any negative connotation. Much of the discussion in this chapter also relates to or affects gender identity asylum claims, but because the Strasbourg Court has so far only dealt with one application related to gender identity asylum, such applications will fall outside the scope of this contribution. The application in question related to a transsexual Iranian refugee in Hungary, already granted international protection who claimed a violation of Article 8 ECHR for having been denied a change of legal status of name and gender. The Court found in favour of the applicant and awarded non-pecuniary damages: Jafarizad Barenji Rana v Hungary, Application no. 40888/17, 16 July 2020.

3. UN General Assembly, 'Convention Relating to the Status of Refugees', 28 July 1951, United Nations, Treaty Series, vol. 189, p. 137.

4. UN General Assembly, Protocol Relating to the Status of Refugees, 31 January 1967, United Nations, Treaty Series, vol. 606, p. 267.

5. Parliamentary Assembly of the Council of Europe, Accelerated asylum procedures in Council of Europe member states, text adopted by the Assembly on 7 October 2005 (32nd Sitting).

6. The European Commission of Human Rights was a body of the Council of Europe that assisted the Strasbourg Court until 1998 in determining whether applications were admissible, reaching friendly settlements and producing statements of facts and opinions on whether a violation had occurred. This Commission ceased to exist with the coming into force of Protocol No. 11 to the ECHR, which, amongst other things, introduced direct access by individuals to the Court: Protocol No. 11 to the Convention for the Protection of Human Rights and Fundamental 
Freedoms, Restructuring the Control Machinery Established Thereby, Strasbourg, 11 May 1994, European Treaty Series - No. 155.

7. For example, Chahal $v$ the United Kingdom, Application no. 70/1995/576/662, 11 November 1996.

8. Bahaddar $v$ the Netherlands, Application no. 25894/94, 19 February 1998.

9. F. $v$ United Kingdom, Application no. 17341/03, 22 June 2004 (further discussed in section 'A bird's-eye view').

10. H.I. v Switzerland, Application no. 69720/16, 14 December 2017.

11. For example, Khlaifia and Others $v$ Italy, Application no. 16483/12, 15 December 2016 (Judgment of the Grand Chamber); O.M. v Hungary, Application no. 9912/15, 5 July 2016 (discussed in section 'A bird's-eye view').

12. B.A.C. $v$ Greece, Application no. 11981/15, 13 October 2016.

13. G.R. v the Netherlands, Application no. 22251/07, 10 January 2012.

14. An updated version, 'The Yogyakarta Principles plus 10 (YP+10)' (2017) is available at: http://www.yogyakartaprinciples.org/ (accessed 22 August 2020).

15. Article 14 ECHR refers exclusively to discrimination in relation to one of the rights in the ECHR. The 2000 Protocol No. 12 to the ECHR (ETS No. 177), which came into force in 2005, does contain a self-standing non-discrimination provision but has so far only been ratified by 20 out of the $47 \mathrm{CoE}$ member states.

16. Dudgeon v UK, Application no. 7525/76, 22 October 1981; Norris v Ireland, Application no. 10581/83, 26 October 1988; Modinos v Cyprus, Application no. 15070/89, 22 April 1993.

17. Smith and Grady $v$ UK, Applications nos 33985/96 and 33986/96, 27 September 1999.

18. L. and V. v Austria, Applications nos 39392/98 and 39829/98, 9 January 2003.

19. Karner v Austria, Application no. 40016/98, 24 July 2003.

20. Salgueiro da Silva Mouta v Portugal, Application no. 33290/96, 21 December 1999.

21. Schalk and Kopfv Austria, Application no. 30141/04, 24 June 2010.

22. Pajić v Croatia, Application no. 68453/13, 23 February 2016; Taddeucci and McCall v Italy, Application no. 51362/09, 30 June 2016.

23. Exceptions to this can be found in the CJEU's jurisprudence on, for example, access to marriage and discrimination, as can be seen in C-267/12, Frédéric Hay $v$ Crédit agricole mutuel de Charente-Maritime et des Deux-Sèvres, 12 December 2013, ECLI:EU:C:2013:823, and C673/16, Relu Adrian Coman and Others $v$ Inspectoratul General pentru Imigrări and Ministerul Afacerilor Interne, 5 June 2018, ECLI:EU:C:2018:385. For a discussion of this jurisprudence, see Danisi, Dustin and Ferreira 2019.

24. 'Recommendation CM/Rec(2010)5 of the Committee of Ministers to member states on measures to combat discrimination on grounds of sexual orientation or gender identity', adopted on 31 March 2010 at the 1081st meeting of the Ministers' Deputies.

25. For a more extensive chronological narrative of this jurisprudence, see Ferreira 2019. For a quick overview, including information regarding the applicants, main legal bases and key outcomes, see the tables of European jurisprudence at Ferreira 2020.

26. This jurisprudence has been identified through a search in the Court's database HUDOC (http://hudoc.echr.coe.int/), scholarly literature and NGO publications. Figures relate to date of decisions and were correct at 21 May 2019. Only cases already decided have been included; applications lodged but not yet decided have not been included. M.E. $v$ Sweden has been included twice, as it has led to two decisions from the Court, although the first one did not become a final decision. The only selection criterion used was that the case must involve - even if not as its main feature - an asylum claim related to the applicant's sexual orientation. The decision in Ayegh $v$ Sweden, Application no. 4701/05, 7 November 2006, was thus excluded, as this case involves same-sex sexual acts (the applicant's son being raped and abused by his school headmaster in Iran) but not the sexual orientation of the applicant herself.

27. See Article 35 ECHR, which establishes the criteria for the Court to consider an application admissible and deal with it, and Article 37 ECHR, which determines the circumstances under which the Court may at any stage of the proceedings decide to strike an application out of its list of cases.

28. See, for example, the database and social media available via www.sogica.org.

29. B. $v$ United Kingdom, Application no. 16106/90, 10 February 1990.

30. Shahram Sobhani $v$ Sweden, Application no. 32999/96, 10 July 1998.

31. F. $v$ United Kingdom, Application no. 17341/03, 22 June 2004.

32. I.I.N. $v$ the Netherlands, Application no. 2035/04, 9 December 2004.

33. A.N. v France, Application no. 12956/15, 19 April 2016. 
34. M.B. $v$ the Netherlands, Application no. 63890/16, 21 December 2017.

35. H.A. and H.A. v Norway, Application no 56167/16, 3 January 2017.

36. I.K. $v$ Switzerland, Application no. 21417/17, 19 December 2017.

37. K.N. and Others $v$ France, Application no. 47129/09, 19 June 2012. This case stands out as the only 'Dublin return' case amongst the Strasbourg SMAC jurisprudence. See 'Regulation (EU) No 604/2013 of the European Parliament and of the Council of 26 June 2013 establishing the criteria and mechanisms for determining the Member State responsible for examining an application for international protection lodged in one of the Member States by a third-country national or a stateless person', OJ L 180, 29.6.2013, pp. 31-59.

38. A.S.B. $v$ the Netherlands, Application no. 4854/12, 10 July 2012.

39. A.E. v Finland, Application no. 30953/11, 22 September 2015.

40. M.B. v Spain, Application no. 15109/15, 13 December 2016.

41. A.T. $v$ Sweden, Application no. 78701/14, 25 April 2017.

42. E.S. $v$ Spain, Application no 13273/16, 19 October 2017.

43. A.R.B. v the Netherlands, Application no. 8108/18, 17 January 2019.

44. R.A. v France, Application no. 49718/09, 8 February 2011.

45. D.B.N. v United Kingdom, Application no. 26550/10, 31 May 2011.

46. M.T. v France, Application no. 61145/16, 27 March 2018.

47. Khudoberdi Turgunaliyevich Nurmatov (Ali Feruz) v Russia, Application no. 56368/17, 2 October 2018.

48. M.K.N. $v$ Sweden, Application no. 72413/10, 27 June 2013.

49. M.E. $v$ Sweden, Application no. 71398/12, 26 June 2014.

50. M.E. $v$ Sweden, Application no. 71398/12, 8 April 2015.

51. O.M. v Hungary, Application no. 9912/15, 5 July 2016.

52. For example, the Court has referred to World Health Organization guidelines in Makshakov v Russia, Application no. 52526/07, 24 May 2016, and Petukhov v Ukraine (No. 2), Application no. 41216/13, 12 March 2019.

53. Joined Cases C-199/12, C-200/12 and C-201/12, X, Y and $Z v$ Minister voor Immigratie, Integratie en Asiel, 7 November 2013, ECLI:EU:C:2013:720.

54. Joined Cases C-148/13 to C-150/13, A, B and C v Staatssecretaris van Veiligheid en Justitie, 2 December 2014, ECLI:EU:C:2014:2406.

55. K.N. and Others $v$ France, A.S.B. $v$ the Netherlands, M.E. $v$ Sweden (Grand Chamber), A.E. $v$ Finland, M.B. $v$ Spain, A.T. $v$ Sweden, E.S. $v$ Spain, M.T. $v$ France, Khudoberdi Turgunaliyevich Nurmatov (Ali Feruz) $v$ Russia, and A.R.B. v the Netherlands.

56. Ilias and Ahmed $v$ Hungary, Application no. 47287/15, 14 March 2017, paras 112-13, 118 and 124 .

57. Although the Strasbourg Court was not, in these cases, dealing with the notion of 'persecution' as such - as there is no right to asylum as such in the ECHR - it is interesting to note that the Strasbourg jurisprudence somehow mirrors the assertion of the CJEU in $X, Y$ and $Z$ that the criminalisation of same-sex conduct does not in itself constitute an act of persecution. This runs against the views of scholars and NGOs alike (ICJ - International Commission of Jurists 2014; Jansen and Spijkerboer 2011).

58. Dudgeon v the United Kingdom, Application no. 7525/76, 22 October 1981.

59. Norris v Ireland, Application no. 10581/83, 26 October 1988.

60. Modinos v Cyprus, Application no. 15070/89, 22 April 1993.

61. See, for example, Soering v the United Kingdom, Application no. 14038/88, 7 July 1989.

62. M.I. $v$ Sweden, Communication No. 2149/2012, Human Rights Committee, views adopted by the Committee at its 108th session (8-26 July 2013), 25 July 2013, para. 7.5, in a case relating to a lesbian claimant from Bangladesh, where legislation criminalising same-sex conduct in itself fosters the stigmatization of LGTB individuals and constitutes an obstacle to the investigation and sanction of acts of persecution against these persons'.

63. Mondal v Sweden, CAT/C/46/D/338/2008, UN Committee Against Torture (CAT), 7 July 2011, para. 7.3, regarding a homosexual Bangladeshi man.

64. Rather astonishingly, the Court's deference to domestic authorities even extends to the Court being more concerned with applying domestic law than with applying the ECHR, as in M.E. $v$ Sweden (para. 85).

65. See, for example, the decision of the Italian Supreme Court: Corte di cassazione, ordinanza n. $4522 / 15$. 


\section{References}

Ammaturo, Francesca Romana. 2017. European Sexual Citizenship: Human rights, bodies and identities. Cham: Palgrave Macmillan.

Ammaturo, Francesca Romana. 2018. 'The Council of Europe and the creation of LGBT identities through language and discourse: A critical analysis of case law and institutional practices', International Journal of Human Rights 23:575-95. https://doi.org/10.1080/ 13642987.2018.1540413.

Bögner, Diana, Jane Herlihy and Chris R. Brewin. 2007. 'Impact of sexual violence on disclosure during Home Office interviews', British Journal of Psychiatry: The Journal of Mental Science 191:75-81. https://doi.org/10.1192/bjp.bp.106.030262.

Bracke, Sarah. 2012. "From "saving women" to "saving gays": Rescue narratives and their dis/ continuities', European Journal of Women's Studies 19:237-52. https://doi.org/10.1177/ 1350506811435032.

Buchinger, Kerstin and Astrid Steinkellner. 2010. 'Litigation before the European Court of Human Rights and domestic implementation: Does the European Convention promote the rights of immigrants and asylum seekers?', European Public Law 16:419-35.

Butler, Judith. 1990. Gender Trouble: Feminism and the subversion of identity. New York and London: Routledge.

CDDH (Steering Committee for Human Rights) and DH-SYSC (Committee of Experts on the System of the European Convention on Human Rights). 2019. 'Draft CDDH report on the place of the European Convention on Human Rights in the European and international legal order as adopted by the DH-SYSC in its 5th meeting (15-18 October 2019)'. Council of Europe. Available at: https://rm.coe.int/steering-committee-for-human-rights-cddh-committee-ofexperts-on-the-s/168098ae3d (accessed 3 March 2020).

Costello, Cathryn. 2016. 'Safe country? Says who?', International Journal of Refugee Law 28:60122. https://doi.org/10.1093/ijrl/eew042.

Crenshaw, Kimberlé. 1989. 'Demarginalizing the intersection of race and sex: A Black feminist critique of antidiscrimination doctrine, feminist theory and antiracist politics', University of Chicago Legal Forum (1):139-68. https://doi.org/10.4324/9780429500480-5.

Danisi, Carmelo. 2009. 'Preventing torture and controlling irregular immigration: The role of the European Committee for the Prevention of Torture and its activity in Italy', Essex Human Rights Review 6:151-76.

Danisi, Carmelo. 2015. Tutela dei diritti umani, non discriminazione e orientamento sessuale. Naples: Editoriale Scientifica.

Danisi, Carmelo, Moira Dustin and Nuno Ferreira. 2019. 'Queering Brexit: What's in Brexit for sexual and gender minorities?' In Gender and Queer Perspectives on Brexit (Gender and Politics), edited by Moira Dustin, Nuno Ferreira and Susan Millns, 239-72. Cham: Palgrave Macmillan.

Dembour, Marie-Bénédicte. 2015. When Humans Become Migrants: Study of the European Court of Human Rights with an Inter-American counterpoint. Oxford: Oxford University Press.

ECRE (European Council on Refugees and Exiles). 2016. 'ECRE comments on the Commission proposal for an Asylum Procedures Regulation COM(2016) 467'. Available at: http://www. ecre.org/wp-content/uploads/2016/11/ECRE-Comments-APR_-November-2016-final.pdf (accessed 3 March 2020).

European Committee for the Prevention of Torture and Inhuman or Degrading Treatment or Punishment. 2017. '26th general report of the CPT: 1 January-31 December 2016'. Council of Europe. Available at: https://rm.coe.int/CoERMPublicCommonSearchServices/DisplayDC TMContent?documentId=090000168070af7a\&utm_ (accessed 3 March 2020).

Falcetta, Silvia. 2015. 'M.E.v Sweden'.ECHR Sexual Orientation Blog. 2015. Available at: http://echrso. blogspot.co.uk/2015/04/me-v-sweden-guest-post-by-silvia.html (accessed 3 March 2020).

Falcetta, Silvia and Paul Johnson. 2018. 'Migration, sexual orientation, and the European Convention on Human Rights', Journal of Immigration, Asylum and Nationality Law 32:210-31.

Fernandez, Bina. 2017. 'Queer border crossers: Pragmatic complicities, indiscretions and subversions'. In Queering International Law: Possibilities, alliances, complicities, risks, edited by Dianne Otto, 193-212. Abingdon: Routledge.

Ferreira, Nuno. 2018. 'Reforming the Common European Asylum System: Enough rainbow for queer asylum seekers?', GenIUS: Rivista di studi giuridici sull'orientamento sessuale e l'identità di genere (Special Issue on SOGI Asylum) (2):25-42. 
Ferreira, Nuno. 2019. 'Sexual minority asylum claimants in the jurisprudence of the Strasbourg Court: A chronology', SOGICA/University of Sussex, 3 May. Available at: www.sogica.org/ database/ferreira-sexual-minority-asylum-claimants-in-the-jurisprudence-of-the-strasbourgcourt-2019/ (accessed 22 August 2020).

Ferreira, Nuno. 2020. 'SOGICA - Tables of European SOGI asylum jurisprudence', SOGICA/ University of Sussex, 16 July. Available at: https://www.sogica.org/database/ferreira-sogicatables-of-european-sogi-asylum-jurisprudence-2020/ (accessed 22 August 2020).

Fraser, Matthew. 2014. 'LGBTI asylum seekers: Discord between the European courts?', EDAL (European Database of Asylum Law), 25 July.

Gonzalez-Salzberg, Damian A. 2019. Sexuality and Transsexuality under the European Convention on Human Rights: A queer reading of human rights law. Portland, OR: Hart Publishing.

Human Rights Council. 2016. 'Resolution adopted by the Human Rights Council on 30 June 2016: Protection against violence and discrimination based on sexual orientation and gender identity' (A/HRC/RES/32/2). Available at: http://www.un.org/en/ga/search/view_doc. asp?symbol=A/HRC/RES/32/2 (accessed 3 March 2020).

ICJ (International Commission of Jurists). 2014. 'X, Y and Z: A glass half full for "rainbow refugees"? The International Commission of Jurists' observations on the judgment of the Court of Justice of the European Union in $X, Y$ and $Z v$ Minister voor Immigratie en Asiel'. International Commission of Jurists (ICJ).

ILGA-Europe. 2017. 'Update from Strasbourg - M.B. v Spain asylum case struck out'. 19 January. Available at: http://ilga-europe.org/resources/news/latest-news/update-strasbourg-mb-vspain-asylum-case-struck-out (accessed 30 June 2020).

Jansen, Sabine. 2019. 'Pride or shame? Assessing LGBTI asylum applications in the Netherlands following the XYZ and ABC judgments'. Amsterdam: COC Netherlands. Available at: https:// www.coc.nl/wp-content/ uploads/2019/01/Pride-or-Shame-LGBTI-asylum-in-theNetherlands.pdf (accessed 3 March 2020).

Jansen, Sabine and Thomas Spijkerboer. 2011. 'Fleeing homophobia: Asylum claims related to sexual orientation and gender identity in Europe'. Amsterdam: Vrije Universiteit Amsterdam. Available at: https://www.refworld.org/docid/4ebba7852.html (accessed 22 August 2020).

Johnson, Paul. 2013. Homosexuality and the European Court of Human Rights. Abingdon: Routledge.

Johnson, Paul and Silvia Falcetta. 2018. 'Sexual orientation discrimination and Article 3 of the European Convention on Human Rights: Developing the protection of sexual minorities', European Law Review 43:167-85.

Langlois, Anthony J. 2018. 'Review article: Curiosity, paradox and dissatisfaction: Queer analyses of human rights', Millennium 47:153-65. https://doi.org/10.1177/0305829818783262.

Mendos, Lucas Ramón. 2019. State-Sponsored Homophobia 2019: Global legislation overview update. Geneva: ILGA World. Available at: https://ilga.org/downloads/ILGA_World_State_ Sponsored_Homophobia_report_global_legislation_overview_update_December_2019.pdf (accessed 22 August 2020).

Millbank, Jenni. 2009. “"The ring of truth”: A case study of credibility assessment in particular social group refugee determinations', International Journal of Refugee Law 21:1-33. https:// doi.org/10.1093/ijrl/een040.

Mole, Richard C. M. 2017. 'Homonationalism: Resisting nationalist co-optation of sexual diversity', Sexualities 20:660-2. https://doi.org/10.1177/1363460716645800.

Peers, Steve. 2016. EU Justice and Home Affairs Law. Volume I: EU Immigration and Asylum Law (4th edn). Oxford: Oxford University Press.

Peroni, Lourdes. 2018. 'The protection of women asylum seekers under the European Convention on Human Rights: Unearthing the gendered roots of harm', Human Rights Law Review 18:34770. https://doi.org/10.1093/hrlr/ngy005.

Phillips, Oliver. 2009. 'Blackmail in Zimbabwe: Troubling narratives of sexuality and human rights', International Journal of Human Rights 13:345-64. https://doi.org/10.1080/ 13642980902758192.

Rackow, Julia. 2016. 'Strasbourg and Luxembourg: A dialogue between law and politics'. Geneva Jean Monnet Working Papers 22/2016.

Ravarani, Georges. 2017. 'Assessment of the credibility of asylum-seekers: The burden of proof and the limits of the ECHR's examination'. European Court of Human Rights. Available at: https://www. echr.coe.int/Documents/Speech_20170127_Ravarani_JY_ENG.pdf (accessed 3 March 2020).

Sedgwick, Eve Kosofsky. 2008. Epistemology of the Closet (updated with a new preface). Berkeley and Los Angeles: University of California Press. 
Shakhsari, Sima. 2012. 'From homoerotics of exile to homopolitics of diaspora: Cyberspace, the war on terror, and the hypervisible Iranian queer', Journal of Middle East Women's Studies 8:14-40. https://doi.org/10.2979/jmiddeastwomstud.8.3.14.

Souter, James. 2011. 'A culture of disbelief or denial? Critiquing refugee status determination in the United Kingdom', Oxford Monitor of Forced Migration 1:48-59.

Spijkerboer, Thomas. 2018. 'Gender, sexuality, asylum and European human rights', Law and Critique 29:221-39. https://doi.org/10.1007/s10978-017-9219-2.

Steendam, Sander. 2014. 'M.E. v. Sweden: Back to the closet', Strasbourg Observers (blog). 28 July. Available at: https://strasbourgobservers.com/2014/07/28/m-e-v-sweden-back-to-thecloset/ (accessed 3 March 2020).

UNHCR. 2012. 'Guidelines on international protection no. 9: Claims to refugee status based on sexual orientation and/or gender identity within the context of Article 1A(2) of the 1951 Convention and/or its 1967 Protocol relating to the Status of Refugees' (HCR/GIP/12/01). Available at: http://www.refworld.org/docid/50348afc2.html (accessed 3 March 2020).

UNHCR. 2019. 'Handbook on procedures and criteria for determining refugee status and Guidelines on international protection under the 1951 Convention and the 1967 Protocol relating to the Status of Refugees'. Geneva: UNHCR. Available at: https://www.unhcr.org/publications/ legal/5ddfcdc47/handbook-procedures-criteria-determining-refugee-status-under-1951convention.html (accessed 22 August 2020).

van der Vleuten, Anna. 2014. 'Transnational LGBTI activism and the European courts: Constructing the idea of Europe'. In LGBT Activism and the Making of Europe: A rainbow Europe? (Gender and Politics), edited by Phillip M. Ayoub and David Paternotte, 119-44. Abingdon: Palgrave Macmillan.

Waaldijk, Kees. 2003. 'Others may follow: The introduction of marriage, quasi- marriage, and semimarriage for same-sex couples in European countries', New England Law Review 38:569-89.

Wintemute, Robert. 2015. 'In extending human rights, which European court is substantively "braver" and procedurally "fitter"? The example of sexual orientation and gender identity discrimination'. In Fundamental Rights in the EU: A matter for two courts, edited by Sonia MoranoFoadi and Lucy Vickers, 179-200. Oxford: Hart Publishing.

'The Yogyakarta Principles: Principles on the application of international human rights law in relation to sexual orientation and gender identity'. 2007. Available at: https://www.refworld.org/ pdfid/48244e602.pdf (accessed 22 March 2020).

Yuval-Davis, Nira. 2006. 'Intersectionality and feminist politics', European Journal of Women's Studies 13:193-209. https://doi.org/10.1177/1350506806065752. 


\section{6 \\ On the government of bisexual bodies: asylum case law and the biopolitics of bisexual erasure}

Christian Klesse

\section{Introduction}

Research into asylum case law in many countries (including the USA, Canada, Australia, New Zealand and the UK) suggests that bisexuals are at serious risk of having their claims dismissed, because their stories and identities are cast as non-plausible or non-consequential (Berg \& Millbank 2009; Rehaag 2008, 2010; Sin 2015). While the 'discretion requirement', i.e. the expectation that lesbian, gay, bisexual or trans* applicants will live 'discreet' lives (or, in other words, 'stay in the closet') to prevent persecution, has been successfully challenged in many jurisdictions, bisexuals are still alleged to be able to 'pass' without hassle, if they only enter heterosexual relations (Spijkerboer 2013). Bisexual claimants often find it impossible to prove their membership of a 'particular social group'. The fluidity bound up with bisexuality and the lack of acceptance of bisexual identities is at odds with the 'immutability' assumption of sexual orientation models (Sin 2015). The common discrimination against bisexuals in asylum law is a direct outflow of what Kenji Yoshino (2000) calls the 'epistemic contract of bisexual erasure'. The obstacles to making bisexual experience intelligible in the field of law and to bisexual claimants' accessing a right to asylum are part of the regulation of the sexuality of migrants' bodies through biopolitical acts of government with all too often necropolitical consequences.

In this chapter, I draw on both queer and bisexual theory, and on recent work on biopolitics and necropolitics that has specifically engaged 
with questions of migration, race/ethnicity and racism (cf. Mbembe 2003; Puar 2007; Farrier 2011; Haritaworn, Kunstman \& Posocco 2014a). I argue that the asylum system operates as a biopolitical/necropolitical apparatus of governance that produces precarious racialised populations who are treated as disposable and stripped of chances for survival through the operation of a rigid deportation regime. LGBTQI people have historically been particularly vulnerable, because international human rights law did not engage in any substantial manner with gender identity and sexuality for a long time (Petchesky 2000; Morgan 2000; O'Flaherty and Fisher 2008; Kollman and Waites 2009). Within these intersecting taxonomies of race and sexuality, bisexual asylum claimants form a population among queer asylum seekers that faces particular challenges when confronting the racist, heterosexist and homonormative asylum and immigration regime. The responses to bisexual asylum claims and their comparatively low chances of success allow us to pinpoint manifold contradictions within international human rights law and expose the hypocrisy of a system that likes to wear a halo of empathic appeals to solidarity, human rights and social justice.

\section{From biopolitics to queer necropolitics: gender, sexuality and postcolonial asylum}

The legal apparatus of the asylum process that forces applicants to produce a coherent subjectivity that corresponds to a history of consistent exposure to violence and persecution (which is immediately drawn into doubt, resulting in threats of non-admission, rightlessness, detention or deportation) can be seen as biopolitical in the sense applied to the term by Michel Foucault. Foucault's work has inspired a critical debate among a wide range of theorists, including Giorgio Agamben (1998, 2005), Roberto Esposito (2008, 2011), Michael Hardt and Toni Negri (Hardt \& Negri 2001, 2005), Achille Mbembe (2003) and Nikolas Rose (2006), which has produced biopolitics as 'an interpretive key to analyse how the production of life is articulated with the production of death' (Lemke 2011, xi). In the following, I draw on some of this work to provide a theoretical framework that helps us understand how race and sexuality interact in the subjection of LGBTQI, asylum seekers to biopolitical technologies with all too often deadly consequences. Apart from Foucault himself, I draw on the work of Achille Mbembe (2003) and Jemima Repo (2018). While the production of death is also emphasised within the concept of biopolitics by Agamben and Esposito, Mbembe's 
discussion of necropolitics brings this aspect to the fore with the greatest emphasis.

Foucault elaborates his concept of biopower in the context of his analysis of modern forms of government to grasp 'the forms of experience and rationality on the basis of which power over life was organized' from the eighteenth century (Sellenart 2004, 370). Governmentality, biopower and biopolitics are all parts of a similar larger and overarching project. For Foucault, 'governmentality' designates a new rationality of power that 'has the population as its target, political economy as its major form of knowledge, and apparatuses of security as its essential technical instrument' (Foucault, quoted in Sellenart 2004, 388).

As Foucault explains in a lecture course, published as Society Must Be Defended, biopower dovetails with disciplinary power but uses different techniques: 'Unlike discipline, which is addressed to bodies, the new nondisciplinary power is applied not to man- [sic] as-body, but to the living man, to man-as-living-being; ultimately, if you like, to manas-species' (Foucault 1997, 242). He also talks of 'a "biopolitics" of the human race' (Foucault 1997, 243). Regulating, ordering, measuring, shaping and transforming human life emerges as a core field of governmental tasks (see Foucault 1990, 1997). However, sovereignty in the modern period continues to exert and establish itself as 'the right of life and death' (Foucault 1997, 240). Yet in contradistinction to prior modes of sovereignty, biopower is bent towards administering life rather than destroying it.

\section{From biopolitics to necropolitics}

Mbembe (2003) is adamant that within modernity sovereignty has always included both biopolitical and necropolitical regimes and tendencies. The division of people into those who are supposed to live and those who are supposed to die is core to the control of populations within the 'biological field' designated by biopolitics. This division entails the delineation of the population through biopolitical acts of administration that imply exclusions at the margins. Foucault refers to the act of categorising people for this purpose as racism. For Foucault, racism and state power are closely intertwined, since this provides the only way for states to enact biopolitical power as a power to create and take life (or alternatively 'to let die'). 'In a normalizing society, race or racism is the precondition that makes killing possible', argues Foucault, or, in a similar vein, 'Once the state functions in the biopower mode, racism alone can justify the murderous function of the state' $(1997,256)$. Foucault uses the term 'racism' 
in a broad way, in the sense of a 'social racism', which provides the rationality for legitimising the banishing and exclusion of groups of people on different grounds (criminality, madness, sexual deviance, etc.) resulting in either 'social death' or actual death - with Nazism providing the prime example of the racial state $(1997,259)$. Foucault limits himself to exploring the implication of Western concepts of governmentality and sovereignty in the extinction of Europe's 'internal Others'. Although he occasionally mentions questions of colonialism in sweeping references (as shown by Hidefumi Nishiyama (2018) and Jemima Repo (2018)), he has been rightly criticised for not addressing the analysis of the history of colonialism in more detail (Stoler 1995).

For Mbembe (2003), slavery and exploitation in the plantation economies, colonial terror and imperial warfare are the prime examples of biopolitical experimentation. With these histories firmly in view, Mbembe presents a different assessment of the history of European theories of sovereignty and stresses that 'the generalized instrumentalization of human existence and the material destruction of human bodies and populations' (2003, 14; emphasis in original) have to be seen as an integral part of the Enlightenment legacy. In the face of these atrocities, many of which have been enabled by the designation of specific racialised groups as infrahuman (Gilroy 2000, 2006), the concept of biopower appears to be limited. Mbembe suggests the term necropower to allow a more focused investigation of the question: 'under what practical conditions is the right to kill, to allow to live, or to expose to death exercised?' (2003, 11). As Repo (2018) demonstrates, Foucault thought primarily of racism when he discussed the death aspect of biopolitics, whereas he considered sexuality to be the primary apparatus allowing the administration of life, ranging from bodies through sexual behaviours to the population as a more abstract category. However, Repo goes on to claim that sexuality, too, can propel the death function of biopolitics, for example through queer-bashing or targeted killing 'as the ultimate punishment for a sexuality that will not discipline and normalise itself' (Repo 2018, 46). As the precarious position of LGBTQI applicants in the asylum process and the creation of a condition of virtual non-intelligibility for applicants with fluid, bi- or pansexual attractions and attachments discussed later in this chapter will show, this is not the only way in which death relates to the biopolitics of sexuality. Both racism and heteronormativity (as an assemblage of anti-gay, anti-lesbian, anti-bi and anti-trans* practices) have underpinned practices that mark entire groups of the population as being disposable - and thus killable - and have thereby normalised cruelty, often within the allegedly benign paradigms of democracy, civilisation, peace, development and humanitarianism. 
The academic debate about biopolitics and necropolitics has explored multiple aspects of contemporary political culture (Pieper et al. 2011; Clough \& Willse 2011; Campbell \& Sitze 2013). The differential distribution of vulnerability to the threat of destruction and the lack of a public culture of mourning the loss of certain - usually racialised - lives follow a calculus that renders certain populations disposable (Butler 2004, 2009). Drawing on the pioneering work of Puar (2007), Haritaworn, Kuntsman and Posocco (2014b, 1) deploy the term queer necropolitics to theorise 'the intersection of gender, sexuality, violence and precariousness' as it affects queer and trans* bodies in the face of the death worlds of war and imperialism (see also Snorton \& Haritaworn 2013; Aizura 2014). This perspective aims to understand 'the ways in which sexual difference is increasingly absorbed into hegemonic apparatuses, in a way that accelerates premature death' (Haritaworn, Kunstman \& Posocco 2014b, 1). Stressing the urgency of racism and the coloniality of power, the critique of queer necropolitics directs attention to 'the everyday death worlds' that range from the explicit 'sites of death making' shaped by war, imperialism, torture and imprisonment to the 'completely normalized violence of the market' (Haritaworn, Kunstman \& Posocco 2014b, 2). This work highlights the divisions created by racism, neoliberalism and the wilful compliance of mainstream LGBT organisations with homonationalist discourses (Puar 2007).

Shakhsari (2014a, 2014b) shows how asylum claims based on gender identity and sexual orientation are overdetermined by a racist discourse that construes the USA and other Western countries as safe havens for LGBTQI people while representing Muslim countries (or the 'Third World') as murderous and hostile towards LGBTQI citizens. In order to present successful and legitimate claims that underscore the urgency of a 'well-founded fear of persecution', asylum seekers are pressurised to present stories that 'demonise' their country of origin (Shakhsari 2014a, 100-1). Neo-imperial politics create a paradoxical dynamic. Wars are legitimated in the name of protecting LGBTQI rights (Haritaworn, Tauqir \& Erdem 2008), while those who are forced to flee the murderous violence of the wars are caught in the transnational border and camp regime (where their existence is reduced to bare life and where they are frequently vulnerable to further abuse and threats to their lives). For Shakhsari (2014a, 95; emphasis in original), this illustrates 'the killability of lives that are simultaneously imbued with and stripped of liberal universal rights; lives that are subjected to the politics of rightful killing'. The spectre of 'the politics of rightful killing', couched within 
networks of biopolitical and necropolitical strategies, fully reveals the complexity of asylum claims based on sexual orientation or gender identity and the difficult circumstances under which they are conducted.

The cruelty of locking up hundreds of asylum seekers who had been victims of torture in UK detention centres, successfully challenged in the courts in October 2017, is a case in point. Reportedly, a bisexual asylum seeker from Nigeria, who was beaten, flogged and knifed because of his sexuality, was among those who advanced the case in the courts (Taylor 2017).

\section{Bisexuality, bisexual erasure and the asylum process}

Research indicates that in many countries asylum claims based on persecution because of bisexuality are much more likely to be turned down than asylum claims not related to sexual minority status in general or claims based on lesbian or gay identification in particular (Berg \& Millbank 2009; Rehaag 2008, 2010; Sin 2015). The relative invisibility of bisexuality in refugee law mirrors its lack of visibility in human rights practice and discourse in general (Rehaag 2010). While bisexuality is nominally included in many documents that deal with human rights from the angle of gender and sexuality, bisexuality-related issues are rarely discussed in detail and do not usually inform policy recommendations. There are of course well-founded concerns as to whether labels such as 'homosexual', 'lesbian', 'gay', 'bisexual', or even MSM (men who have sex with men) or WSW (women who have sex with women), all of which have currency in Western cultural contexts, can be universalised across cultures. However, Hemmings (2007) points out that authors who work within transnational queer studies, where such concerns are frequently raised, direct their criticism with particular rigour and vehemence at bisexuality, whereas they may continue to use 'lesbian and gay' or 'homosexual' as a shortcut to refer to same-sex behaviours globally. "It is as if "lesbian" and "gay" can be understood as strategic uses of identity, but "bisexual" cannot be', Hemmings observes $(2007,22)$. '[B]isexuality is framed as having an almost unique capacity for reinforcing dominant sexual discourse' (Hemmings 2007, 22; emphasis in original). The pronounced hostility towards bisexuality as a concept, category and identity label found in some quarters of queer theory have been noted elsewhere (Angelides 2000; Young 1997). This can be seen as an effect of the widespread marginalisation of bisexuality within social theory at large (cf. Monro, Hines \& Osborne 2017; Klesse 2018). The lack of consideration of bisexuality in 
transnational queer studies extends also to the scholarly work that deals with sexuality, gender identity and asylum. For example, Lewis's (2014) analysis of 'queer asylum' and 'queer anti-deportation activism' in the UK, which is concerned with the normative pressures of an asylum process that aims to establish authenticity through narrative evidence, generically refers to 'gay and lesbian' or 'queer' claims and claimants in most parts of the text. While she talks of 'lesbian and bisexual women' or 'queer women' in order to press a gender-based argument, she analyses the implications of the problem concerned (i.e., stereotypical representations) only with regard to lesbian women's claims. The question of how bisexual women are affected by the flaws of the process is not considered (see also Llewellyn 2017). While bisexuality is occasionally nominally evoked, it keeps lingering in the margins of the text. Few texts consider the position of bisexual claims in relation to and in comparison with other 'sexual minority claims' (Millbank 2009; Berg \& Millbank 2009; Giametta 2014; Murray 2014; Vogler 2016), and even fewer specifically address bisexual asylum seekers' experiences of the application process (Rehaag 2008, 2010; Sin 2015; Gross 2018; Marcus 2018).

\section{The problem with 'sexual orientation'}

The precariousness of the position of bisexuality within human rights practice and discourse is aggravated by the fact that the notion of 'sexual rights' has been modelled on the idea of 'sexual orientation' (see Corrêa \& Muntarbhorn 2007), which according to Waites cannot capture all people 'who do not relate sexually only to one gender' $(2009,151)$, i.e., those people who are commonly considered to be 'bisexual'. Waites (2009) believes that the essentialist ideas underpinning sexual orientation discourse militate against the comprehensibility of 'bisexual' identities and ways of life. Sexual orientation is usually perceived to be an immutable trait of an individual's personality (Murphy 1997; Stein 1999; Wilson \& Rahman 2005). Sexual minorities have frequently had recourse to what Yoshino (2000) calls the 'immutability defense', i.e., a pattern of argumentation which suggests that it is unethical to persecute or punish people who have no choice regarding their sexual attractions and behaviours, because they are allegedly 'born this way'. Bisexual narratives threaten the logic of 'immutability defences' and are at odds with the rigidity of sexual orientation thinking. Some theorists consider multiplicity, fluidity and non-coherence to be the sources of bisexuality's unique queer potential for undoing the dominant gender and sexuality categories of Western binary thought (Alexander \& Anderlini-D’Onofrio 2014). 
At the same time, the very same features underpin the precarious position of bisexuality in the field of the law and in the asylum process.

The 1951 Geneva Convention Relating to the Status of Refugees established an international obligation to aid refugees who are persecuted on the grounds of race, religion, nationality, membership of a particular social group, or political opinion (UNHCR 1951).

The Convention itself and national refugee laws that followed the Convention did not originally contain any references to persecution on the grounds of gender or sexuality. However, the UNHCR's (2008) publication of its official guidelines on claims relating to sexual orientation and gender identity signalled a growing interest in the treatment of lesbian, gay, bisexual, transgender and intersex refugees and asylum seekers (Lewis \& Naples 2014). This includes the recognition of sexual orientation as a cause of persecution in Article 10 of the EU Asylum Qualification Directive 2004 (Council Directive 2004/83/EC) (Council of the European Union 2004), which was later confirmed and elaborated in Article 10 of the Qualification Directive (2011/95/EU) (Council of the European Union 2011), and the publication in the USA in December 2011 of specific guidelines for the evaluation of asylum claims based on sexual orientation and gender identity (White House, Office of the Press Secretary 2011; Vogler 2016). While the development signified by these publications certainly ameliorates the situation of refugees seeking protection from persecution on these grounds, it has been driven partly by the increasing politicisation and instrumentalisation of LGBTQI human rights for the purpose of cultural and geopolitical hegemony as parts of neo-imperial agendas (Shakhsari 2014a, 2014b; Aizura 2014; Haritaworn, Kunstman \& Posocco 2014b; Raboin 2017; Llewellyn 2017).

In the absence of specific provisions for claims on the basis of sexual dissidence or minority status, many claimants who flee persecution because of their sexuality advance asylum claims on the grounds of belonging to a 'particular social group'. In a process starting in the early 1990s, many national or transnational jurisdictions finally accepted sexual orientation and gender identity as relevant grounds of persecution and expanded their legal provisions (see Rehaag 2008). For example, Qualification Directive 2011/95/EU suggests that '[d] epending on the circumstances in the country of origin, a particular social group might include a group based on a common characteristic of sexual orientation' and states that 'gender related aspects, including gender identity, shall be given due consideration for the purposes of determining membership of a particular social group or identifying a characteristic of such a group' (Council of the European Union 2011, Article 10.1(d)). 
A review of Canadian asylum court cases (1994-2004) shows that applicants who applied for asylum on the grounds of sexual identity by claiming membership in a 'particular social group' were less likely to be granted asylum if they stated bisexuality as the reason for their persecution than those who asserted a gay or lesbian orientation (Rehaag 2008). Similar findings have been reported for the UK, the USA, Australia and New Zealand (Rehaag 2010; Berg \& Millbank 2009; Sin 2015).

Asylum seekers who advanced claims related to sexual orientation have deployed different rationales, which include a focus on one of the following themes: (1) 'political opinion' (around histories of activism or non-conforming sexual and gender behaviours), (2) 'religion' (relating to provisions regarding religious dissidence in the UNHCR (2002a) Guidelines on gender-related persecution), and, most frequently, (3) 'membership in a particular group'. In the following, I will highlight the particularly precarious position of bisexuality with regard to the last rationale.

In the 1993 Canadian Supreme Court decision, Canada (AG) v Ward (Supreme Court of Canada 1993), Justice La Forest argues that there are three different types of social groups:

(1) groups defined by an innate or unchangeable characteristic; (2) groups whose members voluntarily associate for reasons so fundamental to their human dignity that they should not be forced to forsake the association; and (3) groups associated by a former voluntary status, unalterable due to its historical permanence.

(Supreme Court of Canada 1993)

Justice La Forest further suggests that ' $[t]$ he first category would embrace individuals fearing persecution on such bases as ... sexual orientation'. This statement welcomes sexual minorities within Canadian asylum law, because sexual orientation would qualify as an 'innate or unchangeable characteristic' (Supreme Court of Canada, see Rehaag 2010, 284). The primary concern of Ward was not sexuality. Rather, it involved the claims of a member of the Irish National Liberation Army (INLA), who had sought asylum in Canada on the grounds of persecution for membership in a particular social group, namely the INLA. Ultimately, the decisions in this case of the Immigration and Refugee Board of Canada (IRB) resolved conflicting interpretations of 'membership in a particular social group' in Canadian asylum law. In Ward, the Supreme Court stated explicitly and clearly that sexual orientation was an innate 
and immutable personal characteristic (LaViolette 1997). This legal opinion had a major impact on asylum cases in Canada and beyond. It has subsequently met with widespread approval in jurisdictions across the world and has entered the UNHCR (2002b) Guidelines on social group claims, and the UNHCR (2008) Guidance on claims relating to sexual orientation and gender identity (Rehaag 2010, 284). While welcoming a decision that opened a window for LGBT asylum claims, many critics of Justice La Forest's ruling suggest that the essentialism implied in the passage and the focus on status rather than behaviour renders invisible the different and complex meanings bound up with non-heterosexual sexualities, intimacies and identities across different cultural contexts. A stronger focus on a fundamental right to human dignity would also have prevented a rigid, reductionist and extremely narrow (merely categorical) interpretation of 'membership in a particular social group' (LaViolette 1997; Rehaag 2008, 2010).

\section{'Immutability' and visibility}

Both of the core concepts that underpin the rationality for legitimising asylum claims ('sexual orientation' and 'membership in a particular social group') are defined with an emphasis on 'immutability'. However, the fluidity ascribed to bisexual desire and identities is at odds with such essentialist assumptions, in particular if asylum cases are built on claims to 'membership in a particular group'. As a result, 'bisexual refugee claimants are at serious risk of having their cases improperly assessed because their life experiences are easily misunderstood' (Reehag 2008, 61).

Berg and Millbank's (2009) research demonstrates that the identity claims of all applicants who claim persecution on the ground of sexual orientation are systematically scrutinised and measured against normative ideas based on stereotypical (mis)representations and unrealistic expectations (cf. Dauvergne and Millbank 2003; Shuman and Bohmer 2014; Bennett and Thomas 2013). The authors' close reading of case decisions reveals the particularly destabilising effects that references to bisexuality tend to have on the identity claims of applicants. Even the bisexual behaviours of a partner or ex-partner (!) have been given as reasons to distrust the credibility of women seeking asylum on the grounds of a lesbian orientation.

Bisexuality is at odds with the dominant belief in the fixity of sexual identities and the assumption of a neat match between behaviour and identification. Moreover, bisexuals are often not able to prove that 'their' group is sufficiently 'visible' and 'recognisable' for the purpose of legally 
qualifying as a 'particular social group'. Visibility is a chief criterion for the definition of 'a particular social group' in many asylum jurisdictions, including US refugee law (Spijkerboer 2013, 221). The burden of having to prove 'visibility' creates a particular predicament for bisexuals as a group for different reasons (some may have been married, there is a lack of a recognisable 'bisexual culture' in most countries, etc.).

A group put at particular disadvantage here is (lesbian, bisexual or queer) women (Lewis 2013, 2014; Llewellyn 2017). This is because the trope of 'visibility' is modelled upon representations of a linear and coherent identity that stretches across the private/public divide. Gay men's experiences are more likely to meet these requirements than women's life trajectories, which are often more constrained and concealed by gender-related expectations of marriage, reproduction, domestic responsibilities, kinship obligations, propriety, etc. Moreover, women's queer cultures are often far less publicly organised and less frequently researched and documented, which means that there is less accurate evidence available that could 'authenticate' women's claims.

The muddled and incoherent frameworks of visibility and discretion have further led to an 'excessive focus on the sexuality of individual claimants' (Lewis 2014, 962). For example, the Czech government has been reported to have deployed compulsory sexual arousal tests in which asylum applicants were exposed to different kinds of pornography (Akin 2017). Research suggests that the submission of explicit visual documentation by gay male applicants was examined as acceptable evidence in UK court procedures, although the official guidelines at the time stated that documentary evidence of sexual activities is not required to provide proof of sexual orientation (Lewis 2014, 959). ${ }^{1}$ Yet the harsh scrutiny by questioning and the frequent reluctance of immigration officials to accept the testimonies of witnesses who did not have sex with the applicant themselves steer asylum seekers and their legal teams towards supporting their cases in this way. Again, a legal culture geared towards the expectation that one will display one's sexuality in such a public way causes particularly serious predicaments for women in the asylum process (Lewis 2014).

Because of the fluidity of bisexuality, which often implies nonlinear life narratives, and the lack of permanent bisexual spaces and cultural and political institutions, bisexual claimants are among the groups that find it difficult to produce the kind of evidence expected by judges in asylum hearings. In the light of the discussion above, we should assume that this problem is aggravated for bisexual women (compared to bisexual men) but so far no comparative data has been collected (see Rehaag 2010). 
Research suggests that many asylum seekers adopt proactive strategies in order to deal with these challenges pre-emptively. These include 'going public' (e.g. through the use of media) or 'looking for organisational support' (which may involve forms of voluntary activism, which also creates affiliation with and visibility within LGBTQI contexts) (Akin 2017). Many organisations in the field of LGBTQI asylum support operate within an ostensibly narrow framework, as indicated by the naming of groups, for example the UK Lesbian and Gay Immigration Group (see UKLGIG 2010, 2013), and the Lesbian Immigration Support Group. The lack of references to and awareness of bisexuality within the wider organisational LGBTQI asylum support spectrum may inhibit biidentified asylum seekers from looking for organisational affiliation as a means of support in the asylum process. They may also be less likely to be encouraged to build a claim based on a bisexual narrative.

\section{The 'LGBT' label: discourse and advocacy}

The 'presentation of an internal identity with a static and linear sexual desire is a Western construct, and necessary for the validation of queer asylum narratives in legal terms', argues Deniz Akin (2017, 467). Lesbian and gay identity claims are more easily recognisable and authenticable within these registers than a bisexual identity marker, but of course 'bisexuality', too, is one optional strategic identity claim. Although an inherently instable and precarious category, the B is part of a wider, transnationally recognisable 'LGBT trope' within the Western human rights discourse that certainly sits uneasily with individual or collective local identifications. David Murray suggests that in most Canadian Immigration and Refugee Board and socio-legal discourses, "sexual minorities" tend to be identified or described as homosexual, lesbian, gay, bisexual and/or transgender, such that individuals who make a claim based on persecution as a member of this "particular social group" do so through the utilization of LGBT terminology' (2014, 463).

Compared with previous US governments, the Obama administration took a rather progressive stance on questions about LGBTQI rights and LGBTQI-related humanitarian matters (Lewis \& Naples 2014). Some researchers suggest that this policy change resulted in major improvements for LGBTQI asylum claimants, including those groups that have reportedly faced serious difficulties in the asylum process. For example, Vogler (2016) reports that many of the lawyers he interviewed for his project claimed that they had successfully defended bisexual, trans* and genderqueer claimants. In a stark reversal of the queer argument of normativity as 
constraint, Vogler hails the asylum process as a site for the proliferation of new sexual and gender identities that exceed the Euro-American cultural horizon: "[T] he flexibility of the "particular social group" category allows petitioners to stake out new claims based on their unique sexualities' $(2016,858)$. Vogler attributes to the asylum system a truly queering potential. The recognition of queer identities 'increasingly blurs any (imagined) crisp dividing line between heterosexuals and homosexuals, as bisexuals and even those with imputed and ambiguous sexual identities are officially recognized by the state' (Vogler 2016, 885). While I appreciate Vogler's attention to indicators of change, he certainly overstates his case when he claims that "concerns about defining sexuality as "immutable" rarely affect applicants in practice today' $(2016,882)$. This contradicts the court experiences of many asylum seekers as evidenced by other researchers (Sin 2015; Llewellyn 2017; Shuman \& Hesford 2014). I am not convinced that the existence of new guidelines (e.g. US Citizenship and Immigration Services 2011) and a small number of positive case decisions (however welcome) really signal a watershed. Research in other countries indicates that existing guidelines are often poorly applied and understood (Bennett \& Thomas 2013; Singer 2015). Media sources suggest that asylum judges continue to reject bisexual claimants' narratives even in the face of compelling evidence (Stern 2016).

Moreover, the anti-LGBTQI and anti-immigration stance of Donald Trump's government casts serious doubts over Vogler's optimistic predictions. The Trump presidency has disastrous implications for LGBTQI asylum seekers. Numbering white supremacists among his advisors, he has implemented draconian anti-immigration measures: he has issued executive orders to suspend the State Department's Refugee Assistance Programme and to impose travel bans on the citizens of several Muslim-majority countries; and under the banners of 'religious liberty' and heterosexual family values he has withdrawn LGBTQI antidiscrimination measures (Gessen 2017; Oppenheim 2017; Alter 2017; Moskowitz 2016).

\section{'Well-founded fear of persecution' and discretion reasoning}

Proving that one belongs to 'a particular social group' is not in itself enough for a successful claim for asylum. The process also assesses whether there is a 'well-founded fear of persecution' (Shakhsari 2014a). In her discussion of sexual orientation-based asylum cases in the USA, Llewellyn (2017) observes that only those cases are likely to be successful in which claimants show that they experience consistent 
attacks that cause significant bodily harm. The establishment of a 'wellfounded fear of persecution' depends on the creation of a plausible scenario that projects this experience into the future. The production of a linear and coherent identity narrative that highlights visibility, public recognition and 'out-ness' is thereby tied into a normative futurity imagined as a temporality of continuity (Luibhéid 2002; Sin 2015)

Bisexual people's claims to asylum have also been particularly vulnerable to refusal on the grounds of a normative expectation of 'discretion'. Applications by lesbian, gay, bisexual or transgendered people have frequently been turned down because of the reasoning that they could live without the risk of persecution if they remained discreet and did not 'flaunt' their identities, in brief, if they stayed closeted. Bisexuals are assumed to be able to pass easily, if they only decide to 'hide' behind an official heterosexual relationship.

In the meantime, the 'discretion requirement' for LGBTQI asylum applicants has been successfully challenged in many countries. However, bisexual claimants' cases are still routinely dismissed, because they are believed to be able to keep up a pretence and 'pass' as heterosexual without hassle (Spijkerboer 2013). Bisexual claimants face multiple predicaments in relation to the visibility requirements of their sexual disposition. Berg and Millbank $(2009,213)$ argue:

Claims for group membership on the basis of bisexuality are particularly challenging for advocates who must take care to fully explore the transition or fluidity in the claimant's sexual orientation and identity and yet at the same time contextualize such variability in terms of the claimant's experience of well-founded fear of persecution.

'Living openly' has emerged as a core requirement for getting recognised as a refugee on the grounds of sexual orientation. In 2010, Chief Justice Lord Rodger argued in the UK Supreme Court decision HJ (Iran) and HT (Cameroon) $v$ Secretary of State for the Home Department (UK Supreme Court 2010) that only those applicants who 'live openly' as 'practising homosexuals' could be seen as belonging to a particular social group as defined by the UN refugee convention. Everybody else is thought to have made a 'voluntary choice of discretion' (Lewis 2014, 961). Those who do not share information on their intimate and sexual lives in public circles are suspected of having chosen 'voluntary concealment', which can be cited as a reason for rejecting their claim. Bisexuals who are in othergender relationships and who are married to one such partner can easily 
be cast as failing the criterion of 'living openly' as understood within the logic of the Supreme Court.

\section{Sexual orientation and gender identity: a mixed blessing}

Bisexual activist circles have started to campaign against the apparent discrimination shown towards bisexual people in the asylum process. For example, in the UK, bisexual organisations such as The Bisexual Index and the conference BiCon have protested against the deportation of Orashia Edwards, a bisexual Caribbean asylum claimant, to his home country, Jamaica, in 2015 and 2016 (The Bisexual Index 2014; Walters 2015; Duffy 2016; Monro 2015). The campaign was finally successful and secured Orashia Edwards's right to stay in the UK. Yet the UK asylum legal system has remained a hostile place for bisexual claimants (Beresford 2016). The UK Bisexuality Report has addressed discrimination against bisexual asylum seekers and called for the elaboration of distinct guidelines for dealing with bisexual cases (Barker et al. 2012, 22; see also Giametta 2014 on LGBTI asylum claims in the UK). Bisexuals have been called the 'invisible asylum seekers' within European asylum jurisdictions (Peyghambarzadeh 2016). It is of great and urgent importance for activist groups who aim to support the quests and struggles of LGBTQI asylum seekers to address the specific challenges faced by claimants who do not limit their partner choice to one gender (that is similar to their own). Such claimants are not only likely to run into specific problems with regard to their asylum cases, they may also find a lack of adequate support within existing networks of solidarity.

Yet how can the injustices towards non-monosexual people in the asylum system be remedied? One approach would consist in building a sustained campaign for the recognition of bisexuality as a 'third' kind of sexual orientation (next to, and as valid as, heterosexuality and homosexuality), laying claim to a 'bisexual right' to asylum. Many of the voices that support the quest of bisexual or non-monosexual asylum seekers are framed in such a way.

Yet there are problems with and limitations to such an approach. For example, does it do anything to challenge the obsessive search and digging for the 'truth' of asylum seekers' gendered and sexual subjectivities? Critical legal scholars who work within a queer framework have raised such doubts (Seitz 2017; Murray 2014; Akin 2017). Even Sean Rehaag, whose pioneering work has been highly effective in raising 
awareness of the marginalisation and discrimination faced by bisexual asylum claimants, doubts whether such a strategy would work. Rehaag (2008) notes that many legal scholars and activists have moved away from strategies that rest on citing membership in a social group due to immutable characteristics towards what he calls an identity-based 'fundamental human dignity approach'. Justice La Forest's second definition of 'membership in a particular social group' in Canada (AG) $v$ Ward focused on 'reasons so fundamental to their human dignity that they should not be forced to forsake the association' (Supreme Court of Canada 1993, see Rehaag 2010, 284). This reasoning, too, was incorporated in a modified way in the UNHCR 'Guidance note on refugee claims relating to sexual orientation and gender identity' (UNHCR 2008). As case law examples in the USA, Australia and New Zealand demonstrate, the jurisdictions of several countries have started to embrace this alternative logic.

The 'fundamental human dignity approach' sidesteps the 'immutability requirement' and does not rely on the notion of sexual orientation. According to Rehaag (2008), relying on the immutability criterion would tie sexual minority refugee protection too closely to trends within scientific sexual orientation research. After all, sexual orientation research has so far been inconclusive and the claims of sociobiological determinists have been contested by social constructivist positions that highlight the malleability of sexual desires and identities (Stein 1999; Rogers 1999; Klesse 2014). We have already seen that, in particular, bisexuals face difficulties in advancing their claims via sexual orientation narratives. It does not give much hope that Rehaag's (2010) research indicates that bisexuals are treated unfavourably within the 'human dignity paradigm', too. This seems to underscore the validity of an earlier argument by Rehaag (2008), according to which the essentialism of sexual orientation thinking in asylum law runs so deep that applicants are best advised to explore alternatives to 'membership in a particular social group' in their applications (such as persecution on the grounds of political opinion and religion, gender or voluntary association).

The salience of identity reasoning within asylum law imposes serious limitations for bisexual claimants in particular. Sexual and gender identity are a mixed blessing, even if they opened up routes for lesbian, gay, bisexual and transgender people to claim asylum. The problem is not only the prevalence of homophobic, biphobic and transphobic attitudes in adjudicators but also the contradictions at the core of the sexual and gender identity models which govern the rationality of case decisions based on sexual orientation (Spijkerboer 2013). Within heteronormative cultures, sexual identity discourses (inclusive of sexual orientation 
models) are set up in a way that puts sexual minorities in a position where they are always expected to settle for less, and to face the paradox of being expected to be discreet and open about their sexuality at the same time. Their identities are excessively scrutinised, which creates exclusive effects at the margins of categories. As an 'intermediate category', bisexuality assumes a particularly precarious position in sexual orientation discourses. It is disposed to disappear, squashed by the poles of the homo/hetero binary or absorbed into the foggy space between them. Any attempt to prove authentic bisexuality is not only normative but also likely to be futile, because of the notorious doubt attached to representations of bisexuality. ${ }^{2}$

Poststructuralist critical legal scholarship has effectively shown that the very concept of 'rights' is dependent on the concomitant construction of an ideal-typical bearer of rights (Stychin 1995; Beger 2002). Inclusive radical sexual politics need to aim at transforming, modifying or transcending identity and rights models, wherever this may be possible (Lalor 2015). This urgent task is complicated by the implication of sexuality and sexual (human) rights discourses in racialised discourse, postcolonial politics and homonationalist agendas (Puar 2007; Haritaworn, Kunstman \& Posocco 2014a).

\section{Conclusion: biopolitics, necropolitics and the asylum system}

Asylum claims are part of transnational and national debates on migration and human rights. While the discourse of human rights is, on the surface, committed to a truly universal humanism, it has always remained incorporated in hegemonic world politics that have used race thinking as a wedge to split the universalism it claims to endorse by creating racialised groups of infrahumanity (Gilroy 2000, 2006). This has enabled the creation of extra-juridical spaces - or states of exception in the words of Agamben (1998) - that are at the same time confused with juridicity itself. Biopolitics (in the Foucauldian sense of a governmental concern with the population) and necropolitics (in the Mbembean sense of a disenfranchisement due to colonial and postcolonial racism) have guided the continuous infringement and disintegration of post-World War II asylum legislation in many countries. Depending on the individual and geopolitical context, the refusal of asylum to individuals or groups of claimants amounts to a decision about life and death. It implies a judgement regarding the disposability of the people concerned. Quests 
for asylum by LGBTQI people were ignored for decades until they were successively incorporated into laws and guidelines regarding asylum applications. As a result of these developments, asylum claims on the basis of gender identity and sexuality had to be articulated in an overcondensed field shaped by multiple and conflicting agendas, including human rights advocacy, LGBTQI social movement activism, nationalist anti-immigration and anti-black government politics, and the cultural ideologies of empire (Haritaworn, Kunstman \& Posocco 2014b). At the same time, the governance of gender- and sexuality-related asylum claims has evolved to follow a genealogy of Western gender and sexuality knowledges steeped in heteronormativity, binary thinking and monosexism that continues to produce (fictionalised) representations of coherent populations based on essentialist qualities (such as men, women, heterosexuals, gay men and lesbians). Bisexuality emerges as an unstable signifier for a phenomenon that is assumed to be temporary, elusive or unreal, which renders it particularly difficult for 'bisexual' claimants to prove that they belong to a 'particular social group' that is supposed to be essential and immutable. This results in a heightened precarity of claimants who refer or allude to bisexuality in their asylum applications.

\section{Acknowledgements}

A longer and slightly different version of this text first appeared in Hannah Richter (ed.), 2018, Biopolitical Governance: Race, gender and economy. Lanham: Rowman and Littlefield, 163-89. I am grateful to the publishers for agreeing to its republication in this volume. I would also like to thank Chiara Addis for inspiring me to write this article in the first place and to Benoit Dillet and Hannah Richter for feedback on previous drafts.

\section{Notes}

1. The current version of the guidelines (Home Office 2016) states that accounts of sexual activity should not be considered (p. 29) and that audiovisual evidence should not be accepted by caseworkers (p. 30), whereas parts of written evidence that are of a sexually explicit nature should be redacted prior to submission (p. 31).

2. The concept 'gender identity' has been seen as an inadequate tool for achieving inclusive strategies of rights allocation by some transgender activists, too. Gender identity foregrounds fixity and categorical non-equivalence. References to 'gender expression', however, could capture blurred or shifting (trans) identifications, too (Currah, Juang \& Minter 2006). These arguments show that identity-based rights allocation is riddled with problems and inevitably spirals into exclusivity. 


\section{References}

Agamben, Giorgio. 1998. Homo Sacer: Sovereign power and bare life. Stanford, CA: Stanford University Press.

Agamben, Giorgio. 2005. State of Exception. Chicago, IL: University of Chicago Press.

Aizura, Aren Z. 2014. 'Trans feminine value, racialized others and the limits of necropolitics'. In Queer Necropolitics, edited by Jin Haritaworn, Adi Kunstamn and Silvia Posocco, 129-47. Abingdon: Routledge.

Akin, Deniz. 2017. 'Queer asylum seekers: Translating sexuality in Norway', Journal of Ethnic and Migration Studies 43:458-74. https://doi.org/10.1080/1369183x.2016.1243050.

Alexander, Jonathan and Serena Anderlini-D'Onofrio (eds). 2014. Bisexuality and Queer Theory: Intersections, connections and challenges. London: Routledge.

Alter, Charlotte. 2017. 'LGBT asylum seekers face extra anxiety under President Trump's travel ban', Time, 8 February. Available at: http://time.com/4661514/lgbt-asylum-seekers-face-extraanxiety-under-president-trumps-travel-ban/ (accessed 25 October 2017).

Angelides, Steven. 2000. A History of Bisexuality. Chicago, IL: University of Chicago Press.

Barker, Meg, Christina Richards, Rebecca Jones, Helen Bowes-Catton and Tracey Plowman with Jen Yockney and Marcus Morgan. 2012. The Bisexuality Report: Bisexual inclusion in LGBT equality and diversity. Milton Keynes: Open University Centre for Citizenship, Identities and Governance and Faculty of Health and Social Care. Available at: http://www.bisexualindex. org.uk/uploads/Main/TheBisexualityReport.pdf (accessed 23 April 2014). https://doi.org/ 10.1080/15299716.2012.702618.

Beger, Nico J. 2002. 'Putting gender and sexuality on the agenda: Queer theory and legal politics'. In An Introduction to Law and Social Theory, edited by Reza Banakar and Max Travers, 173-88. Oxford, and Portland, OR: Hart Publishing.

Bennett, Claire and Felicity Thomas. 2013. 'Seeking asylum in the UK: Lesbian perspectives', Forced Migration Review 42:25-8.

Beresford, Meka. 2016. 'The Home Office quizzed a bisexual asylum seeker on LGBT terminology during his interview process', PinkNews, 12 November. Available at: http://www.pinknews. co.uk/2016/11/12/the-home-office-quizzed-a-bisexual-asylum-seeker-on-lgbt-terminologyduring-his-interview-process/ (accessed 25 October 2017).

Berg, Laurie and Jenni Millbank. 2009. 'Constructing the personal narratives of lesbian, gay and bisexual asylum claimants', Journal of Refugee Studies 22:195-223. https://doi.org/10.1093/ jrs/fep010.

Butler, Judith. 2004. Precarious Life: The powers of mourning and violence. London: Verso.

Butler, Judith. 2009. Frames of War: When is life grievable? London: Verso.

Campbell, Timothy and Adam Sitze (eds). 2013. Biopolitics: A reader. Durham, NC: Duke University Press.

Clough, Patricia Ticineto and Craig Willse (eds). 2011. Beyond Biopolitics: Essays on the governance of life and death. Durham, NC: Duke University Press.

Corrêa, Sonia Onufer and Vitit Muntarbhorn. 2007. 'Introduction to the Yogyakarta Principles'. In The Yogyakarta Principles: Principles on the application of international human rights law in relation to sexual orientation and gender identity, 6-7. Available at: https://www.refworld.org/ pdfid/48244e602.pdf (accessed 23 August 2020).

Council of the European Union. 2004. 'Council Directive 2004/83/EC of 29 April 2004'. Available at: https://eur-lex.europa.eu/eli/dir/2004/83/oj (accessed 6 August 2020).

Council of the European Union. 2011. 'Directive 2011/95/EU of the European Parliament and of the Council of 13 December 2011 .... Available at: https://eur-lex.europa.eu/eli/dir/2011/ 95/oj (accessed 6 August 2020).

Currah, Paisley, Richard M. Juang and Shannon P. Minter (eds). 2006. Transgender Rights. Minneapolis: University of Minnesota Press.

Dauvergne, Catherine and Jenni Millbank. 2003. 'Burdened by proof: How the Australian Refugee Review Tribunal has failed lesbian and gay asylum seekers', Federal Law Review 31:299-342. https://doi.org/10.22145/flr.31.2.2.

Duffy, Owen. 2016. 'Bisexual asylum seeker wins Home Office fight to remain in UK'. The Guardian, 23 January. Available at: https://www.theguardian.com/world/2016/jan/23/bisexualasylum-seeker-orashia-edwards-wins-home-office-uk-jamaica (accessed 15 February 2017).

Esposito, Roberto. 2008. Bíos: Biopolitics and philosophy. Minneapolis: University of Minnesota Press. 
Esposito, Roberto. 2011. Immunitas: The protection and negation of life. Cambridge: Polity.

Farrier, David. 2011. Postcolonial Asylum: Seeking sanctuary before the law. Liverpool: Liverpool University Press.

Foucault, Michel. 1990. The History of Sexuality. Volume 1: An Introduction, translated by Robert Hurley. Harmondsworth: Penguin Books.

Foucault, Michel 1997. Society Must Be Defended: Lectures at the Collège de France 1975-1976. New York: Picador.

Gessen, Masha. 2017. 'How Trump uses "Religious Liberty" to attack L.G.B.T. rights', The New Yorker, 11 October. Available at: https://www.newyorker.com/news/news-desk/howtrump-uses-religious-liberty-to-attack-lgbt-rights (accessed 22 October 2017).

Giametta, Calogero. 2014. 'The sexual politics of asylum: Lived experiences of sexual minority asylum seekers and refugees in the UK.' PhD thesis, London Metropolitan University.

Gilroy, Paul. 2000. Between Camps: Nations, cultures and the allure of race. London: Penguin.

Gilroy, Paul. 2006. After Empire: Melancholia or convivial culture. London: Routledge.

Gross, Jaclyn. 2018. 'Neither here nor there: The bisexual struggle for American asylum', Hastings Law Journal 69(3):985-1008.

Hardt, Michael and Antonio Negri. 2001. Empire. Cambridge, MA: Harvard University Press.

Hardt, Michael and Antonio Negri. 2005. Multitude: War and democracy in the age of empire. London: Hamish Hamilton.

Haritaworn, Jin, Adi Kunstman and Silvia Posocco (eds). 2014a. Queer Necropolitics. Abingdon: Routledge.

Haritaworn, Jin, Adi Kunstman and Silvia Posocco. 2014b. 'Introduction'. In Queer Necropolitics, edited by Jin Haritaworn, Adi Kunstman and Silvia Posocco, 1-27. Abingdon: Routledge.

Haritaworn, Jin, with Tamsila Tauqir and Esra Erdem. 2008. 'Gay imperialism: The role of gender and sexuality discourse in the "war on terror"'. In Out of Place: Interrogating silences in queerness/raciality, edited by Adi Kuntsman and Esperanza Miyake, 71-95. York: Raw Nerve Books.

Hemmings, Clare. 2007. 'What's in a name? Bisexuality, transnational sexuality studies and Western colonial legacies', International Journal of Human Rights 11:13-32. https://doi.org/ $10.1080 / 13642980601176258$.

Home Office. 2016. 'Asylum Policy instruction: Sexual orientation in asylum claims' (version 6.0, 3 August). Available at: https://www.gov.uk/government/uploads/system/uploads/attachment_ data/file/543882/Sexual-orientation-in-asylum-claims-v6.pdf (accessed 22 October 2017).

Klesse, Christian. 2014. 'Polyamory: Intimate practice, identity or sexual orientation?', Sexualities 17:81-99. https://doi.org/10.1177/1363460713511096.

Klesse, Christian. 2018. 'Dancing on the waves or being washed away? Representations of bisexualities in Liquid Modernity', Sexualities 21, 20th anniversary special issue:1360-7. https://doi.org/10.1177/1363460718781540.

Kollman, Kelly and Matthew Waites. 2009. 'The global politics of lesbian, gay, bisexual and transgender human rights: An introduction', Contemporary Politics 15:1-17. https://doi.org/ $10.1080 / 13569770802674188$.

Lalor, Kay. 2015. 'Making different differences: Representation and rights in sexuality activism', Feminist Legal Studies 23:7-25. https://doi.org/10.1007/s10691-015-9277-5.

LaViolette, Nicole. 1997. 'The immutable refugees: Sexual orientation in Canada (A.G.) v. Ward', University of Toronto Faculty of Law Review 55:1-41.

Lemke, Thomas. 2011. Biopolitics: An advanced introduction, translated by Eric Frederick Trump. New York: New York University Press.

Lewis, Rachel A. 2013. 'Deportable subjects: Lesbians and political asylum', Feminist Formations 25:174-94. https://doi.org/10.1353/ff.2013.0027.

Lewis, Rachel A. 2014. “"Gay? Prove it”: The politics of queer anti-deportation activism', Sexualities 17:958-75. https://doi.org/10.1177/1363460714552253.

Lewis, Rachel A. and Nancy A. Naples. 2014. 'Introduction: Queer migration, asylum, and displacement', Sexualities 17:911-18. https://doi.org/10.1177/1363460714552251.

Llewellyn, Cheryl. 2017. 'Homonationalism and sexual orientation-based asylum cases in the United States', Sexualities 20:682-98. https://doi.org/10.1177/1363460716645803.

Luibhéid, Eithne. 2002. Entry Denied: Controlling sexuality at the border. Minneapolis: University of Minnesota Press. 
Marcus, Nancy C. 2018. 'The global problem of bisexual erasure in litigation and jurisprudence', Journal of Bisexuality 18(1):67-85. https://doi.org/10.1080/15299716.2017.1384423.

Mbembe, Achille. 2003. 'Necropolitics', translated by Libby Meintjes, Public Culture 15:11-40.

Millbank, Jenni. 2009. “"The ring of truth”: A case study of credibility assessment in particular social group refugee determinations', International Journal of Refugee Law 21:1-33. https:// doi.org/10.1093/ijrl/een040.

Monro, Surya. 2015. Bisexuality. Identities, Politics, and Theories. Basingstoke: Palgrave Macmillan.

Monro, Surya, Sally Hines and Antony Osborne. 2017. 'Is bisexuality invisible? A review of sexualities scholarship 1970-2015', The Sociological Review 65:663-81. https://doi.org/10.1177/ 0038026117695488.

Morgan, Wayne. 2000. 'Queering international human rights law'. In Sexuality in the Legal Arena, edited by Carl Stychin and Didi Herman, 208-25. London: Athlone Press.

Moskowitz, Peter. 2016. 'Advocates fear disaster for LGBTQ immigrants under Trump', Vice, 22 December. Available at: https://www.vice.com/en_uk/article/jpmn3k/advocates-feardisaster-for-lgbtq-immigrants-under-trump (accessed 22 October 2017).

Murphy, Timothy F. 1997. Gay Science: The ethics of sexual orientation research. New York: Columbia University Press.

Murray, David A. B. 2014. 'The (not so) straight story: Queering migration narratives of sexual orientation and gendered identity refugee claimants', Sexualities 17:451-71. https://doi.org/ $10.1177 / 1363460714524767$.

Nishiyama, Hidefumi. 2018. "Measurement of life": The disciplinary power of racism'. In Biopolitical Governance: Race, gender and economy, edited by Hannah Richter, 59-76. London: Rowman \& Littlefield International.

O’Flaherty, Michael and John Fisher. 2008. 'Sexual orientation, gender identity and international human rights law: Contextualising the Yogyakarta Principles', Human Rights Law Review 8:207-48. https://doi.org/10.1093/hrlr/ngn009.

Oppenheim, Maya. 2017. 'Donald Trump to become first president to speak at anti-LGBT hate group's annual summit', The Independent, 12 October. Available at: http://www. independent.co.uk/news/world/americas/donald-trump-anti-lgbt-address-hategroup-summit-meeting-first-president-us-homphobia-a7997401.html (accessed 23 October 2017).

Petchesky, Rosalind P. 2000. 'Sexual rights: Inventing a concept, mapping an international practice'. In Framing the Sexual Subject. the politics of gender, sexuality, and power, edited by Richard Parker, Regina Maria Barbosa and Peter Aggleton, 81-103. Berkeley: University of California Press.

Peyghambarzadeh, Zeynab. 2016. 'Invisible asylum seekers', Pike \& Hurricane: A Foreign Affairs Magazine, 3 June. Available at: http://magazine.ufmalmo.se/2016/06/03/invisible-asylumseekers/ (accessed 19 April 2017).

Pieper, Marianne, Thomas Aztert, Serhat Karakayali and Vassilis Tsianos (eds). 2011. Biopolitik - in der Debatte. Wiesbaden: VS Verlag für Sozialwissenschaften.

Puar, Jasbir. 2007. Terrorist Assemblages: Homonationalism in queer times. Durham, NC: Duke University Press.

Raboin, Thibaut. 2017. 'Exhortations of happiness: Liberalism and nationalism in the discourses on LGBTI asylum rights in the UK', Sexualities 20:663-81. https://doi.org/10.1177/ 1363460716645802.

Rehaag, Sean 2008. 'Patrolling the borders of sexual orientation: Bisexual refugee claims in Canada', McGill Law Journal 53:59-102.

Rehaag, Sean. 2010. 'Bisexuals need not apply: A comparative appraisal of refugee law and policy in Canada, the United States, and Australia'. In Protection of Sexual Minorities since Stonewall: Progress and stalemate in developed and developing countries, edited by Phil C. W. Chan, 281-302. Abingdon: Routledge. (First published as International Journal of Human Rights 13(2/3), 2009.)

Repo, Jemima. 2018. 'The life function: The biopolitics of sexuality and race revisited'. In Biopolitical Governance: Race, gender and economy, edited by Hannah Richter, 41-57. London: Rowman \& Littlefield International.

Rogers, Lesley. 1999. Sexing the Brain. London: Phoenix. 
Rose, Nikolas. 2006. The Politics of Life Itself: Biomedicine, power, and subjectivity in the twenty-first century. Princeton, NJ: Princeton University Press.

Seitz, David K. 2017. 'Limbo life in Canada's waiting room: Asylum-seeker as queer subject', Environment and Planning D: Society and Space 35:438-56. https://doi.org/10.1177/ 0263775816667074.

Sellenart, Michel. 2004. 'Course context'. In Michel Foucault, Security, Territory, Population. Lectures at the Collège de France 1977-1978, 369-402. Basingstoke: Palgrave Macmillan.

Shakhsari, Sima. 2014a. 'Killing me softly with your rights: Queer death and the politics of rightful killing'. In Queer Necropolitics, edited by Jin Haritaworn, Adi Kunstamn and Silvia Posocco, 93-110. Abingdon: Routledge.

Shakhsari, Sima. 2014b. 'The queer time of death: Temporality, geopolitics, and refugee rights', Sexualities 17:998-1015. https://doi.org/10.1177/1363460714552261.

Shuman, Amy and Carol Bohmer. 2014. 'Gender and cultural silences in the political asylum process', Sexualities 17:939-57. https://doi.org/10.1177/1363460714552262.

Shuman, Amy and Wendy S. Hesford. 2014. 'Getting out: Political asylum, sexual minorities, and privileged visibility', Sexualities 17:1016-34. https://doi.org/10.1177/1363460714557600.

Sin, Ray. 2015. 'Does sexual fluidity challenge sexual binaries? The case of bisexual immigrants from 1967-2012', Sexualities 18:413-37. https://doi.org/10.1177/1363460714550901.

Singer, Debora. 2015. 'How do you prove you are gay? A culture of disbelief is traumatising asylum seekers', The Guardian, 24 November. Available at: https://www.theguardian.com/ commentisfree/2015/nov/24/gay-asylum-seekers-sexuality-home-office (accessed 15 February 2017).

Snorton, C. Riley and Jin Haritaworn. 2013. 'Transsexual necropolitics'. In The Transgender Studies Reader 2, edited by Susan Stryker and Aren Z. Aizura, 66-76. New York: Routledge.

Spijkerboer, Thomas. 2013. 'Sexual identity, normativity and asylum'. In Fleeing Homophobia: Sexual orientation, gender identity and asylum, edited by Thomas Spijkerboer, 217-38. Abingdon: Routledge.

Stein, Edward. 1999. The Mismeasure of Desire: The science, theory, and ethics of sexual orientation. New York: Oxford University Press.

Stern, Mark Joseph. 2016. 'Court holds bisexual asylum-seeker isn't actually bisexual, drawing withering dissent', Slate, 18 August. Available at: http://www.slate.com/blogs/outward/ 2016/08/18/seventh_circuit_rejects_bisexual_asylum_seeker_deportation_relief.html (accessed 19 April 2017).

Stoler, Ann L. 1995. Race and the Education of Desire. Foucault's History of Sexuality and the colonial order of things. Durham, NC: Duke University Press.

Stychin, Carl. 1995. Law's Desire: Sexuality and the limits of justice. London: Routledge.

Supreme Court of Canada. 1993. Canada (Attorney General) v Ward. 2 SCR 689. Available at: https://scc-csc.lexum.com/scc-csc/scc-csc/en/item/1023/index.do (accessed 30 September 2020).

Taylor, Diane. 2017. 'Torture victims were wrongly imprisoned in UK, high court rules', The Guardian, 10 October. Available at: https://www.theguardian.com/uk-news/2017/oct/10/ torture-victims-were-wrongly-imprisoned-in-uk-high-court-rules (accessed 25 October 2017).

The Bisexual Index. 2014. 'UK bisexual community outraged by deportation'. Available at: http:// www.bisexualindex.org.uk/index.php/OrashiaEdwards (accessed 15 February 2017).

UKLGIG (UK Lesbian \& Gay Immigration Group). 2010. Failing the Grade: Home Office initial decisions on lesbian and gay claims for asylum. Available at: http://uklgig.org.uk/wp-content/ uploads/2014/04/Failing-the-Grade.pdf (accessed 19 April 2017).

UKLGIG (UK Lesbian \& Gay Immigration Group). 2013. Missing the Mark: Decision making on lesbian, gay (bisexual, trans and intersex) asylum claims. Available at: http://www.uklgig.org.uk/ wp-content/uploads/2014/02/Missing-the-Mark.pdf (accessed 19 April 2017).

UK Supreme Court. 2010. HJ (Iran) and HT (Cameroon) $v$ Secretary of State for the Home Department. UKSC 31.

UNHCR. 1951. Convention and Protocol relating to the Status of Refugees. Available at: https://www. unhcr.org/uk/3b66c2aa10 (accessed 30 September 2020).

UNHCR. 2002a. Guidelines on International Protection: Gender-Related Persecution within the context of Article 1A(2) of the 1951 Convention and/or its 1967 Protocol relating to the Status of Refugees. Available at: https://www.unhcr.org/uk/publications/legal/3d58ddef4/guidelinesinternational-protection-1-gender-related-persecution-context.html (accessed 29 September 2020). 
UNHCR. 2002b. Guidelines on International Protection: 'Membership of a particular social group' within the context of Article 1A(2) of the 1951 Convention and/or its 1967 Protocol relating to the Status of Refugees. Available at: https://www.refworld.org/docid/3d36f23f4.html (accessed 25 September 2020).

UNHCR. 2008. Guidance Note on Refugee Claims Relating to Sexual Orientation and Gender Identity. Available at: http://www.refworld.org/docid/48abd5660.html (accessed 19 April 2017).

US Citizenship and Immigration Services. 2011. 'Guidance for adjudicating lesbian, gay, bisexual, transgender, and intersex (LGBTI) refugee and asylum claims'. Available at: https://www. uscis.gov/sites/default/files/USCIS/Humanitarian/Refugees\%20\%26\%20Asylum/Asylum/ Asylum\%20Native\%20Documents\%20and\%20Static\%20Files/RAIO-Training-March-2012. pdf (accessed 19 April 2017).

Vogler, Stefan. 2016. 'Legally queer: The construction of sexuality in LGBQ asylum claims', Law \& Society Review 50:856-89. https://doi.org/10.1111/lasr.12239.

Waites, Matthew. 2009. "Critique of "sexual orientation" and "gender identity" in human rights discourse: Global queer politics beyond the Yogyakarta Principles', Contemporary Politics 15:137-56. https://doi.org/10.1080/13569770802709604.

Walters, Caroline. 2015. 'Bisexual asylum seekers' (collective letter). biUK. Available at: https:// bisexualresearch.wordpress.com/2015/05/20/bisexual-asylum-seekers/ (accessed 19 April 2017).

White House, Office of the Press Secretary. 2011. 'Presidential memorandum - international initiatives to advance the human rights of lesbian, gay, bisexual, and transgender persons'. 6 December. Available at: https://obamawhitehouse.archives.gov/the-press-office/2011/12/ 06/presidential-memorandum-international-initiatives-advance-human-rights-1 (accessed 19 April 2017).

Wilson, Glenn and Qazi Rahman. 2005. Born Gay: The psychobiology of sex orientation. London: Peter Owen.

Yoshino, Kenji. 2000. 'The epistemic contract of bisexual erasure', Stanford Law Review 52:353461. https://doi.org/10.2307/1229482.

Young, Stacey. 1997. 'Dichotomies and displacement: Bisexuality in queer theory and politics'. In Playing with Fire: Queer politics, queer theories, edited by Shane Phelan, 51-74. London: Routledge. 


\section{(Des)haciendo fronteras: Latin American LGBTIQ* asylum seekers in Spain in the process of credibility assessment}

Aurora Perego

With reference to the required evidence, we note the scant credibility accorded to the asylum seeker's account of persecution on the grounds of sexual orientation or gender identity, and we can maintain that there is a general suspicion of abuse of the right [to international protection] against individuals who apply on such grounds, [a suspicion] that does not apply in asylum claims based on other grounds.

$(\text { CEAR 2016, 134) })^{1}$

You're in Spain, the 'First World', one of the freest countries in terms of human rights. Outside of Spain we have a rather good image of Europe. You think you will arrive in Europe and then everything is done. So, when you are in the [asylum] process you say: 'Wow, they lack sensitivity here!. ... They have patriarchy and sexism here, too. ... What's the difference between here and there? Well, none. Despite 1,500 years of alleged progress and civilisation, the sex-gender matrix (los esquemas de género $y$ machismo), violence and misogyny are still present.

(Extract from an interview with F., 2017)

Cuando vives en la frontera people walk through you, the wind steals your voice, you're a burra, buey, scapegoat, forerunner of a new race, 
half and half - both woman and man, neither a new gender;

To survive the Borderlands

you must live sin fronteras

be a crossroads.

(Gloria Anzaldúa, Borderlands/La Frontera: The new mestiza, 1987, 194-5)

\section{Introduction}

In recent years, the adjudication of international protection has received prominent attention in the so-called global North. Against this backdrop, in the last decade scholars and advocates have started to address the delicate situation of LGBTIQ*2 asylum seekers, that is, individuals who seek protection on the grounds of their gender identity or sexual orientation. Data gathered by international organisations shows that all over the world LGBTIQ* individuals are subjected to severe forms of violence and are forced to leave their countries in high numbers (UNHCR 2015). Despite a lack of official statistics, ILGA-Europe (2016) indicates that asylum applications on the grounds of gender identity or sexual orientation have increased alarmingly since the 1990s. Furthermore, these claims seem to encounter specific problems in comparison to those made on other grounds, most notably the 'growing trend of rejections based on non-credibility of the sexual orientation or gender identity itself, in many cases based on stereotypes' (ILGA-Europe 2014, 4).

As emphasised by both practitioners and academics (ILGA-Europe 2016; Spijkerboer 2013), these dramatic rejections are mainly related to what is known as the 'credibility assessment', defined as the process through which applicants are required to gather and show evidence that their fear of persecution is well founded (UNHCR 2013). ${ }^{3}$ Decisionmakers examine such evidence together with any other relevant materials and then determine whether the applicants' statements can be regarded as 'credible'. Only if they are found credible do asylum seekers qualify for international or subsidiary protection. In other words, the credibility assessment plays a fundamental role in the possibility of being recognised as a refugee. Therefore, the often implicit meanings given to 
'credibility', the criteria for assessing it and the methods of evaluating it are crucial components of the whole asylum system.

Building on these considerations, the aim of this chapter is to explore the experiences of Latin Americans ${ }^{4}$ seeking asylum in Spain on the grounds of gender identity or sexual orientation, with a specific focus on the credibility assessment performed by Spanish asylum institutions. In particular, the analysis outlined in the following sections presents interconnected aims: on the one hand, it seeks to interrogate the role of the credibility assessment in the (re)production of hegemonic discourses that might justify and foster the rejection of Latin LGBTIQ* populations; on the other hand, it aspires to explore the multiple ways queer Latinxs negotiate their identities in their attempts to deal with the credibility assessment and the whole asylum system. To address these concerns, this research draws on queer migration scholarship, understood as a body of research that 'insists on recovering, theorizing, and valorizing histories and subjects that have been largely rendered invisible, unintelligible, and unspeakable in both queer and migration studies' (Luibhéid 2008, 171). In particular, the analysis presented in the following sections will build on the concept of 'border/frontera' elaborated by queer feminist scholar Gloria Anzaldúa to problematise conventional notions of 'border' and 'border crossing'. In her seminal work Borderlands/La Frontera: The new mestiza (1987), Anzaldúa indeed argues that a border is both a dividing line and an undetermined place that drags marginalised populations into a 'constant state of transition' (p. 3). Drawing on this conceptualisation, borders are hence not merely cartographical representations of lines that demarcate sovereign states but also symbolic boundaries that both sustain and are (re)produced through power hierarchies (Mezzadra \& Nielson 2013). On the other hand, border crossing is understood not simply as the material transit from one (delimited) state to another but also as a trespassing of societal processes that categorise and marginalise individuals (Epps, Valens \& Johnson González 2005). Within this framework, Anzaldúa (1987) claims that the only way for marginalised individuals to survive borders is to embrace their intersectional identities so as to live across and beyond them. Informed by such an intersectional problematisation of the concept of borders, this chapter contributes to an interrogation of the borders that delimit the domain of asylum through the credibility assessment as well as to an exploration of the strategies developed by LGBTIQ* asylum seekers to cope with such borders.

The analysis outlined in the following pages stems from an investigation conducted between February and August 2017 and developed under the framework of community-based participatory research 
(CBPR); that is, it involves a range of practices aimed at questioning the hierarchy and power structures inherent in knowledge production. The research was indeed as far as possible developed in collaboration with the respondents themselves, especially with regard to the analysis and dissemination of results. The research process took place in two phases. The first phase concerned a discourse analysis of 112 rulings delivered by the Spanish national Courts on the asylum claims filed by LGBTIQ* Latin Americans between $1998^{5}$ and 2016 . These rulings do not represent the decision-makers' first adjudication of the asylum claims but address appeals presented by asylum seekers against the negative decisions previously made by asylum institutions. Although these rulings cannot be representative of the totality of asylum applications on the grounds of gender and sexuality presented over the years, they provide us with relevant information on how the 'credibility' of such claims is assessed and interpreted. The second phase of the research used in-depth interviews and participant observation conducted with a group of eight LGBT asylum seekers based in Madrid between February and May 2017. The analysis of the feelings and memories recounted by the research participants was combined with the insights gained through expert interviews held with two professionals (a community liaison practitioner and a lawyer) who have been working with LGBTIQ* asylum seekers for years. This qualitative approach aims to problematise traditional representations of refugees and asylum seekers as both 'helpless victims' (Eastmond 2007, 253) and as 'objects of governmental regulation, depersonalized statistical inquiry, and legal abstraction' (Epps, Valens and Johnson González 2005, 22).

As mentioned above, this investigation focuses on the Spanish asylum context. Previous studies examining the credibility assessment and its consequences for the lives of asylum seekers have tended to concentrate on Northern Europe, Australia and North America. By looking at Spain, this research represents an attempt to contribute to filling the gap that surrounds Southern European asylum procedures. In this sense, before we move to the analysis, it is important to address the peculiarities of the Spanish asylum context in comparison with the rest of the European Union. Eurostat, the Directorate of the European Commission in charge of statistical investigations, reports a drop in asylum applications issued in the 28 EU member states since $2015 .{ }^{6}$ Despite this average decrease, Spain has registered an increase in asylum applications, reaching a peak of 55,749 applications in 2018 (OAR 2019, 24). ${ }^{7}$ Furthermore, Spain is the only EU country in which most of the claims were made by individuals coming from the Americas (37,025 applications in total), in 
particular Venezuelans $(20,053)$ (OAR 2019, 21). ${ }^{8}$ Throughout the following sections, this special relationship between Spain and its former colonies will inform the analysis of both the rulings and the interviews.

The chapter is structured as follows. The first section briefly contextualises the Spanish asylum system, with specific attention to gender- and sexuality-based persecution. The core of the section is devoted to an analysis of the rulings, which shows that the credibility assessment is deployed by Spanish institutions as a means of border control, meaning that it is aimed at creating the image of the 'exceptional queer refugee' (Giametta 2016), from which queer Latinxs are systematically excluded. The second section will explore the asylum experiences recounted during the in-depth interviews. Starting from an enquiry into the material and symbolic borders that characterised their lives as queer Latinxs, the section will develop around the erasure of their stories of persecution at the hands of asylum institutions. It will conclude with an emphasis on the strategies articulated by the respondents to deal with the borders reinforced through the credibility assessment.

\section{Queer (in)credibility: how Spanish jurisprudence adjudicates LGBTIQ" Latin American asylum seekers}

In Spain, the institution of international protection is regulated by Law $12 / 2009$ of 30 October, which, in accordance with the European legislative framework, includes a direct reference to gender identity and sexual orientation as characteristics of a social group that is at risk of persecution (Art. 3). ${ }^{9}$ This Law also regulates the asylum procedure in the following way. The asylum claims are examined by the Oficina de Asilo $y$ Refugio (Office of Asylum and Refuge - OAR), which first evaluates the formal aspects of the application to decide if it is admissible and, if it is, examines the content of the application. The OAR then presents a report to the Comisión Interministerial de Asilo y Refugio (Inter-ministerial Asylum and Refugee Commission - CIAR), which is responsible for proposing the response. The final decision is taken by the Ministry of the Interior and is one of the following options: (1) granting the status of refugee, (2) granting subsidiary protection, and (3) denying the status of refugee and requiring the applicant to leave the country within 15 days of the notification. Art. 29 of the Spanish Asylum Law establishes that appeals against negative decisions can be either submitted to the OAR within one month, or presented before the Juzgados Centrales (Central Court, in the case of inadmissibility) or the Audiencia Nacional (National 
Court, in the case of denial) within two months of the decision. ${ }^{10}$ The latter court has the jurisdiction to re-examine the evidence and to change the decision without returning the case to the Ministry. If the National Court rejects the appeal, Art. 29(2) of Law 12/2009 allows for a further appeal to be filed before the Tribunal Supremo (Supreme Court), which is the highest jurisprudential authority and has the power to nullify the decision taken by the National Court in the event that it considers there were irregularities in the way the Law was applied. In other words, the Supreme Court does not examine the evidence provided by the applicant but interrogates the way the examination was conducted by the Ministry.

Against this backdrop, the courts had already considered the possibility of granting asylum on the grounds of sexual orientation and gender identity before Law 12/2009 was introduced. In 1998, the National Court delivered a ruling (SAN 143/1998) on an appeal against the inadmissibility of the asylum application made by an Ecuadorian citizen identifying as a travestí (cross-dresser). In 2005, the Supreme Court also issued a ruling (STS 4171/2005) on an appeal filed against the denial of refugee status to a Cuban homosexual man. According to legal scholar José Diaz Lafuente $(2014,468)$, national jurisprudence has been particularly influential in giving meaning to two criteria, according to which asylum claims are evaluated: on the one hand, consideration of the applicant's country of residence or origin (the so-called 'objective element'), on the other, evidence of personal (fear of) persecution due to the applicant's gender identity and/or sexual orientation (known as the 'subjective element').

To examine how Spanish jurisprudence defines and interprets the 'credibility' of LGBTIQ* Latin Americans' asylum claims, the analysis presented in the following pages tracks the rulings ${ }^{11}$ issued by the two national Courts between 1998 and 2016. Out of 112 rulings in total, 93 were issued by the National Court and 19 by the Supreme Court. As mentioned above, the National Court has engaged with asylum claims on grounds of gender and/or sexuality since 1998, while the Supreme Court issued its first ruling in 2005. The Courts present a similar shift in the applicants' national profiles: for a few years after the first appeal, most claimants came from Central and South America, while since 2009 (National Court) and 2011 (Supreme Court) the number of African and Asian applicants has been on the rise. Concerning Latin Americans, the number of appeals varies from year to year, without showing a specific trend (Figure 7.1).

Regarding the claimants' profiles, while until 2006 the majority came from Cuba and Ecuador, the number of Costa Ricans, Colombians, Nicaraguans, Venezuelans and Panamanians has increased since 2006. 


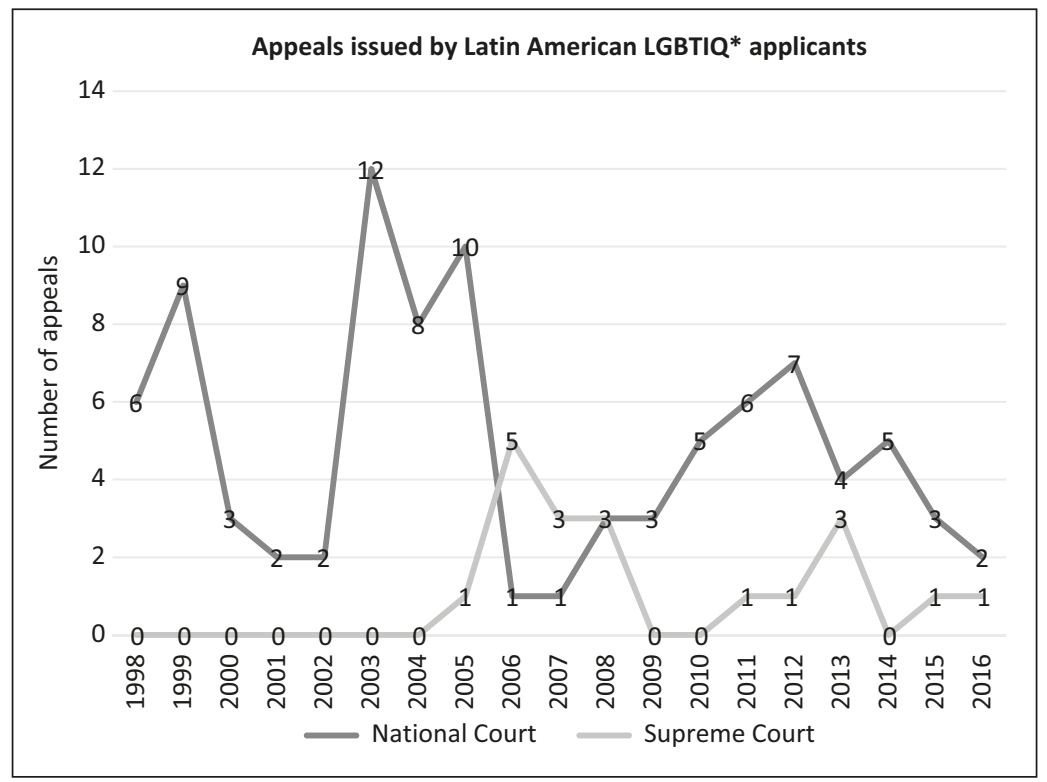

Figure 7.1 Appeals issued by Latin American LGBTIQ* applicants before the Spanish National and Supreme Courts between 1998 and 2016. The figure is based on my own elaboration of the rulings available on the official website: http://www.poderjudicial.es/search/. These rulings were downloaded in February 2017 and analysed between March and May 2017.

Few Mexicans and Salvadorians, just one Brazilian, one Argentinian, one Paraguayan and two Peruvians (a couple) appealed to the National Court. No reference to other Latin American countries was found in the rulings. Concerning the grounds for asylum, only 31 out of 112 appeals were on grounds of gender identity (all of them made by self-identified transgender women). Of the claims on the grounds of sexual orientation, most of the appeals were presented by cisgender gay men, five by lesbian women and one by a bisexual man. None of the applicants identified as intersexual or as a transgender man.

The last important information concerns the number of rejections and admissions: out of 93, the National Court considered five appeals legitimate (5.4 per cent of the total), while four out of 19 appeals were accepted by the Supreme Court (21 per cent). Of the latter, only one claimant appealed against the denial of asylum, while in the remaining three cases the Court revoked previous decisions on the inadmissibility of the applications, meaning that the asylum applications had to be 
re-examined through a process that could still lead to a final denial of refugee status. As expected, the negative adjudications concerned how 'credibility' was assessed by looking at the two aforementioned elements of the asylum claims: the situation in the country of origin (objective component), on the one hand, and the personal and targeted persecution, or fear thereof, suffered by the applicant on the grounds of gender identity or sexual orientation (subjective component), on the other.

\section{The 'objective element': the situation in the country of origin}

With regard to the objective element of the asylum claim, the general jurisprudential assumption concerns the presumed 'safety' of the countries from which the applicants fled. The judges do not explicitly address the meaning of the concept of 'safety' but indirectly refer to the features that a country is expected to show to be considered 'unsafe' for LGBTIQ* individuals: criminalising legislation enforced by state agents. In the Courts' understanding, the lack of a criminalising legislation means that members of the LGBTIQ* local community are protected by the state. However, this criterion seems to be ambiguously applied. On the one hand, LGBTIQ* Latin Americans leaving countries in which discriminatory laws allegedly function de jure but not de facto are denied refugee status precisely because such legislation is not enforced. On the other hand, applicants reporting harms that are tolerated by state institutions but not legally fostered are rejected. The following extracts exemplify this contradictory situation:

Here we are questioning not the [applicant's] homosexuality but whether this constitutes grounds for asylum. To our knowledge, Ecuador does not have legislation that specifically criminalises such situations or, at least, the claimant does not report anything more than police harassment. We do not know why specific manifestations of homosexuality prompt such alleged harassment or whether - which we do not believe - it is just due to failure to conform [to heterosexual norms]; given this lack of precision we cannot affirm that the adjudicators were wrong to consider the application vague and weak; we would almost say that there are no grounds at all for seeking [asylum].

(Spanish National Court, SAN 4388/1998, 2, para. $6^{12}$ ) 
While the applicant insists that Cuban legislation punishes homosexual conduct, a report in the case file shows that there is greater tolerance towards such practices nowadays. As a result, we cannot consider that the mere fact of having such a tendency generates the type of persecution which would require refugee protection.

(Spanish Supreme Court, STS 6142/2008, 2, para. 4)

These extracts outline how allegations of gender- and sexuality-based persecution are not conceived as valid per se but as always related to a presumed 'unsafe' legislative context. However, paradoxically, the Courts maintain that personal persecution on the grounds of sexual identity and gender orientation cannot occur where and when LGBTIQ* identities, desires or practices are not criminalised, while simultaneously asserting that punitive legislations do not necessarily represent persecution. 'Safety' and 'harm' thus seem to acquire contradictory meanings deployed precisely to support and justify rejections of asylum claims related to homo- and transphobia.

Furthermore, both courts often refer to some sort of formal recognition of the local LGBTIQ* community as a sign of an inclusionary society and, hence, of a lack of persecution. For instance, in the case of a homosexual man from Paraguay, the National Court maintains that 'a parliamentary committee is even working on ensuring that the right to sexual freedom is recognised as a human right to be protected' (SAN $4550 / 2010$, 2, para. 2). Similarly, in the case of a transgender woman from Colombia, the Court argues that the fact that she could change her name on her documents is 'evident proof of an absence of persecution of transgender people in the country' (SAN 2858/2015, 4, para. 4). In the Court's understanding of 'safety', a committee working on the recognition of sexual orientation as a human right equates to lack of individual persecution against the LGBTIQ* community. In the same manner, specific procedural mechanisms, such as those concerning sex registration, are interpreted as a sign of socio-political acceptance of the social group to which the asylum seeker belongs. However, as argued by Jansen and Spijkerboer (2011), legislative improvements cannot prevent violence against LGBTIQ* individuals. On the contrary, such a strong reliance on the legislative and procedural framework reveals that the jurisprudential understanding of 'safety' and 'harm' fails to recognise the multiple shapes taken by homo- and transphobia (Spade 2013). In other words, the intersectional violence suffered by LGBTIQ* asylum seekers is erased by uncritical accounts of the national legislation. 
The final aspect concerning the jurisprudential adjudication of the 'objective element' refers to the fact that most of the rulings ${ }^{13}$ report the applicants' failure to provide proof of the (un)safety of the local context together with the risk of being the personal targets of persecutory acts. In other words, the applicants need to provide evidence of both the situation in the country of origin and the (fear of) personal persecution. Consequently, the burden of proof on queer asylum seekers requires both components if it is to be considered 'sufficient'. An example is shown by the following extract:

Well, the applicant has not provided any proof, even circumstantial, of the existence of personal persecution understood within the legal framework of asylum law. In addition, reliable sources confirm that in Paraguay there is no systematic and generalised persecution on grounds of sexual orientation beyond being rejected to some degree in particular areas and concrete situations, which could include the personal incidents recounted by the applicant.... However, even if the situation of homosexuals is not exempt from criticism by some conservative sectors of society (which happens all over the world), the claimant does not cite facts which are sufficient for him to be granted effective protection, i.e., the fact that not all of society approves of his sexual orientation and, above all, does not respect it, is undoubtedly to be criticised, but does not per se entail persecution within the framework of the Geneva Convention, since in Paraguay homosexuality is not formally prohibited.

(SAN 4550/2010, 2, para. $2^{14}$ )

In this ruling, the argument articulated by the Court concerns the lack of indications that the applicant was targeted by persecution. Yet the judge reiterates that the insufficiency of evidence is linked to the absence of formal criminalisation of homosexuality in Paraguay, thus implying that in effect persecutory acts occur only through the enforcement of punitive laws. Furthermore, the Court seems to assert that 'mere' social rejection and lack of respect are unfortunate characteristics of every society around the world, which, while despicable, are not 'serious' enough to be considered 'real' persecution. The events recounted by the applicant, understood as 'simple' discrimination, consist of child abuse, social exclusion and systematic unemployment. However, as outlined above, the judges' understanding of persecution as primarily linked to criminalising legislation fails to consider the harmful and violent consequences that 
could be (and actually are) caused by the multifaceted shapes assumed by homo- and transphobic violence.

\section{The 'subjective element': personal and targeted persecution}

The jurisprudential differentiation between 'socio-political rejection' and 'personal persecution' expressed in the previous quote introduces another important component of the credibility assessment performed by Spanish national Courts: the so-called 'subjective element'. As mentioned, LGBTIQ* asylum seekers are required to present not only evidence of their (fear of) persecution but also proof of the fact that such persecution is related to their gender identity or sexual orientation. Within this framework, an in-depth analysis of the rulings reveals the Courts' persistent tendency ${ }_{15}^{15}$ over the years, to evaluate the facts as 'mere harassment' or 'common crimes', especially when committed by non-state agents.

With reference to 'mere harassment', violent events occurring within the applicant's family, neighbourhood or working environment are often dismissed as 'not severe enough' or 'not sufficient', especially in relation to the fact that, in the judges' account, national authorities could offer protection inside the country. This is, for instance, the case with an Ecuadorian transgender woman, when the National Court asserts that 'conflicts generated within the family are not comprised within the institution of asylum' (SAN 6856/1999, 2, para. 3). In a similar fashion, the Court maintains that the offences committed by non-state agents are 'common delinquency' (SAN 1662/2016, 4, para. 4) linked to the socio-political environment of instability that, according to the judges, characterises many Latin American countries. In this respect, the fact that local gangs systematically threaten, harm, and even kill LGBTIQ* individuals is understood as an incidental feature of a context marked by endemic violence. This interpretation often leads to processes of victim-blaming, particularly in the case of transgender women, as we can see in the Courts' argument that 'the reported problems seem to be mostly related to prostitution [actividad de la prostitución] and the conflicts generated because of it' (SAN 3195/2008, 5, para. 4), as in the case of an appeal filed by a Costa Rican transgender woman. This position seems to hold responsible not the subjects who commit the offences but the activity itself, thus implying that every person who engages in sex work cannot seek protection. In this respect, Spanish jurisprudence 
appears to deploy a sort of 'you asked for it' argument that shifts the focus from the persecution experienced by transgender individuals to the victims of persecution themselves. Furthermore, according to Millbank's (2009a) understanding of the so-called 'discretion reasoning', the judges' emphasis on the claimants' responsibility and 'choice' might be read as a 'discretion requirement'. In other words, if transgender female applicants had not made themselves visible as sex workers and had remained 'discreet', they would not have been persecuted. Millbank (2009a, 40) adds that the logic of discretion is not limited to the expectation that one will hide one's sexuality or gender identity but is also related to a 'lack of recognition of the multiple and intersecting forms of harm' suffered by LGBTIQ* populations. Within this framework, the consequences of such a reasoning not only lead to asylum rejections but contribute to the marginalisation of a whole social group (transgender female sex workers, for instance) that can hence be harmed with impunity.

A final aspect of the 'subjective element' refers to the fact that, when persecutory acts are committed by non-state actors, asylum seekers are required to prove that the offences occurred with the protection and/or complicity of national authorities. In this regard, the only way to show that institutions, such as the police, shelter the perpetrators of persecutory acts would be to give evidence that the applicant turned to those authorities but was rejected. This requirement is articulated in the case of a Colombian transgender woman (SAN 2858/2015), in which the Court maintains that 'in any case, the reported persecution stems from third agents, without any evidence confirming the possibility that national authorities either promote or protect it' (4, para. 4). In other words, the Courts require LGBTIQ* asylum seekers to denounce abuses and seek protection before public institutions in an 'unsafe' environment in order to be able to demonstrate that their requests had been dismissed. Following this logic, applicants are expected to endanger their lives by dealing with authorities that not only tolerate but foster persecutions. Contradictorily, when the perpetrators appear to be state agents (usually police officers), the Courts argue that they did not act as representatives of the national authorities, as was the case in the appeals filed before the National Court by a transgender woman from Panama (SAN 3365/2014) and another from Colombia (SAN 4536/2010). Similarly to how the judges refer to the presence of criminalising legislation, it seems that they refer to state actors in ambiguous and contradictory ways with the aim of rejecting LGBTIQ* asylum seekers. This position not only justifies the denial of the appeals but also endangers LGBTIQ* lives by requiring applicants to turn to national institutions that are often trans- and homophobic. 


\section{The discourse of queer (in)credibility}

The analysis presented above shows that, when dealing with asylum claims on the grounds of gender identity and sexual orientation, Spanish jurisprudence tends to articulate a discourse ${ }^{16}$ of 'credibility' that turns to either one side or the other of the same argument to justify rejection of the appeal. In this sense, the Courts seem to adjudicate on the 'incredibility' of the asylum claims rather than their 'credibility'. However, they do not question the applicants' gender identity or sexual orientation. Rather, the applicants' 'credibility' seems to be the actual target of jurisprudential enquiry, since asylum seekers are expected to provide vast amounts of evidence on several aspects of their claims (local context, enforcement of criminalising legislation, personal persecution, geographical and temporal details). According to previous studies, this tendency is entangled in an institutional fear of abuse of the right to international protection (Díaz Lafuente 2014). In other words, national authorities suspect that non-LGBTIQ* individuals and LGBTIQ* people who are not persecuted could take advantage of the difficulty of assessing gender- and sexualitybased persecution so as to be granted asylum (Spijkerboer 2013). To deal with presumed abuses, the Courts rely on a differentiation between 'true (queer) refugee' and 'bogus (economic) migrant'. For instance, the National Court refers to the claim of an Ecuadorian transgender woman as 'the case purely and simply of an economic migrant looking for better life conditions in the "European paradise" [paraíso europeo] and not the one of an authentic refugee' (SAN 2449/1999, 2, para. 5). Here the judges assume that the lack of persecutory evidence implies a fraudulent desire to benefit from the economic privileges of the 'European paradise'. To phrase it differently, claimants who, according to the Court, cannot present proof of such systematic and physically violent persecution are 'lying' about their necessity to seek international protection. In this respect, Spanish jurisprudence shows its limited and stereotyped understanding of the intricate entanglement of sexuality, gender and homo- and transphobia as well as of the complex realities that lead people to migrate. By failing to address the intersectional violence to which LGBTIQ* individuals are subjected and considering them 'bogus migrants', Spanish jurisprudence directly excludes sexual and gender minorities and reinforces the cis-heteronormative borders of refuge.

Cis-heteronormativity might nonetheless not be the only border against which the 'credibility' of LGBTIQ* asylum seekers is assessed. Building on previous research on the entanglement of international protection with colonialism and racialisation (Luibhéid 2002), the analysis 
of the rulings also examines references to the applicants' ethnic origin. In SAN 5907/1999, the National Court refers to a group of appeals that present shared characteristics being filed by 'Ibero-Americans' (iberoaméricanos) on the grounds of gender or sexuality and being rejected either because the reported facts did not constitute persecution or because they were considered manifestly false (p. 2). Concerning the first statement, we have already seen how sexuality- or gender-related violence is not considered 'bad enough' to constitute persecution, since LGBTIQ* subjectivities 'merely' endure 'social discrimination', 'familial rejection' or 'common delinquency'. Yet dominant representations of Latin American countries (particularly if located in Central America) as marked by corruption and conflict make it rather difficult to prove that persecutory acts are specifically directed at individuals who do not conform to gender and sexual norms. Within this framework, the processes of intersectional violence that target LGBTIQ* subjectivities are not considered persecution but understood and justified in terms of 'social insecurity' (inseguridad ciudadana) (SAN 2471/2015, 2). In other words, if gender identity and sexual orientation are not 'enough' to account for persecution, Spanish jurisprudence belittles their relevance even more in the case of Latin American applicants. According to the Courts the facts do not constitute persecution because every Latin American citizen, LGBTIQ* or not, is potentially in danger. In this way, Latin American asylum seekers' 'queerness', their lack of adherence to the dominant sexgender matrix, disappears by means of their racialisation through the construction of latinidad. ${ }^{17}$

Furthermore, another reason for rejection is the alleged 'evident falsity' of the asylum claims. The common position adopted by the judges in this respect is based on the belief that the 'European paradise' attracts people living in situations of economic precarity and lack of opportunities. Without verifying if they are embedded in systematic discriminations of LGBTIQ* individuals, Spanish jurisprudence interprets the claimants' references to their economic conditions as suspicious. As Anker and Ardalan (2012) explain, legislative understandings of 'persecution' developed after the 1951 Convention do not consider the different forms persecutory acts could assume, including those related to inequalities generated during the current neoliberal era. On the contrary, individuals who move because of intersecting asymmetries of race, gender, sexuality and class are labelled 'bogus migrants'. Furthermore, throughout the rulings we can see that this tendency is fostered by neo-colonial narratives on the (economically) developed 'centre', i.e., Spain, and the backward 'periphery', namely Latin America (Gil Araújo 2010). By 
means of its supposed socio-political and economic instability, latinidad is configured as the implicit reason why LGBTIQ* Latin Americans are denied asylum.

In conclusion, discourse analysis of the jurisprudential assessment of 'credibility' suggests that the hierarchical categories that divide 'bogus migrants' from 'genuine refugees' are traced along the intersections of gender, sexuality and ethnicity. Within this framework, the Spanish judges perform the credibility assessment of LGBTIQ* Latin Americans' asylum claims by relying on the borders of cis-heteronormativity and racialisation. On the one hand, the Courts appear a priori suspicious of LGBTIQ* claimants and tend to deploy controversial arguments to prove the incredibility of their allegations. On the other hand, they resort to the applicants' Latin American origins to maintain that the violence they experience is not personally targeted at them but rather is related to the generalised context of political and economic instability. In both ways, the judges contribute to constructing an understanding of LGBTIQ* Latin Americans as 'bogus migrants' through a discourse that we could name as 'queer (in)credibility'. 'Queer (in)credibility' functions as a coherent and solid narrative that conforms to the cis-heteronormative and racialising borders of asylum (re)produced by Spanish jurisprudence.

\section{Queer Latinxs (des)haciendo fronteras: how LGBT Latin Americans experience asylum}

Building on the analysis presented in the preceding paragraphs, this section seeks to analyse the personal narratives of LGBT Latin Americans living in Madrid with the aim of exploring their experiences across the material and conceptual borders of asylum. As mentioned in the introduction, interviews with eight asylum seekers and two experts based in Madrid were undertaken between February and May 2017. While the experts were interviewed only once, there were at least two meetings with each research participant. The first meeting lasted approximately 20-30 minutes and was intended to position myself, address the aims and methods of the research, clarify the details of the interviews and discuss possible doubts. Such conversations were not recorded but configured crucial spaces in which to build mutual trust and informed consent. The second meeting constituted the main body of the interview, which was held in Spanish and recorded. The conversations varied from person to person, both in terms of time (ranging from 45 minutes to two hours) and level of intimacy. Interviews were opened with my only 
predetermined question, in which I asked the research participants to describe themselves in the ways they felt most comfortable with. This was intended to avoid reproducing the power dynamics which they had to cope with during asylum interviews. In other words, I did not want them to feel obliged to share traumatic and violent experiences or to disclose personal details; on the contrary, such a broad question was meant to give them space to navigate across content, modes of narration, pauses, geographies and temporalities. This approach resulted in unique conversations touching upon intertwined topics, which I consequently coded as (1) self-identification in terms of gender identity and/or sexual orientation, as both an internal process and an externally perceived identity, (2) life before and after migration, and (3) experiences of the credibility assessment.

At the time of the interviews, the research participants were aged between 18 and 30 and were at different stages of the asylum procedure: three had just entered the second phase (finding a job and accommodation), one was close to this stage, two had recently had their asylum interviews and one was waiting to be interviewed. One person had been given notice of the rejection of her application in 2016 but had decided not to appeal against the decision. As for their nationality and personal identity, four were gay men from Venezuela, one was a gay man from El Salvador, two were transgender women from Brazil and Mexico and one was a transgender man from Honduras.

\section{Narrating the credibility assessment: 'Como abrir un baúl'}

As explained in an earlier section, the Spanish institution responsible for the evaluation of asylum applications is the Oficina de Asilo $y$ Refugio (OAR). According to one of the experts interviewed, Dr Juan Carlos Arnaiz, ${ }^{18}$ Senior Protection Associate of the UNHCR Spanish delegation, in Spain the credibility assessment is mainly conducted through oral interviews aimed at verifying the asylum seeker's personal details and the consistency of their application. Since international protection can be sought at the OAR, aliens' offices, Centros de Internamiento de Extranjeros (detention centres) or at any authorised police station, the interviewers are either asylum officers or police officers, who are also responsible for transcribing the interview onto a document signed by the applicant. In Juan Carlos's account, the OAR is not provided with clear directives on how to assess and evaluate 
the credibility of asylum cases - an absence that leads to different procedures being followed. In line with the jurisprudential tendency analysed above, LGBTIQ* applicants' self-identification is apparently not questioned. Indeed, none of my respondents was required to provide material evidence of their gender identity or sexual orientation. Nevertheless, Juan Carlos states that a certain degree of proof might contribute to a positive evaluation. In the metropolitan area of Madrid, LGBTIQ* asylum seekers are therefore usually advised to participate in the activities carried out by local organisations (such as the Federación Estatal de Lesbianas, Gais, Trans y Bisexuales) and to present a psychological report written by the Programa LGBT de la Comunidad de Madrid, ${ }^{19}$ a governmental institution aimed at supporting LGBTIQ* people living in the province of Madrid. Yet such a document does not per se constitute sufficient proof of a wellfounded fear of persecution. As Juan Carlos explains, the burden of proof mainly lies in the interview itself. In his experience, the lack of procedural directives and appropriate training leads to superficial and problematic interviews that consequently affect the credibility assessment and the overall evaluation of the applications.

Within this framework, my informants recounted paying great attention to the expediente (their asylum file). All of them devoted time both to collecting documents and to structuring their stories in the most accurate way. As previously found by Giametta (2016), the phase of preparation is crucial not only in terms of what to say but also in terms of how to present it. In this respect, the free counselling and support provided by lawyers, psychologists and social workers is indispensable for the articulation of 'a recognisable script that will give [the applicant] more chances to obtain the right to remain in the country' (Giametta 2016, 58). However, because of a lack of information, half of my research participants had not been in contact with any organisation before their asylum interview. This meant that no experts advised them or helped them cope with the emotional implications of remembering and recounting traumas. Consequently, during their asylum hearing, they did not mention the persecution they had endured because of their sexuality. Although Juan Carlos explains that it is possible to modify the expediente after the interview, he asserts that any changes must be clearly motivated in order to be considered 'credible'. In this respect, as Millbank (2009b) maintains, the absence of (proper) counselling might lead asylum seekers to present their stories in ways that are perceived as 'inconsistent'. Building on these accounts, we can see that the first obstacle faced by my informants is lack of information about their asylum 
options and scarcity of support in preparing for their interviews and dealing with the requirement to recount traumatic experiences.

Another transversal issue discussed by my informants is the emotional burden triggered by the interview, from preparating for it to the actual hearing. They referred to their experiences in terms of anxiety, vulnerability and lack of privacy. The intensity of such emotions can be exemplified by the following statement:

It is like opening a trunk [como abrir un baúl] and leaving everything there: your life, your traumas, your privacy. ... Everything at the mercy of those who pass by.

(W., Brazilian transgender woman interviewed on 11 March 2017)

Through W.'s words, the asylum interview is described as the act of being forced to open a trunk that reveals one's vulnerabilities. In this respect, W. offered a powerful image of the emotional burden imposed by the credibility assessment, emphasising that such emotions are not only triggered by the asylum interview but are also expected by the adjudicators. This is testified by S., a Venezuelan gay man, who affirms that 'They [asylum adjudicators] want us to be dramatic. But my life has been dramatic enough' (interview conducted on 22 March 2017). Like S., most of my research partners had felt this obligation to show suffering as another burden imposed on them by the asylum procedure: not only were they required to be open about traumatic experiences but they were also expected to show certain feelings. Within this framework, the expression 'como abrir un baúl' reveals a profound contradiction in the credibility assessment as it was experienced by my informants: on the one hand, there was the emotional burden of dealing with the interviewers' questions, on the other the emotional burden of being faced with the interviewers' expectations. 'Como abrir un baúl' hence speaks of how LGBTIQ* asylum seekers are at the same time made vulnerable and victimised by the credibility assessment. Remarkably, as explained by Giametta (2016), the consequences of these requirements are dramatic, since individuals who do not adhere to the 'victim' role are considered 'bogus migrants' and denied asylum. In other words, like Northern European asylum institutions, Spanish adjudicators seem to rely on fixed and Western-centric understandings of gender identity, sexual orientation and 'victims' of gender- or sexuality-related persecution. These cisheteronormative and racialised requirements function as other borders of asylum that create the 'genuine queer victim' as an inaccessible domain. 


\section{'Esto es lo que soy': (un)doing the borders of queer (in)credibility}

Through an exploration of the ways my informants deal with and respond to the credibility assessment, in this final section I will look at how (queer) identities disciplined by the asylum process contribute to challenging and changing its borders. As argued in the previous sections, the credibility assessment reinforces racialised and cis-heteronormative assumptions of who counts as a 'genuine queer refugee'. The way I have hitherto addressed the concept of 'border' concerns its disciplinary force as a biopolitical mechanism that both symbolically and materially restricts access to the domain of life (Mezzadra \& Nielson 2013, 269). Yet, as Mezzadra and Nielson contend, "the "illegal" migrant [] is not only subject to exclusion but also becomes a key actor in reshaping, contesting, and redefining the borders of citizenship' (2013, 256-7). Against this backdrop, the final section of this chapter will be devoted to an exploration of my respondents' strategies for existing across and beyond the borders of asylum. To do this, I will draw on Epps, Valens and Johnson Gonzáles's (2005) articulation of border struggles as 'passing lines': strategies to both 'pass as', that is, adhere to the set of norms embodied by 'proper citizens', and 'pass through', that is, cross the material and symbolic borders of citizenship (Epps, Valens \& Johnson Gonzáles 2005, 4). In other words, the concept of 'passing lines' speaks of how migrant subjectivities may undo the hierarchical borders that render them noncitizens by striving to conform to the logic of border control and thus exposing the constructed origin of such lines.

By means of this theorisation, I approached my informants' responses to the credibility assessment as expressions of their agential efforts to pass the interlocking lines of asylum. I argue that their strategies to deal with the precarity and emotional burden triggered by the asylum procedure can be described through an expression that appeared several times throughout the interviews: 'Esto es lo que soy' ('This is who I am'). After migrating and seeking asylum, my respondents indeed felt the need to rebuild their lives in Spain. However, they reported feeling stuck in a precarious situation, since they were aware that their ability to live their lives as 'who they were' would mostly depend on the acquisition of long-term legal documents. Within this framework, at the time of the interviews they had been developing their own particular mode of coping with their lives as asylum seekers, combining opposition to and cooperation with asylum institutions in a nuanced interplay. 
However, negotiation concerned not only their experiences of the asylum procedure but more broadly referred to how they navigated their queerness and latinidad in relation to and even beyond asylum. Within this framework, 'Esto es lo que soy' speaks of how my informants articulated their identities as queer (and) Latinx asylum seekers in Spain. All of them already identified as Latinx before their asylum application. However, after migrating they dealt with their latinidad in different ways:

Spain is not such a racist country as people say.

(D., Venezuelan gay man interviewed on 26 April 2017)

The truth? Here I am exotic. It is what people tell me and I love it. (L., Venezuelan gay man interviewed on 10 April 2017)

Many [adjudicators] think that people leave Venezuela because of its economic and political situation. ... Or better, that the economic situation is merely an addition to the asylum application [meaning that it is not enough to seek asylum]. Yet I think this is totally dehumanising, because in my country people cannot even get a paracetamol. ... People cannot get food. You tell me if this does not constitute a reason for leaving your country.

(S., Venezuelan gay man)

As these passages emphasise, my respondents have contrasting understandings of their latinidad: an identity that is no longer subjected to Spanish racism; an interplay of physical appearance and behaviour that renders one 'exotic', and therefore interesting to Spanish eyes; and a sublimation of one's geographical origin into one's social status and class. In other words, some of my interviewees seemed to adapt to the narrative of 'ethnic affinity' (Gil Araújo 2010), a principle applied by current Spanish migration policy to facilitate the entrance of migrants who are thought to share the same cultural values as 'modern Spain'. As explained by Gil Araújo (2008, 2010), the principle of 'ethnic affinity' is achieved through the erasure of the histories of exploitation, slavery and colonisation that have accompanied the violent imposition of Spain on Latin American territories. By appealing to the principle of 'ethnic affinity', my respondents strove to fulfil the Western-centric or 'Hispanic' requirements of 'genuine refugees', that is, the dramatic nature of their accounts, the hypervisibility of their gender identity and the exoticism of their bodies (Giametta 2016). However, by playing with these normative discourses that structure the image of the 'truthful (queer) victim' they 
may appear as 'desirable refugees' and may be granted asylum. Hence, their apparent 'desirability', achieved by adapting to the principle of 'ethnic affinity', becomes the way to access international protection.

Yet 'Esto es lo que soy' appears to resist hierarchical categorisations. S. indeed emphasised the racialised equation that links latinidad to economic precarity, and that consequently materialises Latinxs as 'bogus economic migrants'. He troubles the relations between 'safety' and 'ethnic affinity', according to which LGBTI* Latin Americans do not experience gender- and sexuality-based persecution but 'only' live in a context of widespread violence. This position is supported by F., a transgender woman from Mexico, who adds:

You're in Spain, 'First World', one of the freest countries in terms of human rights. Outside of Spain we get a rather good representation of Europe. You think you will arrive in Europe and then everything is done. So when you are inside the [asylum] process you say: 'Wow, they lack sensitivity here!' We cannot be sure about what they publish. ... Here they have patriarchy and sexism, too.... What's the difference between here and there? Well, none. Despite 1,500 years of alleged progress and civilisation, sex-gender matrix, violence and misogyny are still present.

(F., Mexican transgender woman interviewed on 25 April 2017)

F. offers a crucial perspective that condemns the abuses and discrimination suffered both throughout the procedure and in asylum centres. By doing so, she contributes to unveiling the fallacy of the credibility assessment and of the Western-centric liberationist narratives, according to which asylum liberates non-Western queers (Giametta 2016). F.'s and S.'s claims indeed reveal how LGBTIQ* Latinxs are targeted by asylum institutions as both queers and Latinxs: the persecution they suffer is not recognised precisely because the asylum domain excludes queer and racialised subjectivities who do not conform to dominant narratives of 'true queer refugees'.

Within this framework, by unveiling the inextricability that links violence in public spaces with discrimination carried out in private or privatised spheres of life, 'Esto es lo que soy' also represents my respondents' efforts to exist across and beyond the cis-heteronormative and racialising borders of asylum. It describes the multiple and perhaps even contradictory strategies through which my partners strive to live as free, safe and worthy subjects. The presented excerpts show 
that they articulate responses aimed at passing the lines of asylum through two different strategies: on the one hand, they present themselves as 'desirable' migrants who are capable and worthy of integration through the institution of international protection; on the other, they directly question the exclusionary rooting of the asylum system and of the credibility assessment. Although they might seem to reproduce the cis-heteronormative and racialising borders of 'queer (in)credibility', such strategies nevertheless function 'as a response to the continuous monitoring and surveillance' (Viteri 2008, 66). In this way, they have the potential to blend themselves and bend the filtering logic of asylum. By doing (conforming to) and undoing (opposing) the pillars that sustain exclusionary interpretations of 'safety' and 'persecution', their negotiations blur the rigid borders that trace the antagonistic domains of 'genuine (queer) refugee' and 'economic (Latin) migrant'. By reaffirming themselves as 'Esto es lo que soy', my respondents open up a space for transformative articulations of their identities beyond the discourse of 'queer (in)credibility'.

In summary, the research participants' stories show that queer Latinxs experiencing asylum in Spain are caught between the necessity to become the 'good subject' of the asylum system - the 'genuine refugee' and their materialisation as 'bad subject', namely 'bogus migrant'. However, the complexity of their nuanced lives exceeds the fixity of such categories, unveiling how individuals cannot be easily reduced to 'mere' queers or Latinxs, refugees or migrants. Through the reiteration of 'Esto es lo que soy', my respondents strive to make sense of their identities beyond the constraints imposed by the credibility assessment, which pushes them to conform to a dominantly structured way of being queer and Latinx. Building on the margins of queerness and latinidad, they contrast the exclusionary individuality sustained by the asylum system with the multiplicity of their positions, embodiments and desires. In this respect, 'Esto es lo que soy' contributes to a collective imagining of infinite ways to trespass the borders of queerness and latinidad, hence to exist across and beyond normative lines as non-normative subjects. In other words, 'Esto es lo que soy' might have the potential to decolonise queerness and queer latinidad so as to open up a space for queer Latinxs to exist by (des) haciendo fronteras.

\section{Conclusions}

This chapter has articulated a twofold analysis of the borders inherent in the process of the credibility assessment of the asylum cases presented 
by LGBTIQ* Latin Americans in Spain: on the one hand, it has examined how such borders are constructed upon interlocking modes of governance; on the other, it has engaged with the strategies of 'passing lines' that permit my research participants to undo the normative borders of asylum and exist as who they are. In other words, this contribution has explored the interplay of doing (haciendo) and undoing (deshaciendo) the borders (fronteras) that surround LGBTIQ* Latin American asylum seekers.

Yet this investigation leaves us with open-ended questions that need further problematisation. First of all, the living conditions of LGBTI* asylum seekers coming to Spain remain a dramatically under-researched issue: what do sexual and gender minorities experience in asylum centres? How does living in asylum and detention centres affect their identities? What strategies for survival do they adopt? Furthermore, hardly any research has been written with specific regard to how racialisation functions in the case of asylum seekers coming from other regions of the world to Spain. In this respect, a comparative analysis between the Latin Americans and citizens from other former Spanish colonies (such as the Philippines or the Spanish portion of Morocco) might offer a crucial entry point. In conclusion, I believe that academic scholarship needs to engage more and more with subversive practices that unveil hegemonic in/exclusions. By doing so, scholars could support the struggles articulated across the borders of normativity not only by migrants and asylum seekers but also by every subjectivity who is intersectionally materialised as 'non-worthy'.

\section{Appendix: list of analysed rulings}

Audiencia Nacional (National Court):

1. SAN $143 / 1998$

2. SAN $4388 / 1998$

3. SAN $5089 / 1998$

4. SAN $5109 / 1998$

5. SAN 5446/1998

6. SAN 5453/1998

7. SAN $1840 / 1999$

8. SAN $2449 / 1999$

9. SAN $2745 / 1999$

10. SAN $4278 / 1999$

11. SAN $5907 / 1999$ 
12. SAN $6085 / 1999$

13. SAN $6483 / 1999$

14. SAN $6569 / 1999$

15. SAN $6856 / 1999$

16. SAN $1603 / 2000$

17. SAN $1606 / 2000$

18. SAN $7079 / 2000$

19. SAN $3311 / 2001$

20. SAN $3708 / 2001$

21. SAN $5684 / 2002$

22. SAN $7018 / 2002$

23. SAN $1080 / 2003$

24. SAN $1173 / 2003$

25. SAN $1357 / 2003$

26. SAN $1477 / 2003$

27. SAN $1482 / 2003$

28. SAN $2263 / 2003$

29. SAN $2628 / 2003$

30. SAN $3058 / 2003$

31. SAN $3418 / 2003$

32. SAN $4391 / 2003$

33. SAN $4491 / 2003$

34. SAN $7167 / 2003$

35. SAN $60 / 2004$

36. SAN $62 / 2004$

37. SAN $99 / 2004$

38. SAN $2717 / 2004$

39. SAN $4724 / 2004$

40. SAN $5170 / 2004$

41. SAN $6480 / 2004$

42. SAN $6635 / 2004$

43. SAN $1763 / 2005$

44. SAN $1790 / 2005$

45. SAN $1820 / 2005$

46. SAN $2858 / 2005$

47. SAN $3039 / 2005$

48. SAN 5962/2005

49. SAN $6046 / 2005$

50. SAN $6433 / 2005$

51. SAN $6495 / 2005$

52. SAN $7460 / 2005$ 
53. SAN $3138 / 2006$

54. SAN $200 / 2007$

55. SAN $1492 / 2008$

56. SAN 3195/2008

57. SAN 3530/2008

58. SAN 4033/2008

59. SAN 5465/2009

60. SAN 6009/2009

61. SAN 2141/2010

62. SAN 2297/2010

63. SAN $4536 / 2010$

64. SAN 4550/2010

65. SAN 5206/2010

66. SAN 1758/2011

67. SAN 1338/2011

68. SAN 1893/2011

69. SAN 4405/2011

70. SAN 4839/2011

71. SAN 5139/2011

72. SAN 2186/2012

73. SAN $2539 / 2012$

74. SAN 2862/2012

75. SAN $3109 / 2012$

76. SAN 4025/2012

77. SAN 5299/2012

78. SAN 5353/2012

79. SAN $140 / 2013$

80. SAN $1040 / 2013$

81. SAN $1256 / 2013$

82. SAN $1693 / 2013$

83. SAN $159 / 2014$

84. SAN 2122/2014

85. SAN 2984/2014

86. SAN 3365/2014

87. SAN 4099/2014

88. SAN $4565 / 2014$

89. SAN $2221 / 2015$

90. SAN $2471 / 2015$

91. SAN $2858 / 2015$

92. SAN $15 / 2016$

93. SAN $1662 / 2016$ 


\section{Tribunal Supremo (Supreme Court):}

1. STS $4171 / 2005$

2. STS $2266 / 2006$

3. STS $2331 / 2006$

4. STS $3122 / 2006$

5. STS $5782 / 2006$

6. STS $8650 / 2006$

7. STS $149 / 2007$

8. STS $5650 / 2007$

9. STS $8251 / 2007$

10. STS $27 / 2008$

11. STS $6142 / 2008$

12. STS $6881 / 2008$

13. STS $3854 / 2011$

14. STS $5907 / 2012$

15. STS $4500 / 2013$

16. ATS $8316 / 2013$

17. ATS $9065 / 2013$

18. ATS $2016 / 2015$

19. ATS $11354 / 2016$

\section{Notes}

* This investigation is the basis of my final dissertation of the Research Master's Programme in Gender and Ethnicity at Utrecht University (the Netherlands). Therefore, my intention in this chapter is to give an overview of a broader work, whose results are only partially discussed here.

1. The original quotation is in Spanish. Unless otherwise specified, translations from Spanish into English are my own.

2. Throughout the chapter, I use both 'LGBTIQ"' and 'LGBT'. I deploy 'LGBT' specifically to describe the group of asylum seekers who collaborated with my research, because of the absence of self-identified intersexed, gender-variant, gender-fluid, gender-queer and gendernon-conforming participants. When making a more general reference to all those individuals who, in different ways, do not conform to hegemonic notions of heterosexuality and cisnormativity, I use 'LGBTIQ*'.

3. Academic scholarship enquiring into practices of evidentiary assessment has unveiled its multiple pitfalls when it comes to defining, and consequently evaluating, the 'credibility' of LGBTI* applicants in the USA, Australia and Northern Europe. For an overview and analysis of the credibility assessment in asylum procedures, see: Bobis 2012; Millbank 2002, 2009a, 2009b; Berg and Millbank 2007; Dauvergne and Millbank 2003; Noll 2005. For an investigation into queer migration to the USA, see Luibhéid and Cantú Jr 2005. Refer to Epps, Valens and Johnson González 2005 to explore the entanglement of sexuality and migration with a specific focus on Latin America. For accounts of the various asylum procedures carried out in Europe in relation to the evaluation of credibility, see: Akin 2017; Cohen 2001; Connely 2014; Gartner 2015; Giametta 2016; Jordan 2009; Lewis 2014; Spijkerboer 2013; Wessels 2013. Although this list is not exhaustive, it is important to notice a lack of research on credibility assessment in Southern Europe. 
4. With the development of the analysis, I will problematise the terms 'Latin American' and 'Latinx', and their embodied identity known as latinidad. Although these references represent the geographical focus of the investigation, their significances will be problematised through an enquiry into the dominant discourses that construct latinidad as a neo-colonial essentialised category. Building on Rodriguez (2003, 2014) and Viteri (2008), my use of the term 'Latin American' speaks of individuals from Central and South America, whose latinidad will not be taken for granted but scrutinised in relation to both queerness and asylum.

5. The year of the first ruling issued by the Audiencia Nacional in the case of a homosexual asylum seeker from Ecuador.

6. Data available at: https://ec.europa.eu/eurostat/statistics-explained/index.php/Asylum_ statistics (accessed 15 October 2019).

7. See OAR (2019).

8. See OAR (2019).

9. A 'refugee' is defined in Spanish Law as any 'person who, owing to well-founded fears of persecution on the grounds of race, religion, nationality, political beliefs, membership of a particular social group, linked to either gender identity or sexual orientation, is outside their country of nationality and cannot or, given such fears, does not want to seek protection in that country; or any stateless person who, not being a citizen of any country and being outside their country of habitual residence, cannot or, given such fear, does not want to return to that country due to well-founded fears of persecution ....'. The original text: 'La condición de refugiado se reconoce a toda persona que, debido a fundados temores de ser perseguida por motivos de raza, religión, nacionalidad, opiniones políticas, pertenencia a determinado grupo social, de género u orientación sexual, se encuentra fuera del país de su nacionalidad y no puede $\mathrm{o}$, a causa de dichos temores, no quiere acogerse a la protección de tal país, o al apátrida que, careciendo de nacionalidad y hallándose fuera del país donde antes tuviera su residencia habitual, por los mismos motivos no puede o, a causa de dichos temores, no quiere regresar a él .... Available at: https://www.boe.es/buscar/pdf/2009/BOE-A-2009-17242-consolidado. pdf (accessed 1 August 2020).

10. Before 2004 both types of appeal were filed before the National Court (CEAR-Euskadi 2009, 119).

11. The rulings were collected from the website of the National Council of Jurisprudential Power (www.poderjudicial.es/search) by entering each of the following terms (translated into Spanish): gay, lesbian, homosexual, bisexual, transsexual, transgender, travestí, intersexual. The personal details of the applicants are not included in the publicly available copies of the sentences. However, references to specific events that recur in some of the appeals may indicate that different sentences issued by the National and Supreme Courts concern the same person. Consequently, the presented data might may not reflect the actual number of applicants.

12. The original text: 'La condición de homosexual no vamos a cuestionarla aquí pero lo que sí cuestionamos es que ello sea causa de asilo. En lo que sepamos no hay normativa específica en Ecuador represora de estas situaciones, o al menos no se nos habla más que de acoso policial. Ignoramos por qué manifestaciones concretas de la homosexualidad se produce ese supuesto acoso o si es, que no creemos, por el simple hecho diferencial, y en esta nebulosa no podemos decir que sea errónea la calificación administrativa de la pretensión como evanescente y poco sólida, casi diríamos nosotros, que no hay ni siquiera causa de pedir.'

13. To name a few: SAN 143/1998; SAN 4278/1999; SAN 7018/2002; SAN 1080/2003; SAN 1820/2005; SAN 2186/2012; SAN 2471/2015. A complete list of the analysed rulings can be found in the appendix to the chapter.

14. The original text: 'Pues bien, el interesado nada ha acreditado, ni directa ni indiciariamente, sobre la realidad de una persecución personal susceptible de ser incardinada en el regimen jurídico de asilo, siendo así que a la vista de fuentes fiables puede afirmarse que en Paraguay no existe una persecución generalizada o sistemética por razones de orientación sexual, más allá de cierto rechazo en determinados ámbitos y situaciones concretas, como incluso pudieran ser los incidents personales que el promovente relata. ... Sin embargo, a pesar de que la situación de los homosexuales nunca está exenta de críticas por parte de ciertos sectores conservadores de la sociedad (lo cual ocurre en todo el mundo), el solicitante no alega hechos de entidad suficiente que hagan necesaria una efectiva protección, es decir, el hecho de que no toda la sociedad apruebe su condición sexual, y sobre todo, que no la respete, es algo sin duda digno de crítica, pero no conlleva en sí mismo una persecución en el sentido que la Convención 
de Ginebra otorga a ese término, pues en Paraguay la homosexualidad no está prohibida formalmente.'

15. To name a few: SAN 4278/1999; SAN 6856/1999; SAN 7079/2000; SAN 4550/2010; SAN $1662 / 2016$.

16. The term discourse is used in line with Stuart Hall's definition as 'a group of statements which provide a language for talking about - i.e. a way of representing - a particular kind of knowledge about a topic. When statements about a topic are made within a particular discourse, the discourse makes it possible to construct the topic in a certain way' ([1996] 2006, 165).

17. The term 'latinidad' is here understood not as a fixed and stable identity but as an expression that 'contains within it the complexities and contradictions of immigration, (post) (neo)colonialism, race, color, legal status, class, nation, language, and the politics of location' (Rodriguez 2003, 10).

18. Interview conducted on 26 April 2017.

19. For more information, please consult: http://www.madrid.org/cs/Satellite?c=CM_ ConvocaPrestac_FA\&cid $=1142667355193 \&$ noMostrarML $=$ true $\&$ pageid $=1331802501671 \&$ pagename $=$ PortalCiudadano\%2FCM_ConvocaPrestac_FA\%2FPCIU_fichaConvocaPrestac\&v est $=1331802501621$ (accessed 28 October 2019).

\section{References}

Akin, Deniz. 2017. 'Queer asylum seekers: Translating sexuality in Norway', Journal of Ethnic and Migration Studies 43:458-74. https://doi.org/10.1080/1369183x.2016.1243050.

Anker, Deborah and Sabrineh Ardalan. 2012. 'Escalating persecution of gays and refugee protection: Comment on Queer Cases Make Bad Law', New York University Journal of International Law and Politics 44:529-57.

Anzaldúa, Gloria. 1987. Borderlands/La Frontera: The new mestiza. San Francisco, CA: Aunt Lute Books.

Berg, Laurie and Jenni Millbank. 2007. 'Constructing the personal narratives of lesbian, gay and bisexual asylum claimants', Journal of Refugee Studies 22:195-223. doi.org/10.1093/jrs/ fep010.

Bobis, Zsolt. 2012. 'You are not what you ought to be: Credibility assessment in sexuality-based asylum cases.' MA thesis, Central European University.

CEAR. 2016. Informe 2016: Las personas refugiadas en España y Europa. Madrid: Oficinas Centrales de CEAR. Available at: https://www.cear.es/wp-content/uploads/2016/06/Informe_CEAR_ 2016.pdf (accessed 25 February 2020).

CEAR-Euskadi. 2009. El sistema de asilo español frente a la violación de los derechos humanos de las mujeres y de lesbianas, gays, bisexuales y transexuales. Bilbao: CEAR-Euskadi. Available at: https://www.cear-euskadi.org/producto/persecucion-motivos-genero-derecho-asilo-delcontexto-global-al-compromiso-local/ (accessed 25 February 2020).

Cohen, Juliet. 2001. 'Questions of credibility: Omissions, discrepancies and errors of recall in the testimony of asylum seekers', International Journal of Refugee Law 13:293-309. https://doi. org/10.1093/ijrl/13.3.293.

Connely, Elizabeth. 2014. 'Queer, beyond a reasonable doubt: Refugee experiences of "passing" into "membership of a particular social group"', UCL Migration Research Unit Working Papers no. 2014/3. Available at: https://www.geog.ucl.ac.uk/research/research-centres/migrationresearch-unit/publications/working-papers/files/Elizabeth\%20Connely\%202014\%203.pdf (accessed 25 February 2020).

Dauvergne, Catherine and Jenni Millbank. 2003. 'Burdened by proof: How the Australian Refugee Review Tribunal has failed lesbian and gay asylum seekers', Federal Law Review 31:299-342. https://doi.org/10.22145/flr.31.2.2.

Díaz Lafuente, José. 2014. 'Refugio y asilo por motivos de orientación sexual y/o identidad de género en el ordenamiento constitucional español.' Doctoral thesis, Universitat de València. Available at: https://core.ac.uk/download/pdf/71035381.pdf (accessed 25 February 2020).

Eastmond, Marita. 2007. 'Stories as lived experience: Narratives in forced migration research', Journal of Refugees Studies 20:248-64. https://doi.org/10.1093/jrs/fem007. 
Epps, Brad, Keja Valens and Bill Johnson González (eds). 2005. 'Introduction'. In Passing Lines: Sexuality and immigration, edited by Brad Epps, Keja Valens and Bill Johnson González, 3-48. Cambridge, MA, and London: David Rockefeller Center for Latin American Studies and Harvard University Press.

Gartner, Johannes Lukas. 2015. '(In)credibly queer: Sexuality-based asylum in the European Union'. In Transatlantic Perspectives on Diplomacy and Diversity: Select essays from the 2014 Diplomacy and Diversity Fellowship, edited by Anthony Chase, 39-66. New York: Humanity in Action Press. Available at http://www.humanityinaction.org/knowledgebase/578-incredibly-queer-sexuality-based-asylum-in-the-european-union (accessed 25 February 2020).

Giametta, Calogero. 2016. 'Narrativising one's sexuality/gender: Neo-liberal humanitarianism and the right of asylum'. In Sexuality, Citizenship and Belonging: Trans-national and intersectional perspectives, edited by Francesca Stella, Yvette Taylor, Tracey Reynolds and Antoine Rogers, 55-72. New York: Routledge.

Gil Araújo, Sandra. 2008. 'Migraciones latinoamericanas hacia el Estado español: La reactivación del sistema migratorio transatlántico'. In Postcolonialidades históricas: (In)visibildades hispanoamericanas/colonialismos ibéricos, edited by Ileana Rodríguez and Josebe Martínez, 189-220. Barcelona: Anthropos.

Gil Araújo, Sandra. 2010. 'The coloniality of power and ethnic affinity in migration policy: The Spanish case'. In Decolonizing European Sociology: Transdisciplinary approaches, edited by Encarnación Gutiérrez Rodriguez, Manuela Boatca and Sérgio Costa, 179-94. Farnham and Burlington, VT: Ashgate.

Hall, Stuart. 2006. 'The West and the rest: Discourse and power'. In The Indigenous Experience: Global perspectives, edited by Roger C. A. Maaka and Chris Anderson, 165-88. Toronto: Canadian Scholars' Press. https://doi.org/10.1215/9781478002710-009.

ILGA-Europe. 2014. 'Good practices related to LGBTI asylum applicants in Europe'. Available at: https://www.ilga-europe.org/sites/default/files/good_practices_related_to_lgbti_ asylum_applicants_in_europe_jul14.pdf (accessed 25 February 2020).

ILGA-Europe. 2016. 'Seeking refuge without harassment, detention or return to a "safe country"'. Available at: https://www.ilga-europe.org/sites/default/files/Attachments/ilga_europe_ briefing_on_lgbti_asylum_issues_-_february_2016.pdf (accessed 25 February 2020).

Jansen, Sabine and Thomas Spijkerboer. 2011. 'Fleeing homophobia: Asylum claims related to sexual orientation and gender identity in Europe. Amsterdam: COC Netherlands and Vrije Universiteit Amsterdam'. Available at: https://www.refworld.org/docid/4ebba7852.html (accessed 25 February 2020).

Jordan, Sharalyn R. 2009. 'Un/convention(al) refugees: Contextualizing the accounts of refugees facing homophobic or transphobic persecution', Refuge 26:165-82. https://doi.org/10.25071/ 1920-7336.32086.

Lewis, Rachel A. 2014. “"Gay? Prove it”: The politics of queer anti-deportation activism', Sexualities 17:958-75. https://doi.org/10.1177/1363460714552253.

Luibhéid, Eithne. 2002. Entry Denied: Controlling sexuality at the border. Minneapolis and London: University of Minnesota Press.

Luibhéid, Eithne. 2008. 'Queer/migration: An unruly body of scholarship', GLQ: A Journal of Lesbian and Gay Studies 14:169-90. https://doi.org/10.1215/10642684-2007-029.

Luibhéid, Eithne and Lionel Cantú, Jr (eds). 2005. Queer Migrations: Sexuality, U.S. citizenship, and border crossings. Minneapolis: University of Minnesota Press.

Mezzadra, Sandro and Brett Nielson. 2013. Border as Method, or, The Multiplication of Labor. Durham, NC, and London: Duke University Press.

Millbank, Jenni. 2002. 'Imagining otherness: Refugee claims on the basis of sexuality in Canada and Australia', Melbourne University Law Review 26(1):144-77.

Millbank, Jenni. 2009a. 'From discretion to disbelief: Recent trends in refugee determinations on the basis of sexual orientation in Australia and the United Kingdom', International Journal of Human Rights 13:391-414. https://doi.org/10.1080/13642980902758218.

Millbank, Jenni. 2009b. “"The ring of truth": A case study of credibility assessment in particular social group refugee determinations', International Journal of Refugee Law 21:1-33. https:// doi.org/10.1093/ijrl/een040.

Noll, Gregor. 2005. Proof, Evidentiary Assessment and Credibility in Asylum Procedures. Leiden and Boston, MA: Martinus Nijhoff Publishers. 
OAR (Oficina de Asilo y Refugio). 2019. 'Asilo en cifras 2018'. Madrid: Ministerio del Interior, Secretaría General Técnica. Available at: http://www.interior.gob.es/documents/642317/ 1201562/Asilo_en_cifras_2018_126150899.pdf/bd2b18d8-bacf-4c2a-9d08-e1952d53a10a (accessed 14 July 2020).

Rodriguez, Juana María. 2003. Queer Latinidad: Identity practices, discursive spaces. New York: New York University Press.

Rodriguez, Juana María. 2014. 'Latino, Latina, Latin@'. In Keywords for American Cultural Studies (2nd edn), edited by Bruce Burgett and Glenn Hendler, 146-9. New York and London: New York University Press.

Spade, Dean. 2013. 'Intersectional resistance and law reform', Signs: Journal of Women in Culture and Society 38:1031-55. https://doi.org/10.1086/669574.

Spijkerboer, Thomas (ed.). 2013. Fleeing Homophobia: Sexual orientation, gender identity and asylum. Abingdon: Routledge.

UNHCR. 2013. Beyond Proof: Credibility assessment in EU asylum system. Brussels: UNHCR. Available at: https://www.unhcr.org/protection/operations/51a8a08a9/full-report-beyondproof-credibility-assessment-eu-asylum-systems.html (accessed 25 February 2020).

UNHCR. 2015. Protecting Persons with Diverse Sexual Orientations and Gender Identities: A global report on UNHCR's efforts to protect lesbian, gay, bisexual, transgender, and intersex asylumseekers and refugees. Geneva: UNCHR. Available at: https://www.refworld.org/pdfid/ 566140454.pdf (accessed 25 February 2020).

Viteri, María Amelia. 2008. "Latino" and "queer" as sites of translation: Intersections of "race", ethnicity and sexuality', Graduate Journal of Social Science 5:63-87.

Wessels, Janna. 2013. 'HJ (Iran) and HT (Cameroon) - Reflections on a new test for sexualitybased asylum claims in Britain', International Journal of Refugee Law 24:815-839. 
8

\title{
Between homonationalism and Islamophobia: comparing queer Caribbean and Muslim asylum seeking in/to the Netherlands
}

\author{
Keith E. McNeal and Sarah French Brennan
}

The turn of the twenty-first century in the Netherlands has witnessed a surge of xenophobic nationalism in relation to currents of migration from the former Dutch colonies and the néerlandophone Caribbean as well as from Turkey and Morocco. Dutch nationalists warn of the threat to national culture and its mythic tradition of liberalism - with gay liberation as the poster child - accompanied by especially prominent anxieties concerning Islam and Muslims. Reports concerning the ostensibly exceptional homophobia of Muslim communities have ignited moral panic over 'tolerating intolerance', a debate amplified by the dramatic increase in refugees and migrants to Europe in 2015. In a sociopolitical climate that has produced politicians such as Pim Fortuyn, who crusaded to end Muslim immigration to the country, and his more recent successor - Geert Wilders - who campaigned to ban the Qur'an and 'send Moroccans back', Islamophobia is a real political force. While many consider both politicians far-right extremists, their messages of moral panic concerning the 'Islamisation of the Netherlands' have nonetheless profoundly influenced national sentiment and shaped public discourse. Indeed, debates about multiculturalism, Islam and national identity have been particularly intense in the Netherlands (Bracke 2011).

As a growing number of analysts have observed, research is needed regarding the rise of homonationalisms correlated with increasing Islamophobia throughout the global North. This concerns not only conservative, far-right political parties and rhetoric but so-called liberals 
and progressives as well. As North Atlantic nation-states have come to embrace lesbigay rights as sacred commitments, they have also espoused intensified forms of Islamophobia - inverting the moral status of queer citizens by replacing the formerly abject homosexual Other-from-within with the newly ensconced Muslim Other-from-without. These corollary developments must be understood in terms of realignments within contemporary capitalism and the neoliberalisation of political culture, which drive the commodification and gentrified mainstreaming of certain aspects of queer culture along with fixation upon the circumscribed privileges of LGBT 'rights'. A further consequence of these interrelated developments has been the fetishisation of global Southern 'homophobia' as the homonationalist West's new Savage slot, which has necessitated Western disavowal of forms of homophobia from within (see Trouillot 2003 on the colonial genealogy of the 'Savage slot' in North Atlantic ideology).

Jasbir Puar (2013) defines 'homonationalism' as acceptance of lesbigay subjects as an index of both progress and national sovereignty, emphasising queer rights seen through the prism of legalisation and decriminalisation (also Duggan 2002). Homonationalism is institutional change that incorporates queer subjects into the nation-state through the legal recognition involved in overturning anti-sodomy laws, attaining gay marriage, obtaining queer adoption access and securing the right to serve openly in the military, among other developments, such as harbouring queer refugees and granting them asylum. As an assemblage, homonationalism is characterised by a host of developments that seek to 'normalise' lesbigay life by bringing it into the cultural mainstream, especially via the politics of representation and practices of consumption. And homonationalisms have also been increasingly working through Islamophobia in North Atlantic states and political cultures in complex and nefarious ways.

We take 'Islamophobia' to be an ideological assemblage involving overt and covert forms of discrimination against, denigration of, hostility to, and even violence towards Islam as a religion and Muslims as people. In this regard it can be considered a form of cultural racism that manifests in multifarious ways from housing and labour markets to political discourse and ideologies of citizenship. Debates rage concerning whether Islamophobia is akin to older forms of anti-Semitism in Europe (see Özyürek 2015, 8-13). Yet Matti Bunzl reminds us: '[W]hereas antiSemitism was designed to protect the purity of the ethnic nation-state, Islamophobia is marshaled to safeguard the future of European civilization' (2005, 506). Centuries of European merchant and dignitary 
accounts, as well as literary travel writing, show that as concepts of a culturally and geographically bound Europe began to develop, the 'Otherness' ascribed to Muslim nations created European identities as much as it said anything about countries in which the Muslim faith is practised (Said 1978; Scott 2007; Ewing 2008; Nussbaum 2012). The current monolithic construction of the Muslim as Europe's primary and negative Other emerged in the post-Cold War period and became ascendant with the West's post-9/11 War on Terror. Whereas an earlier state-based 'multiculturalist' paradigm in the United Kingdom, then in the Netherlands and later in Germany saw ethnic groups of migrant backgrounds as distinctive and separate, this began to change with the transgenerational development of non-white European minority populations (Chin 2017). Yet with post-industrial realignments in the capitalist world-system and the rise of neoliberal 'globalisation', discontents began brewing within European political space and 'migrants' became an easy scapegoat. Explicit anti-immigrant sentiment steadily gained ground among mainstream European politicians from the late 1980s and throughout the 1990s. The Muslim Other - seen as essentially patriarchal and conservative, therefore culturally backward and ostensibly outside the timespace of modernity - has also been constructed as inherently heterosexist and homophobic, pitting it against the ostensibly progressive values of European civilization that now equate women's and gay rights with democracy and freedom (Massad 2007; Butler 2008; Haritaworn, Tauqir \& Erdem 2008; El-Tayeb 2011, 2012, 2013; Shakhsari 2014; Haritaworn 2015; De Genova 2017; Scott 2018).

As a methodological strategy for investigating the ways these tense twin dynamics of homonationalism and Islamophobia manifest beyond the formal political and mainstream public spheres in the Netherlands, we compare and contrast the experiences of queer and transgender refugees and asylum seekers from the anglophone Caribbean - a largely nonMuslim region - and from Muslim-majority Middle Eastern countries as well as queer Muslims from Uganda. We examine how homonationalism and Islamophobia become operationalised at the 'border' of an empirical nation-state. Immigration control serves gate-keeping functions related to entangled nationalist, state and capitalist projects, the meanings and limits of which are always conflicted and changing. As Luibhéid (2005, xviii) observes, 'Border zones and detention centers not only disrupt the presumed homology between territory, nation, and citizenship, but also highlight the structured exclusions, limits, and ongoing violence through which normative constructions of nation, citizenry, and citizenship are actively produced and contested.' Indeed, queer migration trajectories 
are symptomatic of all the structural inequalities and political tensions they embody, traverse and negotiate (McNeal 2019). By considering asylum seeking as a modality of migration, our analysis reveals how the dialectics of homonationalism and Islamophobia play out within the border-and-migration apparatus of the world's great self-appointed national vanguard for gay liberation.

We do so in a relative statistical void. A study - 'Fleeing homophobia' (Jansen \& Spijkerboer 2011) - reported that an average of approximately 200 persons applied for asylum in the Netherlands annually around that time citing fear of persecution in their home countries for their sexual orientation or gender identity. The report estimates that some 10,000 LGBT-related asylum applications were submitted in the European Union annually around the beginning of the second decade of the twenty-first century. More recent estimates are difficult to come by. The EU Agency for Fundamental Rights estimated the number of asylum seekers in the Netherlands in 2016 with claims linked to sexual orientation and gender identity to be between one hundred and one thousand (EUFRA 2017). The source of those numbers herself told us that the report only serves to 'demonstrate the lack of reliable data' (Sabine Jansen, personal communication, 2017). In any case, immigration and customs statistics nonetheless suggest that successful acceptance rates for asylum seekers - for all reasons - in the Netherlands steadily rose from 40 per cent in 2010 to 70 per cent at the height of the European refugee crisis in 2015, then tapered back down to 54 per cent the following year (IND 2016). We see these trends as symptomatic of the onset of a Fortress Europe mentality more generally, inflected by Dutch tendencies. The lack of robust statistical information heightens the significance of ethnographic methods and materials.

We first consider the genealogy of contemporary Dutch political culture and the emergence of the Netherlands as a paradigmatic case of homonationalism. This sets the scene for our comparative examination of queer Caribbean and Muslim asylum seeking in the Netherlands, allowing us to examine differential operations of racism and racialisation within the border-and-migration regime as well as the ways being Muslim and the national politics of Islam play out in the experiences of queer and trans asylum seekers. In conclusion, we consider the comparative results of our investigation in relation to more recent developments in the Netherlands and Europe more broadly.

Among the populations considered here are individuals who are racialised in the Dutch context in varied and intersectional ways. Because the concept of biological race is so closely tied to the Holocaust 
in the post-war Dutch imagination, any allusion to race is strongly taboo, and anti-racism has become orthodoxy in Dutch legislation. Yet despite the 'powerful narrative of Europe as a colorblind continent, largely untouched by the devastating ideology it exported all over the world' (ElTayeb 2011, xv), as well as specifically Dutch efforts to project anti-racism as a national characteristic in the long shadow of World War II (Wekker 2016; Siebers 2017), colourism and racialisation are inextricable from the politics and experience of asylum. Whereas colour and biology are avoided in public discourse, yet tacitly at work, as our interlocutors attest, references to culture, religion and nationality have become potent signifiers of threat, unassimilability and Otherness - what some analysts refer to as the shift from biological to cultural racism.

A note on terminology: at the time of our studies (2014-18), 'LGBT' and sometimes 'LGBTI' (in Dutch, LHBTI: lesbienne, homoseksueel, biseksueel, trans, intersex) were the relevant legal categories for asylum seekers. The literature on queer and trans migration and asylum seeking also often employs the acronym SOGI, which refers to sexual orientation and gender identity. We use 'queer' here as a catch-all term at times for the sake of discussion; however, we are entirely mindful of complex and nuanced distinctions and differences related to sexual orientation and gender identity, especially between cisgender LGB and transgender forms of experience, as we also indicate along the way. Of course, questions of terms, labels and identifying oneself are culturally fraught and contextual. It was not uncommon for some individuals to use various terms at different moments to describe or refer to themselves, whereas others felt strongly associated with specific terms and did not deviate from those designations.

\section{Homonationalism and Islamophobia in the Netherlands}

The Netherlands is the archetypal case of homonationalism. It was the first country in the world to erect a monument to homosexual victims of the Holocaust, in 1987, and the first to legalise same-sex marriage in 2001, a year after legalising sex work (Hekma \& Duyvendak 2011). Amsterdam is widely seen as the world's gay capital, 'exemplifying the neoliberal creative city with its mixture of quaint architecture and edgy metrosexual culture, idyllic canals and multicultural markets, liberal drug and prostitution laws' (El-Tayeb 2011, 128). Central to the national imagination is the concept of 'tolerance', born of pragmatism in relation to the sociohistorical dynamics of very different earlier times. Yet this 
earlier 'pillar' system had collapsed by the end of the 1960s because of the sexual revolution, student revolt, the rise of the baby boomers and the promise of a liberal-bourgeois consumerist utopia. Thus the Dutch tradition of tolerance based on ecumenical non-interference morphed into one emphasising secular equality premised upon liberty of choice in consumption as the ideological basis for Dutch unity (van der Veer 2006, 118-24). But this ship began running aground in the late 1990s, and a new kind of populism, with xenophobic tendencies, emerged as difficulties in dealing with globalisation and immigration increased. Attacking conservative migrants and Muslims as signs of rejection of sexual liberty and consumerism became an assertion of a retrenched Dutch identity.

The emergence of Pim Fortuyn onto the political scene was the harbinger of this new dispensation. Throughout his 2002 campaign, the former-leftist-sociology-professor-turned-rightwing-journalist harped on the difference between the 'modern' Netherlands and the culturally 'backward' countries from which many migrants to the country originate. He touted his ability to be an out gay politician as evidence of enlightened Dutch tolerance. Fortuyn told the Volkskrant newspaper: 'In what country could an electoral leader of such a large movement as mine be openly homosexual? How wonderful that that's possible. That's something one can be proud of. And I'd like to keep it that way, thank you very much' (Poorthuis \& Wansink 2002). Fortuyn targeted Muslims in particular, railing against Islam as a 'hostile religion' and a 'backward culture'. His 1997 book Against the Islamisation of Our Culture advocated banning Muslims from entering the country. He intentionally provoked conservative imams, "because each time they responded with some diatribe about unnatural behavior and Western decadence, his supposed progressiveness only gained' (Lesage \& Asselberghs 2002). Before he was assassinated by a fellow Dutchman just six days before the national elections in May 2005, it was widely speculated that Fortuyn might well have ended up becoming the next Dutch prime minister. In an impressive posthumous debut, his newly leaderless party - Lijst Pim Fortuyn - nonetheless won an unprecedented 26 out of 150 seats in Parliament.

A rowdy new type of iconoclast, Fortuyn personified an emerging pro-gay, yet neoconservative populist, zeitgeist in spectacular form. Lesage and Asselberghs observe: 'Queer though he was, his ideas were square. His tough stance and simplistic solutions ensured that his mainly heterosexual constituents gladly forgave him his homosexual coquetry. His straight followers tended to overlook the fact that "their Pim" was gay. They didn't care: he gave voice to what they felt.' Fortuyn enabled the Netherlands to forthrightly homonationalise, embodying 
the transition to a sexualised - rather than asexual - sexual politics in an era of hyper-mediatisation and the commercialisation of citizenship. He was notoriously vulgar, publicly declaring his fondness for rimming and salaciously flaunting his love of young boys, once even infamously stating that he wanted the right to 'fuck young Moroccan boys without having to deal with their backward imams' (cited in van der Veer 2006, 120). Paradoxically, this vulgarity allowed him to pre-empt any potential scandal and offered resolution to the newly emergent dilemma of reconciling political power with an explicitly gay sexual life.

Indeed, Fortuyn 'understood like no other media celebrity that giving explicit details on his sexual activities would allow him to make his far bolder, blatantly racist and nonsexually intolerant statements unhindered' (Lesage \& Asselberghs 2002). He linked openness about homosexuality in politics with neoconservative ethno-nationalist recourse to racism and xenophobia: 'In the eyes of many an uneasy and concerned voter, the unabashed homosexual may well look like a tower of strength. Someone who dares to make an autonomous decision about his or her sexual identity - especially one so clearly unconventional - and manages to stay in control over the private sphere that is the body surely must stand out like a rock in a society that is subject to such rapid and radical change it practically seems adrift' (Lesage \& Asselberghs 2002). And his position on Islam, Muslims and migration was crystal clear. Sexuality should not be controlled but Dutch identity most certainly should. Gays can do what they want but outsiders must assimilate. Society cannot tolerate 'intolerance'.

Since Fortuyn's assassination in 2002, homosexuality has had 'an unprecedented centrality to Dutch politics' (Dudink 2017, 3) and has become more deeply entangled with Islam in public discourse, with further entrenchment of the notion that Muslims are unassimilable into Dutch culture. His death left a void in politics, and, while his party saw a huge win in the election just after his funeral, it had disbanded by 2006. Into the void stepped Geert Wilders, less bombastic than his predecessor, yet even more zealous in his campaign against Muslims. His apocalyptic warnings of the Islamisation of the country, calls for banning the Qur'an and declarations that Muslim migration means 'the end of European and Dutch civilization as we know it' (quoted in de Leeuw \& van Wichelen 2014 , 145) garnered international attention. For years, he has argued for a ban on immigration from Muslim countries, and his public remarks are so vitriolic that lawsuits have been brought against him for hate speech. In 2011 Wilders was found not guilty of inciting discrimination against and hatred of Moroccans and acquitted of all charges, although 
the presiding judge observed that his comments were on the 'edge' of acceptability. Wilders came under legal fire again for a 2014 speech railing against Muslims. Ironically, his defence centred on freedom of speech, although one of his most famous platforms is a book ban on the Qur'an. In December 2016, Wilders was finally convicted of inciting discrimination against Moroccans; yet the conviction came with no penalty (Darroch 2016).

In 2008, meanwhile, the populist politician Rita Verdonk - having recently founded her own short-lived party, Proud of the Netherlands (Trots op Nederland), after splitting from the liberal rightist VVD - opined that 'Dutch people simply do not have it in them to discriminate! We have been a hospitable people for centuries' (quoted in Balkenhol 2016, 278). However, echoing a sentiment that has become dispersed throughout the political spectrum, she continued by declaring: 'Enough! There are limits.' Those limits and the qualifications for inclusion are questions of great contention and enormous consequence. During Verdonk's tenure as Minister for Integration and Immigration in the 2000s, the government introduced a new immigration exam including questions about views on lesbians and gays and displaying an image of two men kissing. The addition of this component of the exam was prompted by concerns about allowing conservative Muslims to migrate into the country, effectively making lesbigay rights part of the litmus test for Dutch citizenship (Hekma \& Duyvendak 2011, 626-7). Being Dutch meant being progay. Never mind the fact that 42 per cent of Dutch natives interviewed around the same time reported disliking seeing two men kissing in the street (Keuzenkamp et al. 2006, 36). Indeed, a study of homophobia in the Netherlands (Keuzenkamp \& Kuyper 2013) suggests that Dutch social acceptance of queers lags behind state recognition of legal equality and that lesbigay Dutch norms are overwhelmingly cisgender (also see Hekma \& Duyvendak 2011). Buijs, Hekma and Duyvendak (2011) identify gender conservatism underlying patterns of anti-gay violence in the Netherlands among perpetrators who otherwise espouse the prevailing gay-tolerant rhetoric. It is additionally revealing that certain groups are exempted from taking the immigration gay litmus test: EU nationals, asylum seekers, skilled workers who make more than €45,000 per year, and citizens of the USA, Australia, New Zealand, Canada, Japan and Switzerland, 'where presumably homophobia is not to be found or where, rather, importing impressive income levels clearly preempts concerns over importing homophobia' (Butler 2008, 4).

In the wake of vociferous anti-refugee rallies throughout the country, accompanying rancorous public debate about resettlement, 
and demands by Wilders that Muslim men should be incarcerated, the ruling against him in late 2016 for inciting discrimination against Muslims came three months before a general election. Wilders vowed to put migration and 'Islamisation' at the heart of his campaign, pledging to close every mosque in the Netherlands and ban the Qur'an from public buildings. On the heels of Trump's election in the USA, opinion polls put his PVV in front with 24 per cent of the vote, ahead of his nearest rival, the Liberals (VVD), led by the prime minister, Mark Rutte. The latter decried Wilders's remarks, yet had himself promised, in 2011, to 'return this beautiful land to the Dutch, because that is our project', trafficking in political discourse that framed 2nd-, 3rd- and even 4th-generation non-white Dutch as 'migrants' and 'allochthons' (El-Tayeb 2011; Wekker 2016). Rutte's VVD won in 2017 but lost parliamentary seats. Political commentators noted that Rutte benefited from his recent hardline stance in a diplomatic standoff: he refused to allow two Turkish government ministers to address rallies in Rotterdam about a referendum expanding President Recep Tayyip Erdoğan's powers. Wilders's PVV came in second place, gaining 12 parliamentary seats.

The 2018 municipal elections saw the emergence of yet another new nationalist party - the Forum for Democracy (FVD), led by Thierry Baudet, which touts native Dutch cultural superiority and denounces the European Union - that suggests a splintering within the country's far right. The party competed only in Amsterdam, traditionally a liberal bulwark, where it gained 4.9 per cent of the vote, and national polls placed it as the third most popular party in the Netherlands. Baudet is an avowed admirer of Trump who espouses explicitly sexist and racist views, claiming that the Dutch are being 'diluted' by 'mixing' with people from all over the world. His party has drawn adherents from the PVV, which polled seventh in the nation despite having the second-largest representation in Parliament. The PVV launched a high-profile ad campaign claiming that 'Islam is Discrimination' in bold red block letters flashing on the television screen accompanied by a booming musical score, then by an ominous drumbeat soundtrack. 'Discrimination' was sequentially switched to 'Violence', then 'Terror', then 'Jewish Hate', ending on 'Christian Hate' (Egherman 2018). The VVD retained primacy in the municipal elections, with Rutte campaigning against preferential housing treatment for refugees and asylees (Sterling 2018). Then, in the 2019 elections, Baudet's FVD gained a significant number of parliamentary seats, tying with Prime Minister Rutte's VVD as one of the country's two largest parties. Wilders's PVV lost seats because many of its supporters realigned with the ascendant FVD. 


\section{Seeking queer asylum in the Netherlands}

When someone seeks SOGI-based asylum in the Netherlands, their official journey usually begins at one of two places. If arriving and claiming asylum at Amsterdam's international airport, they are likely to begin processing at the Schiphol centre. However, most people apply for asylum at the immigration reception centre at Ter Apel in the north-east Netherlands, just across the border from north-west Germany. There they will be registered, have their identities verified and undergo a health screening. According to the Centraal Orgaan Opvang Asielzoekers (COA), the organisation charged with reception of asylum seekers, this facility is meant for short-term stays of a maximum four days, but we have found that some people stay for weeks. Next they are moved to a 'process reception location' for what is supposed to be no more than 12 days, and then to an Asielzoekerscentrum (asylum seekers' centre, AZC) - commonly known as 'camps' - until the resolution of their case. During this time they will be interviewed by asylum officials, have access to a lawyer and be provided with healthcare, housing and a small stipend. Conditions in residential asylum centres vary considerably and placement seems to be somewhat luck-of-the-draw. An asylum seeker may share a room with several others or have a room of their own; some centres provide all meals; others have individual or shared kitchen facilities and grocery stipends; some are located in the outskirts of cities, whereas others are more rural or remote and difficult to access by public transport. In some cases, lesbians, gay men and transgender people are housed together on the assumption that they will get along better, although this is not always the case, especially when those involved hail from different countries and backgrounds, as a number of our interlocutors attest.

Because the asylum process requires that a judge in the Netherlands determines whether an asylum seeker is credible in their assertion that they are (1) eligibly LGBT and (2) justifiably fearful of persecution in their home country, there is an embedded assumption not only of the universality of the sexual categories and the experience of persecution but that both are readily recognisable and understandable by many judges. 'Country reports' compiled by various NGOs and other sources may be available for use by these judges to assess the credibility of an asylum seeker's story against the known circumstances in their home country. However, how these reports are used seems to vary widely. While some judges inform themselves about the cultural diversity of sexual expression and understandings throughout the world, others use the report to 
add colour to existing stereotypes or neglect the content of the reports altogether. The reports may themselves be partial or problematical concerning social conditions in asylum seekers' countries of origin, and their use - and abuse - as 'expert' documents within the legal bureaucratic matrix often extends well beyond the meanings and intentions of their authors (Murray 2017; McNeal 2019).

There have been various cases across Europe - including in the Netherlands - in which an asylum claim is denied because the applicant's appearance and story do not fit stereotypes of what an LGBT individual is assumed to look like, act like, know about and experience in their home country. Others have been denied because the applicants were not familiar with the laws on homosexual behaviour or with the gay and lesbian bars in their countries of origin. Applicants who are married to a person of another sex or who have children have also been denied because they do not fit conventional notions of being queer or trans. These examples demonstrate that not only stereotypes about LGBT individuals but also preconceptions about the home countries and cultural backgrounds of the applicants are used in adjudicating these cases. (In this chapter, we do not address complex questions of 'homophobia' and SOGI liveability in countries of origin, issues which deserve their own full attention and interrogation and which of course vary considerably from country to country.)

\section{From the Caribbean}

The majority of queer and transgender refugees from the anglophone Caribbean who come to the Netherlands hail from Jamaica and the twinisland Republic of Trinidad and Tobago (TT), two of the largest nationstates in the region in which homosexuality has been against the law, although a legal challenge in 2018 overturned TT's anti-sodomy legislation and is now under appeal by the government. McNeal's research in the Netherlands has focused upon asylees from TT, yet everything he has learned about Jamaicans migrating there under similar circumstances suggests strong parallels with the portrait painted of Trinbagonians. The Dutch Immigration and Naturalisation Service (IND) does not release statistics based on SOGI asylum claims, but, since most people seeking asylum from the anglophone Caribbean do so on the basis of sexual orientation and gender identity, the total number of first-time asylum applications from these countries (IND 2018a) gives us some sense of the number of queer and trans asylum seekers entering the country. The number of Trinbagonian asylum applicants has steadily increased, from 
nine in 2015 to 22 in 2016 and to 34 in 2017, whereas Jamaican application rates have decreased, from 68 in 2015 to 34 in 2016 and to 14 in 2017 , for reasons we discuss below regarding the 2016 reclassification of Jamaica as a 'safe' country of origin.

Indeed, until recently, the trajectories and success rates of anglophone Caribbean asylum seeking based on sexuality or gender expression largely confirms a robust view of homonationalist Dutch commitments, with most claimants either receiving asylum on the basis of their initial application or, if initially rejected, by successfully navigating the appeal process. The problem of Islamophobia is largely kept in abeyance in this context, given that most queer and trans Caribbeans seeking asylum in the Netherlands are not Muslim, and those few that are (usually of South Asian descent) are not especially pious, and the fact that they come from a regional background not coded as Muslim substantially recontextualises whatever residual religious identity they may carry. These circumstances enable queer anglophone Caribbeans to sidestep the most egregious manifestations of Dutch xenophobia within the refugee and asylum system. Paradoxically, these asylum seekers benefit rhetorically from another form of racialised imagery: the dominant global stereotype of the Caribbean - and Jamaica in particular - as virulently 'homophobic' societies from which one would naturally flee in search of freedom. The Dutch state may therefore function ideologically as the benevolent homonationalist patron, saving queer Caribbeans from their own 'backward' societies without adding any more 'problematic' Muslims into the national mix.

This dynamic is exemplified in an online publication by the IND (2018b) featuring a testimonial by a 37-year-old gay man from Tobago, with the emboldened headline, 'The Netherlands equals freedom to me'. The accompanying subheadline explains: 'As a gay man from Trinidad and Tobago, Jason Williams had to keep his nature secret for years. Now he can talk freely: "I want a life without fear, because fear is always present in my country." Williams travelled to the Netherlands via Curaçao in 2016, applying for asylum immediately upon arrival at Schiphol. The first full quotation from him focuses on his engagement with Dutch immigration officials at the airport: 'I was anxious and insecure and walked to the Marechaussee. An official asked kindly what he could do for me. I told him while crying that I wanted to apply for asylum because I am gay and fear for my life. The man tried to put me at ease and said "we will take care of you". That felt so warm and welcoming to me, it was as if a load fell from my shoulders.' Williams is next quoted reporting the hostility and maltreatment he faced at home in TT: 'I was constantly afraid to 
be open about my sexual preference. Gay men are regularly maltreated, threatened and even killed. I too have been attacked, because although I didn't tell anything myself, apparently people react to my behaviour and draw their conclusions from it. I was so terribly afraid of my life and what the future would bring me.' Regarding his questioning by asylum agents, 'My contact with the IND went well. The IND official also tried to put me at ease.' He continues by briefly commenting upon his time in a refugee camp in the small southern Dutch town of Baexem, where he notes experiencing 'a cultural shock' in the midst of so many different people from all over the world, and even notes how he had to remain closeted there in order to protect himself, only able to be fully himself while out of the camp attending gay parties in the glitzy city of Eindhoven. But his time in the camp passed more or less uneventfully and he was eventually placed in housing in the small nearby town of Brunssum after being granted asylum. 'The Netherlands equals freedom for me; you can live your life as you wish,' he observes. Aspiring to master the Dutch language, move to a larger city and find proper work, Williams concludes: 'I have now reached a point where I feel comfortable. My life has started again, I feel really reborn.'

Something specific about the Trinbagonian asylum scene in the Netherlands is that a relatively high proportion of the asylees are transgender, the rest consisting of gay men alongside a few lesbians. Intensified patterns of transgender refugeeism seem to be the result of cumulative network migration developing in the wake of the first three trans Trinbagonian asylum migrations in 2011, combined with the push effects of newly emergent patterns of Western-style homonormativity among queer Trinbagonians at home. This latter dynamic is not only due to intergenerational change in line with late modern patterns of postcolonial globalisation and the circulation of global Northern homonationalist media and politics, but also hedged in by an intensifying international political economy of homophobia promulgated by North American evangelicals on a global mission to 'defend family values'. These transformations have created a pressure towards a certain sort of lesbigay respectability and 'normalisation' that leaves less room for the full spectrum of queer expression - and especially for transgender liveability - in TT. The local battle against homophobia has therefore tended to seek its gains at the expense of trans people, leaving transgender Trinbagonians in the lurch (see McNeal 2020).

Overall, anglophone Caribbean acceptance rates for Dutch asylum based on sexual orientation and gender identity are high compared with those of the United Kingdom, where they are strikingly low (see McNeal 
2019). Every Trinbagonian asylee McNeal has spoken with has attested that they are able to live more openly regarding their sexuality or gender in the Netherlands, but were shocked to discover how racist Dutch people can be. 'I never thought I'd come here to finally be myself and have to deal with the colour of my skin!' one trans woman complained. In this regard, queer and trans Caribbean asylees perceive both openings for and limits to their 'integration' into Dutch culture. They are confronted not only by the legacies of colonial racism but also by contemporary xenophobic nationalism. Yet their relationship to this early twenty-first-century ethno-nationalist ideology is complex, ambivalent and paradoxical as non-Muslims. Indeed some but certainly not all - have come to evince forms of Islamophobia in their attitudes towards the Muslim migrants they are exposed to or interact with in the refugee camps as well as in Dutch society more generally, sentiments they may post and comment about on social media platforms. We interpret this as a painfully poignant index of their ultimate structural inability as non-white would-be citizens to fully 'integrate' into the national body politic. This interpretation is akin to Aihwa Ong's (2003) findings concerning Cambodian refugees in the USA learning their place in the racial order through interpellation by national structures of governmentality. In other words, they are ready to critique and push back against the colonial legacy of colour-based racism on the basis of their experiences as non-white queer migrants, but nonetheless also imbibe forms of Islamophobia circulating in homonationalist political culture.

This brings us to the question of queer asylum seekers from Muslimmajority countries of origin and from Uganda, which is not Muslimmajority, but has a sizeable Islamic population, from which a number of queer refugees hail.

\section{From the Muslim Middle East and Africa}

Muslim LGBT asylum seekers come to the Netherlands from a wide swathe of the globe, primarily North Africa, the Middle East and South Asia, although Brennan's informants are largely Iraqi, Iranian, Syrian and Ugandan. Only one person in the study was trans and she is Moroccan. Men who identified themselves as gay predominated among asylum seekers from the Middle East but the Ugandan group was somewhat less starkly split between queer men and women in this study's population. Differences in mobility, financial resources and family responsibilities between men and women may account for some of this sexed disparity. As a young Egyptian man put it, if parents find out a child is queer, 'gay men are kicked out of the house; lesbian women are locked in'. 
It may be that there are also stronger pull factors for men than for women: globalised images of 'authentic' gay male lifestyles are much more social, urban and linked to specific kinds of communal spaces. The image of gay bars in Western cities has become a potent symbol as a central space in gay life. Manalansan (2003) argues that the gay bar has come to be seen as a universal 'home' to gay men everywhere, limited though it may be as a largely privileged, white gay male space. As one gay Syrian asylum seeker voiced it, 'Look at me! Before, I never, never go to a bar in my life in Syria. Not possible. Now, I can go, and I can meet friends, I can dance there. I feel home.' Of course, economic, cultural and ethnoracial barriers make this image of the gay bar as home available only to some. Still, for queers imagining their options when confronted by fear and threat in home communities, some men may have a sharper image in their minds of a new 'home' to which they can flee, making it a more thinkable terminus. Social networking and dating websites, very popular among young migrants, also provide a conduit for network migration, as is also the case among Caribbeans.

Many echoed Caribbean asylee sentiments about feeling freer in terms of their sexuality and gender expression in the Netherlands. But most experienced a dramatic contrast with their Caribbean counterparts when it came to their religious backgrounds and identity, feeling that they must hide their religious beliefs from authorities to varying degrees. Almost all were asked in asylum interviews about their religion. For many, questions to the effect of 'How can you be both gay and Muslim?' left asylum seekers with the sense that they must disavow their faith or face deportation. A young Iraqi man who had received asylum several years earlier recounted that he had felt that even his attorney did not believe that he could both 'really be gay' and 'really be Muslim'. His friend chimed in: 'The Dutch, they don't understand this. It's like an impossible thing', to which the Iraqi man responded, 'Understand what? I just am!' A Ugandan woman who did not want to disclose her legal status said several times that she thought asylum officials were 'very suspicious' of any queer person who was a practising Muslim. Several other queer Muslim asylum seekers stated that they felt targeted and that they did not believe asylum seekers of other religions would be asked such leading questions, or about their religions at all.

Not everyone had this view of asylum officials and procedures, however. Others reported feeling that their religious beliefs were 'respected', in part because Muslim prayer schedules and dietary restrictions were honoured, and because questions about religion in interview sessions were perceived as understandable and 'normal', rather than intrusive or 
hostile. Reports of treatment at the residential asylum centres and in the surrounding communities were similarly varied but, particularly in more rural areas, asylum seekers have had some trouble with local residents. One woman reported that in a grocery store another shopper asked her about her headscarf in a way that was 'not friendly', which made her feel unsafe and hypervisible afterwards. More commonly, asylum seekers said they 'got looks' from locals or were ignored altogether.

Middle Eastern and North African asylum seekers were especially aware of debates in the Netherlands about refugees. A Syrian man who was proud of how much Dutch he had managed to teach himself, mostly by watching TV and reading the newspapers that were offered at his asylum centre, described the anxiety of feeling unwanted and recounted a 'crazy' moment in which he was trying to read a newspaper article - in Dutch - about how Syrian refugees do not want to integrate and learn Dutch. While many - perhaps conscious of their precarious legal and social position in the country - preferred not to comment on it, others expressed some resentment that measures they had taken to stay alive appeared to be such an imposition in this host country. 'I don't want to be here either!' declared one young man. 'Of course I prefer to be in my country, but I cannot.' This position is all the more poignant in the light of the legacies of European colonialism in the Middle East and Africa and the wars and military interventions of recent decades.

Asylum seekers are often clustered according to nationality and language in Dutch refugee camps, and queer asylum seekers - more of whom arrive alone than non-queer asylum seekers - frequently find themselves housed with people they fear share the homophobia they have fled from. Several incidences of harassment and aggression against queer asylum seekers living in the camps have been reported, resulting in the establishment in Amsterdam in 2016 of a residential centre specifically for queer asylum seekers. However, most queer asylum seekers are not able to live in this centre because of its limited capacity, and many find themselves afraid to be open about their sexualities or associate with other queer asylum seekers. As a result, these individuals do not always form the social networks that connect them with queer organisations in the Netherlands, which may have a detrimental effect on their asylum applications, since demonstrating participation in gay life since arriving in the Netherlands may be useful in establishing credibility as queer in an asylum claim. Queer Muslims are not the only SOGI asylum seekers targeted with the aggression referred to above, but several interviewed by Brennan reported incidents of harassment, and the majority of media reports on this topic discussed violence against Muslim or Middle Eastern queer asylum seekers. 


\section{Seeking asylum between homonationalism and Islamophobia in Fortress Europe}

While it is more difficult to ascertain success rates among Muslim asylum seekers from the Middle East and Africa than among those from the Caribbean, given the demographics and the number of countries involved, our overall impression is that the Netherlands border-andmigration system is in fact generally predisposed to grant asylum to queer and transgender applicants - or at least was until very recently. These trends reflect strong Dutch homonationalist commitments, as compared with the United Kingdom, where queer asylum acceptance rates are quite low despite homonationalist pronouncements to the contrary (McNeal 2019). In this regard, we must appreciate that the Netherlands is willing to extend the benefits and privileges of full LGBT rights not only to its native citizens but also to some queers seeking asylum from around the world. Indeed, 'saving' LGBT Caribbeans from their own 'homophobic' societies ideologically bolsters Dutch homonationalist identity.

Yet things are less straightforward when it comes to queer Muslim asylum seeking precisely because of the Islamophobia factor. On the one hand, the dynamic is similar, ostensibly saving non-white people from their own 'backward' societies; yet on the other hand, queer Muslims from the Middle East and North Africa must navigate the realities of Dutch Islamophobia within the migration system, the refugee camps and society at large. They realise that they must often distance themselves from their religious backgrounds and commitments in the midst of the asylum assessment process in order to make it through. In other words, queer Muslims must often relocate from the sexual to the religious closet.

Seen in a different light, however, granting queer Muslim asylum may be a type of exception to the anxiety over Muslim migration that has panicked Europe for decades. In a speech railing against 'the rising tide of Islam' and calling for the halt of migration to the Netherlands, for example, Wilders mentions homosexuals being jailed and threatened in Iran and stipulates that, 'when it comes to asylum-seekers, it's a different story' (quoted in Dowling 2013). Queer Muslims become tolerable because they are seen as subverting Islam, a religion that has been stamped exceptionally and uniquely homophobic in the public imagination. What is seen as exceptionalism within their faith makes them desirable members of the nation. They also work as an ideological buffer against accusations of racism, as their admission seems to say: We're not Islamophobic - look at these queer Muslims we saved from their culture. Moreover, queer refugees do not evoke the spectre of hyperfertility linked 
to the 'demographic threat' that has figured so prominently in discourses concerning Muslims in Europe.

In addition to the patterns and dynamics we outline here, however, there is a larger problem now materialising in a time-released fashion in response to the increase in numbers of asylum seekers in Europe that climaxed in 2015. While spikes in the numbers of asylum seekers have been seen periodically since the concept of asylum was codified in 1951, the apocryphal language and imagery - largely Islamophobic and xenophobic - employed by mainstream politicians and media in the mid2010s has resulted from a 'perfect storm' of social, economic and political currents dating back to the 1970s (Lucassen 2018), which catalyses an intensified Fortress Europe mentality across the continent (De Genova 2017). These developments have brought about loud and rancorous debate and discourse about national identity, immigration and security, especially in the Netherlands, as discussed above. We noted earlier that the overall asylum acceptance rates in the Netherlands rose steadily during the first half of the second decade of the twenty-first century, from 40 per cent in 2010 to 70 per cent in 2015, falling back to 54 per cent in 2016. If this pattern indicates a trend, and we increasingly believe, on the basis of what we have been seeing and hearing anecdotally since 2017, that it does, then one should not be surprised to witness continued falling rates of asylum acceptance in the coming years, with consequences for queer and trans asylum seeking.

Indeed, it is telling that Jamaica was reclassified as a 'safe' country of origin by the Netherlands in 2016, although an exceptional clause was retained in the policy regarding LGBT asylum seekers from there (AIDA 2016). Yet as we noted above, most asylum seeking from Jamaica is based on SOGI claims, and the number of asylum applications made in the Netherlands by Jamaicans dipped precipitously in the wake of Jamaica's reclassification. Therefore the possibility of future queer asylum seeking from the Caribbean nation seen by many as the most homophobic in the region has, to all intents and purposes, been undermined. And closing down the possibility of queer asylum seeking from the country that has generated the highest percentage of queer and trans anglophone Caribbean asylees effectively decreases the overall rate of asylum seeking from the region more generally. Moreover, TT was also reclassified as a safe country of origin in 2017, with a similar clause noting that LGBT claimants may still be considered (AIDA 2017). And there is every reason to expect that what happened with Jamaica will happen with TT as well, especially since it is not as infamous as Jamaica for its homophobia (and the eventual resolution of TT's 2018 High Court case will definitively 
reset the rules of the game). In fact reports from Trinbagonian asylees in the Netherlands claim exactly this to be the case. These developments are difficult to decipher except in the light of the border tightening associated with Fortress Europe. Indeed, a range of activists, advocacy organisations, lawyers, and asylum seekers themselves, have reported that overall rejections of queer asylum applications are on the rise, so much so that a formal protest regarding the matter was held outside the Dutch Parliament in October 2017 (Rainey 2017).

Because of their differently positioned backgrounds, queer and transgender asylum seekers from different countries of origin encounter and navigate different patterns of experience in the Netherlands, somewhere between homonationalism and Islamophobia, whose logics play out in perversely intertwined ways. Indeed our findings corroborate a view of Dutch nationalism and political culture as characterised by the twin dynamics of homonationalism and Islamophobia operationalised within the border-and-migration apparatus. Yet we also see evidence of change, complexity, slippage and contradiction. For example, an intensifying preoccupation with 'credibility' and the problem of 'fraud' suggests that denying queer asylum claims on the basis of lack of credibility enables Dutch officials to maintain an ideological commitment to homonationalism while cutting back on the number of queer migrants granted asylum and eventually citizenship.

Another important sign of possible change concerns the experience of a gay Trinbagonian man who entered the Netherlands in June 2017 and was asked, several weeks into his time in the refugee camp, to 'tone it down' regarding his gayness and to take his rainbow flag down from his bedroom door in order to respect fellow Muslims in the camp. This was a distressing experience for him and served only to fuel both anti-Muslim sentiment and a criticism of repressive camp authorities. He could not believe that this would be possible in the land of gay liberation. This is but one anecdote, of course, yet it does not embody any simplistic characterisation of the immigration system as militantly homonationalist and unremittingly Islamophobic. Perhaps an emerging national consciousness about overreach in expressions of Dutch Islamophobia - exemplified by the symbolic censure of Geert Wilders - may be fostering an ever so slight, yet significant, rethinking of Islamophobic attitudes.

We would like to close our discussion with a final anecdotal note. At the time of writing (2019), two of the 14 transgender Trinbagonian women asylees in the Netherlands have Afghani boyfriends, whom they met in their respective refugee camps. In many regards, the two couples have very different experiences from one another but, taken together, 
we see them as representing new vectors of convergent queer globalisation as well as accentuating the significance of viewing the immigrationand-asylum system as a microcosm of Dutch globalisation more generally - indeed central, rather than marginal, to twenty-first-century Dutch society. These relationships are a poignant counterpoint to other queer Caribbean asylees mentioned earlier who have begun espousing Islamophobic attitudes as a result of their partial assimilation to Dutch society and political culture. Thus while our comparative analysis of queer asylum seeking corroborates a view of the perversely twinned significance of homonationalism and Islamophobia as operationalised within the Dutch border-and-migration system, we want to conclude by highlighting signs of change and contradiction as well as unintended social consequences emerging from below.

\section{References}

AIDA (Asylum Information Database). 2016. Netherlands: The expanding list of safe countries of origin. Available at: http://www.asylumineurope.org/news/24-02-2016/netherlandsexpanding-list-safe-countries-origin (accessed 15 February 2018).

AIDA (Asylum Information Database). 2017. Netherlands: Safe country of origin. Available at: http://www.asylumineurope.org/reports/country/netherlands/asylum-procedure/safecountry-concepts/safe-country-origin (accessed 1 January 2018).

Balkenhol, Markus. 2016. 'Silence and the politics of compassion: Commemorating slavery in the Netherlands', Social Anthropology 24:278-93. https://doi.org/10.1111/1469-8676.12328.

Bracke, Sarah. 2011. 'Subjects of debate: Secular and sexual exceptionalism, and Muslim women in the Netherlands', Feminist Review 98:28-46. https://doi.org/10.1057/fr.2011.5.

Buijs, Laurens, Gert Hekma and Jan Willem Duyvendak. 2011. "'As long as they keep away from me": The paradox of antigay violence in a gay-friendly country', Sexualities 14:632-52. https://doi.org/10.1177/1363460711422304.

Bunzl, Matti. 2005. 'Between anti-Semitism and Islamophobia: Some thoughts on the new Europe', American Ethnologist 32:499-508. https://doi.org/10.1525/ae.2005.32.4.499.

Butler, Judith. 2008. 'Sexual politics, torture, and secular time', British Journal of Sociology 59:123. https://doi.org/10.1111/j.1468-4446.2007.00176.x.

Chin, Rita. 2017. The Crisis of Multiculturalism in Europe: A history. Princeton, NJ: Princeton University Press.

COA (Centraal Orgaan opvang asielzoekers). 'Shelter in different types of reception centres'. Available at: https://www.coa.nl/en/shelter-different-types-reception-centres (accessed 7 August 2020).

Darroch, Gordon. 2016. 'Geert Wilders found guilty of inciting discrimination', The Guardian, 9 December. Available at: https://www.theguardian.com/world/2016/dec/09/geert-wildersfound-guilty-in-hate-speech-trial-but-no-sentence-imposed (accessed 2 March 2018).

De Genova, Nicholas (ed.). 2017. The Borders of 'Europe': Autonomy of migration, tactics of bordering. Durham, NC: Duke University Press.

de Leeuw, Marc and Sonja van Wichelen. 2014. 'Doing “integration” in Europe: Postcolonial frictions in the making of citizenship'. In Gender, Globalization, and Violence: Postcolonial conflict zones, edited by Sandra Ponzanesi, 145-60. New York: Routledge.

Dowling, James. 2013. 'Protesters call Dutch MP Geert Wilders a racist as he calls for end to mass migration from Islamic countries', Herald Sun, 20 February. Available at: http://www. heraldsun.com.au/news/victoria/protesters-call-dutch-mp-geert-wilders-a-racist-as-he-callsfor-end-to-mass-migration-from-islamic-countries/news-story/491ec48ee31ab469f9ec18dc 16b43895?sv=a3ec0332d266bff414f798c2edd6cb24 (accessed 11 June 2017). 
Dudink, Stefan. 2017. 'A queer nodal point: Homosexuality in Dutch debates on Islam and multiculturalism', Sexualities 20:3-23. https://doi.org/10.1177/1363460716642153.

Duggan, Lisa. 2002. 'The new homonormativity: The sexual politics of neoliberalism'. In Materializing Democracy: Toward a revitalized cultural politics, edited by Russ Castronovo and Dana D. Nelson, 175-94. Durham, NC: Duke University Press.

Egherman, Tori. 2018. 'Anti-Islam TV spot in the Netherlands has Dutch calling for more love, less hate', Global Voices Online, 20 March. Available at: https://globalvoices.org/2018/03/20/anti-islam-tvspot-in-the-netherlands-has-dutch-calling-for-more-love-less-hate/ (accessed 1 December 2018).

El-Tayeb, Fatima. 2011. European Others: Queering ethnicity in postnational Europe. Minneapolis: University of Minnesota Press.

El-Tayeb, Fatima. 2012. 'Gays who cannot properly be gay: Queer Muslims in the neoliberal European city', European Journal of Women's Studies 19:79-95. https://doi.org/10.1177/ 1350506811426388.

El-Tayeb, Fatima. 2013. 'Time travelers and queer heterotopias: Narratives from the Muslim underground', Germanic Review: Literature, Culture, Theory 88:305-19.

EUFRA (European Union Agency for Fundamental Rights). 2017. 'Current migration situation in the EU: Lesbian, gay, bisexual, transgender and intersex asylum seekers', 24 March. Available at: http://fra.europa.eu/en/publication/2017/march-monthly-migration-focus-lgbti (accessed 1 May 2017).

Ewing, Katherine Pratt. 2008. Stolen Honor: Stigmatizing Muslim men in Berlin. Stanford, CA: Stanford University Press.

Haritaworn, Jin. 2015. Queer Lovers and Hateful Others: Regenerating violent times and places. Chicago, IL: University of Chicago Press.

Haritaworn, Jin, Tamsila Tauqir and Esra Erdem. 2008. 'Gay imperialism: Gender and sexuality in the "war on terror"'. In Out of Place: Interrogating silences in queerness/raciality, edited by Esperanza Miyake and Adi Kuntsman, 71-95. York: Raw Nerve Books.

Hekma, Gert and Jan Willem Duyvendak. 2011. 'Queer Netherlands: A puzzling example', Sexualities 14:625-31. https://doi.org/10.1177/1363460711422303.

IND (Immigration and Naturalisation Service). 2016. 'De IND in 2016: Jaarverslag' (annual report). Available at: http://cdn.instantmagazine.com/upload/2392/ind_jaarverslag_2016. d1ec3734061a.pdf (accessed 1 December 2015).

IND (Immigration and Naturalisation Service). 2018a. 'Asylum trends'. Available at: https://ind.nl/en/ about-ind/figures-and-publications/Pages/Asylum-Trends.aspx (accessed 17 February 2019).

IND (Immigration and Naturalisation Service). 2018b. 'Stories: "The Netherlands equals freedom to me"'. Available at: https://ind.nl/en/about-ind/stories/Pages/\%27The-Netherlandsequals-freedom-to-me\%27.aspx (accessed 17 February 2019).

Jansen, Sabine and Thomas Spijkerboer. 2011. 'Fleeing homophobia: Asylum claims related to sexual orientation and gender identity in Europe'. Vrije Universitiet, Amsterdam. Available at: http://www.refworld.org/docid/4ebba7852.html (accessed 21 July 2017).

Keuzenkamp, Saskia, David Bos, Jan Willem Duyvendak and Gert Hekma. 2006. Gewoon Doen: Acceptatie van homoseksualiteit in Nederland. The Hague: Sociaal en Cultureel Planbureau (SCP).

Keuzenkamp, Saskia and Lisette Kuyper. 2013. 'Acceptance of lesbian, gay, bisexual and transgender individuals in the Netherlands'. Netherlands Institute for Social Research. May 16. Available at: https://www.scp.nl/english/Publications/Publications_by_year/ Publications_2013/Acceptance_of_lesbian_gay_bisexual_and_transgender_individuals_in_ the_Netherlands_2013 (accessed 21 July 2017).

Lesage, Dieter and Herman Asselberghs. 2002. 'Homo politicus. Pim Fortuyn: A case study', Lecture, B-Visible Laboratory, Arts Centre Vooruit, Ghent, 5 November. Available at: http:// sarma.be/docs/2846 (accessed 31 March 2016).

Lucassen, Leo. 2018. 'Peeling an onion: The "refugee crisis" from a historical perspective', Ethnic and Racial Studies 41:383-410. https://doi.org/10.1080/01419870.2017.1355975.

Luibhéid, Eithne. 2005. 'Introduction'. In Queer Migrations: Sexuality, U.S. citizenship, and border crossings, edited by Eithne Luibhéid and Lionel Cantú, Jr, ix-xlvi. Minneapolis: University of Minnesota Press.

Manalansan, Martin F. 2003. Global Divas: Filipino gay men in the diaspora. Durham, NC: Duke University Press.

Massad, Joseph A. 2007. Desiring Arabs. Chicago, IL: University of Chicago Press. 
McNeal, Keith E. 2019. 'Confessions of an ambivalent country expert: Queer refugeeism in the UK and the political economy of (im)mobility in and out of Trinidad and Tobago', Anthropological Theory 19:191-215. https://doi.org/10.1177/1463499618812600.

McNeal, Keith E. 2020. 'Level 5: Betwixt-and-between "homophobia" in Trinidad and Tobago'. In Beyond Homophobia: Centring LGBTQ experiences in the anglophone Caribbean, edited by Moji Anderson and Erin MacLeod. Kingston, Jamaica: University of the West Indies Press.

Murray, David A. B. 2017. 'The homonational archive: Sexual orientation and gendered identity refugee documentation in Canada and the USA', Ethnos 82:520-44. https://doi.org/10.1080/ 00141844.2015 .1080747$.

Nussbaum, Martha C. 2012. The New Religious Intolerance: Overcoming the politics of fear in an anxious age. Cambridge, MA: Harvard University Press.

Ong, Aihwa. 2003. Buddha is Hiding: Refugees, citizenship, the new America. Berkeley: University of California Press.

Özyürek, Esra. 2015. Being German, Becoming Muslim: Race, religion, and conversion in the new Europe. Princeton, NJ: Princeton University Press.

Poorthuis, Frank and Hans Wansink. 2002. 'Pim Fortuyn op herhaling: "De islam is een achterlijke cultuur"'. De Volkskrant, 5 May. Available at: https://www.volkskrant.nl/binnenland/ pim-fortuyn-op-herhaling-de-islam-is-een-achterlijke-cultuur a611698/ (accessed 15 February 2018).

Puar, Jasbir K. 2013. 'Homonationalism as assemblage: Viral travels, affective sexualities', Jindal Global Law Review 4:23-43.

Rainey, Venetia. 2017. “"Not gay enough”: Dutch authorities challenge asylum-seekers to prove their sexuality', The World [radio programme], 9 November. Public Radio International (PRI). Available at: https://www.pri.org/stories/2017-11-09/not-gay-enough-dutch-authoritieschallenge-asylum-seekers-prove-their-sexuality (accessed 3 March 2018).

Said, Edward. 1978. Orientalism. New York: Pantheon Books.

Scott, Joan Wallach. 2007. Politics of the Veil. Princeton, NJ: Princeton University Press.

Scott, Joan Wallach. 2018. Sex and Secularism. Princeton, NJ: Princeton University Press.

Shakhsari, Sima. 2014. 'Killing me softly with your rights: Queer death and the politics of rightful killing'. In Queer Necropolitics, edited by Jin Haritaworn, Adi Kuntsman and Silvia Posocco, 93-110. New York: Routledge.

Siebers, Hans. 2017. "Race" versus "ethnicity"? Critical race essentialism and the exclusion and oppression of migrants in the Netherlands', Ethnic and Racial Studies 40:369-87. https://doi. org/10.1080/01419870.2017.1246747.

Sterling, Toby. 2018. 'New-look Dutch nationalist party wins seats in Amsterdam election', Reuters, 21 March. Available at: https://www.reuters.com/article/us-netherlands-election/new-lookdutch-nationalist-party-wins-seats-in-amsterdam-election-idUSKBN1GX1SO (accessed 19 July 2018).

Trouillot, Michel-Rolph. 2003. Global Transformations: Anthropology and the modern world. New York: Palgrave Macmillan.

van der Veer, Peter. 2006. 'Pim Fortuyn, Theo van Gogh, and the politics of tolerance in the Netherlands', Public Culture 18:111-24. https://doi.org/10.1215/08992363-18-1-111.

Wekker, Gloria. 2016. White Innocence: Paradoxes of colonialism and race. Durham, NC: Duke University Press. 
9

\section{'They sent me to the mountain': the role space, religion and support groups play for LGBTIQ+ asylum claimants}

Moira Dustin and Nina Held

\section{Introduction}

While there is a growing body of literature addressing the sexual orientation and gender identity (SOGI ${ }^{1}$ ) asylum process in European countries (Dustin 2018; Gartner 2015; Held 2017; McDonald-Norman 2017; Millbank 2009; Rehaag 2008; Shuman \& Bohmer 2014; Spijkerboer 2013; Miles 2010; UKLGIG 2010, 2013; Wessels 2011), the social experiences of SOGI claimants have been less explored, and the intersections between the social and legal experiences even less so.

The Refugee Convention and EU law require that asylum claims be assessed individually, objectively and consistently. ${ }^{2}$ Scholarship has shown that, for SOGI minority asylum claimants, this is not always the case (Dustin 2018; Gartner 2015; Held 2017; Spijkerboer 2013; McDonald-Norman 2017; Shuman \& Bohmer 2014). A separate body of scholarship has highlighted the often negative experiences of these same individuals beyond the asylum system, in relation to health, accommodation, community engagement and what is often termed 'integration' (Allsopp, Sigona \& Phillimore 2014; Kahn 2015; Kahn et al. 2018; Lewis 2013; Namer and Razum 2018). Research connecting asylum claimants' and refugees' social and legal experiences is less common, including in the context of SOGI, although there are some exceptions, largely building on the work of NGOs (for example Dyck 2019; Stuart 2012). 
None of these studies, however, look at the experiences in depth by drawing on data collected in different countries. In addition, none of these studies consider the impact of different social factors on the asylum process. To address this gap, by drawing on data from the SOGICA ${ }^{3}$ project relating to Germany, Italy and the UK, this chapter considers three social factors - space, religion and LGBTIQ + support - and the relevance of these factors to LGBTIQ+ claimants' legal experience. We argue that a better understanding of these factors might lead to fairer decisionmaking in SOGI-based asylum claims as well as to broader improvements in the quality of life for the people concerned.

Our starting point is that all asylum applications should be assessed 'individually, objectively and impartially', ${ }^{4}$ and with the same guidelines and regulations followed consistently, if not across the European Union (EU), then at least within each member state, to enhance fairness, legal certainty and equal treatment. For this to be the case, the impact of social factors outside the legal asylum process must be addressed, because asylum law does not operate in a vacuum.

Making these connections not only addresses a gap in research and scholarship in order to increase our understanding of the reality of how asylum law operates, it also contributes to praxis in this field: by demonstrating the way factors outside formal legal processes may significantly impact on the outcomes of asylum claims, we hope to inform the work of lawyers and NGOs working with SOGI claimants; by highlighting support needs and showing how such support can help LGBTIQ + claimants navigate the asylum process and secure positive decisions, we draw attention to the invaluable work that many non-governmental organisations and support groups carry out.

As a socio-legal and interdisciplinary project, SOGICA is well positioned to address this gap (see 'Methodology', below). The project found that LGBTIQ+ individuals are disadvantaged in specific ways within the asylum process and also experience hostility and marginalisation in wider society on the basis of multiple factors (Danisi et al. 2021). Moreover, as we will demonstrate in this chapter, their experiences outside the legal system have a direct bearing on whether their claims are successful. We attribute this to a number of factors, three of which are discussed in this chapter. In 'Space', below, we consider the importance of place and space in a broad sense, by focusing on experiences with asylum accommodation and their surroundings, as well as detention facilities. 'Religion' explores religion and faith on an individual and an organisational level, in terms of both the practical and the emotional support available to claimants, and how decision-makers interpret the intersections 
of religion and sexuality. The third factor we consider (in 'LGBTIQ+ support', below) is the significance of the LGBTIQ+ support provided by NGOs and grassroots organisations. As we will show, the support and care offered by such groups is invaluable for LGBTIQ+ claimants going through the asylum process. We address each of these three factors in turn after providing an overview of the research methodology.

\section{Methodology 5}

As mentioned above, this chapter draws on data collected during the SOGICA project, and in particular on 143 semi-structured interviews, 16 focus groups and 24 non-participant observations of court hearings that were conducted during the project. The advantages of a mixed-method approach have been highlighted in the literature as offering breadth and an in-depth understanding (Blanck 1993; Epstein and King 2002; Travers 1999; Travers \& Manzo 1997). ${ }^{6}$

The individual interviews were conducted with participants in Germany, Italy and the UK, as well as with professionals involved with EU and CoE institutions, such as policy-makers, decision-makers, members of the judiciary, legal representatives, SOGI asylum claimants and refugees, representatives of NGOs, and other professionals. The focus groups were conducted solely with SOGI asylum claimants and refugees. In total, 158 asylum claimants and refugees participated in the semi-structured interviews and focus groups (64 in semi-structured interviews and 94 in focus groups). ${ }^{7}$ We conducted interviews in a wide range of locations in Germany, Italy and the UK to gain understanding of regional (and, in the case of the UK, national) differences, and we recruited a diverse sample of participants to gain understanding of intersectional experiences with regard to different social identifiers (see Danisi et al. 2021, ch. 2). Many of the asylum claimant and refugee participants were recruited through contacts with local, national and international NGOs offering support to asylum claimants, or through legal practitioners, or through the researchers' personal contacts with claimants. The interviews and the focus groups were conducted in semi-public places (for example, spaces in universities or quiet cafés) or in places familiar to the participants (local LGBTIQ+, refugee and migrant organisation venues or the offices of law firms). It was important to us to grant participants the autonomy to decide for themselves whether they wanted their accounts to be anonymised or not (Clark-Kazak 2017; Krause 2017), and approximately three-quarters chose to be anonymous. Therefore, in this chapter we use 
real names for some participants and pseudonyms for those who did not want to be named. All the interview and focus group audio files were transcribed, and all data, including observation notes and documents, was analysed according to a coding framework that we developed in the software programme NVivo, which allowed us to carry out a comparative analysis.

Fulfilling ethical standards is important for any project. However, because of the particular situation in which SOGI asylum claimants find themselves and the trauma they have experienced, considering ethical implications when conducting research with this group of participants was particularly important, as we explore elsewhere (Held 2019). Before we started the project fieldwork, several ethical issues were identified and ethical approval was obtained from the University of Sussex's Ethics Committee. ${ }^{8}$ All participants gave us their informed consent to use their contributions for our project, and they were given the opportunity to withdraw consent at any point before publication, and request the destruction of any data relating to them.

The interdisciplinary and intersectional approach that SOGICA adopted to explore the social and legal experiences of SOGI claimants in Europe is particularly useful for our analysis in this chapter. ${ }^{9}$ The interdisciplinary approach encapsulates legal and sociological theoretical and analytical frameworks and methods and therefore contributes to the slowly developing field of refugee studies that take a socio-legal approach (Anderson et al. 2014; Güler, Shevtsova \& Venturi 2019; Khan 2016; Lukac 2017; Venturi 2017). Employing a wide range of quantitative and qualitative methods from disciplines in the social sciences and humanities, socio-legal approaches look at the social factors involved and the social impact of law and practice. These approaches recognise that 'the law cannot be objectively isolated' (McConville \& Chui 2007, 20) and are therefore especially useful for exploring how social factors such as space, religion and support structures shape LGBTIQ+ experiences of asylum law and policies. Socio-legal approaches are also invaluable for analysing the relationship between sexuality, gender identity and the law, and their intersections with other social relations of power.

The project's intersectional approach is based on the idea that the 'major systems of oppression are interlocking' (Combahee River Collective 1977, 13). Coined by Crenshaw (1989) but having a much longer history in black feminist thought, 'intersectionality' provides us with a framework for understanding how the experiences of LGBTIQ+ claimants are shaped not only by gender and sexuality, but also by 
other social categories such as 'race', class, nationality, religion, age and (dis)ability (Danisi et al. 2021).

Applying these approaches to the topics of space, religion and LGBTIQ+ support sheds light on how what happens outside the legal asylum process impacts on the outcome of the claim in a way that traditional research methods with a focus on one issue and situated within one discipline are less likely to do. We seek to demonstrate this in the three sections that follow.

\section{Space}

LGBTIQ+ claimants' experiences are shaped within different locations or asylum spaces, and, as we will demonstrate in this section, not only is looking at 'space' important for gaining understanding of LGBTIQ+ claimants' experiences in social spaces, but these spatial experiences also impact on the legal asylum process. Human geographers have shown how spaces are gendered, sexualised, classed and racialised. The field of queer geographies specifically has explored how space shapes sexuality and sexuality shapes space. As Browne, Lim and Brown $(2009,4)$ argue:

[S] exuality - its regulation, norms, institutions, pleasures and desires - cannot be understood without understanding the spaces through which it is constituted, practised and lived. Sexuality manifests itself through relations that are specific to particular spaces and through the space-specific practices by which these relations become enacted.

Hence, as we will show, asylum spaces shape LGBTIQ+ refugees' sexual and gender identities in particular ways. This is most prevalent in spaces of asylum accommodation and their surroundings, as well as in carceral spaces such as detention centres.

When claimants are provided with asylum accommodation in Germany, Italy or the UK, they have no choice about where to live but, like other claimants, are usually randomly dispersed by the state on the basis of where moderately priced housing and/or reception facilities are available. ${ }^{10}$ While the place that is chosen for them should not play a role in the outcome of their asylum claims, it often does. LGBTIQ + refugees' experiences of accommodation are shaped by a multiplicity of issues. Like other refugees, they often have to live in overcrowded low-standard 
accommodation, sometimes mixed-gender, dirty and unhygienic (for instance, Angel, Germany; Jayne, UK; Trudy Ann, Germany).

They struggle with not being able to prepare their own food, lacking privacy, and the (sometimes real) fear of having belongings stolen (for instance, Dev, Italy; Marhoon, Germany; Nelo, Italy; Odosa, Italy; Prince Emrah, Germany; Tina, Germany). The accommodation providers (sometimes hotel owners or private landlords) often provide too little oversight and may harass residents (Lynn, Germany; Mayi, Germany). Moreover, especially in Germany and Italy, it is common practice for claimants to share a room, flat or house with strangers. For LGBTIQ+ claimants this brings specific concerns. LGBTIQ+ refugees are very often fearful of outing themselves or being outed, which makes it imperative to have a private space to which they can retreat. In addition, housing providers, other authorities, and sometimes even psychologists and NGO workers may suggest that claimants stay 'in the closet' (Julia, Germany; Julian, focus group, Germany; Marhoon, Germany). Some claimants out themselves, but, when they experience discrimination and violence and are lucky enough to be moved to another accommodation, may then go back into the closet (Ken, Italy; Kings, focus group, Italy).

Not having a private place to retreat to is particularly difficult when refugees experience discrimination and hate crime outside the accommodation centres. Many participants talked about experiencing homophobia, transphobia and racism in the areas where they lived, and not 'being wanted' as LGBTIQ+ black refugees (Winifred, focus group, Germany). Some participants who were accommodated in the south of Bavaria talked about specific experiences with what Haritaworn (2015, 14) calls 'anti-Black racism in Germany'. For instance, they told us of incidents in which people on public transport appeared reluctant to sit next to them or moved away, and one participant witnessed a person pull their shirt over their nose to suggest our participant smelled bad (Hilda and Winifred, focus group, Germany). Mayi (focus group, Germany) heard the comment 'Blacks are smelling', while Ayeta (focus group, Germany) described an experience she had while walking through town: 'there was a lady coming towards me. When she saw ... I was black she held her nose, then she turned and spat.'

Because LGBTIQ+ claimants often face discrimination and hate crime inside their shared accommodation, NGO workers and others in all the three countries studied have campaigned to establish accommodation specifically for LGBTIQ+ claimants. Indeed some provision already exists. ${ }^{11}$ While many of our participants supported the establishment of LGBTIQ+-specific accommodation (Antonella, LGBTIQ+ 
volunteer, Italy; Diego and Riccardo, LGBTIQ+ group volunteers, Italy; Giulia, LGBTIQ + group volunteer, Italy; Mara, lawyer, Italy; Ham and Stephen, focus group, Germany; Ken, Italy; Kennedy, Italy; Odosa, Italy; Gbona, Italy; Buba, Italy; Moses, Italy; Mamaka, Italy; Nice guy, focus group, Italy), some did not favour segregated provision, preferring an integrated approach (Alphaeus, Germany; Celeste, social worker, Italy; Giulio, LGBTIQ+ group volunteer, Italy; Mahoon, Germany; Nicola, LGBTIQ+ group volunteer, Italy; Siri, Italy; Silvana, judge, Italy; William, Germany).

LGBTIQ + refugee housing is created on the basis of residents sharing a common sexual orientation or gender identity, thus being a purposely constructed sexualised space. Yet these spaces are not only sexualised but also gendered, racialised, classed, and so on, and many of our participants argued that the intersections of identities also needs to be considered in LGBTIQ+-specific housing (Jonathan, LGBTIQ+ group volunteer, Italy; Juliane, public official, Germany; Kadir, NGO worker, Germany; Louis, LGBTIQ+ group volunteer, Germany). However, for others, being moved from general accommodation to LGBTIQ+ accommodation was crucial to their well-being. For instance, one of Melisa's (NGO worker, UK) intersex clients, whose passport stated male as birth sex but presented as a woman, had initially been accommodated with men where they faced bullying and sexual harassment:

At some point they [the client] had to leave the house in the night and take a walk in the night or try and find a friend who was available where they could stay on their sofa. In some instances they were forced to just stay in the kitchen, you know, to just sit there and wait until the other person slept, so it was a continual harassment and ... they tried complaining to different departments within the housing provider, the COMPASS ${ }^{12}$ providers, and they were not supported or they didn't get the help that they needed.

Only when Melisa's organisation stepped in did the UK Home Office act, and the client was moved to the organisation's safe accommodation: 'The first thing they said when I went to pick them up, they cried, so much.'

Campaigns for LGBTIQ+-specific accommodation can be a delicate and contentious matter, as they might reinforce stereotypes of 'asylum seekers', as a group, being sexist and homophobic, thereby feeding homonationalist discourses of a gay-friendly West as a source of refuge from the rest of the world (Puar 2007, 2013). These debates risk homogenising both SOGI and non-SOGI claimants, and allowing the 
struggles of LGBTIQ + refugees to be instrumentalised for racist discourses (Awadalla \& Rajanayagam 2016). Of course, we find homophobic attitudes not only in asylum accommodation centres but in many different spaces in society. We should therefore consider asylum accommodation centres to be similar to many other spaces, which are heteronormatively structured. As geographers of sexualities have shown, everyday spaces (such as the street, the home, the workplace) are constituted as heterosexual through repetitive heterosexual performances (Bell \& Valentine 1995; Johnston \& Valentine 1995; Valentine 1993, 1996).

Heteronormative environments make many claimants feel 'out of place' when they are accommodated with heterosexual families and obliged to share a room with heterosexual men and women. Some felt as if they were 'stick[ing] out like a sore thumb' (Angel, Germany). In addition, accommodation centres too are gendered spaces. These binarygendered environments are especially difficult for trans or gendernon-conforming claimants, whether or not they are accommodated appropriately according to their gender. If claimants are visibly trans or gender-non-conforming, they often experience harassment; if they are 'passing', then there is a constant fear of people finding out, for instance when male trans claimants wear breast bandages but have to share rooms, and cannot even lock the bathroom (Kamel, Italy; Bebars, Germany). This can affect physical health, for instance when bandages are worn for much longer than they should be. Such experiences also put an enormous strain on SOGI claimants' mental health and prevent them from thinking about their future. As William (Germany) explained, 'And when life is safe, you can have a future to think about. We sit down and think about what next.'

Heteronormative spaces can also be difficult for lesbian claimants, who may face 'advances' from men and feel pressured by the other women they live with to have a relationship with a man (Tina and Hilda, focus group, Germany). Many women do not feel safe. For instance, Julian (focus group, Germany) told us of men coming into her room - which she could not lock - at night, which could make any woman feel unsafe.

All of these experiences are likely to impact on the asylum claim. For instance, Liz (focus group, Germany) had to stay in a reception centre for an entire year, during which time she experienced sexual harassment by men on a number of occasions, and the other women would pressure her to have a relationship with a man and introduce her to their male friends. These intimidating experiences had a negative impact on her asylum claim in two ways. First, she felt unable to open up to anyone about her sexuality and kept it hidden. Second, to make matters worse, 
when, after a year in the centre, she had her asylum interview, she found that the interviewer and the interpreter were men:

So when I went to interview, the interviewers were all men. And I did not talk my whole story because they were all men, and I was not comfortable telling them, but I tried to, to give them an ... a small link about what was going on. Then after, I had to wait. Within three months I got back my negative.

Because of having spent a year hiding her sexuality in the heteronormative and sexist environment of the accommodation centre, Liz did not feel able to speak about her sexuality in the interview in front of two men. As in Liz's case, the heteronormative environments, plus the fear of 'outing' themselves or being 'outed', can negatively impact on LGBTIQ+ asylum claims and on the ways in which they can express themselves in the interview.

Furthermore, the impact of heteronormativity on asylum applications is often exacerbated by the social isolation LGBTIQ+ claimants face when they are accommodated in remote and rural areas: many of our participants were 'scattered, lost in places that are not accessible by public transport' (Anna, LGBTIQ+ group volunteer, Italy). Winifred (focus group, Germany), for instance, said that she cried when they took her to a village, after she had lost everything in her life. Her claim was rejected on the grounds that she had not been able to express herself:

But the reason [I don't express my sexual orientation] is [that] you've sent me in[to] the village. The moment I reached here I could not express myself because of the environment I was in. I didn't know anyone.

(Winifred, focus group, Germany)

Because of the social isolation LGBTIQ + refugees who are accommodated in rural areas face, they 'become crazy by staring at the walls' (Matthias, social worker, Germany). When they are accommodated in the middle of nowhere, with nothing to do, it is also impossible to 'escape the reality of the camp' (Ibrahim, Germany), receive support from the LGBTIQ+ community and 'not feel alone' (Veronica and Julia, Germany). For SOGI (and other) claimants, 'mobility remains a big issue' (Noah, NGO worker, Germany). Many participants talked about the obstacles to leaving their rural location and having some contact with peer groups. Most social 
activities happen in urban areas, but public transport is not always available and may not be affordable for people surviving on asylum support (Noah, NGO worker, Germany).

In Germany in particular, where the majority of participants had at some point during their asylum process lived in a rural area, we heard many accounts of feeling 'out of place' or 'out of category', as Zouhair described it: 'As queer refugees, I think we are out of category, so we do not belong to one [Germans], or the other [refugees].' This feeling can be intensified by additional experiential layers like disability, which was the case with Betty, a disabled black lesbian, who told us, 'People think I am useless, they do not want to associate with us, most of the time.' She feels excluded even by other lesbian women: 'Maybe they think that I have another category of people where I should go to.' Betty's account reminds us how important it is to look at the intersectional experiences of LGBTIQ+ refugees, and treat them not as a homogeneous group, but like any other group based on identities that are shaped by inclusions and exclusions (Butler 1991).

The place where someone is accommodated also determines the evidence that can be provided. For instance, being housed remotely makes it difficult, if not impossible, for claimants to participate in LGBTIQ+ events and join support groups. A support letter from an LGBTIQ + organisation may strengthen an individual's asylum claim (see 'LGBTIQ* support', below), but if they cannot attend organisational events they are unlikely to be able to secure this (Jolly, focus group, Germany).

Simply making contact with other LGBTIQ+ people is difficult for someone living in a remote location. As Sandy (focus group, Germany), for instance, explained, she tried to meet lesbian women on Facebook, but when she told them where she lived, 'Nobody wants to be my friend because I live too far [away] and they're not coming so far.' Because of limited mobility, most SOGI claimants housed in rural areas find it impossible to find romantic and sexual partners. Yet during the asylum process they are often asked whether they have sexual relationships. As Nana (focus group, Germany) explained, 'We can't go to parties because like me, in the interview they say I have to look for a girlfriend. Every time I go to look for a girlfriend when I'm in the village, how am I going to do that?'

More crucially, claimants need to find legal representation in order to make a good first claim or to appeal if their claim is rejected, and it is harder to find a lawyer with expertise in SOGI claims in rural areas. A negative outcome of the asylum claim then impacts on the social 
experience, as claimants will sometimes need to stay in their accommodation for a very long time while waiting for their appeal hearing. ${ }^{13}$

An extreme form of social isolation that impacts on the legal claim characterises detention in the UK. Here, claimants at all stages of the asylum process are liable to be detained in Immigration Removal Centres. Nine of our asylum claimant and refugee participants in the UK spoke of their direct experiences of detention (Irma, Lubwa, Luc, Lutfor, Miria, Patti, SGW, Stephina and Wabz), and it is likely that others had been detained but did not wish to talk about it. Participants working in NGOs also talked about their clients' experiences of being detained (Chloe, Amelia, Ashley, Oliver). People were detained for varying and sometimes long periods, ranging from one week (Miria) to 32 months (Luc). The arbitrary duration of detention is not surprising, as the UK is the only country in the EU that does not have a time limit on detention. ${ }^{14}$

Research by UK Lesbian and Gay Immigration Group (UKLGIG) and Stonewall found that 'LGBT asylum seekers face discrimination and harassment in detention centres' and that 'Trans asylum seekers face particular threats of violence in detention' (Stonewall \& UKLGIG 2016, 8). This is the case, in particular, when they are placed in detention centre accommodation that is based not on their gender identity but on the sex assigned to them at birth. Zadeh (2019) argues, 'Detention centres are possibly the most dangerous places in the country for LGBT+ people.' It is thus clear that the lack of a detention time limit 'adds to the already traumatising experience of the government taking away your liberty' (Zadeh 2019). Even after claimants are released from detention, the time they have spent incarcerated will often have an enormous detrimental effect on their physical and mental well-being (Zadeh 2019), which may impact on their ability to prepare and present their cases.

As Allan Briddock, a lawyer, pointed out, SOGI claimants not only face homophobic abuse in detention, but their vulnerability also makes it more difficult to work on their claim, for instance if they 'are worried about a fax from UKLGIG coming in' that will expose them. Preparing cases in detention is more difficult because of limited phone and internet access; some websites are blocked, which makes it difficult to retrieve the evidence necessary to build a strong case for protection (Singer 2019, 11; Stonewall \& UKLGIG 2016, 25).

Such challenges can be worse for SOGI claimants than for other asylum claimants, because the lawyers who are assigned to them in detention (if they do not already have one) may not have experience of 
SOGI cases or have limited time available in which to prepare these often complex cases. For instance, while Stephina was in a detention centre, her lawyer had very little time to spend on her case and did not advise her well. SGW (focus group) was also detained, and during that period her solicitor dropped her case and said he couldn't do anything else for her. She was not able to find another solicitor, so she 'ended up ... sitting before a judge, with my little paperwork, you know'. She felt that this situation 'has progressively gotten worse now with the strains with the legal aid. So that is a big problem.'

As this section has demonstrated, space affects not only the social experience of LGBTIQ+ claimants, but also their legal experience. The gendered, sexualised and racialised environments in which SOGI claimants are housed impact on how openly they can live their SOGI and on their ability to collect the necessary evidence, and this can influence the asylum interview and decision. These spaces are also shaped significantly by religion, which we now explore.

\section{Religion}

The previous section analysed factors relating to space as ones that should be, but often are not, recognised as having a bearing on the asylum claims of LGBTIQ+ people. In contrast, religion often is addressed in these claims, but not in the way that it ought to be.

SOGI persecution is often legitimised on religious grounds. This is something that is formally recognised in UNHCR guidance (UNHCR 2012, 11-12), as well as by national authorities:

Religion may also be a relevant factor in sexual orientation claims, such as where the attitude of religious authorities towards LGB people is hostile, or where being LGB is seen as an affront to religious beliefs in society.

(Home Office 2016, 10)

As expected, religion featured regularly in the accounts of SOGICA participants, both as one of the ways that they identified themselves and as a factor in their persecution. Of the 64 asylum claimants or refugees who were individually interviewed for the SOGICA project, 13 identified as agnostic, atheist, humanist or non-religious, while 36 identified as some form of either Muslim, Christian or Jewish (15 did not specify). 
A number of participants explained how religion contributed to their reasons for fleeing their families and communities: Meggs, a UK participant, told us, 'Because we are Christians, Zimbabwe is a very Christian country, so homosexuality is just a sin. I grew up knowing that from the word go.' Momo, claiming asylum in Italy, had been told he would not be given a funeral when he died: 'Because you are gay, you are not worthy, you are not a Muslim.' Siri, also claiming asylum in Italy, came from a Muslim family and had wanted to tell his father he was gay but his mother forbade him: 'No, if you talk to him, he'll kill you.' Siri left home on the day of this conversation.

Despite this, of the five Refugee Convention grounds that are the basis for asylum claims, ${ }^{15}$ SOGI claims are rarely based on religion but tend to rely on the more encompassing category of particular social group (Markard 2016; Arnold 2013; Millbank 2009). The focus is thus on the identity and behaviour of the claimant and not on the legitimating factors of the persecutor. The default deployment of the particular social group category for SOGI claims has been criticised (Danisi et al. 2021, ch. 7; Arnold 2013). It has been argued that decision-makers should make better use of the category of religion for sexual orientation claims (Braimah 2015). This has not yet happened; rather, we see religious affiliation or a religious upbringing deployed against the claimant. The belief held by decision-makers - both in the first instance and on appeal in the three country case studies - is often a simplistic one: that sexual and gender non-conformity is condemned in conservative interpretations of the major world religions. Therefore, 'genuine' claimants must either renounce their faith or struggle to reconcile it with their sexuality or gender identity.

One Italian decision-maker articulated this very clearly in describing the case of a young man who had told him about his difficulties in going to pray with his friends, and who had talked about homosexuality as something that was against God. He had told the decision-maker that he 'had a problem with not being a good believer'. The decision-maker told us: 'This sentence is very strong. In other words, it makes it clear that the person ... experienced this personal characteristic of the discovery of his sexual orientation in a very troubled manner' (Titti, Italy). For this decision-maker, the claimant's credibility was strengthened by the trouble he had in accepting that he could be a good believer and also be gay.

In contrast, in a UK appeal we observed (observation of First-tier Tribunal, London, February 2018), the claimant's failure to problematise his faith was used to undermine his claim, as we see in the following exchange: 
Home Office Why is it that he [the appellant's father] never representative discussed the teachings of the Qur'an on homo(HO) sexuality?

Appellant (A) These issues are not discussed there, it is not in the culture, these sensitive issues.

HO

But if it's a shunned thing, you were not warned against it?

A

I have not told anybody, so why would this issue be raised?

HO

And you had no inclination before that homosexuality was wrong?

A

No.

In his subsequent summing up, the Home Office presenting officer argued that this lack of awareness was implausible, 'simply because there must be something that pushes an individual to realise that this is a negative behaviour'.

This line of argument breaches Home Office guidance, which states that a 'claimant's religion is not a basis for rejecting their claim. LGB individuals may be adherents of religions that disapprove of homosexuality, preach against it, or indeed forbid it' (Home Office 2016, 35). However, this was not an isolated incident. A solicitor with a firm that specialises in SOGI claims confirmed this as a common approach:

I have thus seen a lot of questions about Muslim clients, about how they lived, the fact that Islam is against it, if they are religious. So they [the Home Office representative] would often ask, 'You are religious, are you practising?' Erm ... if their answer is positive, 'How does that fit with your sexual identity?'

(Nath, UK)

One claimant's refusal was in part based on this kind of argument:

You claim that you are a practising Christian. However, staying in Malawi, it does not seem that you have any internal conflict with the views of Christianity on homosexuality. You state that you went to church and ignored what the Bible said about homosexuality and that you felt 'normal' and 'okay' with this. Given that you are a practising Christian, your failure to raise any potential conflict in relation to your behaviour and belief raises doubts regarding your credibility.

(Anonymised refusal letter from the Home Officer, July 2018) 
In Italy, there is evidence of a similar approach, although the authorities may not admit or be aware of the fact. Daniele, a decision-maker, insisted that religion was not a factor in assessing credibility, stating, 'Elements such as political opinions, religion, marital status, etc., we certainly keep them free from the element of the assessment of credibility. The assessment of credibility is done only on the basis of the experience that a person provides about their knowledge of their sexual orientation or gender identity or the difficulties that they, in fact, have lived in the country of origin.'

Yet a LGBTIQ+ group volunteer gave a conflicting account: 'A question that the [Territorial] Commission can ask - but how is it that you, as a believer, still manage to be homosexual even if you are a believer, a Muslim?' (Antonella, Italy). Antonella said that this kind of question was asked 'very often'.

As these examples show, official lines of argument are often unsophisticated: homosexuality is forbidden by Christianity (African Christianity in particular) and by Islam, the most common faith of Asian and Middle Eastern asylum claimants; therefore claimants must demonstrate that they have renounced or at least had an internal struggle with their faith. This approach, as a basis for undermining LGBTIQ+ claimants' credibility, appears to be common and is starting to be identified as problematic in different European countries (Dyck 2019; Giametta 2014; Jansen 2019, 83; Tschalaer 2020). However, as an explanation of the relationship between sexuality and religion in the context of asylum, it is inadequate. The reality of individual religiosity is more complex, and claimants explained their faith in a variety of ways; some people rejected organised religion while continuing to believe in God, like Michael: 'I do believe God is there, I believe in the power and, yes, I believe in God but I do not want anything in between' (UK). Similarly, Diamond (UK) stated, 'Yes, I am religious. ... Because there is no book of religions of Hindu that [has] written that gay is sin.' Or, as Mamaka in Italy told us, 'I pray my five daily prayers. Because I am a lesbian doesn't mean I should leave my religion.' For all these individuals, the fact that their persecution had been legitimated on religious grounds did not mean that they were willing or able to walk away from their faith.

Persecution that is justified on religious grounds may be one of the reasons individuals flee their countries of origin. However, such discrimination does not stop at the borders of Europe. It occurs in mainstream religious institutions and organisations, as well as in diaspora community organisations and networks that provide support to asylum claimants. An NGO worker with a refugee women's organisation in the UK explained 
that the women members of the group choir had been reluctant to sing at a Pride event: 'When we told the choir what it was, none of them wanted to do it. And that was just really shocking. And upsetting. Because I just had no idea, which was so naïve of me' (Chloe). A participant in Germany told us of the experiences of LGBTIQ+ refugees: 'For example, if they are living in Bavaria or in Munich, in conservative Christian communities, they are facing a lot of problems' (Ibrahim). Silver, in Italy, shared a house and regularly cooked with his housemates before telling one of them he was gay. '[The housemate said,] "Ah, I didn't know. So, from today, I don't eat with you any more". And then I was the only Christian living with them, they were Muslims. Then they separated the pans and the spoons.'

These experiences of exclusion and hostility are not only wounding on an emotional level, they also inhibit individuals from making a full and honest asylum application and from preparing their case. Fearing the continuation of the discrimination they experienced at home, newly arrived asylum claimants needing practical and emotional support from refugee and migrant organisations or from NGOs supporting refugees and migrants often find it expedient to keep their sexuality concealed. A UK psychotherapist working with victims of torture explained: 'They find themselves in the new closet of not talking about their cases in the asylum accommodations that they have, because often they are with people from good strong faith backgrounds, or whose cultures are deeply homophobic' (Ashley). Giulio, an LGBTIQ+ group volunteer in Italy, had found that Muslims 'live the social stigma more. ... They are less inclined to tell their story.' He felt this put them at a disadvantage.

It must be deeply distressing and frightening for individuals who have fled SOGI-based persecution in their home country to experience similar hostility and prejudice in what should be their country of refuge. Worse than that, continuing to conceal one's sexuality makes a successful application less likely. Patti (UK) told us that she loved going to church and singing in the chapel there but also spoke of how church members preached against gays and lesbians.

So I couldn't tell anyone, even my room-mate didn't know about it. I always hide my papers, all the papers - I just hide them. I didn't want, like, anyone to know about it. I don't want to be, like, people pointing at me .... When immigration came they say, oh they don't believe me, no one know me, oh why I am not open about it. Well I am not going to go around and start telling people, I am this, I am 
this, I am this. I am not going to - at the end of the day I am in a black community where people don't like it.

This might be described as a 'chill' factor, where the knowledge that many people interpret their faith in ways that are hostile to SOGI minorities prevents people - particularly new arrivals lacking support and resources - being open about their sexual identity. They then find it difficult to 'prove' to decision-makers that they are LGBTIQ+, because they lack evidence. This stifling effect arose in another situation, when claimants were given a visibly religious interviewer. In Germany, a lawyer explained that she had had a client from an Islamic background who was severely traumatised by his experiences and who was 'practically unable to speak' in the presence of a listener in a headscarf (Evelyne and Anna, lawyers, Germany).

An asylum claimant in the UK explained:

My interviewer is a covered woman, so she is Muslim, she is covered, and the questions the interviewer asked are very personal, and please don't take it as an offence, one of the questions [was] like, 'What did you use to do when you get aroused?' I was so uncomfortable [with] these questions, to the extent I felt so dizzy and they asked the security to come and take me to the toilet, because I was almost going to faint. So they took me to the toilet, and then I was speaking to my lawyer and [I] was like, 'How am I going to answer a covered woman, how am I going to tell a covered woman that I watch porn and I masturbate?'

(Kareem)

Similarly, Jayne, in the UK, told us, 'I was interviewed by a Muslim girl, and I remember her pulling her face and I was thinking, Well even if you pull your face but this is what I am telling you.' Jayne was also asked how she reconciled her religion with her sexuality: the Home Office did not find her response - 'Yes, I am a Catholic and I am a lesbian by sexual orientation and I don't need to reconcile anything with anything there' a convincing one, and her initial application was refused. While there may not be an easy solution to this situation that protects the rights of all parties, it does show how complicated people's relationship with their faith is, how different it is for everyone, and of course how it impacts on the legal asylum process.

What the above accounts demonstrate is that the fear of being out is often explained on the grounds of religion or 'community', and at times 
our participants seemed to attach the label of homophobia to a certain group of people, hence homogenising them, and sometimes following homonationalist discourses (Puar 2007, 2013; 'Space', above). This issue is of course much more complex, and our participants themselves experienced their faiths in many ways, from complete disengagement ('I hated practising religion', said Ali in the UK) to a deep personal relationship ('I am a religious person, I never stop believing in God. Because I think in the end, it's just him who stayed with me because I live many things', from Ximena, also in the UK). While some people's experiences had led them to develop a personal approach to religion, unmediated by religious organisations, others had instead sought out LGBTIQ+-friendly churches.

This diversity in experiences and identities is unrecognised by decision-makers who, in their questioning and their decisions, often showed culturally inappropriate understandings of faith and its role in the lives of people claiming asylum. This was expressed by Anna, an LGBTIQ+ group volunteer in Italy, who pointed out that in a secularised society, there are no 'cultural tools' to understand the importance of religion in Maghreb countries. In Italy, if the Church rejects you because you are gay, the solution is simple: 'All right, let's go out. The Church doesn't want us, we just go out.'

Moreover, religion may be generally perceived, certainly by immigration officials, as a source of homophobia, but on a grassroots level it is also a significant source of support. LGBTIQ+-friendly religious organisations, as well as LGBTIQ+ groups established by asylum claimants and refugees and with a religious ethos, provide much practical support, in particular in the UK. Support groups with their roots in the Metropolitan Community Church (MCC) operate in Manchester, Birmingham and other cities to provide meeting spaces and resources for LGBTIQ+ claimants. A report commissioned by the MCC described how, for many African claimants, finding an accepting church was 'the beginning of healing' (Dyck 2019, 3), while in a survey as part of the same report, 94 per cent of respondents confirmed the 'positive effects of LGBT-affirming faith-based support' (Dyck 2019, 42). In Manchester, the First Wednesday group, of upwards of 60 individuals, meets at the LGBT Foundation on the first Wednesday of every month, providing information about the asylum process, refreshments, travel expenses and networking opportunities. In Birmingham, Journey Church runs a regular asylum drop-in at the LGBT centre. What is important to attendees is the sense of welcome and warmth towards SOGI minorities, and not necessarily the tenets of a particular religion. A Muslim man we talked to attended a 
(presumably) Christian or Catholic church: 'I am a Muslim by faith and I practise and it is really difficult for me to open up with a lot of people with my religion. So, I try to join groups, like I go to church, because they are more welcoming, so I go to church and because I believe God is just God with different names' (focus group participant, UK). In Northern Ireland, where there are fewer LGBTIQ+ asylum support groups, an NGO worker explained:

Interestingly, there is a feeling of integration with some Christian groups, even if they are Muslim - maybe up to a dozen or more individual LGBT asylum seekers that have had some kind of welcoming contact with Christian groups.

(Dean, UK)

Faith-based organisations were a source of emotional and psychological as much as practical support. In Italy, Giulio, an LGBTIQ+ group volunteer described how people who attended their gatherings said that, apart from the group, 'they had nothing but the church'. In Germany, Shany, a BerberJewish woman from Morocco, had support from the Jewish community when she feared deportation back to Morocco. She told us that people from the synagogue had said to her, 'Okay, listen, we're gonna help you. If it's very bad then you go to Tel Aviv, and that's it, we send you to Israel.' Miria (UK) had also found a supportive church: 'Here they are preaching about love, which is the most important thing, and loving your neighbour; you feel more comforted.' Similarly, Meggs (UK) told us: 'When I am at church, my spiritual inner [woman] gets fed, because it is something that I was missing back home. I could not be a Christian and a gay person.'

For many of the claimants who participated in the SOGICA project, religion was an important but complicated feature of their lives: a source of persecution and of support, sometimes at the same time, and in both their country of origin and their country of asylum. Where it was a source of support in the country of asylum, some of that support came from engagement with 'gay-friendly' community organisations and churches, part of the wider network of support structures discussed in the next and final section.

\section{LGBTIQ+ support}

In recent years, some of the research on LGBTIQ+ asylum claims in Europe and beyond has looked at the social experiences of LGBTIQ+ 
claimants and their physical and mental health needs (Allsopp, Sigona \& Phillimore 2014; Kahn 2015; Kahn et al. 2018; Lewis 2013; Namer \& Razum 2018). Some studies demonstrate:

the importance of building grassroots, community-based support structures (formal or informal), by bringing sexual minority refugees together, raising critical consciousness, and providing opportunities for self-representation when engaging in knowledge production and social justice-related activities.

(Lee \& Brotman 2011, 268)

These studies show the need for such support to navigate the heteronormative and cisnormative asylum spaces (Lee \& Brotman 2011), for 'integration' purposes (Alessi et al., 2020) and for building resilience (Alessi 2016). What has been less explored is how those support structures might impact on the legal experiences of LGBTIQ+ claimants, and here we will focus specifically on support received from LGBTIQ+ NGOs as well as grassroots organisations that support LGBTIQ+ asylum claimants and refugees.

Research in the UK dating as far back as 2009 pointed out that SOGI claimants rely mostly upon personal relationships or social networks in the absence of more traditional support from family and ethnic networks (Bell \& Hansen 2009, 43). In our country case studies, it was therefore no surprise that many of the claimants we interviewed were involved with such groups and that the support they received from such groups, often volunteer-led, was invaluable. Socially, these groups and organisations provide a space for LGBTIQ+ claimants to be together; they organise social events, art projects, etc. Some host accommodation centres for LGBTIQ+ refugees have drop-ins and offer café spaces. They may also provide health and mental health services such as HIV counselling, offer empowerment workshops and language courses, and help LGBTIQ+ refugees to find housing and employment. As we will demonstrate below, LGBTIQ+ support groups also offer wide-ranging legal support and both the social and the legal support that LGBTIQ+ claimants receive from such groups and organisations can have a positive impact on their asylum claims.

It is noteworthy, however, that support structures specifically for LGBTIQ+ claimants have existed for at least a decade in the UK, while in Germany and Italy most of the groups that exist have been established since the wave of migration in 2015 (Il Grande Colibri 2019).

As Ibrahim explained, when he arrived in Germany in 2015 there were no support groups for LGBTIQ+ claimants: 
Now you have supporting groups for LGBT refugees. There are new politics, there are a lot of activities. There are special houses for LGBT refugees. In 2015, the topic was not known here. There was only a new group just creating themselves, and when I went over there, there was around a hundred German people and I was the only gay refugee.

According with Ibrahim's experience, support groups for LGBTIQ+ claimants have often been established by white Europeans, but there are also groups that have been established by LGBTIQ+ claimants themselves (for example, African Rainbow Family in the UK, Sofra in Germany). Ibrahim, who now works as a support worker in a local NGO for LGBTIQ+ asylum claimants, created a Facebook group for LGBTIQ+ claimants, a database where claimants can find sources of support and lawyers, and a local support group (Sofra Cologne), where once a month LGBTIQ+ claimants and refugees and supporters come together and share food, cook together, socialise, drink tea, share information, invite speakers from organisations who give useful information, and make contacts. It is important to highlight asylum claimants' and refugees' agency in establishing networks, support groups, and other forms of refugee activism (Bhimji 2016). Some organisations also make sure that services for LGBTIQ+ claimants are delivered and led by other refugees (Melisa, NGO worker, UK) or at least by people with migrant backgrounds (Mariya, NGO worker, Germany).

One of the main ways in which LGBTIQ+ support groups have a positive impact on claimants' asylum process is through the provision of adequate legal and practical support throughout the process, and especially before the main interview. A survey that was conducted by several NGOs and support groups in North Rhine-Westphalia (Germany) on experiences relating to the asylum interview (which SOGICA supported by analysing the data and writing the report) clearly demonstrated the importance of accessing LGBTIQ+ support before the interview (Held 2018). Eleven respondents to the survey did not mention their SOGI in the main interview, thus weakening their claims: of these, none had received support or advice beforehand. Hence, often it is the support claimants receive from LGBTIQ + groups that make it possible for them to claim asylum on grounds of SOGI in the first place. For instance, Diarra (Italy) recalled that he had not been aware of this possibility until he attended an awareness meeting on 'SOGI rights in Italy' organised by an LGBTIQ+ support group in his reception centre. As he put it, 'Today I can say that I'm gay. After that meeting, I went to talk to the reception centre's staff.' 
Support groups may also inform the authorities of the SOGI nature of the claim (Chiara, NGO worker, Italy; Cristina, UNHCR officer, Italy), request SOGI-friendly arrangements (a sensitive interpreter, for instance) and make sure rights are respected during the procedure. Some of our participants also mentioned that accompanying SOGI claimants to their interview increases the chances of the interview being carried out in a sensitive way, and with that the chances of a successful claim (Thomas, NGO volunteer, Germany).

Such support also makes people more aware of their rights, for instance that they are able to request a special officer trained in LGBTIQ + issues to conduct the interview, as is possible in Germany. Of the 51 respondents to the North Rhine-Westphalia survey, only seven had requested a special officer, and all these respondents had had advice from LGBTIQ+ groups before their interview. The five claimants who got a special officer were all granted refugee status. In general, whereas the claims of over 30 per cent of the SOGI claimants who had filled in the survey had been refused, only one claim out of the 20 claimants who had received LGBTIQ + specific support was rejected (Held 2018, 15).

This suggests that it is crucial to make independent SOGI support available to claimants. In Germany, while NGOs and support groups provide advice to SOGI claimants assessed through the regular procedure, their support is increasingly hampered by the creation of AnkER centres. ${ }^{16}$ In these centres it is difficult to obtain independent advice and collect evidence, a problem exacerbated by the brevity of the period between a claimant entering the centre and having their interview (Nina, lawyer; Frank S., legal advisor). In such circumstances, claimants are often still in 'flight mode', not able to relax, concentrate and present their claim to the best of their ability, as expected in a fair decision-making process. Nor will they have had time to develop any local connections with LGBTIQ+ communities for advice and evidence.

In all three SOGICA country case studies, decision-makers often ask for 'proof' that the claimant is LGBTIQ+, and also that they live an 'out and proud' gay life. Claimants are often asked about their experiences of frequenting LGBTIQ+ venues, being members of LGBTIQ+ associations, and attending LGBTIQ+ events such as Pride (for instance, Shany, Germany; Barbara, lawyer, Germany; Giulia, LGBTIQ+ group volunteer, Italy; Allan Briddock, lawyer, UK). What decision-makers ignore here is that many 'native' LGBTIQ + people are also not involved with the LGBTIQ+ community (Sofia and Emma, staff members at NGO LeTra, Germany). In addition, SOGI claimants usually have limited economic resources, and they often live in isolated areas far away from LGBTIQ+ 
community support structures (see 'Space', above). They often suffer from physical and mental health issues, or have experienced transphobia and racism in LGBTIQ+ spaces, which may hamper their desire to visit those spaces (Caroline, NGO worker, UK; Diane, Germany; Giulio, LGBTIQ+ group volunteer, Italy; Ibrahim, Germany; Kamel, Italy).

Nevertheless, decision-makers often rely on such evidence, and here LGBTIQ+ support groups often provide this 'evidence' by writing statements. In Italy, this goes so far as LGBTIQ+ support groups giving out 'membership cards' and decision-makers requesting such evidence to establish credibility. Hence, such membership can have a positive impact on the outcome of the claim (Antonella, LGBTIQ+ group volunteer; Celeste, social worker, Italy; Nicola and Giulio, LGBTIQ+ group volunteers, Italy; Titti, decision-maker, Italy; tribunal observation, northern Italy, 2018). However, this is not to say that decision-makers necessarily accept statements from LGBTIQ+ groups and organisations. Participants in Germany, for example, reported that such statements are generally disregarded, as they are seen as 'partisan' (Sofia, staff member at NGO LeTra). Despite this, the use of such statements was often seen as critical by participants, as they can also have a negative impact on the case if they contain information that contradicts what the claimant has said in the interview (for instance, Thomas, NGO volunteer). There was also some caution expressed that the more of these statements are handed out, the less value they might have (Sofia and Emma, staff members at NGO LeTra; court observation, Hesse, 2018). In the UK, in court observations we witnessed the Home Office dismissing NGO supporting statements on the basis that it would be easy to 'fake' one's sexuality for the purpose of obtaining such a statement (Upper-tier Tribunal observation, London, 2018). Even when supporters from LGBTIQ+ groups and organisations provide oral evidence in court as witnesses, this might not help to convince the judge of the claimant's sexuality, as was experienced by one of the authors of this chapter (Held 2017).

While it is debatable whether supporting statements by LGBTIQ+ groups and organisations necessarily have a positive impact, SOGI claimants would often be lost in the often complex legal procedures if they had not received such support, as was expressed by Meggs (UK):

I was told we are supposed to appeal again, [but] he [the lawyer] said, 'Oh no, we don't have a case. ... Just go and find new evidence. If you find it, come back to me', and I didn't know what new evidence would that be. [I] don't know what is [a] fresh claim or what I have to look for - yes? So if we didn't have, like, the kind 
of organisation - First Wednesday, Lesbian Immigration Support Group - where you meet and they tell you, like, 'This is how it is done', I wouldn't even know until today. Because I didn't know what I was looking for.

Despite often operating with minimal or no funding, and on a largely voluntary basis, LGBTIQ + groups and organisations frequently support claimants through the whole asylum journey and beyond, and the support they offer is enormous and wide-ranging: they give general legal advice, prepare claimants for interviews and appeal hearings, write support letters and collect other evidence for their claims (such as country of origin information), accompany claimants to interviews and court hearings, act as witnesses in hearings, find solicitors with expertise on SOGI claims, help cover the legal costs, and of course provide emotional support - all of which may contribute to a positive outcome of the claim. In addition, NGO workers and volunteers raise awareness, campaign for change, influence policy-making and provide training for decision-makers and other professionals who provide services for LGBTIQ+ claimants (for instance in reception and accommodation centres).

While the support LGBTIQ+ claimants receive from such organisations does not necessarily lead to a positive result of the claim, without such support the situation for LGBTIQ+ claimants would often look bleak. For instance, according to Damiano, a lawyer in Italy, the impact of all this 'laborious' voluntary work is shown by the high percentage of recognition of SOGI claims at administrative level in recent years. And most importantly, LGBTIQ+ groups and organisations are at the forefront of anti-deportation campaigns, and provide support when SOGI claimants are detained (as is the case especially in the UK; see 'Space', above). For example, in her interview, Meggs (UK) told us about women she knew at the Lesbian Immigration Support Group (LISG), an organisation in Manchester supporting bisexual and lesbian asylum claimants. The women had been detained when they signed in with the authorities, as they were required to do, but were released with support from LISG. In her opinion,

Unless the organisations that are out there know you are in there, then they will [not] start to ... do the petition for you, to fight for you, so that you can be released while you are waiting on your claim, then it helps a lot. But if no one knows anything about you, definitely you are gone. 
Participants were often grateful for all the support they received and spoke fondly about the groups they belonged to, sometimes referring to them as 'family'. This came through particularly strongly in the focus groups held in all three countries. However, this is not to say that LGBTIQ+ groups and organisations do not face issues that also exist in other social settings. Often stark power differences exist between workers/volunteers/supporters on the one hand and LGBTIQ+ claimants on the other, which at their worst put claimants at risk of (sexual) exploitation. And of course, there exist many differences in the degree and kind of support available to claimants within the broad LGBTIQ+ category. Looking at the term LGBTIQ+, we found that most of the support available is targeted at and dominated by gay men, while a smaller number of support groups existed to meet the needs of lesbian asylum claimants. As Jonathan (Italy), who created a group that brings Italians and migrants together, told us, it is important to get women on board, as they are less visible: 'it is important to have women, in the LGBT world in general, [as they] are less visible, but also with regard to LGBT migration we are constantly talking about men; women are still fewer'. Trans asylum claimants also face difficulties in finding specific social support and community groups, which leads to particular forms of isolation (TGEU 2016 , 7), while claimants who identify as bisexual, intersex or queer are expected to fit into the groups that are available.

\section{Conclusion}

As this chapter has demonstrated, it is important to look at both the legal and the social experiences of SOGI claimants, as they impact on each other. EU asylum law and policies are based on the premise that asylum claimants should have the same chance of success in each of the 27 member states. However, even within one member state differences in the treatment of asylum claims can emerge, which are due to intersectional experience and certain social factors. Therefore, in order to establish more just asylum systems, we need to examine these social factors.

By focusing on LGBTIQ+ asylum claimants' and refugees' experiences in Germany, Italy and the UK, this chapter has examined the relevance of space, religion and LGBTIQ+ support to LGBTIQ+ claimants' legal experience and the outcomes of their asylum claims. These social factors are important to many asylum claimants, but perhaps particularly to LGBTIQ + people in the light of the kinds of support they need, and are able or unable to access. They are important on a social 
and psychological level, but, as we have demonstrated, they also impact on the asylum decision-making process, specifically affecting individuals' willingness to be open about their SOGI, and their access to the resources they need in order to present their case as fully as possible.

For many individuals, religion - or rather, particular interpretations of religious affiliation and requirements - was a factor that had played an important part in their reasons for flight from their home country. Yet, at the same time, religion remained a key source of personal support and connection with others for many SOGI asylum claimants. Keeping their faith was often a factor that prevented them from making a strong claim for asylum and having it heard fairly, as decision-makers were not able to grasp fully the intersections of sexuality and religion.

As we have shown, LGBTIQ+ claimants often feel unsafe in asylum spaces, including their assigned accommodation and its surroundings, or detention centres. 'Space' here impacts on their ability to live their SOGI comfortably, without fear, which is a precondition for being able to feel confident and safe in other asylum spaces, such as the interview setting and the court room. While the establishment of housing specifically for LGBTIQ+ claimants was largely, though not unanimously, supported, there was a consensus among our participants that LGBTIQ+ claimants should be housed in areas where they can access LGBTIQ+ structures and support. As we have shown, access to such structures is vital, and the support that is offered by LGBTIQ+ NGOs and grassroots organisations is enormous. LGBTIQ+ claimants valued the opportunity to have support structures that validate their identities as LGBTIQ+ and refugees. Over the years, such support organisations have also increased their value by developing expertise on SOGI asylum-related matters. As in any sector of society, power relations and exclusionary practices exist in LGBTIQ+ communities, but the existence of supportive networks, including formal and informal organisations, demonstrates the positivity, strength and care that exist within these communities, who deserve greater recognition and resourcing than they currently receive.

Here we have highlighted the role of these communities alongside some of the other kinds of social and psychological support that contribute to whether or not SOGI-based applications for protection will be granted. We recognise that their presence or absence has significance that reaches far beyond the formal application and appeals processes, and that the lives of people claiming asylum should not be reduced to legalities and administrative procedures. However, at the same time it is important to highlight the interrelation between the social and legal dimensions of SOGI asylum claimants' lives, in order to ensure that 
individual claimants have a fair chance of telling their story and making their case on the basis of the rules of the (asylum) game in Europe and in the particular state in which they are claiming.

\section{Acknowledgements}

This chapter has been significantly improved in response to comments by Elizabeth Craig, Carmelo Danisi, Nuno Ferreira, Rose Gordon-Orr, Darcy Leigh and anonymous reviewers. We thank them all, while stressing that any errors are entirely the responsibility of the authors.

This contribution has been produced within the context of the project 'Sexual Orientation and Gender Identity Claims of Asylum: A European human rights challenge' (SOGICA; http://www.sogica.org). The project has received funding from the European Research Council (ERC) under the European Union's Horizon 2020 research and innovation programme (grant agreement No. 677693).

\section{Notes}

1. This chapter draws on findings from the project SOGICA - Sexual Orientation and Gender Identity Claims of Asylum, which is a four-year (2016-20) project supported by the European Research Council and based at the University of Sussex. While the chapter uses both SOGI and LGBTIQ+, the SOGICA project largely uses SOGI, choosing a characteristic rather than an identity-based approach in an attempt to avoid reinforcing Westernised concepts of personhood for individuals claiming asylum.

2. UN General Assembly, 'Convention Relating to the Status of Refugees', 28 July 1951, Annex II, Article 3; European Union, 2013, Article 10, 3(a) 3; Hathaway and Foster 2014[BIB-031], 108-9.

3. For more information on the SOGICA project see: www.sogica.org.

4. Council of the European Union, 'Directive 2013/32/EU of the European Parliament and of the Council of 26 June 2013 on common procedures for granting and withdrawing international protection (recast)', 29 June 2013, Article 10, 3(a). Available at: https://www.refworld.org/ docid/51d29b224.html (accessed 28 December 2019).

5. Full details of the project's methodology and ethical standards are available in Danisi et al. 2021, ch. 2.

6. In addition to the semi-structured interviews, focus groups and non-participant observations, the project's methodology included two online surveys, documentary analysis and freedom of information requests.

7. In addition, 82 LGBTIQ+ claimants completed the online survey.

8. Certificate of approval for Ethical Review ER/NH285/1.

9. In addition, the project adopted a comparative approach that aimed to address the issue of disparate (and occasionally low) standards across EU and Council of Europe member states in asylum legal adjudication. Focusing on Germany, Italy and the UK, the project aimed to explore 'good' and 'bad' practices and to identify distinctive trends to guide future asylum decision and policy-making. These three countries were chosen because of the volume of asylum claims, their contrasting adjudication systems and their different socio-legal approaches to SOGI. In this chapter, we do not follow a strictly comparative approach.

10. Provision differs between member states. In Italy and Germany, claimants may be accommodated in reception centres; in the UK, accommodation is contracted out to a number 
of private companies but claimants may also be detained in Immigration Removal Centres (see Danisi et al. 2021, chs 5 and 8; ECRE 2019).

11. Such as that provided by Micro Rainbow in the UK (available at: https://microrainbow.org/ housing/ (accessed 25 January 2020)), and by Schwulenberatung in Germany (available at: https://www.thelocal.de/20160223/berlin-opens-germanys-first-gay-refugee-centre (accessed 25 January 2020)), and proposed by MIT in Italy (available at: www.quiikymagazine.com/ bologna-apre-primo-centro-accoglienza-rifugiati-lgbt/ (accessed 25 January 2020)).

12. COMPASS was the Commercial and Operational Managers Procuring Asylum Support Services contracts system in the UK until September 2019.

13. For instance, in Germany, in 2018 the appeal process took on average 12.5 months, up from 7.8 months in 2017. However, as a large number of these appeals (45.5 per cent) were terminated without actually having had a hearing, the average time for appeals to be decided is significantly longer than the 12.5 months average (and indeed some refused participants of our study had already been waiting for 1-2 years or more) (see ECRE 2018, 27). According to BAMF statistics, from the initial claims that were decided in 2017, the whole process, including appeals, took on average 13.2 months; however, again this figure includes the terminated cases. See Das Bundesamt in Zahlen 2017. Available at: https://www.bamf.de/SharedDocs/ Anlagen/DE/Statistik/BundesamtinZahlen/bundesamt-in-zahlen-2017.html?nn=284738, 57 (accessed 26 August 2020).

14. In July 2019, the Home Office rejected the UK Parliamentary Human Rights Committee's recommendation to introduce a time limit on immigration detention ('Home Office rejects Human Rights Committee's call for a time limit to immigration detention', 31 July 2019. Available at: https://www.parliament.uk/business/committees/committees-a-z/joint-select/humanrights-committee/news-parliament-2017/time-limit-immigration-govt-response-published17-19/ (accessed 25 January 2020)).

15. Race, religion, nationality, membership of a particular social group, or a political opinion (which must be the reason for persecution).

16. The so-called AnKER centres were introduced in 2017 with the aim of speeding up the assessment of asylum claims (applications are usually decided within a few days). These centres handle all the asylum-related stages (BAMF 2019) and claimants who are hosted in these centres receive all the information on the asylum process through the BAMF.

\section{References}

Alessi, Edward J. 2016. 'Resilience in sexual and gender minority forced migrants: A qualitative analysis', Traumatology 22:203-13. https://doi.org/10.1037/trm0000077.

Alessi, Edward J., Sarilee Kahn, Brett Greenfield, Leah Woolner and Dean Manning. 2020. 'A qualitative exploration of the integration experiences of LGBTQ refugees who fled from the Middle East, North Africa, and Central and South Asia to Austria and the Netherlands', Sexuality Research and Social Policy 17:13-26. https://doi.org/10.1007/s13178-018-0364-7.

Allsopp, Jennifer, Nando Sigona and Jenny Phillimore. 2014. 'Poverty among refugees and asylum seekers in the UK: An evidence and policy review', IRiS Working Paper Series, No. 1/2014. Birmingham: Institute for Research into Superdiversity.

Anderson, Jessica, Jeannine Hollaus, Annelisa Lindsay and Colin Williamson. 2014. 'The culture of disbelief: An ethnographic approach to understanding an under-theorised concept in the UK asylum system'. Refugee Studies Centre Working Paper Series no. 102, Oxford Department of International Development.

Arnold, Samantha K. 2012. 'Nexus with a convention ground: The particular social group and sexual minority refugees in Ireland and the United Kingdom', Irish Law Journal 1:93-119.

Arnold, Samantha K. 2013. 'Identity and the sexual minority refugee: A discussion of conceptions and preconceptions in the United Kingdom and Ireland', Human Rights Brief 20:26-31. https://doi.org/10.1163/2210-7975_hrd-9969-3008.

Awadalla, Ahmed and Iris Rajanayagam. 2016. 'LGBT ${ }^{*}{ }^{*} \mathrm{Q}$ refugees in Germany', Lernen aus der Geschichte. Available at: http://lernen-aus-der-geschichte.de/International/content/12840 (accessed 22 February 2020). 
BAMF (Bundesamt für Migration und Flüchtlinge). 2019. 'Branch offices in AnkER facilities'. Available at: http://ankommenapp.de/EN_nvam/DasBAMF/Aufbau/Standorte/ ASinAnKEREinrichtung/aussenstelle-in-anker-einrichtung-node.html (accessed 4 July 2020).

Bell, David and Gill Valentine (eds). 1995. Mapping Desire: Geographies of sexualities. London: Psychology Press.

Bell, Michael and Cole Hansen. 2009. 'Over not out: The housing and homelessness issues specific to lesbian, gay, bisexual and transgender asylum seekers.' Metropolitan Support Trust, London.

Bhimji, Fazila. 2016. 'Visibilities and the politics of space: Refugee activism in Berlin', Journal of Immigration and Refugee Studies 14:432-50. https://doi.org/10.1080/15562948.2016.1145777.

Blanck, Peter D. (ed.). 1993. Interpersonal Expectations: Theory, research, and applications. Cambridge: Cambridge University Press.

Braimah, Tim S. 2015. 'Defining a particular social group based on the meaning of nondiscrimination in international human rights law: Utilizing the definition in deciding refugee claims based on sexual orientation', Global Journal of Human-Social Science C: Sociology \& Culture 15:23-31.

Browne, Kath, Jason Lim and Gavin Brown. 2009. Geographies of Sexualities: Theory, practices and politics. Farnham: Ashgate.

Butler, Judith. 1991. 'Imitation and gender insubordination'. In Inside/out: Lesbian theories, gay theories, edited by Diana Fuss, 13-31. New York: Routledge.

Clark-Kazak, Christina. 2017. 'Ethical considerations: Research with people in situations of forced migration', Refuge: Canada's Journal on Refugees 33:11-17. https://doi.org/10.7202/ 1043059ar.

Combahee River Collective. 1977. 'Combahee River Collective statement'. Available at: https:// combaheerivercollective.weebly.com/the-combahee-river-collective-statement.html (accessed 22 February 2020).

Crenshaw, Kimberlé. 1989. 'Demarginalizing the intersection of race and sex: A Black feminist critique of antidiscrimination doctrine, feminist theory and antiracist politics', University of Chicago Legal Forum (1):139-68.

Da Lomba, Sylvie. 2004. The Right to Seek Refugee Status in the European Union. Oxford: Intersentia.

Danisi, Carmelo, Moira Dustin, Nuno Ferreira and Nina Held. 2021. Queering Asylum in Europe: Legal and social experiences of seeking international protection on grounds of sexual orientation and gender identity. Cham: Springer.

Dustin, Moira. 2018. 'Many rivers to cross: The recognition of LGBTQI asylum in the UK', International Journal of Refugee Law 30:104-27. https://doi.org/10.1093/ijrl/eey018.

Dyck, Jordan. 2019. LGBT African Asylum Seeker Research Project Report. Commissioned by the Metropolitan Community Church of North London and supposed by UKLGIG and the Enfield LGBT Network. Available at: http://mccnorthlondon.org.uk/wp-content/uploads/2019/09/ LGBT-African-Asylum-Seeker-Research-Project-Report.pdf (accessed 22 February 2020).

El-Enany, Nadine. 2008. 'Who is the new European refugee?' European Law Review 33:313-35.

Epstein, Lee and Gary King. 2002. 'The rules of inference', University of Chicago Law Review 69:1134. https://doi.org/10.2307/1600349.

ECRE (European Council on Refugees and Exiles). 2018. AIDA - Asylum Information Database country report: Germany. Available at: http://www.asylumineurope.org/sites/default/files/ report-download/aida_de_2017update.pdf (accessed 22 February 2020).

ECRE (European Council on Refugees and Exiles). 2019. Asylum Information Database country reports: Germany. Available at: https://www.asylumineurope.org/reports/country/germany (accessed 22 February 2020); Italy. Available at: https://www.asylumineurope.org/reports/ country/italy (accessed 22 February 2020); UK. Available at: https://www.asylumineurope. org/reports/country/united-kingdom (accessed 22 February 2020).

Ferreira, Nuno and Dora Kostakopoulou (eds). 2016. The Human Face of the European Union: Are EU law and policy humane enough? Cambridge: Cambridge University Press.

FRA (European Union Agency for Fundamental Rights). 2010a. 'Access to effective remedies: The asylum-seeker perspective'. Available at: https://fra.europa.eu/en/publication/2010/accesseffective-remedies-asylum-seeker-perspective (accessed 22 February 2020).

FRA (European Union Agency for Fundamental Rights). 2010b. 'The duty to inform applicants about asylum procedures: The asylum-seeker perspective'. Available at: https://fra.europa. eu/en/publication/2010/duty-inform-applicants-about-asylum-procedures-asylum-seekerperspective (accessed 22 February 2020). 
Gartner, Johannes Lukas. 2015. '(In)credibly queer: Sexuality-based asylum in the European Union'. Available at: https://www.humanityinaction.org/knowledge_detail/incredibly-queersexuality-based-asylum-in-the-european-union/ (accessed 22 February 2020).

Giametta, Calogero. 2014. "'Rescued" subjects: The question of religiosity for nonheteronormative asylum seekers in the UK', Sexualities 17:583-99. https://doi.org/10.1177/ 1363460714526130.

Güler, Arzu, Maryna Shevtsova and Denise Venturi (eds). 2019. LGBTI Asylum Seekers and Refugees from a Legal and Political Perspective: Persecution, asylum and integration. Cham: Springer.

Haritaworn, Jin. 2015. Queer Lovers and Hateful Others: Regenerating violent times and places. London: Pluto Press.

Hathaway, James C. and Michelle Foster. 2014. The Law of Refugee Status (2nd edn). Cambridge: Cambridge University Press.

Held, Nina. 2017. 'What does a genuine lesbian/gay relationship look like in the eyes of asylum decision makers?', Discover Society, 2 May. Available at: https://discoversociety.org/2017/05/ 02/what-does-a-genuine-lesbiangay-relationship-look-like-in-the-eyes-of-asylum-decisionmakers/ (accessed 22 February 2020).

Held, Nina. 2018. 'Projektbericht: Erfahrungen mit der Anhörung von LSBTIQ* Geflüchteten'. Rainbow Refugees Cologne-Support Group e.V., Aidshilfe Düsseldorf e.V., You're Welcome - Mashallah Düsseldorf, Kölner Flüchtlingsrat, Projekt Geflüchtete Queere Jugendliche, Fachstelle Queere Jugend NRW / Schwules Netzwerk NRW e.V.

Held, Nina. 2019. 'Sexual orientations and gender identity: Claims of asylum in Germany'. In Refugees and Queers: Forschung und Bildung an der Schnittstelle von LSBTTIQ, Fluchtmigration und Emanzipationspolitiken, edited by Carolin Küppers, 53-80. Bielefeld: Bundesstiftung Magnus Hirschfeld.

Home Office. 2015. 'Asylum Policy instruction: Assessing credibility and refugee status', version 9.0. UK Home Office.

Home Office. 2016. 'Asylum Policy instruction: Sexual orientation in asylum claims', version 6.0. UK Home Office.

Il Grande Colibri. 2019. 'Storie di vita [Life stories]'. Available at: http://www.sogica.org/it/life_ stories/el-fil-essere-rifugiato-in-un-paese-come-litalia-significa-per-me-dover-imparare-aessere-paziente/ (accessed 22 February 2020).

Jansen, Sabine. 2019. 'Pride or shame? Assessing LGBTI asylum applications in the Netherlands following the XYZ and ABC judgments'. Amsterdam: COC Netherlands. Available at: https:// www.coc.nl/wp-content/uploads/2019/01/Pride-or-Shame-LGBTI-asylum-in-theNetherlands.pdf (accessed 22 February 2020).

Johnston, Lynda and Gill Valentine (eds). 1995. 'Wherever I lay my girlfriend, that's my home: The performance and surveillance of lesbian identities in domestic environments'. In Mapping Desire: Geographies of sexualities, edited by David Bell and Gill Valentine, 99-113. London: Routledge.

Jordan, Sharalyn and Chris Morrissey. 2013. “"On what grounds?” LGBT asylum claims in Canada', Forced Migration Review 42:13-15.

Kahn, Sarilee. 2015. 'Cast out: "Gender role outlaws" seeking asylum in the West and the quest for social connections', Journal of Immigrant \& Refugee Studies 13:58-79. https://doi.org/ 10.1080/15562948.2014.894169.

Kahn, Sarilee, Edward J. Alessi, Hanna Kim, Leah Woolner and Christina J. Olivieri. 2018. 'Facilitating mental health support for LGBT forced migrants: A qualitative inquiry', Journal of Counseling \& Development 96:316-26. https://doi.org/10.1002/jcad.12205.

Khan, Tawseef. 2016. 'Investigating the British asylum system for lesbian, gay and bisexual asylum-seekers: Theoretical and empirical perspectives on fairness.' PhD thesis, University of Liverpool.

Krause, Ulrike. 2017. 'Researching forced migration: Critical reflections on research ethics during fieldwork'. Refugee Studies Centre Working Paper Series no. 123, Oxford Department of International Development. Available at: https://www.rsc.ox.ac.uk/publications/ researching-forced-migration-critical-reflections-on-research-ethics-during-fieldwork (accessed 22 February 2020).

Lee, Edward O. J. and Shari Brotman. 2011. 'Identity, refugeeness, belonging: Experiences of sexual minority refugees in Canada', Canadian Review of Sociology / Revue canadienne de sociologie 48:241-74. https://doi.org/10.1111/j.1755-618x.2011.01265.x. 
Lewis, Rachel. 2013. 'Deportable subjects: Lesbians and political asylum', Feminist Formations 25:174-94. https://doi.org/10.1353/ff.2013.0027.

Lukac, Enes. 2017. 'LGBT asylum seekers in Sweden: Conceptualising queer migration beyond the concept of "safe third country".' Oxford Research.

Markard, Nora. 2016. 'Persecution for reasons of membership of a particular social group: Intersectionality avant la lettre?', Sociologia del Diritto (2):45-63.

McConville, Mike and Wing Hong Chui (eds). 2007. Research Methodsfor Law. Edinburgh: Edinburgh University Press.

McDonald-Norman, Douglas. 2017. 'No one to bear witness: Country information and LGBTQ asylum seekers', Refuge 33:88-100. https://doi.org/10.7202/1043066ar.

Miles, Nathanael. 2010. No Going Back: Lesbian and gay people and the asylum system. Stonewall. Available at: https://www.stonewall.org.uk/resources/no-going-back-2010 (accessed 24 August 2020).

Millbank, Jenni. 2009. "“The ring of truth”: A case study of credibility assessment in particular social group refugee determinations', International Journal of Refugee Law 21:1-33. https:// doi.org/10.1093/ijrl/een040.

Namer, Yudit and Oliver Razum. 2018. 'Access to primary care and preventive health services of LGBTQ+ migrants, refugees, and asylum seekers'. In Access to Primary Care and Preventative Health Services of Migrants (SpringerBriefs in Public Health), edited by Aldo Rosano, 43-55. Cham: Springer.

Puar, Jasbir K. 2007. Terrorist Assemblages: Homonationalism in queer times. Durham, NC: Duke University Press.

Puar, Jasbir. 2013. 'Rethinking homonationalism', International Journal of Middle East Studies 45:336-9. https://doi.org/10.1017/s002074381300007x.

Rehaag, Sean. 2008. 'Patrolling the borders of sexual orientation: Bisexual refugee claims in Canada', McGill Law Journal / Revue de droit de McGill 53:59-102.

Shuman, Amy and Carol Bohmer. 2014. 'Gender and cultural silences in the political asylum process', Sexualities 17:939-57. https://doi.org/10.1177/1363460714552262.

Singer, Sarah. 2019. "'Desert island" detention: Detainees' understandings of "law" in the UK's immigration detention system', Refugee Survey Quarterly 38:1-29. https://doi.org/10.1093/ rsq/hdy020.

Spijkerboer, Thomas (ed.). 2013. Fleeing Homophobia: Sexual orientation, gender identity and asylum. Abingdon: Routledge.

Stonewall and UKLGIG. 2016. 'No safe refuge: Experiences of LGBT asylum seekers in detention'. Available at: https://www.stonewall.org.uk/system/files/no_safe_refuge.pdf (accessed 22 February 2020).

Stuart, Alasdair. 2012. 'Over not out refreshed 2012: An update on progress against the original recommendations of the "Over not out" report (2009)'. London: Metropolitan Migration Foundation/MBARC. Available at: https://www.metropolitan.org.uk/images/MetropolitanMF-LGBT-Over- Not-Out2012-final1.pdf (accessed 5 July 2020).

TGEU (Transgender Europe). 2016. 'Welcome to stay'. Available at: http://tgeu.org/wp-content/ uploads/2016/10/TGEU_TransAsylumBrochure_WEB.pdf (accessed 22 February 2020).

Travers, Max. 1999. The British Immigration Courts: A study of law and politics. Bristol: Policy Press.

Travers, Max and John F. Manzo (eds). 1997. Law in Action: Ethnomethodological and conversation analytic approaches to law. Aldershot: Ashgate.

Tschalaer, Mengia. 2020. 'Between queer liberalisms and Muslim masculinities: LGBTQI+ Muslim asylum assessment in Germany', Ethnic and Racial Studies 43:1265-83.

UKLGIG. 2010. 'Failing the grade: Home Office initial decisions on lesbian and gay claims for asylum'. London: UK Lesbian and Gay Immigration Group.

UKLGIG. 2013. 'Missing the mark: Decision making on lesbian, gay (bisexual, trans and intersex) asylum claims'. London: UK Lesbian and Gay Immigration Group.

UN General Assembly. 1951. 'Convention relating to the status of refugees', 28 July, United Nations, Treaty Series, vol. 189. Available at: https://www.refworld.org/docid/3be01b964.html (accessed 22 February 2020).

UNHCR. 2012. 'Guidelines on International Protection No. 9: Claims to Refugee Status Based on Sexual Orientation and/or Gender Identity within the Context of Article 1A(2) of the 1951 Convention and/or Its 1967 Protocol Relating to the Status of Refugees'. Available at: http:// www.unhcr.org/509136ca9.pdf (accessed 22 February 2020). 
United Nations. 'What is the rule of law'. Available at: https://www.un.org/ruleoflaw/what-is-therule-of-law/ (accessed 22 February 2020).

Valentine, Gill. 1993. 'Negotiating and managing multiple sexual identities: Lesbian time-space strategies', Transactions of the Institute of British Geographers 18:237-48. https://doi.org/ $10.2307 / 622365$.

Valentine, Gill. 1996. '(Re)negotiating the "heterosexual street": Lesbian productions of space'. In BodySpace: Destabilizing geographies of gender and sexuality, edited by Nancy Duncan, 146-55. London: Routledge.

Venturi, Denise. 2017. 'Reflections on empirical research with LGBTI refugees: A legal scholar's perspective', Oxford Monitor of Forced Migration 6:20-3.

Wessels, J. 2011. 'Sexual orientation in refugee status determination'. Refugee Studies Centre Working Paper Series no. 74, Oxford Department of International Development.

Whittaker, David. 2006. Asylum Seekers and Refugees in the Contemporary World. Abingdon: Routledge.

Zadeh, Leila. 2019. 'Opinion: Detention is one of the most dangerous places for LGBT+ refugees. The government must enforce a time limit', The Independent, 13 September. Available at: https://www.independent.co.uk/voices/lgbt-refugees-detention-government-refusaltime-limit-28-days-hostile-environment-a9103726.html (accessed 22 February 2020). 
10

\section{The (micro-)politics of support for LGBT asylum seekers in France}

Sara Cesaro

\section{Introduction}

A major theme in French social science research, both academic and non-academic, in the past two decades has been the links between immigration and 'State thinking' (pensée d'État) following Abdelmalek Sayad's $(1999,6)$ idea that 'thinking immigration is thinking the State' ('penser l'immigration, c'est penser l'État'). This research is mainly based on ethnographies of immigration offices (guichets) and on observing the daily work of the street-level bureaucrats (Lipsky 1980) in charge of immigrants and aliens ${ }^{1}$ who, for different reasons and through different processes, try to obtain or renew their papers (mainly residency permits linked to work, family reunification, etc.) in the country (Hajjat 2012; Jakšić 2013; Le Courant 2015; Mazouz 2017; Spire 2008). By studying everyday interactions between migrants and state officials, this research shows how, on the one hand, 'the state adopts repressive laws which seemingly respect fundamental rights but, on the other, it delegates to subordinate sections of the administration the task of rendering these rights inoperative' (Spire 2016, 28). ${ }^{2}$ Civil society groups are among those to which the state has delegated administrative responsibilities, leading to an increasing professionalisation of those organisations that work with migrants. These organisations are fighting against 'policies of suspicion' (D'Halluin-Mabillot 2012), while at the same time they are compelled to implement them, eventually becoming new immigration offices themselves (Pette 2014). Research focused on LGBT migrants 
in France addresses the topic mainly from the point of view of asylum institutions (Kobelinsky 2012) or examining migrants' trajectories and subjectivities (Amari 2018; Chossière 2017; Fassin \& Salcedo 2015). Organisations supporting LGBT migrants have been studied in relation to binational couples (Bécasse 2015; Salcedo Robledo 2015) and, more recently, in an attempt to conceptualise the asylum process as a filtering device, in which organisations take part as 'elusive borders' (Giametta 2018). However, no research to date has sought to understand the way these organisations seek to help LGBT migrants and asylum seekers. The aim of this chapter therefore is to examine the (micro-)politics of support these organisations provide to asylum seekers. How should volunteers' actions be understood? How do volunteers discuss their engagement? What fractures exist between their discourses and their practices? In order to answer these and other questions, I will draw on empirical material collected during ongoing fieldwork in one particular organisation, Ardhis, ${ }^{3}$ over a four-year period.

\section{Overview of the organisations supporting LGBT migrants in France}

Emerging in the mid-1990s, the field of organisations supporting LGBT migrants consisted mainly of groups fighting against AIDS on the blueprint of Act Up. Act Up itself developed strategies and expertise in defence of migrants who were being deported as undocumented while affected by AIDS; Ardhis was founded around 1998-9, specialising in supporting binational same-sex couples (Bécasse 2015; Broqua 2006; Salcedo Robledo 2015). Timely forms of coalition existed, addressing specific topics in order to bring about changes to existing laws, especially concerning civil unions. Around 2004, Ardhis started to work specifically on asylum, by helping Amnesty International and La Cimade (a leading migrant support organisation in France) with a number of SOGI claims. The organisation had been identified by these and other actors, including migrants, as the main - and for some time the only - organisation working with LGBT migrants.

A restructuring of the field happened around 2009. Two new organisations focusing on asylum emerged, one lesbian-only organisation (Les Lesbiennes qui Dépassent les Frontières) and one founded by and for lesbian women of colour (LOCs), some of them refugees. At the same time, Ardhis officially created a so-called 'asylum pole', separating support for binational couples seeking residency for the non-French partner from support for asylum seekers. In 2009 another organisation emerged from a previous social movement, Acceptess-T, founded by and for South American sex worker 
trans women. Although it only rarely deals with asylum, often asking other organisations for support, Acceptess-T became crucial in the field for the fights it embodies, at the heart of the struggle for migrants' and sex workers' rights, and against AIDS.

Since 2009, Ardhis has helped more than 4,000 asylum seekers; it is considered the leading organisation in the field in terms of its scope of action (encompassing legal help) and of its expertise; it has participated numerous times in formal and informal discussions with the asylum administration, political parties, etc. Official statistics concerning the success rate do not exist, but we can affirm that it is way beyond the overall 30-40 per cent yearly overall rate of international protection given by Ofpra (Office français de protection des réfugiés et apatrides; French Office for the Protection of Refugees and Stateless People), the first asylum authority with which asylum seekers are confronted, and CNDA (Cour nationale du droit d'asile; the National Court of Asylum), the second asylum authority, to which asylum seekers can appeal in the event of a first rejection.

As an analytical framework, I will mainly draw on a sociological approach inherited from the study of service relationships developed primarily by Everett Hughes (1956). This allows a description and analysis of the interactions between volunteers and asylum seekers, not only as part of a political, moral or ethical engagement, but also as work that needs to be objectified as such. My main argument is that, by considering what volunteers do on a daily basis, we might depart from a conception of volunteers and organisations as autonomous beings/spaces and see them as embedded in a broader apparatus in which the division of labour is important and determinant; second, we can stop thinking about this space as a mere filtering device. Thus we employ the idea of working for and working to people, addressing the 'ambiguities in those kinds of work called personal or professional services' (Hughes 1956, 3) in which people, in this case asylum seekers, might have the impression that some things are not just done for them (for their own benefit) but to them. This may have given them the impression that those helping them, in this case volunteers, might even hurt them, or that they might benefit others or try to modify them, and that the helpers might seek to benefit from it in some way. This idea will be central to our understanding of how the organisation's space is structured; it will be instrumental for understanding both the organisation of the system of interactions and how the relationships with asylum seekers are conceived: volunteers aim at structuring their work so as to have as much time as possible to work on a claim, which simultaneously 
means to work on, with and to asylum seekers, helping them build and shape a narrative that might help them pass through a specific step, be it a national border or the asylum procedure.

\section{Truth as trouble?}

Sociologist Mathilde Pette (2015) argues that organisations that support migrants in the north of France have to adapt to the ever-changing global and local politics of the state, and so find themselves in a 'humanitarian impasse': in an ongoing and seemingly endless state of emergency they are compelled to conform to a humanitarian action that focuses on emergency and everyday help. The idea of the impasse is functional: what structures the field I study over time is not mainly (or exclusively) a situation of ongoing humanitarian emergency but rather the need to develop strategies in order to make SOGI claims intelligible (Giametta 2017). In other words, organisations are compelled to (help) solve a problem inherent in the relationship between migrants and the asylum administration: are migrants telling the truth about themselves?

We will consider asylum claims as a social system of interactions (Hughes 1984) between asylum seekers, volunteers and different asylum administrations, each group constantly interacting with the others, each one having a particular role. The division of labour and the division into roles, in particular the division of tasks between volunteers and employees of the asylum administrations, needs to be studied carefully. Albeit occupying somewhat very different roles, at least symbolically, some tasks are very similar and lead to similar problems: both volunteers and personnel from the asylum administration interview asylum seekers. The volunteers do so in order to help the asylum seekers go through the asylum procedure, while the personnel from the asylum administration do so in order to evaluate the asylum seekers and decide whether or not to grant international protection. They face a similar problem: are asylum seekers telling the truth? For asylum seekers, the core question is 'Will they believe me?', and it is addressed to both volunteers and the personnel from the asylum administration, albeit (sometimes) in different ways. In the former case they want to be reassured or helped, in the latter they are conscious of the decision-makers' power. The idea of 'problems' as 'trouble' has been developed in interactional sociological scholarship (Goffman 1961; Emerson \& Messinger 1977; Emerson 2015), which asserts that in the construction of a troubled situation there are four 
actors: the complainant, the victim, the troubleshooter and the troublemaker. Here, the trouble is not a mere interactional issue, even if it manifests itself in interactional situations, but more of a fundamental and structural element of the relationship between asylum seekers and the state, whereby suspicion and mistrust are at the core of (anti-)migration policies and practices of hearing.

\section{An impossible negotiation ...}

This context de facto leads to trouble in the interaction, as it structures, for the most part, the conversation as a place for suspicion to be uncovered and the truth to be found. The expression of the trouble can be identified during interviews and hearings, and can be clearly found in written rejection decisions, in which the Eurocentric implications of the understanding of asylum seekers' narratives have already been well analysed (Giametta 2018): they typically state that the person's statements concerning his or her sexual orientation didn't convince the Office (Ofpra), and so the validity of the claim cannot be established. The trouble relates more specifically to the elements that contribute to the credibility of the narratives of asylum seekers, what makes them intelligible and readable and, most of all, should they not be readable or intelligible enough, how the problem can be overcome. Organisations can be helpful in solving this problem; that is, they may act as 'troubleshooters', as this volunteer asserts:

Ofpra's dream is that Ardhis [will start] sorting out good migrants from bad migrants, real [homosexuals] from fakes. ${ }^{4}$ This is all too problematic, as it implies that the asylum seekers supported by Ardhis will obtain the status and the poor guy from another city will not be granted asylum because he is alone and will be treated differently depending on whether he's supported or not by our organisation.

(O., 35 years old, June 2016)

We find confirmation of this statement during hearings and interviews, in which asylum seekers are frequently questioned about their belonging to LGBT organisations. In the eyes of the asylum administration LGBT organisations become a space for validating subjectivities (Cesaro \& Carnassale 2018): being unable to determine whether the asylum seeker is part of a 'social group' according to the Geneva Convention of 1952 and the New York Protocol of 1967 in his or her home country, the 
asylum administration seems to rely on the asylum seeker's attendance at certain social spaces to determine whether or not the person is part of a social group in the host country. LGBT organisations find themselves in a 'witness impasse': their role, understood at the beginning as a source of support and help, becomes that of a witness, doing the administration's job (Hajjat 2012) by unwittingly evaluating and contributing to the chances of each asylum seeker obtaining state protection, rendering volunteers unable to coherently accomplish their work as they conceive it. In this context, their discretionary power and the autonomy they have in respect of their hierarchy confers on volunteers a decisive role in the application of public policies (Lipsky 1980). This impasse creates a certain pressure on organisations and their members, as they feel partly responsible for the success or failure of the claim.

\section{... and a necessary selection}

The organisation faces another form of pressure, that of not being able to help each and every person requesting it. The main way the organisation provides support is on a one-on-one basis: every month each volunteer starts to help a certain number of asylum seekers, providing personal help to each claimant. Over the years, a volunteer can help tens or hundreds of people individually. This support system, understood as functional as it creates the possibility of close working relationships, so that migrants feel confident to tell their stories and be better prepared for interviews, puts a lot of pressure on volunteers, who may at times be overburdened, and so stop 'taking on new people'. This, and the fact that the number of migrants requesting help from the organisation has been steadily increasing, led volunteers to establish and implement a form of selection in order to make their work easier. The selection logic is itself a part of the micro-politics of support, as it gives an idea of the role volunteers have and are willing to embody. It is based on a series of priorities that take into account the different stages of the asylum process.

1. The person has an interview with Ofpra scheduled in the coming weeks or days. This leaves some time for the volunteers to prepare the asylum seekers for the interview, explain what to expect and give some advice.

2. The person has to return his or her first Ofpra registration papers in the coming weeks or days. This allows the asylum seeker to receive 
help with writing his or her story, and plenty of time to prepare for the interview.

3. The person is waiting for Ofpra to schedule the interview. As this waiting time is based on the month in which the asylum seeker first registered at Ofpra, the closer the registration is to the day the asylum seeker first made contact with Ardhis, the less urgent the claim is considered. If people in this category are not assigned a volunteer, they are asked to come back or contact the organisation once they receive an appointment (always at least one month before the interview), whereupon they are assigned to category 1 .

4. The person has yet to start the process or have a meeting scheduled with a prefecture. As the number of people coming has been growing each month, this category of asylum seeker is often asked to come back the following month, by which time they will probably be in category 2.

5. The person has already been rejected by Ofpra and is now appealing to CNDA. Usually, they are not assigned a volunteer.

These criteria allow volunteers to work long term with asylum seekers: it is more useful and beneficial to help asylum seekers from the early stages of their claim, than to try to help those who are already at an advanced stage. Thus it is more beneficial for asylum seekers, and more valuable to volunteers, to have the chance to work to (a long-term working relationship) than to work for (a short-term relationship). However, exceptions to this system exist. It is common for volunteers and asylum seekers to have to work under pressure, particularly before an Ofpra interview. The adopted criteria leave room for two chances of obtaining asylum (the interview and the appeal). In the case of a difficult and urgent situation, volunteers can already start thinking about some appeal strategies.

\section{Restructuring the welcoming space: changing a micro-social structure of interaction to re-signify a macro-social structure of power?}

One of the key dates in the organisation's calendar is the monthly meeting at the Paris LGBT Centre, ${ }^{5}$ when asylum seekers come to request and receive support from the organisation. Every month, tens of people queue in front of the Centre; one by one they pass through the doors and a team of volunteers welcomes them inside. They all receive information about the organisation and its activities and the asylum process more 
generally. A number of them (usually around 30) are assigned a volunteer, who will track and support their claims individually.

The morphology of this meeting and the process of assigning or not assigning volunteers to asylum seekers have been widely debated and critiqued by most of the volunteers over the years. On numerous occasions they openly expressed the feeling that the organisation was 'looking like a prefecture', thus enforcing state violence through selection and border enforcing. In this case, volunteers not only feel like a guichet, they look like one, and they feel that the barriers or borders they might enforce are not only symbolic but physical. I will retrace the history of this meeting and its morphology in order to underline the changes over time - they are important if we are to understand the evolution of the organisation's politics - showing how this moment was restructured over time in an attempt to re-signify the symbolical space of deployment of volunteers' first interactions with asylum seekers.

\section{Division of labour and exclusion of migrants from welcome meetings}

The first meetings were roundtables, that's what we called them. They took place on Tuesday night: we all sat down to talk and exchange. The new people, those who came for the first time, were asked to explain their situation, administratively speaking. ... Then there were the old ones, either with the [refugee] status or still in the process, and they gave them, together with us, some advice, where to go, what do to, what to expect. ... And that was it. At the beginning it was really informal and cosy. Then, more and more people started to come, and more and more, until we couldn't handle it that way any more.

(C., man, 42 years old)

As this volunteer recalls, when the first meetings to welcome asylum seekers were held, three groups were clearly identified: newcomers, looking for information and support; volunteers, mainly French men and women; and asylum seekers and refugees who were already being supported. The last two groups were providing direct experience and advice to the first. The division between volunteers and 'people who were already being helped' was based on citizenship; the first were French, the latter were migrants. However, both were considered to have some kind of expertise on asylum, and asylum seekers were not excluded from 
the possibility of giving support - quite the contrary. This collective way of functioning lasted a few years, roughly from 2005 until 2009, when the growing number of people seeking help brought about a first restructuring, one that would mark a significant change in the functioning of the organisation.

Volunteers decided to implement what appeared to them to be a more structured and professional system with different filters, necessary to identify priority claims and assign asylum seekers to the right person when necessary (as legal resources and knowledge, in particular, were and are not evenly shared among volunteers). They implemented a more formal division of labour among themselves, which was accompanied by the gradual disappearance of the 'people who were already being helped' from the welcome meetings. From here on, people who were potentially part of this group had a subaltern role in relation to the French volunteers, mainly talking informally with newcomers, assigning people to the 'right' volunteer (one having a specific role in the meeting, e.g. registration) and providing manual help with chairs, tables, etc. Those filling this role were asylum seekers who had been activists in their home countries, who could 'find continuity in their engagement by doing something in the organisation' (H., man, 28 years old, July 2016). In this new setting, however, all the official talks (welcoming, explanations, registration) were given by French volunteers. It appeared more and more that this symbolic division was also a racial one: white people held symbolic power linked to knowledge and the authority to speak to a group of people, while black or brown people were those either being helped or in a subordinate position, no longer having the opportunity to stand in front of an audience.

During this period, the morphology of the welcome meeting changed greatly. Asylum seekers, ranging in number from 50 to more than 100 , started to queue outside the LGBT Centre; a couple of volunteers would stay with them and, at around 11 a.m., would start to examine, assess and separate them according to their administrative situation. Those whose situation was considered a priority would enter the Centre, where they would queue again at the welcome desk on the opposite side of the room. Here, two other volunteers would assess their administrative situation for a second time, in order to identify high-priority claims (e.g. someone who had an interview with Ofpra the following week or had been placed under the Dublin Regulation), and ask how they knew about the organisation. They would eventually hand them a form and invite them to go downstairs, where other volunteers were waiting for them. Once there, volunteers would take the form from the asylum seekers' 
hands and proceed to fill it in, by asking the asylum seeker, for a third time, questions about their administrative situation. They would discuss it briefly and give initial advice. Subsequently, the asylum seekers were asked to wait again - this time sitting - in order to be registered one by one by another volunteer, seated at a desk and typing all the information into a computer; only at this point were they assigned to the volunteer(s) who would support and assist them throughout the claim procedure. This whole process usually took about two hours. Once all the asylum seekers who were admitted downstairs had been assigned a volunteer, the person in charge of the registration would give a short speech about the role of the organisation, what it could do (legal support, administrative procedures, opportunities for socialising) and what it could not do (provide housing, give money) to help them.

The monthly meeting started to be unofficially but commonly called the 'sorting session'. It was understood as highly problematic by certain volunteers, in particular because of the repetitive dimension of the interactions with the asylum seekers, who were asked to queue and explain their situation numerous times, and because most of those who came to the door were asked to leave with little to no information, but only with the suggestion that they come back the following month. Facing the same problems as prefectures or other immigration offices, volunteers were using a similar solution to deal with their inability to welcome everybody, confining migrants to a space of relegation outside the organisation, thus reinstating a symbolic and formal border.

\section{Restructuring and re-signification of social roles}

As previously stated, volunteers had a clear impression that they were sorting those who would and could be helped from those who could not. Thus, significant changes were brought to the morphology of the meeting. The spatial organisation and the chain of interactions between volunteers and asylum seekers were rethought, at least inside the LGBT Centre. One by one, all the asylum seekers queuing outside were let in, which abolished the symbolic barrier (and border) that previously existed between the inside and the outside of the Centre and was formalised in the exclusion of some and the letting in of others. At the door, they are asked to wait for a volunteer to be free to take charge of them. When one becomes available, he or she goes towards the door in order to welcome one person; a brief talk about the administrative situation leads to the volunteer giving a small piece of coloured paper, which 
allows the asylum seekers to be divided into different groups according to the previously quoted priority. One at a time, asylum seekers are invited to go downstairs, where two volunteers give a long presentation of the work of the organisation; in particular, they give the dates of the different meetings and activities in the following weeks and invite those who might be interested to participate. Another symbolic border was abolished with the opening of these activities to all the asylum seekers, not only to those who will receive individual support but to all, regardless of their administrative status. During this presentation, group after group of asylum seekers is asked to go back upstairs. Here, volunteers are waiting for them with a form (the same one as before) which they will fill in; once the form is completed, the asylum seekers have to queue one last time to be assigned a volunteer, and can then leave.

In order to try and break down the barrier between those who will receive individual support and those who were asked to leave, volunteers organised different collective meetings: for those at the very beginning of their claim procedure a joint meeting is scheduled for the following week. Those who have been rejected by Ofpra and are thus waiting for their hearing at CNDA can take part in a collective meeting (so-called 'training'), just after the monthly welcome meeting, during which they can engage with volunteers about the hearing - to learn what they should expect and what is expected of them - as well as about their individual claims. Ironically, in the previous configuration this group was asked to leave first, without the possibility of entering the Centre; it is the last one to leave in the new set-up.

By reorganising and re-signifying its welcome space, the organisation aimed at distancing itself from immigration offices, defined by the erection of physical and symbolic barriers, and associated with the image of total institutions (Goffman 1961). Breaking down the symbolic and physical barriers between volunteers and asylum seekers, restructuring the welcome space as a multiplicity of rather short interactions and symbolically inviting asylum seekers to join different activities can be seen as a quest for respectability (Hughes 1984), characterised by a change of attitudes towards asylum seekers. In doing so, volunteers are not only re-signifying their working space and their actions, but their audience as well. This modification of the welcome process aims at signifying asylum seekers as, somehow, less like asylum seekers than they would be at a prefecture.

The value of the immigration office being proportional to the prestige of the people it welcomes, the immigration officers 
find themselves downgraded [déclassés] by the downgrading

[déclassement] of the immigrants who show up at [their] doors.

(Infantino 2010, 14)

Inversely - but coherently - we can affirm that by restructuring and re-signifying the welcome space, changing the way we treat asylum seekers and distancing our practices from 'institutional' procedures, we contributed to a temporary reclassification of migrants themselves; in return, volunteers are reclassified as not merely 'immigration officers', as they might otherwise feel themselves to be. Thus they insist on the fact that their work needs to be understood as work for rather than work to.

In the next section I will shift from the study of the organisation of the system of interaction to the concept of the relationships between volunteers and asylum seekers. I will try to show that, even though the shift might ask for a radically different analytical framework focused on relationships rather than interactions, the one we adopted for this paper still helps us understand how these relationships are conceived as well as some of the political implications of their conceptualisation.

\section{Everything but race? Class, age, gender and the discourses of support}

Volunteers are in a position of exerting different forms of superiority over asylum seekers, which is considered for the most part a consequence of the nature of their relationship as one between help-givers and help-receivers. Volunteers have different types of knowledge which they have to share with, and sometimes inculcate in, asylum seekers (Bourdieu \& Passeron 1970). Therefore, this conception of the relationship is informed by race, gender and age. In this part, I will focus on how volunteers engage in a certain amount of negotiation on a daily basis in order (not) to address issues of power over asylum seekers. The question from which I will start is one that is often (implicitly and explicitly) asked by and heard among volunteers: which criteria do we employ to decide if a person is going to benefit from our help, and to what extent?

First, I will analyse the discourses of male volunteers in order to understand how they conceptualise their role and the ways in which they manage their position over asylum seekers, mainly other men. I will then focus on the discourses of female volunteers, underlining the differences and similarities, and how their discourse is presented and can be understood as a form of resistance to a hegemonic conception of support. By considering men's discourse first, I do not intend to say, 
unproblematically, that they represent a matrix against which I will subsequently compare women's discourse. This has to do with the fact that, historically, volunteers and asylum seekers have mainly been men, they occupy most of the symbolic and physical space, and the way support has been shaped is now understood as masculine. Thus, I will try to underline how the conception and materiality of the support are far from neutral and how putting different discourses and practices in perspective can lead to a deconstruction of a hegemonic conception of support.

\section{Truth and belief as a form of governance}

The logic of deservedness and necessity underlined by Calogero Giametta (2018), drawing on the categories identified by Jon Elster and Nicolas Herpin (1994) and used by the sociologist Milena Jakšić (2013) to describe sex workers' support organisations, is central and important to the discourses of volunteers. However, if the discourse of deservedness, based on the supposed truth of a migrant's narrative and thus of their sexual orientation, and on the importance of the reputation of the organisation (supposedly helping only true homosexuals), is clearly described by Giametta (2018), the discourse identified as the one of necessity, which affirms that helping everybody, no matter their truth, is more complex. Let us take into consideration this declaration from a volunteer:

Yes, I help everybody, and I always say it, I am here to have a hundred per cent score. ... And those who don't have their status, well I expected that, because I was myself not sure about their story, I didn't necessarily believe them.

(G., man, 60 years old)

Far from showing a radical stand against the discourse of deservedness, this quote introduces the idea that the volunteer might hold a form of knowledge, the ability to understand the asylum system, his or her truth, and the extent to which they will conform to the administration's standard, such as being able to predict and anticipate the result of a claim. The issue of truth is displaced from the complexities of migrants' realities and identifications (Fassin \& Salcedo 2015) to the 'ability' of the volunteer to understand these narratives. The displacement is then from truth to belief, the latter being linked to the exercise of power over asylum seekers. A certain feature of this power, for example granting access to resources, and the very same access to the symbolic capital embodied by 
the volunteer him- or herself, is entangled in this belief. Aware of their role, volunteers are conscious of their contribution to a form of differentiation among asylum seekers: those who benefit from their help and time may have a better chance of obtaining asylum than those who do not, whether they are homosexuals or not, which is true of any organisation working with asylum seekers (D'Halluin-Mabillot 2012).

The discourse of the quoted volunteer is understood in the space of the organisation as extreme, in the sense that it places too much importance on the volunteer, thus contributing to a 'heroisation' of the person. However, often enough, other volunteers would say that they would put in less effort when they do not believe a person to be homosexual. Supporting a person differently according to one's belief in that person is linked to the habitus of guichet personnel (Dubois 1999) but can also be seen as a form of 'production brake' (Roy 1953). By pointing out that 'they are just volunteers', volunteers imply that they do not receive any material remuneration for the time they spend with asylum seekers; the remuneration and recognition are strictly symbolic and are to be found in their reason for being there: helping homosexuals to obtain asylum. When the basic element in this equation, (the belief in) the homosexuality of the asylum seeker - thus the affiliation to the same community - which could lead to a form of remuneration or recognition, is lacking, they 'do less'. However, if, in Roy's study, production braking is a form of control over work and remuneration, the same cannot be said for volunteers helping asylum seekers without pointing out the interpersonal and political implication of this form of braking. If the control of support and help appears to be a form of governance (Foucault 2012) that volunteers exercise over asylum seekers, using their belief and trust as a tool that informs their implication in the relationship, this framework needs to be put into perspective with the one we adopted at the beginning of this chapter, the difference between working to and working for.

In the end, I am not interested in knowing if he is really homosexual or not. ... But it is true that some narratives are just so incredible, or seen again and again. ... I tell them, if it's not true, just tell me, I don't care, we rewrite your history, it's no big deal. Sometimes it works; they say, 'Yes, it's not true.' Well, it makes my work easier, at least we know where we are starting from. ... But the worst is when they stick to these stories, I don't know what to do and I just feel I should stop.

(F., 37 years old, November 2018) 
According to this volunteer, the problem appears to be less the 'truth of sex' ('la vérité du sexe'; Foucault 1994), or a form of governance over asylum seekers, than the materiality of work: by helping a person they do not trust, volunteers lose the feeling of working to someone. Trust needs then to be understood as a key element in the construction of the feeling of working to someone, as a tool that helps them build relationships with asylum seekers. The following paragraphs will further explore this issue, by addressing different conceptions of the relationship between volunteers and asylum seekers.

\section{Framing and discussing relationships: colour-blind paternalism and integration discourses}

A My word is at the same time a didactic and a persuasive one; it's like the word a teacher might have for his student. ... On one side one considers and assumes one's authority over the person who's on the other side, and one thinks the latter is aware of and accepts that!

Q So you assume an authority over the person in front of you?

A Well yes, yes! The word 'inequality' is disturbing, as it implies someone is on a higher level, and someone else on a lower one. But we are not in an equal relationship! ... Having a $\mathrm{PhD}$ from the Sorbonne is not the same thing as having spent five years in a Qur'anic school, I'm sorry! We face kind of 'losers' (paumé) ... - well, not losers, but 'disoriented' people! They are not in their own country, we do not share the same codes, the same culture!

Q So do you think the organisation should work in such a way that these people learn the codes and the culture we have?

A No, our role is to help them to get refugee status, we do not have enough energy to do it all.

(Discussion with G., 47 years old, June 2017)

The conception of the relationship between this volunteer and asylum seekers stems directly from the analysis Bourdieu and Passeron (1970) develop in their work on the education system in France. The transmission of knowledge is coupled with, and at the same time builds, the authority of one person over another, based on the (inculcated) assumption that what is being inculcated is legitimate and valid. What this volunteer is saying is that he is lucidly aware of the symbolic violence in his relationship with asylum seekers and that it would be silly to think otherwise. 
He takes into consideration issues of class, and in particular education, which lead him to accept unquestioningly the structure of this relationship; race and to a lesser extent migration are absent from his discourse.

How would framing the relationship between volunteers and asylum seekers differently, for example as white French citizens and migrant people of colour, both living in a postcolonial society, impact the understanding of the relationship itself? Would it frame the previous discourse as paternalist and thus racist (Memmi 1957)? Excluding race in the context of the organisation could be considered a form of colour blindness (Bonilla-Silva 2003); the provision of support helps to maintain and reproduce the social roles of the help-giver and the help-receiver, and is thus a form of subordination, reinforcing the idea of the volunteer as executing some form of work (like that of a teacher in relation to a student) that needs to be done. However, framing the relationship in terms of race might lead to a questioning of the support as not mere work, and of the legitimacy of the position and the positionality of the volunteer as a help-giver. As the content of the work (asking questions, allowing access to resources, etc.) is very similar to that accomplished in other immigration offices, the support could again be understood as enhancing a form of state power over asylum seekers which is embedded in the colonial dimension of contemporary migration, rather than as a form of help. This critique in terms of coloniality, linked to the framing of the relationship though race, is present among volunteers, as we will see below.

A second view of the work considers the moment and space of support as a way for asylum seekers to start a broader integration path into French society and, contrary to the previous statement, considers the volunteer as a fundamental part of this process:

What I like in the first place is all these meetings we have with [asylum seekers], in which we work with them in order to discuss their lives, you know. ... And we help find some meaning, some value, a richness, and every time we put it in perspective with what we think of Western society, the differences there might be between Western society and [the asylum seeker's] original society. ... I want the person to become conscious of herself, I want them to realise they have an identity, I want them to be able to integrate the parameters of homosexual culture, of European culture and the link there might be between these two, and at the same time [I want them to] create their identity and learn how to protect themselves. We have to operate with 
them a sort of cultural hybridisation. ... To them we are a sort of guard rail.

(P., 51 years old, November 2017)

This volunteer uses the idea of hybridisation of Édouard Glissant, which in the French context is understood as a 'complex relationship between different [identitarian] elements, which transform one another, but which don't end up in a form of assimilation' (Chancé 2012, 125). However, in this case, this idea serves to build the subjectivity of the volunteer as a guide and guardian over the asylum seekers he supports, thereby reproducing some sort of subordination. Clearly, the relationship is not only one of work and support; it implies that the volunteer watches over the person he supports. Gender, race and age are central to the construction of this subjectivity:

They see us as white and, of course, the white Westerner is 'he who knows'. Furthermore, I have a white beard, so .... We are those who know, for two reasons. The first one is that we're white, the second is that we're old; it's a basic principle of African culture. And even if I am against it, I would like to break this logic - not of the fact of being old, because that's important in their culture - but that the whites know, for me it is unacceptable, but well, we are taken into this prism, and the fact that they come here for help, well ...

(P., 51 years old, November 2017)

The same volunteer adopts a cultural prism through which he understands the way asylum seekers look at him. This leads him to a selective uneasiness of being considered to be in a position of 'natural' superiority. Being considered superior and wise as older, is, for him, a 'basic principle of African culture', and so politically neutral as far as he is concerned; however, being considered superior as white is less acceptable and should be fought, as it is not linked to culture but to history and to politics, notably colonisation and postcolonial migration. Like the previous volunteer, he excludes race from his framework, choosing another referent in order to explain and understand his relationship with asylum seekers, namely age. The first volunteer is a 'master', a 'father'; the second understands himself more as a guide, an advisor. The two, however, share an assumption, which is that they possess the knowledge necessary for the asylum seeker to succeed, whatever 'succeeding' means, be it obtaining refugee status or integrating into French society, culture, etc. 


\section{Women's discourses and approach to support: a (feminist) critique of men's hegemony?}

Women generally admit to trying to 'develop a different relationship' with the asylum seekers they support from the ones we have previously analysed. Most of them also openly admit to trying, in the way they offer support, to distance themselves from what is understood to be the hegemonic model. The attention they pay to setting limits with asylum seekers is often cited as one of the main differences, as women consider men's approach 'limitless':

I can't do as much as they do, I can't take on that many. ... For me it's a work relationship, not cold but serious. I don't ask them about their lives unless they write to me. I try to maintain some sort of distance with them. We have to talk about really intimate stuff, we are compelled to do it, but that doesn't mean that it goes beyond a work relationship, quite the contrary for me!

(A., 33 years old, October 2017)

For me, it was clear from the beginning that I was not going to entertain any personal relationship with them before they had their [refugee] status. It's a job, that's all, and I would not be able to have a relationship, to be friends, or anything else, with someone over whom I have a lot of power. ... to be in a friendly relationship with someone who is in a position so different from mine. I mean, almost all the people I help are older than me, and I am there sitting explaining stuff to them, it's already hard in that way.

(J., 23 years old, September 2017)

These two volunteers directly identify their role of volunteer as mere work, thus excluding anything that could go beyond this frame (integration, for example), whose aim is to obtain refugee status. Their conception of their role is certainly that they will help as much as possible, but they do not feel able, or they do everything in order to refuse, to develop relationships that are other than that, paying particular attention to the intimate dimension. Women volunteers work in groups, for example by running collective training sessions and meetings, both in order to spend less time seeing every person individually and also to enhance forms of knowledge exchange with asylum seekers. The fact that there are far fewer women and trans asylum seekers and refugees than men 
is the main reason they run these meetings in this way. However, before these meetings and trainings were pooled among different volunteers, each volunteer had already started, on her own, to organise collective work sessions, something men volunteers never mention doing or having done. By using an existing organisational resource (sharing information and knowledge of those 'already being helped'), they enlarge the conception of working to someone from being exclusively a one-on-one dynamic to being a collective one.

More broadly, the individualistic approach to work echoes wider debates concerning the understanding of migrants as vulnerable subjects. If 'vulnerability requires and implies the need for protection and the strengthening of paternalistic forms of power at the expense of collective forms of resistance and social transformation' (Butler, Gambetti \& Sabsay 2016, 1), the issue here is hardly that of collective forms of resistance, as asylum as a process is not shaped as a possible moment for resistance but, on the contrary, as a moment of subjection, at least in the obligation it imposes of producing a narrative about oneself, specifically, one that inverts the conception of queer migrants as tacit subjects (Decena 2011). The collective dimension proposed by women volunteers aims, however, to counteract not only the isolation but the paternalistic relationships that can be produced and reproduced in the case of individual support. What we could call the 'management of paternalism' appears to be a gendered issue: men decide to bear it and to find justifications that accord with class and 'culture', failing to see the racial and historical implications, while women try to develop different strategies, starting by organising collectively.

Women problematise at the same time the gendered and racial implications underlying their engagement and the space of the organisation. Often discussed exclusively among women, this critique of the very masculine - and white - dimension of the organisation, which goes with the political implications we analysed above, sometimes 'goes public'. An open letter questioned, among other things, the neo-colonialism of members who suggested, during a public event organised by the City Hall to celebrate the organisation's being awarded a medal, that 'asylum seekers could come dressed in their traditional costumes and cook typical dishes for everybody', as quoted in an email addressed to all volunteers. While none of them did that and none of the volunteers, men or women, suggested that they should do so, the email raised questions about the legitimacy of volunteers to make decisions about and for asylum seekers in the first place; furthermore, it pointed out something considered 'problematic' by some, namely the culturalist understanding of asylum 
seekers and refugees. The email raised questions about the possibility of a feminist and anti-racist agency (and agenda) in an organisation that was, at the time, composed mainly of male volunteers. This question lies unanswered, as during the last few years the structure and the functioning of the organisation, apart from the changes we have emphasised, has remained constant. Pointing out such issues as whiteness and the hegemonic conception of support has led to an exacerbation of the already present fractures between men and women and between younger and older volunteers.

\section{Conclusion}

In this chapter I have, first, aimed to show what can be considered to be the basics of the (micro-)politics of support towards LGBT asylum seekers in France; that is, the way in which support is collectively and individually organised, thought and discussed, as well as its sociological and political implications. Focusing on a particular organisation, I have traced how it organised over time the welcoming of new asylum seekers in need of support. I have shown that subsequent changes to this welcoming meeting aim to re-signify both the people welcomed and the people welcoming, asylum seekers and volunteers. Second, I have sketched the different ways in which volunteers frame their relationships with asylum seekers. In doing so, I aimed to analyse their interactions in greater depth, by not only looking at them from an external vantage point but also taking into consideration the way they were conceptualised by volunteers. The multiple nuances of these discourses need to be considered: they range from an approach framed through class, to one focused on integration framed through class and age - both of which exclude race as a frame and as a discursive category - and finally to one trying to thwart the isolation and rhetoric of vulnerability. This two issues are not separate: by studying them together I aimed to take into consideration the tension that exists between support as work, particularly as work to, and the political and ethical implications that can be found in the arranging of relationships between volunteers and asylum seekers.

\section{Notes}

1. In French law, an alien is a person living in France without holding French nationality, whether he or she was born in France or not; an immigrant is a person born an alien outside of France and currently living in the country. In this chapter, I will use 'migrant(s)' and 'asylum seeker(s)' interchangeably to refer to the people supported by the organisation, as these are 
the ways in which volunteers refer to them; conversely, for the latter I will mainly use the word 'volunteers', as that's the way migrants refer to them, and how volunteers refer to each other. In other words, these words signify social roles in a defined space rather than closed administrative, legal or professional categories.

2. The original text: '[D]'un côté, l'État adopte des lois répressives qui respectent en apparence des droits fondamentaux mais de l'autre, il délègue aux fractions subalternes de l'administration le soin de rendre ces droits inopérants.'

3. Association pour la défense des droits des personnes homosexuelles et trans à l'immigration et au séjour (Organisation for the recognition of the right of homosexuals and trans people to immigration and residence).

4. The English word fake is widely used among volunteers.

5. The Centre has three floors: the ground floor consists of a big room with chairs, a few tables, a small bar and a desk; the basement consists of a big room with chairs and tables, no windows and no aeration system; the first floor consists of a couple of offices, a small library, and a larger meeting room.

\section{References}

Amari, Salima. 2018. Lesbiennes de l'immigration: Construction de soi et relations familiales. Paris: Éditions du Croquant.

Bécasse, Julien. 2015. 'L'Émergence politique d'une association de soutien aux étranger/ères gays, lesbiennes et transgenre.' MA dissertation, Université de Paris Diderot - Paris 7.

Bonilla-Silva, Eduardo. 2003. Racism without Racists: Color-blind racism and the persistence of racial inequality in the United States. Lanham, MD: Rowman \& Littlefield.

Bourdieu, Pierre and Jean-Claude Passeron. 1970. La Réproduction: Éléments pour une théorie dy système d'enseignement. Paris: Éditions de Minuit.

Broqua, Christophe. 2006. Agir pour ne pas mourir! Act Up, les homosexuels et le sida. Paris: Presses de Sciences Po.

Butler, Judith, Zeynep Gambetti and Leticia Sabsay. 2016. Vulnerability in Resistance. Durham, NC: Duke University Press.

Cesaro, Sara and Dany Carnassale. 2018. 'Validated subjectivities? The assessment of SOGI-based asylum claims in France and Italy.' Paper presented at the 8th Ethnography and Qualitative Research Conference, University of Bergamo.

Chancé, Dominique. 2012. 'Hybridité, créolisation, tout-monde, aux Antilles', Canadian Review of Comparative Literature/Revue Canadienne de Littérature Comparée 39(2):125-38. Available at: https://journals.library.ualberta.ca/crcl/index.php/crcl/article/view/25620 (accessed 6 August 2020).

Chossière, Florent. 2017. 'Demander l'asile, habiter l'espace d'accueil: Demandeurs d'asile et réfugiés pour orientation sexuelle et identité de genre.' MA dissertation, École normale supérieure de Lyon.

Decena, Carlos Ulises. 2011. Tacit Subjects: Belonging and same-sex desire among Dominican immigrant men. Durham, NC: Duke University Press.

D’Halluin-Mabillot, Estelle. 2012. Les Épreuves de l'asile: Associations et réfugiés face aux politiques du soupçon. Paris: EHESS.

Dubois, Vincent. 1999. La vie au guichet: Relation administrative et traitement de la misère. Paris: Economica.

Elster, Jon and Nicolas Herpin (eds). 1994. The Ethics of Medical Choice. New York: Pinter.

Emerson, Robert. 2015. Everyday Troubles: The micro-politics of interpersonal conflict. Chicago, IL: University of Chicago Press.

Emerson, Robert and Sheldon Messinger. 1977. 'The micro-politics of trouble', Social Problems 25:121-34. https://doi.org/10.1525/sp.1977.25.2.03a00010.

Fassin, Eric and Manuela Salcedo. 2015. 'Becoming gay? Immigration policies and the truth of sexual identity', Archives of Sexual Behaviour 4:1117-25. https://doi.org/10.1007/ s10508-015-0551-z.

Foucault, Michel. 1994. Dits et Ecrits 1954-1988, vol. 4. Paris: Gallimard. 
Foucault, Michel, 2012. Du Gouvernement des vivants: Cours au Collège de France (1979-1980). Paris: Seuil.

Giametta, Calogero. 2017. The Sexual Politics of Asylum. New York: Routledge.

Giametta, Calogero. 2018. 'New asylum protection categories and elusive filtering devices: The case of "Queer asylum" in France and the UK', Journal of Ethnic and Migration Studies 46:142-57. Available at: https://doi.org/10.1080/1369183X.2018.1500172 (accessed 3 March 2020).

Goffman, Erving. 1961. Asylums. New York: Anchor Books.

Hajjat, Abdellali. 2012. Les Frontières de l'identité nationale': L'Injonction à l'assimilation en France métropolitaine et coloniale. Paris: La Découverte.

Hughes, Everett Cherrington. 1956. 'Social role and the division of labour', Midwest Sociologist 18:3-7.

Hughes, Everett Cherrington. 1984. The Sociological Eye: Selected papers. New Brunswick, NJ: Transaction Books.

Infantino, Federica. 2010. 'La frontière au guichet: Politiques et pratiques des visa Schengen à l'Ambassade et au Consulat d'Italie au Maroc', Champ Pénal 7:1-22. https://doi.org/10.4000/ champpenal.7864.

Jakšić, Milena. 2013. 'Le mérite et le besoin: Critères de justice et contraintes institutionnelles des associations d'aide aux victimes de la traite', Terrains \& Travaux 22:201-16. https://doi.org/ 10.3917/tt.022.0201.

Kobelinsky, Carolina. 2012. 'L'Asile gay: Jurisprudence de l'intime à la Cour nationale du droit d'asile', Droit et Société 82:583-601. https://doi.org/10.3917/drs.082.0583.

Le Courant, Stefan. 2015. 'Vivre sous la menace: Ethnographie de la vie quotidienne des étrangers en situation irrégulière en France.' PhD thesis, Université de Nanterre - Paris 10.

Lipsky, Michael. 1980. Street-Level Bureaucracy: Dilemmas of the individual in public services. New York: Russell Sage Foundation.

Mazouz, Sarah. 2017. La République et ses autres: Politiques de l'altérité dans la France des années 2000. Lyon: ENS Éditions.

Memmi, Albert. 1957. Portrait du colonisé, précédé du Portait du colonisateur. Paris: Buchet/Chastel.

Pette, Mathilde. 2014. 'Associations: Les nouveaux guichets de l'immigration? Du travail militant en préfecture', Sociologie 5:405-21. https://doi.org/10.3917/socio.054.0405.

Pette, Mathilde. 2015. 'Les associations dans l'impasse humanitaire?', Plein Droit 104:22-6. https://doi.org/10.3917/pld.104.0022.

Roy, Donald. 1953. 'Work satisfaction and social reward in quota achievement: An analysis of piecework incentive', American Sociological Review 18:507-14. https://doi.org/10.2307/2087434.

Salcedo Robledo, Manuela. 2015. 'Amours suspectes, couples binationaux de sexe différent ou de même sexe sous le régime de I'“immigration subie".' PhD thesis, EHESS, Paris.

Sayad, Abdelmalek. 1999. 'Immigration et "pensée d'État"', Actes de la Recherche en Sciences Sociales 129:5-14. https://doi.org/10.3406/arss.1999.3299.

Spire, Alexis. 2008. 'Histoire et ethnographie d'un sens pratique: Le travail bureaucratique des agents du contrôle de l'immigration'. In Observer le travail: Histoire, ethnographie, approches, edited by Anne-Marie Arborio, Yves Cohen, Pierre Fournier, Nicolas Hatzfeld, Cédric Lomba and Séverin Muller, 61-76. Paris: La Découverte.

Spire, Alexis. 2016. 'La politique des guichets au service de la police des étrangers', Savoir/Agir 36:27-31. https://doi.org/10.3917/sava.036.0027. 


\section{1 \\ 'How much of a lesbian are you?' Experiences of LGBT asylum seekers in immigration detention in the UK}

Sarah Singer

\section{Introduction}

This chapter explores the experiences of lesbian, gay, bisexual and transgender (LGBT) asylum seekers who have been subjected to immigration detention in the UK. While much research has focused on the legal barriers that immigration detainees experience (Costello 2015; De Bruycker \& Tsourdi 2016; Wilsher 2011; Hailbronner 2007), on how detainees deal with the uncertainty that immigration detention presents and on the impact of detention on their physical and mental health (Bosworth 2014; Hasselberg 2016; Griffiths 2013; Turnbull 2016; Rotter 2016), little to date has focused specifically on detained LGBT asylum seekers as a discrete and particularly vulnerable group. That which does exist primarily concerns immigration detention in the USA (Zitsch 2015), particularly the treatment of transgender detainees (Anderson 2010; Resendiz 2018; Collier \& Daniel 2019), or explores the question of the detention of LGBT migrants more broadly (Tabak \& Levitan 2014). Research on LGBT(QI) asylum seekers has tended to focus on questions of 'credibility' in the asylum process and the difficulties such persons may have in establishing an asylum claim (Millbank 2009; Tobin 2012; Hathaway \& Pobjoy 2012; Bennett 2014; Berg \& Millbank 2009; LaViolette 2009; Wessels 2011; Murray 2014), rather than on experiences in and of detention. This chapter seeks to bridge the gap between these bodies of literature, drawing on interviews conducted with LGBT asylum seekers detained in immigration removal centres (IRCs) in a number of locations across the UK, to 
explore how they, as LGBT-identifying persons, experience immigration detention.

Immigration detention - the deprivation of liberty on immigrationrelated grounds - is on the rise and the subject of increased attention both in the UK and globally (UNHCR 2014). The power to detain in the UK is set out broadly (Costello 2015) and the UK is unique in Europe in not placing an express time limit on immigration detention. ${ }^{1}$ The UK system is also unusual in lacking automatic judicial oversight of detention. This being so, immigration detainees do not have the certainty of a prison sentence with a determinate period of detention, nor the well-developed checks and balances that guard against the arbitrary imposition of power in the criminal justice system (Bhui 2016). Serious problems have been found in nearly all aspects of the UK's immigration detention system (House of Commons Home Affairs Committee 2019), including physical and verbal abuse from staff, wrongful detention and lack of judicial oversight of the decision to detain, and prevalence of violence, self-harm and suicide. Particular attention has been given to the failings of the system towards vulnerable adults in detention (pp. 35-45).

We do not know how many LGBT people are held in the UK's immigration detention estate, since the UK Home Office does not record such statistics. However, it is clear that LGBT asylum seekers are a particularly vulnerable subset of immigration detainees, who can encounter particular problems while held in immigration detention, including harassment, bullying and intimidation (Zadeh 2019). Additionally, LGBT asylum seekers face a number of barriers to securing a claim for asylum. Attention has focused on the high number of LGBT asylum claims which are refused by the Home Office (Grierson 2019), often because of a negative assessment of the 'credibility' of asylum applicants (Zadeh 2019). Problems in credibility assessments also seem to permeate the asylum tribunal system (Booth 2019).

Indeed, authors such as Murray (2014) and Puar (2007) have described a 'heteronormativity' or 'homonationalism', which permeates Western states' relationships with LGBT politics and, by extension, LGBT migrants and asylum seekers. Puar argues that Western states rely on sexuality regimes that only acknowledge certain forms of being that fit into a pre-existing palette of identities, e.g. 'lesbian', 'gay', 'bisexual' and 'transgender'. She describes how Western states' 'protection' of LGBT asylum applicants is based on the idea of 'saving' deserving asylum seekers from sexually repressive regimes. Yet, to be considered 'genuine' or 'deserving', such persons must conform to a certain sexual stereotype of 'gayness', typically being 'out and proud'. 
However, such an approach fails to recognise the complex realities of sexual and gender self-identification lived by many migrants and asylum seekers from the global South. LGBT asylum seekers who are claiming asylum on the basis of their sexual orientation or their gender identity will, by definition, have experienced stigma or violence related to their LGBT identity. In such situations, non-disclosure is a common learned strategy for survival. As Wimark $(2019,11)$ notes, 'These expectations fail to comprehend that it is common for queer refugees to hide their sexual desires and to perform gender according to cis-gendered expectations.' Berg and Millbank's (2009) research, for example, draws attention to the difficulties many asylum applicants experience in being explicit about their sexuality, given the levels of internalised homophobia, feelings of shame and negative connotations associated with labels such as 'lesbian' that they have to negotiate. As Millbank (2009, 392) notes, '[Refugee] decision-makers in both Australia and the UK have been slow to fully absorb and apply the insight that gay people are secretive about their sexuality and relationships as a result of oppressive social forces rather than by "choice".'

Equally, the approach often employed by decision-makers fails to appreciate the fluid nature of sexual orientation and gender identity (Dustin \& Held 2018). In the UK, sexual and gender minorities have come to be understood in terms of fixed identities, with rights framed around stable ideas of being lesbian, gay, bisexual or transgender (LGBT). For people growing up in other contexts, however, identities are unlikely to be so stable (Powell 2019). There is increasing recognition of the indeterminacy of identity categories and the ways in which such identities are continuously constructed by the various actors with whom asylum claimants interact (Akin 2017, 461).

Given this, it is perhaps unsurprising that credibility has loomed large as an issue for LGBT asylum applicants and has been the subject of a growing body of academic literature. This research builds on this literature by exploring how LGBT asylum seekers' sense of identity and self plays out in the detention estate and how LGBT asylum seekers navigate their relationships with the various actors with whom they come into contact during their time in detention, be they Home Office caseworkers, detention centre staff, legal representatives or other detainees.

\section{The present study}

This research comes out of a project on the experiences of LGBT asylum seekers who have been held in immigration detention in the UK (Stonewall \& UKLGIG 2016). In-depth interviews were conducted 
with 22 asylum seekers between November 2015 and March 2016. Participants were from 11 countries in Asia, Africa and the Caribbean, plus one from Russia.

The participants comprised 14 women, seven men and one transgender woman currently in transition (male to female). Of the 14 female participants, 10 self-identified as lesbian, while four self-identified as bisexual. Of the seven male participants, six self-identified as gay, one self-identified as bisexual and one described himself as exclusively attracted to men but did not self-identify as 'gay'. Given that all participants had been through, or were at some stage in, the asylum process, the extent to which the asylum process itself may have influenced their self-categorisation or narratives is unclear (Dhoest 2019).

Interviews were conducted in person with participants who had recently been released from immigration detention: almost 70 per cent of participants had been held in detention in the previous year and all had been in detention in the previous three years. The length of time participants had spent in detention ranged from three days to 18 months. The legal status of participants at the time of interview varied: some had been recognised as refugees, some were failed asylum seekers, and the legal status of many was unclear. ${ }^{2}$ Interviews were audio-recorded, transcribed, and thematically coded and analysed to draw out key themes and sub-themes, patterns and relationships between narratives. For the purposes of this chapter the names and details of participants have been anonymised.

The UK has one of the largest networks of immigration detention facilities in Europe. Immigration detention centres in the UK are officially known as immigration removal centres (IRCs), and sometimes individuals are held in short-term holding facilities (STHFs). There are currently eight IRCs in the UK. Participants were held in different detention centres in England and Scotland, including Brook House, Colnbrook, Dungavel, Harmondsworth, Pennine House and Yarl's Wood. It was not uncommon for participants to have been placed in multiple centres over the course of their detention, or to have been detained on more than one occasion.

The participants in this study had been detained at various stages of their immigration processes. Some were detained when they first claimed asylum or when they reported to the Home Office. ${ }^{3}$ Others claimed asylum while held in detention for 'overstaying', having failed to leave the UK on expiry of their visa and subsequently being apprehended by the authorities. Two participants were foreign national offenders (FNOs) who claimed asylum while held in detention pending removal from the UK. 


\section{Findings}

This research seeks to explore how LGBT asylum seekers' sense of identity and self plays out in the detention estate and how LGBT asylum seekers navigate the various demands on their identities as mandated by the different groups with whom they interact. Therefore specific attention is given to detainees' relationships with others, including detention centre staff and other semi-authoritative figures in the detention estate, other detainees, Home Office caseworkers and legal representatives. While this study focuses on the experiences of participants in immigration detention, the lived experiences of the participants involved in this research often have roots in their pre-detention experiences and persist long after the period of incarceration has ended. Reference is therefore also made to individuals' pre- and post-detention experiences in order to contextualise their accounts in detention and their experiences as LGBT asylum seekers.

\section{Pre-detention}

For many participants, the narrative of their asylum journey began with stories of fear, insecurity, violence and intimidation. Many reported being subjected to severe physical violence and threats as a direct result of their sexual orientation or gender identity. As related by Selena from Jamaica, 'Well, I have been shot, I have been raped, I have been beaten, all sorts. ... They don't tolerate LGBT people.' Participants described abuse suffered at the hands of the police and prison authorities, including imprisonment, rape and beatings.

Other participants, when reflecting on their reasons for leaving their home countries, described violence from their local communities and, in many cases, from family members. Enforced marriage was also a common theme, with homosexuality seen by families as something that could be 'grown out of' (Esther, Nigeria) or 'cured' (Kasun, Sri Lanka). Some had been subjected to violent reprisals from their family, disowned, or, in one instance, detained in a psychiatric institution (Irene, Uganda). A number of participants in this study reported that they no longer had contact with their family, while, of those who had kept in contact, some maintained a pretence of heterosexuality.

Many of the participants involved in this research displayed feelings of shame or guilt associated with their sexual orientation or gender 
identity. These often stemmed from the perceptions of homosexual, bisexual or transgender individuals that prevailed in their home country. Irene from Uganda explained:

In the African culture, I mean being lesbian is something - it is like an abomination, it is unacceptable, completely unacceptable. Nobody will accept you, nobody will actually think you deserve to live a life of a human being, they will treat you differently, they will call you all sorts of names.

For many, this resulted in a disjointed sense of self or belonging. The impact of these feelings of shame and guilt on participants' sense of identity was in some cases profound. Some found it difficult to selfidentify as gay and displayed symptoms of internalised homophobia. Ali explained: 'In Pakistan when you think about gays you think about drag queens. ... I had never seen myself fitting in anywhere. I am not camp and I don't do drag at all. But I like men. So I didn't see myself, you know, anywhere.' Salma spoke about her experience of living discreetly in Morocco as a lesbian woman, presenting different personalities to the people she interacted with. Sara described what life would have been like as a transgender woman in India - 'You have to do prostitution or begging' - and the concordant effect this had had on her perception of her gender identity as something to be hidden carefully.

For some, these feelings of stigma and shame persisted on their arrival in the UK. Adroa from Uganda explained:

I had that fear I could not come out, come out as a bisexual person so I had that inferiority complex. I had that fear because where I was growing up I was told you were not to come out like this and I didn't know in England you are a free person and it took me a long time to come out.

Ali described how he went to his GP in the UK, asking for medication which could 'fix' him. Many described difficulties interacting with members of their local community while in the UK, or indeed said that they actively avoided interaction with people from their home country, and continued to hide their sexual orientation or gender identity except in relation to specific friends or groups. These patterns of behaviour reflect the findings of Wimark (2019) and Berg and Millbank (2009), who note the difficulties many LGBT asylum seekers have in being open about their sexuality. 
Indeed, many participants in this study were explicit about the way in which they presented different identities while in the UK, depending on the person or group there were interacting with, in a similar manner to Manalansan's (2003) descriptions of queer migrants' sense of identity and self being negotiated according to the context in which they find themselves.

However, many participants related a narrative of freedom and empowerment on arrival in the UK. Alex from Russia said, 'When I was here, I realised it's, like, my God, it's absolutely a different world here, it's fine to be gay here, it's absolutely fine. I still sometimes cannot believe it.' Many told stories of 'coming out' to close friends, integrating into the LGBT community via support groups for asylum seekers and migrants, and living more openly than they had previously. For some this was a continuation of the resilience they had displayed while in their home country. Some had participated in, or been leading figures in, LGBT rights movements, or in providing support for LGBT people, in their home countries. Diana from Uganda explained: 'We used to go into different places of the country into villages, mostly because it was an LGBT group but it used to also help people affected with HIV AIDS.' As will be considered further in the following sections, these narratives of resilience and community often persisted and presented in those participants' accounts of their behaviour while they were detained in the UK.

While these narratives of empowerment clearly held true for certain participants in this study, it must also be noted that they accord more readily with the 'hetronormativity' described by authors such as Murray (2014) and Puar (2007), whereby participants, unconsciously or deliberately, present a narrative more in line with the dominant Western typology of queerness: being 'out and proud' and clearly identifying with fixed queer typologies such as 'lesbian' and 'gay'. Indeed, it is unclear to what extent the asylum process itself may have influenced the narratives of participants in this study. All participants were at some stage of the asylum process and, as explained by authors such as Millbank (2009), success in making an asylum claim can depend on the extent to which queer asylum seekers demonstrate that they fit the preconceived, heteronormative categories and narratives most familiar to decisionmakers. Thus individuals may adjust or present a narrative that they believe will be in line with what is expected by a Western decision-maker (Dhoest 2019) or, in this instance, a Western researcher. This potential for bias must be borne in mind as the following analysis of participants' experiences in detention is read. 


\section{LGBT and in immigration detention}

All participants in this study reported feelings of intimidation and fear when placed in detention. IRCs themselves are not prisons, although they are often conceived as akin to prisons by both detainees and staff (Turnbull 2016, 61). The architecture and the security practices of IRCs mimic those of prisons and, although detainees are typically provided greater freedom than prisoners, staff, and detainees themselves, regularly refer to IRCs as prisons (Bosworth 2016). As one participant noted, the physical similarities between prisons and IRCs are very prominent: 'It's a prison. They tell me, No, it's not a prison, [but] it is a prison because the walls are high, you have got barbed wires and you cannot go through the gates, so it is a prison' (Selena, Jamaica).

All the participants in this study described the experience of being detained as highly traumatic. For those who had been subject to abuse in prison in their home countries, the experience was even more distressing. Irene from Uganda explained:

This was bringing it all back again. I could just see it exactly how it happened in Uganda, the same thing that was in detention, the way these guards would come although these ones were not abusive. ... Sometimes at night I could wake up with a panic attack and my heart is thumping and I am scared. I just think I am in that prison cell again.

Once detained, individuals are given no information about the length of their stay. In the UK there is no time limit on immigration detention and periods of detention range from days to years. This uncertainty and the persistent threat of removal to their home country have a profound impact on detainees' sense of insecurity (Griffiths 2013). This pervasive insecurity permeates the entire detention experience for all detainees and, as examined below, can impact particularly on LGBT detainees. The following sections will explore LGBT detainees lived experiences of immigration detention as they navigate complex relationships with authority figures, other detainees and the legal asylum process itself.

\section{Relationships with others}

Relationships with DCOs During their time in detention, detainees will come into contact with a variety of authoritative and semi-authoritative figures. On a day-to-day basis, Detainee Custody Officers (DCOs) 
manage the reality of incarceration and preparing people for deportation (Griffiths 2013, 265). Though they have no formal role in the Home Office's decision-making processes, as everyday points of contact with individuals in detention, DCOs have a significant impact on detainees' lived experiences of immigration detention. The role of other authoritative figures, such as legal representatives and Home Office caseworkers, will be considered in the following section, 'Navigating the asylum process'.

Those who had been subjected to abuse and violence from the police or prison guards in their home country often found their distrust of authority figures magnified in the detention estate. Although none reported being subjected to physical violence from staff, many participants described feeling intimidated or humiliated when interacting with DCOs. Female participants in particular highlighted the distress caused by male guards entering their rooms unannounced at various times of day and night: 'You don't have privacy at all, you don't have privacy. First of all, the door, they got master key, every morning they just come and open the door. You don't have privacy at all' (Marie, Cameroon). Many reported apathy and lack of interest on the part of DCOs. Cynthia from Cameroon explained:

The staff don't care, they are just doing their job. Even when you go up to them with questions they never give you answers. So they didn't really care whether you are gay or not, wherever you are from - no, they are just doing their job.

All IRCs should be served by an LGBT officer and provide support to LGBT detainees. While some participants in this study reported having access to an LGBT officer, the majority were unaware of the existence of such a person or were informed that no LGBT support existed. Some reported ridicule from DCOs when they enquired about the support available:

I said, 'Okay sir, please, I want to see LGBT officer.' And he said, 'What is the LGBT officer?' Then they start smiling a little to each other, like, you know, a joke. They say, 'No, what is the LGBT officer?' I say, 'You don't know LGBT officer? Who is in your building, he's in your detention centre, you don't know?' They say, 'No, no, you explain [to] us.' I said 'I am gay, and LGBT officer mean lesbian, gay, bisexual, transgender, he is here in every detention centre for support of us. So please call him, I want to meet him.' Then they very clearly smile, like - disgusting situation. I feel embarrassed.

(Amir, Pakistan) 
Although he asked repeatedly, Amir was never put in contact with an LGBT officer.

Some participants described active hostility from DCOs, which compounded emotional insecurities related to past abuse. Selena from Jamaica said:

They [DCOs] talk to you but they sort of keep their distance away from you and they look at you. To me they look at me like I was a disease. That's how I felt because that's what I have been told from when I was a teenager, that I am a disease, that something is wrong with me.

Irene described the constant jibes made by DCOs: 'They would make remarks that is kind of abusive, like, they will say "Oh, but you are a lesbian, you said you are a lesbian so why are you sending a letter, are you sending it to your boyfriend?" Very intimidating.' The apathy or active hostility reported of many DCOs magnified the feelings of insecurity narrated by participants in this study. Many reported feeling 'unprotected' by (Joan, Uganda), or actively fearful of interaction with, DCOs.

The transgender participant in this study also reported ridicule and hostility from DCOs. Although transitioning, as she was selfmedicating she did not fall within the Home Office's narrow definition of transgender and, as a result, was held in a male IRC. When initially detained she was wearing women's clothes and described the taunts of DCOs: 'He said, "Feel free to wear these clothes." ... It's like making a joke, in a male prison wearing female clothes.' She felt humiliated and upset: 'Making you feel like you are different and then that difference makes you vulnerable for all sorts of - I mean harm, physical harm. That's what I chose not to do it. I asked them for a jumper and trousers.' She reported that some DCOs deliberately used the term 'Mr' to address her when she was detained, which she felt was a deliberate attempt to mock and humiliate her.

Such behaviour from staff in the detention estate led many participants to feel conflicted and confused. Kasun, for example, explained that he felt he was in the paradoxical situation of experiencing similar discrimination to that he had experienced in Sri Lanka:

The Home Office talking about my country, go back and relocation, but I am having same problem in their detention centre. They got all the powers and everything, they control their staff, but still I am having discrimination with their staff. 
Such behaviour from DCOs compounded the acute sense of insecurity felt by all the participants while they were being detained with a potentially hostile community of other immigration detainees.

Relationships with other detainees A key concern expressed by all the participants in this study related to their relationships with other detainees. Participants described experiencing harassment and discrimination from other detainees because of their sexual orientation or their gender identity. Many felt forced to hide their identity while in detention to avoid being bullied and abused. As a consequence, many suffered particular isolation. Even those who had not been subjected to violence and abuse were wary of being open about their sexuality. Marie from Cameroon explained, 'When in detention most people are from Africa, and they will know, they think differently. First the culture that we grew up, don't allow people doing those things.'

A number of the participants in this study, particularly those held in male detention centres, described intimidation and violence from other detainees: 'I had my head rammed through a door, I was bullied, I got my food taken from me ... because they don't like gay people' (Michael, Nigeria). For some this abuse had a profound impact on their self-identity, resulting in feelings of shame and confusion. Zahid (Pakistan) described an incident when he was playing pool with another detainee:

He pushed me as well and he abused me. He said, 'You look like a fucking gay'. ... I came back in the room and I was standing in front of the mirror and I said, Why did he say that? ... I was really confused, like, how did people know that thing because I didn't share, even my parents don't know what's happening.

The transgender participant in this study (Sara) described extreme feelings of fear and insecurity while she was detained in male IRCs. As she lost weight her breasts became more pronounced and she was subjected to taunts from other detainees. She also faced problems with a lack of appropriate accommodation and bathroom facilities. In one IRC she was housed in the unit for those with psychological disorders, as this was one of the few areas in the IRC which had en suite bathroom facilities. Located directly above an isolation area used for detainees who had been violent, Sara described the incessant screams from those held in the unit with her and in the isolation unit below, which had a profound impact on her mental health. Eventually, following complaints about these conditions, she was moved to the induction unit but continued to fear 
other detainees' perceptions of the 'special treatment' she was receiving, which marked her out as different and opened her to abuse.

In another IRC Sara was forced to use communal shower and toilet facilities, which made her fear for her physical safety:

It's a communal shower and the pool table down here, and people used to stand around and watch the pool game. Obviously you can't go to the shower and people are watching you, so they see you, you're in big trouble. ... I never used to shower, for 15 days I never used the shower.

She described the difficulty she experienced in hiding her gender identity while detained and the emotional distress caused by having to relive the discretion she had had to employ in her home country and the concordant fear of discovery: 'You lose your freedom in effect. I mean it is like going back to being depressed.'

Even those who did not experience threats and intimidation from other detainees were nervous about being open about their sexual orientation while detained. Some recounted the ostracism and abuse suffered by other detainees when their sexual orientation was revealed. Participants described being 'careful', 'secret' and 'afraid'. Esther from Nigeria said, 'I didn't let my guard down because I didn't want to be judged or made to feel like I am less of a human being.'

For many participants the experience of hiding their sexual orientation or gender identity while detained felt perverse. Joan explained, 'It felt like I was running away from my country for my sexuality but then again I've been detained in a place where I'm not too sure what people think about me.' Ali described how confusing he found the experience, having come out in the UK: 'And I felt very, you know I was feeling like I was going over again and again and those memories how I used to have it. I mean you have to pretend.'

The impact of living multiple identities while detained was felt very keenly by nearly all the participants in this study. There were very few who felt able to be open about their sexuality while in detention, and those who did reported suffering stigma from other detainees as a result. Romy (Zimbabwe) and Diana (Uganda) described how they formed friendships with a small group of women who made a conscious effort to engage with other LBT detainees, to encourage them to feel welcome and comfortable. However, this resulted in their being ostracised by other detainees and they were asked to leave the church group of which they were part. Despite the stigma which attached to them because they were 
open about their sexuality, these participants demonstrated exceptional resilience in challenging other detainees who sought to exclude them from activities and in raising concerns with DCOs.

Relationships with semi-authoritative figures In addition to DCOs, detainees will come into contact with a number of semi-authoritative figures during their time in detention. These include medical staff and faith leaders such as priests or imams who serve the IRCs. While some participants reported positive relationships with such individuals, a greater number related more problematic relationships. Kasun from Sri Lanka described how the imam in his IRC advised him to 'stop being gay' and to return home to 'make his parents happy':

He told me that if you are not happy with your parents then God is not going to be happy with you. He said make your parents happy and go back. It means just leave my sexuality, just make them happy, it mean just going for a normal life.

This led him to doubt himself and question his identity: 'When he talked to me I just felt that maybe he is right, maybe I am wrong. ... I thought maybe he's right, everyone telling me the same thing. Maybe I am just wrong, because that's why I am here today' (Kasun). Similarly, many reported hostility from medical staff, often centred around disbelief of their claim to LGBT status. Yasmine from Algeria recounted how a member of staff serving in the health centre appeared to befriend her in order to extract information that could be used to disprove her asylum claim. Selena from Jamaica felt the hostile treatment she received from medical staff and the refusal to reissue her antidepressant medication was related to her sexuality. Problems in accessing medication, including HIV medication, were a pervasive theme highlighted by the majority of participants in this study.

Sara, the transgender participant in this study, was not permitted to continue her hormone therapy while in detention and experienced severe side effects, including hot flushes, anxiety and blistering around her neck. She also experienced regrowth of her facial hair. Detained on multiple occasions, she described episodes of transitioning when released from detention, being denied her medication when detained, and beginning transitioning again on release. The impact of these ongoing processes, as she sought to establish and then hide her gender identity, was both physically and emotionally draining. 
Significant limitations were also apparent in mental health support and counselling, where this was available, for the participants in this study. For those who had sought to access these services, the lack of LGBTspecific support was a barrier felt keenly. Kasun described attending an emotional support group run at the IRC by an external organisation:

It was in, like, a group, like ten people in the room, they have to share their emotions. For me, I am LGBT, normally I am discreet, I don't want to share my sexuality, but there's plenty of people so how can I share with them?

The devastating impact of immigration detention on detainees' mental health has been well documented. Robjant, Hassan and Katona (2009, 309) report that 'feelings of despair, hopelessness, depression, anxiety, post-traumatic stress disorder, psychosis and suicidal ideation are commonly reported by detainees, and in some systems suicide and incidents of self-harm occur at much higher rates than among undetained asylum seekers'. For LGBT detainees who suffer additional isolation, exclusion and fear in detention, the mental health impacts are compounded and the lack of LGBT-specific support in the UK's detention estate is a serious cause for concern. Many participants in this research reported instances of attempted suicide or self-harm, anxiety and depression. Of those who had been subjected to torture and abuse in their home country, many experienced significant symptoms of trauma, such as flashbacks and recurring nightmares. Experiences of rapid weight loss and hair loss, anxiety, loss of appetite and sleeping problems were described by many participants; most pointed to the detention environment as directly causing a deterioration of their mental health and well-being. As will be shown in 'Post-detention: "free" but still chained' below, these effects often persisted long beyond the period of detention itself.

For the majority of the participants in this study, the cumulative impact of their lived experiences in immigration detention was an overwhelming pressure to hide their sexual orientation or gender identity. For the many who had employed discretion or suffered abuse and violence in their home country, this represented a regression in their selfidentity, going 'backwards': 'In a Western country where you feel safe and feel like, "Okay, I am finally here, I am finally happy" and then you put back in a terrible place' (Cynthia, Cameroon). Yet, as will be discussed in the next subsection, this represents a stark contradiction with a concurrent pressure to be explicit and open, as required by the asylum process. 


\section{Novigating the asylum process}

The difficulties that LGBT asylum applicants have in making a successful asylum claim on the basis of their sexual orientation or gender identity have been explored by a number of authors (Millbank 2009; Tobin 2012; Hathaway \& Pobjoy 2012; Bennett 2014; Berg \& Millbank 2009; LaViolette 2009; Wessels 2011; Murray 2014). Particular difficulties surround issues of 'credibility', as decision-makers expect LGBT asylum applicants to confirm to heteronormative notions of 'fixed' categories: 'lesbian', 'gay', 'bisexual' and 'transgender' and to a certain sexual stereotype of 'gayness', most typically being 'out and proud' (Puar 2007). However, these expectations fail to appreciate that it is common for LGBT asylum seekers to be discreet about, and have difficulty explicitly vocalising, their sexual orientation or gender identity (Wimark 2019), and to appreciate the fluid nature of these concepts in practice (Dustin \& Held 2018). Many participants reported that their Home Office interviewing officers lacked an understanding of the diversity of LGBT identities - 'You don't look transgender' (Sara) - and even posed questions which have been strongly discouraged by the Home Office: 'Were you naked, were you half-naked? How long did you sleep with her?' (Joan). The style of questioning employed was interpreted by many as a deliberate attempt to discredit them. Joan explained, 'I felt like she was punishing me. Even the questions, it was just like torture.... Like, I'm going to ask this, that, until you say the wrong stuff.'

For LGBT asylum seekers in detention, such obstacles are magnified, since individuals are faced with the obligation to conform to cisgendered notions of being 'out and proud', while often simultaneously hiding their identity in the hostile detention environment.

Relatedly, a number of authors have highlighted the problems many LGBT asylum applicants face in collating objective 'evidence' to support their asylum claim (Bennett 2014; McGhee 2000; Berg \& Millbank 2009; Wessels 2011): applicants have typically been required to produce reports, documents, photographs, emails, letters and, where possible, witness statements. In this respect, specific barriers are faced by LGBT asylum seekers in detention. In previous work I have described the 'desert island' of immigration detention, that is, being cut off from legal information, assistance and the means of collating evidence to support a legal case (Singer 2019). Cases often hinge on securing such documentary evidence, which is not easy to obtain when detainees are separated from their property. Detainees additionally face significant barriers in maintaining communication with those outside the detention estate who may be able to help support or provide such evidence. 
When an individual is detained their mobile phone is confiscated and they are provided with a simple phone to receive and make calls. The motivation behind confiscating mobile phones seems to be to prevent detainees from having access to camera phones with which they could document conditions inside the IRCs. For both detainees and visitors to IRCs, mobile phones with cameras or internet access are not permitted. Detainees have to top up their new phones using cash. Many reported that the charges were extortionate and difficult if not impossible to maintain. Kasun from Sri Lanka explained: 'Normally in detention we use top-up, ... pay-as-you-go. When I was detained they gave me the same cell[phone], ... one minute charged me 32 pence. So first I charge around three hundred pounds, first month.' This was echoed by Joan from Uganda, who struggled to maintain contact with her partner, who was helping collate evidence to support her asylum claim:

Well, I felt like I was trapped in there, like I can't get this information, it's very important information, and even talking was very, very costly for me. Calling her or her calling me, it was just very, very costly. It was like a barrier, like they're stopping me from getting this evidence.

While these problems pertain for all immigration detainees, for LGBT detainees they are magnified, since individuals are additionally faced with the constant presence of DCOs and other detainees, which makes it difficult to speak freely with their solicitors or others who could provide evidence to support their case. Kaun explained, 'I have to be careful what I am talking because I am sharing with someone, a room. I have to make sure that I am not exposing my sexuality when I'm speaking with my partner.'

Lack of sufficient access to the internet and other forms of communication such as faxes was also raised by participants as a serious obstacle to preparing their legal cases. While IRCs provide a certain number of computers with internet access, a large number of sites are blocked and unavailable. Zahid explained, 'In that centre, like in the Gatwick centre, on the internet every single thing is blocked; even, you can't access the internet banking.' This was echoed by other participants: 'There's no internet, you can't get information from the internet there, it was limited, they block so many sites' (Cynthia, Cameroon).

Limited internet access often has severe consequences for detainees' ability to collate information for their asylum cases. One participant was denied legal aid, as they failed to secure their bank information in time 
(Esther, Nigeria). Another had their claim rejected because they failed to provide supporting evidence within the timeframe required (Joan, Uganda). Many reported problems securing home country information detailing the treatment of LGBT people. Simple communication was raised as a significant issue by all the participants in this study; this extended to the use of other services and devices such as faxes and scanners, access to which was often controlled by DCOs.

For all immigration detainees, lack of access to information extends to difficulties with Home Office communications and accessing caseworkers (House of Commons Home Affairs Committee 2019). Home Office caseworkers are generally based in offices far from the IRCs, and are difficult for detainees to contact. As Griffiths notes from her own research into the UK detention system, 'Telephones go unanswered, caseworkers do not have answerphones and faxes are not always replied to' (Griffiths 2013, 272). The geographical distancing of IRCs from city centres and public transport means that detainees have limited physical contact with Home Office officials and legal representatives and are increasingly reliant on other forms of communication, such as phone, fax and email, to communicate with them.

Access to legal advice and representation for detainees is a significant problem highlighted not only by participants in this study but also by a number of reports on immigration detention in the UK (Lindley 2017; Shaw 2016; Refugee Action 2018; House of Commons Home Affairs Committee 2019). There is high demand for legal advice in IRCs and many firms are oversubscribed. Some detainees have to wait weeks for an appointment (Lindley 2017, 39). Even after securing an appointment, detainees often only have a 30-minute window to speak to a legal representative about their case. Furthermore, the availability of legal aid advice for immigration and asylum is very uneven geographically and the number of firms servicing the different IRCs may be limited. Successive government cuts to legal aid funding and the removal of most non-asylum immigration matters from the ambit of legal aid have led to a dramatic reduction in the number of legal aid providers in the immigration and asylum field (Refugee Action 2018, 11). This has led to legal aid 'deserts' in this area of law. Participants voiced frustration that, even when these obstacles are overcome, they were unable to contact their legal representatives. These complaints are reflected in Griffiths's findings:

$[\mathrm{M}]$ isinformation and uncertainty also exists for those who do have legal representation. Many detainees spoke of being unable to get 
hold of their solicitors or obtain information from them, and many felt their solicitor was doing nothing for them. A surprising number did not even know if they had a solicitor or not.

(Griffiths 2013, 273)

Being geographically distanced from the community and having limited access to other forms of communication seriously impacts the ability of detainees to navigate their immigration processes. One participant said:

To get moving and speak to your solicitor it takes days. You're trying to get to him but you get the voicemail. If you can't put credit then it's not their problem, so if you don't have any money on you, you won't be able to communicate. Maybe the best way is through email and also in the computer room internet is on and off. Most sites are blocked so if you wanted to do research on your country all sites are blocked.

(Romy, Zimbabwe)

These problems can be compounded for LGBT asylum seekers when they are faced with legal representatives who have limited knowledge or understanding of the complexities of LGBT asylum cases, or are in some instances openly hostile. Esther described her first meeting with her solicitor: 'At first when he knew about what I was using [sexual orientation] for asylum seeking he told me point blank that he felt uncomfortable with it.' Kasun felt his solicitor had limited understanding of LGBT claims: 'Sometimes your lawyer, maybe he's [a] very specialist lawyer and he's a really experienced lawyer. But when he come to you, LGBT case, I felt that they don't know much.' Given these cumulative pressures, many found it difficult to substantiate an asylum claim and provide evidence to support their asylum claim. Others voiced concerns at the constant pressure to conform to the Home Office's preconceived 'ideal' of homosexuality. Romy explained:

Before I ended up in detention, I didn't feel the need to go outside and shout 'Yes, I'm a lesbian.' Now it's like everything I do I have to prove something. If I don't put pictures of myself or my new haircut on my Facebook they will be saying I'm not open enough. ... It's not about who you are, it really isn't; it's never been about who you are. You know it's just about who you say you are and how much you can prove that you are who you say you are. It's 'How much of a lesbian are you? Do you go to gay clubs? Do you hang around 
with other lesbians? How many lesbians can write a letter for you to say, "Yes, I know her, she's a lesbian", and of those lesbians how many of those lesbians have been accepted by the Home Office or are British?'

Faced with these pressures, many participants in this study found themselves in the almost Kafkaesque situation of being required to conform with decision-makers' conscious or unconscious biases about what it means to be LGBT, and support this ideal by reference to objective evidence, while concomitantly being held in an environment in which they found they had to hide their sexual orientation or gender identity for fear of reprisal from DCOs or other detainees, and cut off from the outside world and the means of collating such evidence.

\section{Post-detention: 'free' but still chained}

For all the participants in this study, their experiences of detention did not end with their period of incarceration. Once released from detention, those subject to immigration control continue to wait in the community under a variety of conditions and restrictions, most commonly the obligation to report to the Home Office at regular intervals. The majority are unable to work, volunteer or study and some may have additional bail conditions to comply with. One participant in this study was fitted with an electronic tag and had a 7 p.m. curfew. She explained:

They say it [detention] is a place where you should be kept to be safe, it's like housing while they deal with your case, but at the same time it's not really like that: It's more of a place to oppress you, or it's more of a place to control you until they decide what it is that they want to do with you, it's more like that. If you're not in there they're controlling your person in another way, like for me it's the tag, for me it's signing, for somebody else it could be 'You can't work', for somebody else it's 'You have to live in a hostel'.

(Romy, Zimbabwe)

Participants described waiting in the community under a variety of control mechanisms outlined above, 'stagnant' or 'stuck' and uncertain of what the future will bring. Selena (Jamaica) explains how this waiting and uncertainty manifest as extreme control over her as an individual: 'The Home Office - they take away my normality, my independence, they take away my life. I am in some invisible chain and shackles 
right now, I am stagnant, I can't move.' Diana (Uganda) describes the mental anguish of being unable to do anything but wait for the next communication from the Home Office:

Right now time is, to sit here and wait every day, every day you wait for a letter from the Home Office, you don't even know what they are going to say to you. I could get a letter today that they refused me and the next day they are knocking on my door to take me back into detention. It kills me.

Unable to work or to form new lives for themselves, those subject to immigration proceedings wait in limbo for an uncertain and indeterminate period of time. For many participants in this research, this resulted in narratives of helplessness. Many were forced to rely on charitable organisations in order to survive, and existed under the pervasive threat of being re-detained, with the constant pressure to 'evidence' their sexual orientation or their gender identity through social media, engagement with LGBT groups or forming and maintaining sexual relationships.

Many described continued mental health problems, lack of financial or emotional support and a pervasive feeling of helplessness and apathy. A number of participants in this study reported that they no longer had contact with their family while, of those who had kept in touch, some kept up a pretence of heterosexuality. Some reflected that they were being punished: Cynthia (Cameroon) felt she was 'paying' for being gay, and Michael (Nigeria) said:

I look at my life and everything that's happened to me just because I am gay. It is not because of me trying to break the law. If I was not gay I wouldn't be attacked, I wouldn't run away from my country, I wouldn't leave my home, I won't have a family that disowned me. I just want to be as normal as everyone, you know, just - it's just like that's the only subject in my life right now, gay.

\section{Conclusions}

This study has explored the experiences of LGBT asylum seekers in detention in the UK. What emerges is a perverse and almost Kafakaesque situation, in which LGBT asylum detainees are held in a hostile environment, experiencing marginalisation, abuse and sometimes violence on account of their sexual orientation or gender identity. At the same 
time, they find themselves required to accord with decision-makers' preconceived notions of what it means to be LGBT, most typically 'out and proud', and to support this narrative with documentary evidence, while held in a remote environment in which it is incredibly difficult to access such information or maintain communication with others who could. This all takes place against a backdrop of individuals' experiences of abuse, stigma and, often, internalised feelings of shame and guilt.

The resulting narratives related by the participants in this study demonstrate a profound confusion and frustration, both with the UK's asylum system and with their own difficulties in meeting the expectations put on them. Some resort to self-doubt and blame, others relate narratives of helplessness and apathy. Even those who demonstrated the strongest resilience voice frustration at the lack of understanding, and their inability to communicate their own identities. Romy explained:

It's a constant cycle of seeking acceptance, a constant cycle in the whole immigration system, in detention. That whole sector is a constant cycle of wanting to be accepted, of wanting people to understand you. You're wanting people to understand your situation, what you're going to go through if you go back there, what you're going through now being in this place. It's ongoing.

\section{Notes}

1. Except in the case of pregnant women and families.

2. That many participants were unable to explain their immigration status is an indication of the lack of clarity many experienced when faced with UK immigration law (Singer 2019).

3. A condition applied to many of those subject to immigration processes is regular reporting to the Home Office at weekly or fortnightly intervals.

\section{References}

Akin, Deniz. 2017. 'Queer asylum seekers: Translating sexuality in Norway', Journal of Ethnic and Migration Studies 43(3):458-74. https://doi.org/10.1080/1369183X.2016.1243050.

Anderson, Laurel. 2010. 'Punishing the innocent: How the classification of male-to-female transgender individuals in immigration detention constitutes illegal punishment under the Fifth Amendment', Berkeley Journal of Gender, Law \& Justice 25:1-31.

Bennett, Claire. 2014. 'Lesbians and United Kingdom asylum law: Evidence and existence'. In Gender in Refugee Law: From the margins to the centre, edited by Efrat Arbel, Catherine Dauvergne and Jenni Millbank, 138-56. Abingdon: Routledge.

Berg, Laurie and Jenni Millbank. 2009. 'Constructing the personal narratives of lesbian, gay and bisexual asylum claimants', Journal of Refugee Studies 22:195-223. https://doi.org/10.1093/ jrs/fep010. 
Bhui, Hindpal Singh. 2016. 'Can inspection produce meaningful change in immigration detention?', Global Detention Project Working Paper No. 12, May. Available at: https://www. globaldetentionproject.org/can-inspection-produce-meaningful-change-in-immigrationdetention (accessed 3 March 2020).

Booth, Robert. 2019. 'Judge rejected asylum seeker who did not have gay "demeanour"', The Guardian, 21 August. Available at: https://www.theguardian.com/uk-news/2019/aug/21/ judge-rejected-asylum-seeker-who-did-not-have-gay-demeanour (accessed 3 March 2020).

Bosworth, Mary. 2014. Inside Immigration Detention. Oxford: Oxford University Press.

Bosworth, Mary. 2016. 'Border criminologies: Assessing the changing architecture of crime and punishment', Global Detention Project Working Paper No. 10, February. Available at: https:// www.globaldetentionproject.org/wp-content/uploads/2016/06/bosworth_global_detention_project_feb_2016.pdf (accessed 7 July 2020).

Collier, Megan and Meghan Daniel. 2019. 'The production of trans illegality: Cisnormativity in the U.S. immigration system', Sociology Compass 13:e12666. Available at: https://doi.org/ 10.1111/soc4.12666 (accessed 3 March 2020).

Costello, Cathryn. 2015. 'Immigration detention: The grounds beneath our feet', Current Legal Problems 68:143-77. https://doi.org/10.1093/clp/cuv015.

De Bruycker, Philippe and Evangelia Tsourdi (eds). 2016. 'Special Issue: The challenge of asylum detention to refugee protection', Refugee Survey Quarterly 35:1-127. https://doi.org/ 10.1093/rsq/hdv022.

Dhoest, Alexander. 2019. 'Learning to be gay: LGBTQ forced migrant identities and narratives in Belgium', Journal of Ethnic and Migration Studies 45:1075-89. https://doi.org/10.1080/ 1369183x.2017.1420466.

Dustin, Moira and Nina Held. 2018. 'In or out? A Queer intersectional approach to "Particular Social Group" membership and credibility in SOGI asylum claims in Germany and the UK', GenIUS: Rivista di studi giuridici sull'orientamento sessuale e l'identità di genere, 2018(2):74-87. Available at: http://sro.sussex.ac.uk/id/eprint/80393/.

Grierson, Jaimie. 2019. 'Home Office refused thousands of LGBT asylum claims, figures reveal', The Guardian, 2 September. Available at: https://www.theguardian.com/uk-news/2019/ sep/02/home-office-refused-thousands-of-lgbt-asylum-claims-figures-reveal (accessed 3 March 2020).

Griffiths, Melanie. 2013. 'Living with uncertainty: Indefinite immigration detention', Journal of Legal Anthropology 1:263-86. https://doi.org/10.3167/jla.2013.010301.

Hailbronner, Kay. 2007. 'Detention of asylum seekers', European Journal of Migration and Law 9:159-72. https://doi.org/10.1163/138836407x190415.

Hasselberg, Ines. 2016. Enduring Uncertainty: Deportation, punishment and everyday life. Oxford: Berghahn.

Hathaway, James and Jason M. Pobjoy. 2012. 'Queer cases make bad law', New York University Journal of International Law and Politics 44:315-89.

House of Commons Home Affairs Committee. 2019. 'Immigration detention: Fourteenth report of session 2017-19', 12 March. Available at: https://publications.parliament.uk/pa/cm201719/ cmselect/cmhaff/913/913.pdf (accessed 3 March 2020).

LaViolette, Nicole. 2009. 'Independent human rights documentation and sexual minorities: An ongoing challenge for the Canadian refugee determination process', International Journal of Human Rights 13:437-76. https://doi.org/10.1080/13642980902758234.

Lindley, Anna. 2017. 'Injustice in immigration detention: Perspectives from legal professionals'. The Bar Council, November. Available at: http://www.aviddetention.org.uk/sites/default/ files/images/171130_injustice_in_immigration_detention_dr_anna_lindley.pdf (accessed 26 August 2020).

Manalansan, Martin F. 2003. Global Divas: Filipino gay men in the diaspora. Durham, NC: Duke University Press.

McGhee, Derek P. 2000. 'Accessing homosexuality: Truth, evidence and the legal practices for determining refugee status - the case of Ioan Vraciu', Body and Society 6(1):29-50.

Millbank, Jenni. 2009. 'From discretion to disbelief: Recent trends in refugee determinations on the basis of sexual orientation in Australia and the United Kingdom', International Journal of Human Rights 13:391-414. https://doi.org/10.1080/13642980902758218. 
Murray, David A. B. 2014. 'Real queer: "Authentic" LGBT refugee claimants and homonationalism in the Canadian refugee system', Anthropologica 56:21-32.

Powell, Alex. 2019. 'Interviews with asylum seekers reveal why the Home Office rejects so many LGBT claims', The Conversation, 4 September. Available at: https://theconversation.com/ interviews-with-asylum-seekers-reveal-why-the-home-office-rejects-so-many-lgbt-claims122905 (accessed 3 March 2020).

Puar, Jasbir K. 2007. Terrorist Assemblages: Homonationalism in queer times. Durham, NC: Duke University Press.

Refugee Action. 2018. 'Tipping the scales: Access to justice in the asylum system'. Available at: https://www.refugee-action.org.uk/wp-content/uploads/2018/07/Access-to-JusticeJuly-18-1.pdf (accessed 3 March 2020).

Resendiz, Chantiri Duran. 2018. 'Effects of privatization of immigration detention in the lives of detained transgender Latina immigrants', Harvard Journal of Hispanic Policy 30:39-50.

Robjant, Katy, Rita Hassam and Cornelius Katona. 2009. 'Mental health implications of detaining asylum seekers: Systematic review', British Journal of Psychiatry 194:306-12. https://doi.org/ 10.1192/bjp.bp.108.053223.

Rotter, Rebecca. 2016. 'Waiting in the asylum determination process: Just an empty interlude?', Time \& Society 25:80-101. https://doi.org/10.1177/0961463x15613654.

Shaw, Stephen. 2016. 'Review into the welfare in detention of vulnerable persons: A report to the Home Office by Stephen Shaw' (the Shaw report), January. Available at: https://www.gov. uk/government/uploads/system/uploads/attachment_data/file/490782/52532_Shaw_ Review_Accessible.pdf (accessed 3 March 2020).

Singer, Sarah. 2019. "'Desert island" detention: Detainees' understandings of "law" in the UK's immigration detention system', Refugee Survey Quarterly 38:1-29. https://doi.org/10.1093/ rsq/hdy020.

Stonewall and UKLGIG (UKLesbian and Gay Immigration Group). 2016. 'No safe refuge: Experiences of LGBT asylum seekers in detention', October. Available at: https://www.stonewall.org.uk/ system/files/no_safe_refuge.pdf (accessed 7 July 2020).

Tabak, Shana and Rachel Levitan. 2014. 'LGBTI migrants in immigration detention: A global perspective', Harvard Journal of Law \& Gender 37:1-44.

Tobin, John. 2012. 'Assessing GLBTI refugee claims: Using human rights law to shift the narrative of persecution within refugee law', New York University Journal of International Law and Politics 44:447-84.

Turnbull, Sarah. 2016. "'Stuck in the middle": Waiting and uncertainty in immigration detention', Time \& Society 25:61-79. https://doi.org/10.1177/0961463x15604518.

UNHCR (United Nations High Commissioner for Refugees). 2014. 'Beyond detention: A Global Strategy to support governments to end the detention of asylum-seekers and refugees, 2014 2019'. Available at: http://www.unhcr.org/uk/protection/detention/53aa929f6/beyonddetention-global-strategy-support-governments-end-detention-asylum.html (accessed 3 March 2020).

Wessels, Janna. 2011. 'Sexual orientation in refugee status determination'. Refugee Studies Centre Working Paper Series no. 74, Oxford Department of International Development. Available at: https://www.rsc.ox.ac.uk/files/files-1/wp74-sexual-orientation-refugee-statusdetermination-2011.pdf (accessed 3 March 2020).

Wilsher, Daniel. 2011. Immigration Detention: Law, history, politics. Cambridge: Cambridge University Press.

Wimark, Thomas. 2019. 'Homemaking and perpetual liminality among queer refugees', Social \& Cultural Geography. Available at: 10.1080/14649365.2019.1619818 (accessed 3 March 2020).

Zadeh, Leila. 2019. 'The UK must stop persecuting people who seek asylum based on sexuality', The Guardian, 9 July. Available at: https://www.theguardian.com/commentisfree/2019/jul/09/ lgbt-asylum-seekers-detention (accessed 3 March 2020).

Zitsch, Lauren. 2015. 'Where the American dream becomes a nightmare: LGBT detainees in immigration detention facilities', William \& Mary Journal of Race, Gender, and Social Justice 22:105-28. 


\section{Index}

affinity

ethnic 151, 152

Amsterdam 20, 166, 170, 171, 177

Asielzoekerscentrum 171

asylum adjudication 98, 133, 135, 139, 141

asylum seekers' centre

see Asielzoekerscentrum

asylum system $80,89,94,100,110,173,181$, 184, 208, 239, 258

French 228

legal aspects 123

queer potential 121

Spanish 135-7

AZC see Asielzoekerscentrum

Baudet, Thierry 170

benefit of the doubt 87, 98, 102

border

control 14, 76, 150

crossing 3,134

Brazilian migration to Germany $63,65-8$

Caribbean 123, 162-81

Trinidad and Tobago, asylum seekers to the Netherlands 172-3

Centraal Orgaan Opvang Asielzoekers 171

Central Agency for the Reception of Asylum Seekers see Centraal Orgaan Opvang Asielzoekers

CJEU see Court of Justice of the European Union

COA see Centraal Orgaan Opvang Asielzoekers

COI see country of origin information

Commission Against Torture 82

concealment 8, 86, 96, 122

Council of Europe 5, 17, 19, 24, 78-103

Committee of Ministers 84

Parliamentary Assembly 80

country of origin information 91, 99, 102

Court of Justice of the European Union 7, $20-5,78,83,88,89,96,100,101$

CPS see European Committee for the Prevention of Torture and Inhuman or Degrading Treatment or Punishment credibility $80,118,171,177,180,196,197$, 198, 206, 220, 238-40, 252 assessment 85-7, 96-8, 100, 133, 137, 139,147

discourse 144-6

interview 147-8

objective element 138-42 subjective element 141-3

criminalisation $16,85,95,141$; see also decriminalisation

decriminalisation 163; see also criminalisation deference 79, 97

dehumanisation 94; see also dehumanised dehumanised 93; see also dehumanisation detachment 78, 81, 83, 97

diaspora 2, 3, 5, 100, 198

engagement $57,63-5,74$

queer $59-62,65,68$

disbelief 9, 11, 96, 97, 250

discourse analysis 135, 146

discreet 7, 44, 87, 96, 109, 122, 125, 243, 251, 252; see also concealment

discretion 6-12, 89, 91, 96, 121, 122, 143, 249, 251; see also concealment

discrimination $1,14,15,17,23,35,41,49$, 72, 189, 194, 199, 247

anti-bisexual 123, 124

ethnic 168

LGBTQI anti-discrimination

measures 121

religious 163,170

sexual orientation $82,96,99,100$

Dutch Immigration and Naturalisation Service 172

EComHR see European Commission of Human Rights

ethnicity 5, 40, 41, 72, 100, 101, 110, 146

European Commission of Human Rights 16, $25,80,84,103$

European Committee for the Prevention of Torture and Inhuman or Degrading Treatment or Punishment 80

European Court of Human Rights 5, 16, 78; see also Strasbourg Court

European Union 13, 20, 63, 74, 76, 78, 135, $165,170,185$

evidence $7,8,80,92,93,96-9,132,133,137$, $141-4,148,167,252-8$

authentication 119

narrative 115

visual documentation (of sex acts) 121

family reunification $14,82,87,216$

Fortuyn, Pim 162, 167, 168

Forum for Democracy 170

frontera see border 
homonationalism 239

Islamophobic 164-6, 178, 180, 181

homophobia 32, 34, 41, 72, 73, 162, 163, 165, 169, 172, 174, 177, 179, 201, 240, 243

IND see Dutch Immigration and Naturalisation Service

internal relocation 87, 91, 98, 99, 102

intersectional 35, 49, 79, 81, 88, 90, 92, 95, $99,101,102,103,134,140,144,145$, $154,165,186,187,193$

Islam 162-81, 197, 198, 200

Islamophobia 162-81

Jamaica, asylum seekers to the Netherlands 123, 172, 173, 179

Ki-moon, Ban 1

late disclosure 98-102

latinidad 145-6, 151-3

queer 153

Latinxs 152

queer 134, 136, 146, 153

Lijst Pim Fortuyn 167

Middle East and North Africa, asylum seekers to the Netherlands $164,175-8,198$

Muslims 166-170, 199

nationalism 175

national identity $23,61,63,65-77,167$, 168,179

Netherlands 15, 17, 20, 21, 85-97, $100,162-81$

non-discrimination 14; see also discrimination

passing lines 150, 154; see also border crossing persecution 1-9, 15, 81, 91, 99-124, 132-53, 165, 195, 198, 199, 202

fear of $5,6,91,101,113,117,121-3$, $133,137,141,142,148,165,171$

Pim Fortuyn List see Lijst Pim Fortuyn

Polish migration to Germany $63-5$

populism 167

Proud of the Netherlands 169

PVV 170

Qur'an 162, 168-70, 197, 230

queer diaspora 59-62

queer migration $3-5,32-3$

motivations $4-5,36-41$

queerness 7, 49, 50, 51, 145, 151, 153, 244

racism $110-13,125,151,163,165,166$, $168,175,178,189,206$
Refugee Convention 5, 6, 8, 91, 116, 122, 184, 196

refugee

bogus v. genuine 144-6, 149, 152, 153

religion $60,85,101,117,124,163,166,167$, $176,178,195-202$

religious beliefs 99, 100, 176, 195; see also religion

Russian migration to Germany 68-73

safe country 91, 92, 173, 179

safety 90, 92, 139, 140, 141, 152, 153, 249

Savage slot 163

sexual migration see migration, queer

sexual minority/minorities 1-6, 9, 10, 57, 70, 75, 114-17, 120, 124, 125, 144, 154, 203, 240

asylum jurisprudence 81-91

Council of Europe 80-3

Spain 20, 24, 33, 86, 89, 97, 100

asylum system see asylum system, Spanish migration policy; see also affinity, ethnic

stereotypes 133, 144, 172, 173, 190, 239,252

Strasbourg Court 78-103; see also European Court of Human Rights

transphobia 73, 140, 144, 189, 206

Trots op Nederland see Proud of the Netherlands

Uganda, asylum seekers to the Netherlands $164,175,176$

UNHCR 7, 88, 91, 93, 95, 98, 99, 116, 124, 147, 195

UNHRC 117, 118; see also United Nations Human Rights Council

United Nations High Commissioner for Refugees see UNHCR

United Nations Human Rights Council 1; see also UNHRC

United Nations 14, 82

Verdonk, Rita 169

violation

systematic, 81, 82, 141, 142, 144, 145

vulnerability, 33, 87, 113, 149, 194, 235

Wilders, Geert 162, 168-70, 178, 180

xenophobia 168,173

Yogyakarta Principles 13, 82, 88 
Europe is a popular destination for LGBTQ people seeking to escape discrimination and persecution. Yet, while European institutions have done much to promote the legal equality of sexual minorities and a number of states pride themselves on their acceptance of sexual diversity, the image of European tolerance and the reality faced by LGBTQ migrants and asylum seekers are often quite different.

To engage with these conflicting discourses, Queer Migration and Asylum in Europe brings together scholars from politics, sociology, urban studies, anthropology and law to analyse how and why queer individuals migrate to or seek asylum in Europe, as well as the legal, social and political frameworks they are forced to navigate to feel at home or to regularise their status in the destination societies. The subjects covered include LGBTQ Latino migrants' relationship with queer and diasporic spaces in London; diasporic consciousness of queer Polish, Russian and Brazilian migrants in Berlin; the role of the Council of Europe in shaping legal and policy frameworks relating to queer migration and asylum; the challenges facing bisexual asylum seekers; queer asylum and homonationalism in the Netherlands; and the role of space, faith and LGBTQ organisations in Germany, Italy, the UK and France in supporting queer asylum seekers.

Richard C. M. Mole is Professor of Political Sociology at the School of Slavonic and East European Studies, UCL. He is the editor of Soviet and Post-Soviet Sexualities (Routledge 2019) and has published in Slavic Review, East European Politics and Societies, Ethnicity and Health, Nations and Nationalism, European Journal of Social Psychology and Sexualities. 